ORP-11242

Revision 3A

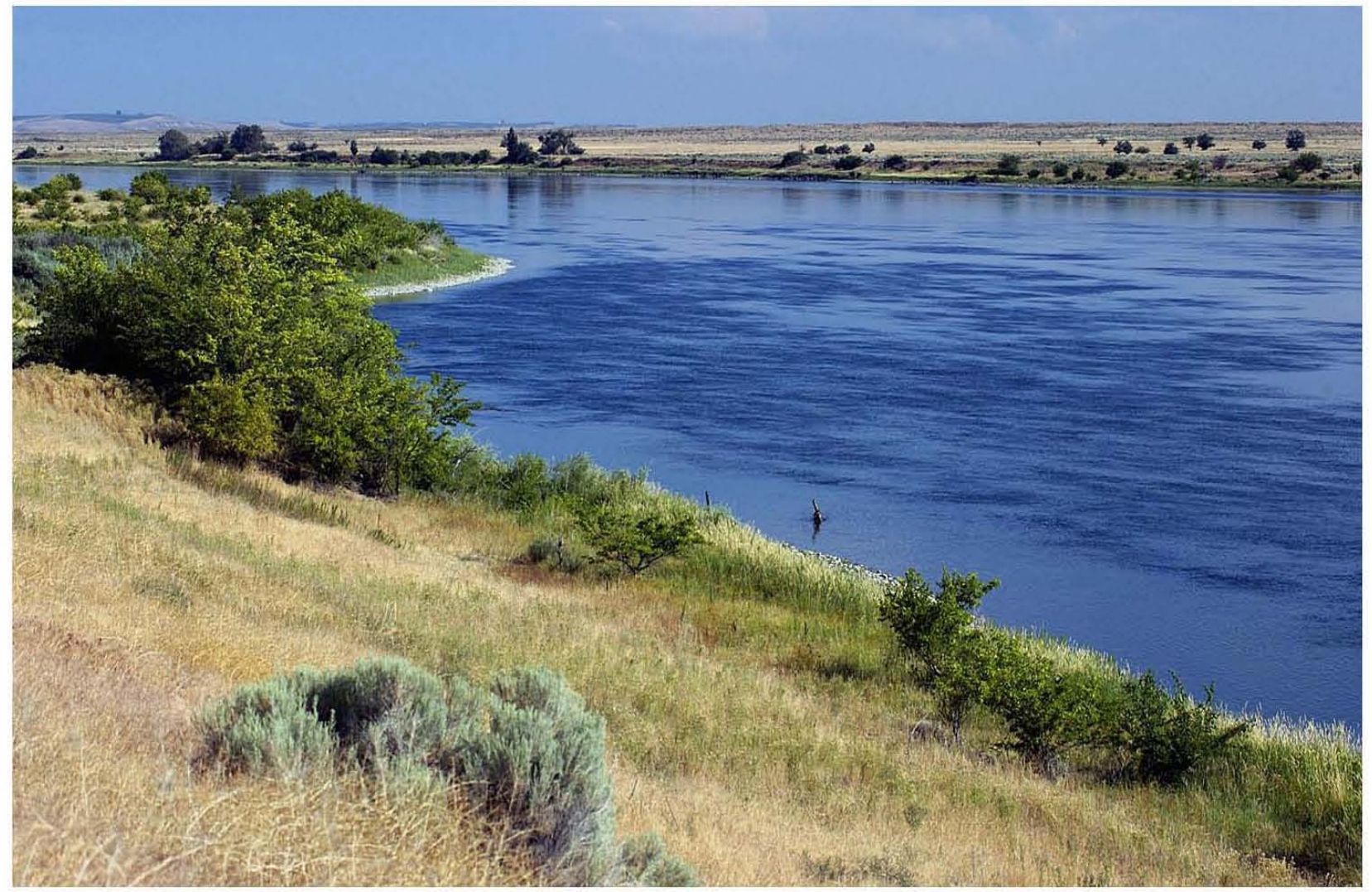

RETRIEVE AND TREAT HANFORD'S TANK

WASTE AND CLOSE THE TANK FARMS TO

PROTECT THE COLUMBIA RIVER 


\title{
River Protection Project System Plan
}

\author{
P. J. Certa \\ CH2M HILL Hanford Group, Inc.
}

July 2008

Prepared for the U.S. Department of Energy

Assistant Secretary for Environmental Management

\section{Office of River Protection}

P.O. Box 450

Richland, Washington 99352

R. A. Rasolal $\frac{07 / 10 / 2008}{\text { Date }}$ 
ORP-11242, Rev 3A

DISCLAIMER

Some of the activities describe herein may be subject to and/or undergoing the analysis required by the National Environmental Policy Act (NEPA), 42 U.S.C. \$4321, et seq. They are included within this document for planning purposes only, not for decisional purposes which will be conducted following the NEPA process.

\section{TRADEMARK DISCLAIMER}

Reference herein to any specific commercial product, process, or service by trade name, trademark, manufacturer, or otherwise, does not necessarily constitute or imply its endorsement, recommendation, or favoring by the United States Government or any agency thereof or its contractors or subcontractors.

Scientific or technical information is available to U.S. Government and U.S. Government contractor personnel through the Office of Scientific and Technical Information (OSTI). It is available to others through the National Technical Information Service (NTIS).

This report has been reproduced from the best available copy.

Printed in the United States of America 


\section{Office of River Protection}

\section{River Protection Project System Plan - Revision 3A}

Prepared by:

P. J. Certa

G. K. Allen

T. W. Crawford

T. M. Hohl

K. N. Jordan

R. A. Kirkbride

R. L. Lytle

Approval of this System Plan indicates that the scenario evaluated and presented in this document is suitable for strategic planning purposes only. This document is not intended as a budget request, nor does it represent contractual commitments on behalf of any party.

Some of the activities describe herein may be subject to and/or undergoing the analysis required by the National Environmental Policy Act (NEPA), 42 U.S.C. $\$ 4321$, et seq. They are included within this document for planning purposes only, not for decisional purposes which will be conducted following the NEPA process.

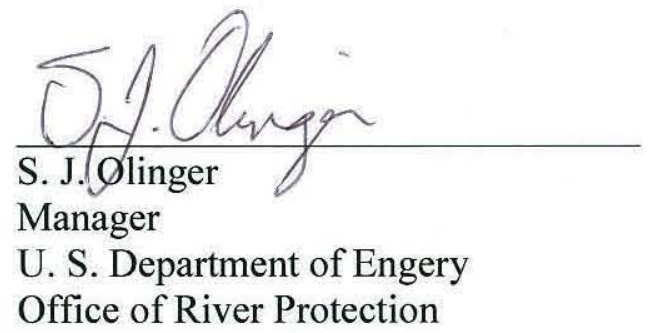


ORP-11242, Rev 3A

\section{History Sheet}

\begin{tabular}{|c|c|c|c|}
\hline Revision & Date & Reason for revision & Revised by \\
\hline 0 & August 2002 & Initial Issuance & K. R. Wells \\
\hline 1 & April 2003 & $\begin{array}{l}\text { Reflect proposed changes and additions to the Waste } \\
\text { Treatment Processes \& Facilities to accelerate mission } \\
\text { completion }\end{array}$ & K. R. Wells \\
\hline 2 & September 2003 & $\begin{array}{l}\text { Reflect a Target Case which depicts the mission based } \\
\text { on how ORP expects the WTP to perform and a Stretch } \\
\text { Case which depicts the mission if significant increases } \\
\text { in both WTP and Non-WTP LAW treatment } \\
\text { performance are realized. }\end{array}$ & P. J. Certa \\
\hline 3 & May 2008 & $\begin{array}{l}\text { Reflects a Reference Case which depicts a mission } \\
\text { scenario based on beginning full WTP operations in } \\
2019 \text {, in conjunction with Supplemental LAW } \\
\text { Treatment and Supplemental TRU packaging. } \\
\text { Generally aligned with key features of the FY } 2007 \\
\text { baseline. }\end{array}$ & P. J. Certa \\
\hline $3 \mathrm{~A}$ & July 2008 & $\begin{array}{l}\text { Incorporate comments from The Office of Management } \\
\text { and Budget. }\end{array}$ & P. J. Certa \\
\hline
\end{tabular}




\section{EXECUTIVE SUMMARY}

The U.S. Department of Energy (DOE), Office of River Protection (ORP) manages the River Protection Project (RPP). The RPP mission is to retrieve and treat Hanford's tank waste and close the tank farms to protect the Columbia River. As a result, the ORP is responsible for the retrieval, treatment, and disposal of the approximately $57^{1}$ million gallons of radioactive waste contained in the Hanford Site waste tanks and closure of all the tanks and associated facilities.

The previous revision of the System Plan was issued in September 2003. ORP has approved a number of changes to the tank waste treatment strategy and plans since the last revision of this document, and additional changes are under consideration.

The ORP has established contracts to implement this strategy to establish a basic capability to complete the overall mission. The current strategy for completion of the mission uses a number of interrelated activities. The ORP will reduce risk to the environment posed by tank wastes by:

- Retrieving the waste from the single-shell tanks (SST) to double-shell tanks (DST) for treatment and disposal;

- Constructing and operating the WTP, which will safely treat all of the high-level waste $^{2}$ (HLW) and about half of the low-activity waste ${ }^{2}$ (LAW) contained in the tank farms, and maximizing its capability and capacity;

- Developing and deploying supplemental treatment capability or a second WTP LAW Facility that can safely treat about half of the LAW contained in the tank farms;

- Developing and deploying treatment and packaging capability for transuranic (TRU) tank waste for shipment to and disposal at the Waste Isolation Pilot Plant (WIPP);

- Deploying interim storage capacity for the immobilized HLW and shipping that waste to Yucca Mountain for disposal;

\footnotetext{
${ }^{1}$ This is the total volume of waste in the tanks as January 2007 . The volume varies depending on how much water is added during waste retrieval and how much of that water has been removed by the waste evaporator.

${ }^{2}$ Tank waste has not yet been classified. Until such classification has been made, the tank waste is managed as if it were high-level waste. As used in this System Plan, the term HLW refers to the faction of the tank waste containing most of the radioactivity that will be immobilized into glass and disposed at an off-site repository; the term LAW refers to the fraction of the tank waste that will be immobilized into glass and disposed on-site.
} 
- Operating the Integrated Disposal Facility for the disposal of immobilized LAW, along with the associated secondary waste.

- Closing the SST and DST tank farms, ancillary facilities, and all waste management and treatment facilities.

- Developing and implementing technical solutions to mitigate the impact from substantially increased estimates of $\mathrm{Na}$ added during the pretreatment of the tank waste solids. This involves a combination of: 1) refining or modifying the flowsheet to reduce the required amount of additional sodium, 2) increasing the overall LAW vitrification capacity, 3 ) increasing the incorporation of sodium into the LAW glass, or 4) accepting an increase in mission duration.

ORP has made and continues to make modifications to the WTP contract as needed to improve projected plant performance and address known or emerging risks. Key elements of the implementation of this strategy are included within the scope of the Tank Operations Contract, currently in procurement.

Since 2003, the ORP has conducted over 30 design oversight assessments ${ }^{3}$ of the Waste Treatment and Immobilization Plant (WTP). The estimated cost at completion has increased and the schedule for construction and commissioning of the WTP has extended. The DOE, Office of Environmental Management (EM), sanctioned a comprehensive review ${ }^{4}$ of the WTP flowsheet, focusing on throughput. In 2005, the TFC completed interim stabilization of the SSTs and as of March 2007, has completed the retrieval of seven selected SSTs. Demonstration of supplemental treatment technologies continues.

The ongoing tank waste retrieval experience, progress with supplemental treatment technologies, and changes in WTP schedule led to the FY 2007 TFC baseline submittal in November $2006 .{ }^{5}$ The TFC baseline submittal was developed before the WTP schedule was fully understood and

\footnotetext{
${ }^{3}$ One of the key assessments deals with the high-level waste pretreatment capacity of the WTP Pretreatment Facility. See D-03-DESIGN-005, 2004, "HLW Feed Preparation System: Ultra-Filtration Process System," ORP WTP Engineering Division, for more details. Nota bene - this document number was also used for a different report issued in 2003.

4 "Comprehensive Review of the Hanford Waste Treatment Plant Flowsheet and Throughput, Assessment Conducted by an Independent Team of External Experts, "March 2006 , transmitted under cover of letter CCN: 132846.

${ }^{5}$ Baseline Change Request RPP-06-003, Rev. 1, "Alignment of TFC Lifecycle Baseline," November 2006.
} 
ORP-11242, Rev 3A

approved by ORP, and therefore reflects an earlier start date for the WTP facilities. This System Plan is aligned with the current WTP schedule with hot commissioning beginning in 2018 and full operations beginning in 2019.

Major decisions regarding the use of supplemental treatment and the associated technology, the ultimate needed capacity, and its relationship to the WTP have not yet been finalized. This System Plan assumes that the outcome of this decision will be to provide a supplemental LAW treatment system using in-container vitrification $\left(\mathrm{ICV}^{\mathrm{TM}}\right)$ as the enabling technology. No final implementation decisions regarding supplemental technology can be made until the Tank Closure and Waste Management Environmental Impact Statement is completed and a Record of Decision is issued by the DOE.

\section{Purpose}

This version of the System Plan establishes a Reference Case that will be used to provide a description of how the mission could play out, and communicate the potential mission impacts of key issues and uncertainties on the mission. The Reference Case demonstrates how ORP could use the WTP with supplemental LAW and supplemental TRU treatment to complete the treatment and disposal of Hanford tank waste in a reasonable time frame. This case assumes that the WTP being constructed by Bechtel National, Inc. (BNI) will perform better than the minimum contractual performance requirements. Key assumptions have been adjusted to result in a more realistic scenario for this System Plan revision, without undue optimism or pessimism. The Reference Case approximates the key features of the current baseline and underlying technical basis; it not an exact depiction of the current baseline, a budget request, nor contractual or regulatory commitment on behalf of any party.

The Reference Case continues the alignment of the baseline plan for waste feed delivery, SST retrieval, and supplemental treatment with the hot commissioning and ramp-up plans for the WTP. Identification of those areas that might benefit from resolution of issues and uncertainties allows the ORP to hone its risk mitigating strategy.

\section{Results (Life-cycle Mission Scenario)}

The Reference Case shows that the WTP, together with supplemental LAW and TRU treatment, can treat the Hanford tank waste by 2049 , with approximately 30 years of WTP operations. 
Closure of the waste management areas and decontamination and decommissioning of the facilities is projected to finish in 2055. Key features of the Reference Case are summarized in Table ES-1.

Under the assumptions for the Reference Case, the mission duration is now being driven by the SST retrieval capabilities, followed by total (WTP and supplemental) LAW vitrification capacity and HLW vitrification capacity. Since 2003, the original planning assumptions for the SST retrieval were replaced with more detailed assumptions that reflect recent field experience in terms of overall retrieval durations and water additions. The significantly longer retrieval durations and water usage for the $67 \mathrm{SST}$ s assumed to have leaked resulted in delays in delivery of HLW feed to the WTP in this modeled scenario. Also, since 2003, the projected HLW glass mass has increased by about 34 percent, primarily because of updates in the estimated tank inventory and the water-wash and caustic leach factors and a slight reduction in the degree of incidental blending. Revision 2 of the System Plan assumed that supplemental LAW treatment capacity was simply available "as-needed" to treat the desired quantities of feed. The current plan assumes the deployment of a specified number of melter lines, each using the flowsheet and testing for the Demonstration Bulk Vitrification System (DBVS) as the basis for its net capacity, as reflected in the current TFC lifecycle baseline.

The Reference Case also developed overall system mass balances for the Waste Treatment Complex. Estimates of secondary waste were found to be sensitive to the overall configuration of the Waste Treatment Complex, the process splits for each unit operation, and the process-specific internal recycles. A simplified flowsheet for the Reference Case is shown in Figure ES-1. 
Figure ES- 1. Simplified Hanford Tank Waste Flowsheet for the Reference Case.

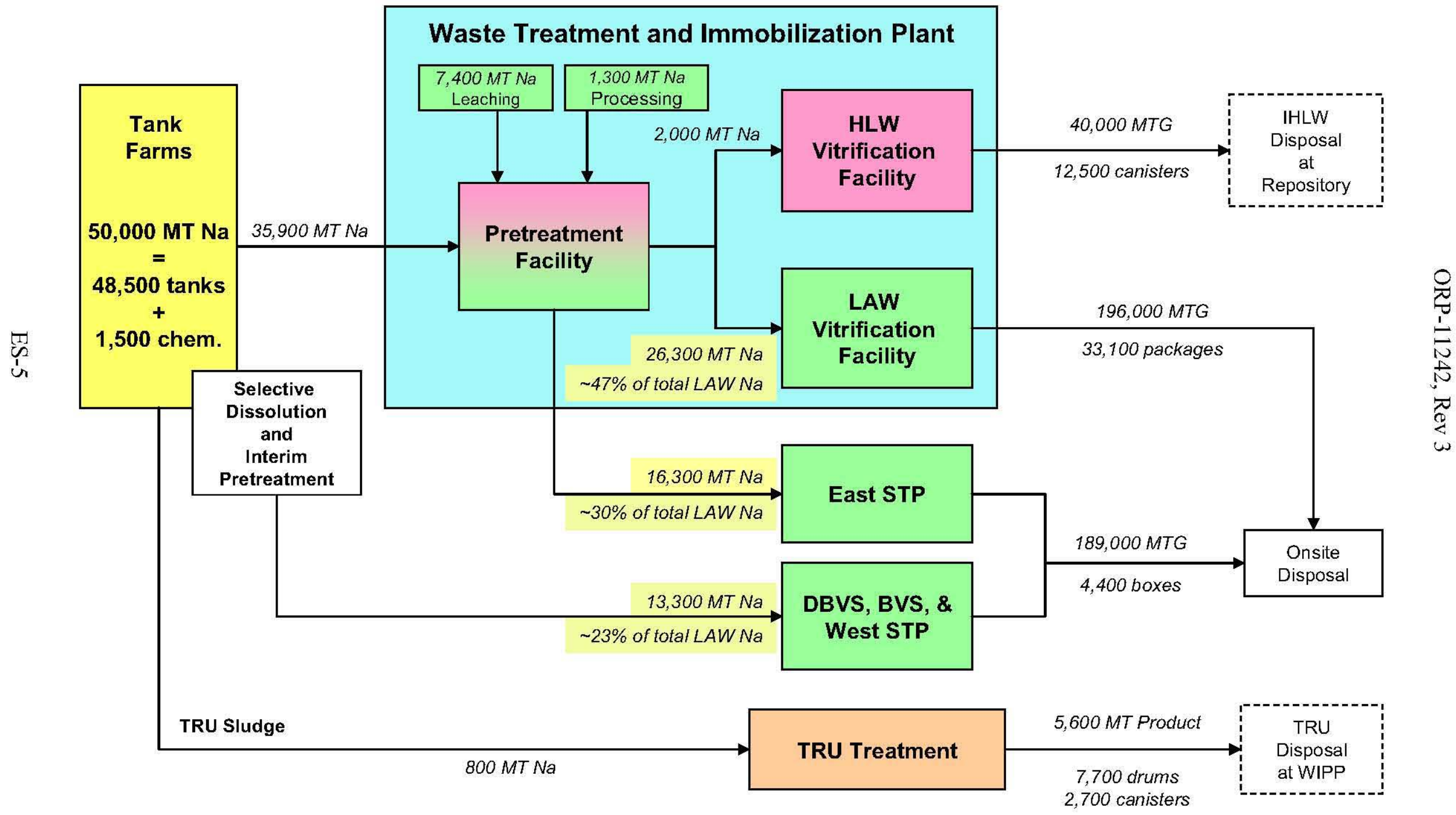

Note - Mass balance has been simplified omitting all secondary waste and recycle streams, tank residuals, and glass forming chemicals. Results are rounded. 


\section{Opportunities}

Under the assumptions for the Reference Case, the mission duration is being driven by the SST retrieval capabilities, followed by total (WTP and supplemental) LAW vitrification capacity and HLW vitrification capacity. Since 2003, the SST retrieval capabilities were updated to reflect recent field experience in terms of overall retrieval durations and water additions. Key efforts being pursued by ORP to address issues with the underlying assumptions and shorten the treatment mission duration include:

- Continued testing and refinement of SST retrieval technologies, their interface with the DST System, and balancing of logistical and resource constraints to reduce the overall time needed to retrieve the SSTs.

- Continued glass formulation work to improve waste loading to decrease the projected amount of LAW and HLW glass.

- Implementation of oxidative leaching in the WTP to reduce the impacts of chromium.

- Reduction of the total amount of HLW glass to be produced by treating the TRU separately from the HLW and disposal at WIPP.

- Exploring the early startup of the WTP LAW Vitrification Facility in conjunction with an Interim Pretreatment System (IPS) to begin treating tank waste before startup of the rest of the WTP, freeing DST space for continued retrieval of the SSTs;

- Development of second generation LAW and HLW melters to increase net production rates.

- Development of supplemental LAW treatment technologies.

- Exploring technologies to reduce the amount of sodium hydroxide that is expected to be added during pretreatment of the HLW to reduce the needed LAW treatment capacity. This may include process changes or new unit operations to recycle sodium hydroxide.

- Implementing flowsheet, equipment, and operating mode improvements at the WTP Pretreatment (PT) facility to increase pretreatment capacity. 
Table ES-1. Key Features of the Reference Case.

\begin{tabular}{|c|c|c|}
\hline Key Feature & $\begin{array}{c}\text { Projected Schedule } \\
\text { CY }\end{array}$ & $\begin{array}{c}\text { Quantity } \\
\text { [Net Capacity] }\end{array}$ \\
\hline Waste Treatment Completed & 2049 & $\begin{array}{c}149 \text { SSTs }+28 \text { DSTs }+43 \text { IMUSTs } \\
+17 \text { MUSTs }\end{array}$ \\
\hline C-Farm Retrievals Completed & 2016 & $16 \mathrm{SSTs}$ \\
\hline West Area SST Retrievals Completed & 2047 & 83 SSTs \\
\hline SST Retrievals Completed & 2047 & 149 SSTs \\
\hline WTP Hot Commissioning & $5 / 2018-9 / 2018$ & $\begin{array}{l}56 \text { canisters IHLW }+ \\
188 \text { packages ILAW }\end{array}$ \\
\hline WTP Full Operations* & $\begin{array}{l}10 / 2018-2048 \\
30 \text { years duration }\end{array}$ & $\begin{array}{c}\text { 12,513 canisters IHLW } \\
{[\mathbf{5 . 2 5} \mathbf{M T G} / \mathbf{d}]} \\
\text { 33,065 packages ILAW } \\
{[\mathbf{2 1 . 0} \mathbf{M T G} / \mathbf{d}]}\end{array}$ \\
\hline Total Estimated Treated Product from all facilities & - & $\begin{array}{c}40,000 \text { MTG IHLW } \\
\text { 384,200 MTG ILAW } \\
\text { 2,200 MT CH-TRU } \\
\text { 3,400 MT RH-TRU }\end{array}$ \\
\hline CH-TRU Packaging (from 11 SSTs) & $10 / 2013-2019$ & 7,67855 -gal drums \\
\hline RH-TRU Packaging (from 3 DSTs and 6 SSTs) & $5 / 2025-2037$ & 2,723 RH-TRU Waste Canisters \\
\hline DBVS & $3 / 2011-10 / 2012$ & 36 Boxes [3.66 MTG/d] \\
\hline BVS & $10 / 2013-2017$ & 103 Boxes [3.66 MTG/d] \\
\hline IPS \& West STP & $7 / 2014-2046$ & 1,845 Boxes [14.65 MTG/d] \\
\hline East STP & $2 / 2019-2049$ & 2,439 Boxes [14.65 MTG/d] \\
\hline 242-A Evaporator Operations & $2007-2039 * *$ & $\begin{array}{c}93 \text { Mgal Feed } \\
64 \text { Mgal Waste Volume Reduction }\end{array}$ \\
\hline CSB Operation & $\begin{array}{l}6 / 2018-2050 \\
\text { Full in } 11 / 2020 \\
\end{array}$ & 880 canisters \\
\hline Shipping IHLW to Yucca & $11 / 2020-2050$ & 12,513 canisters IHLW \\
\hline LAW Sodium to WTP ILAW, Percent & - & $\sim 47 \%$ \\
\hline HLW Average Waste Oxide Loading & - & Relaxed GPM $(\sim 28 \%)$ \\
\hline ILAW Average Sodium Oxide Loading - WTP & - & DOE Model $(\sim 18 \%)$ \\
\hline $\begin{array}{l}\text { ILAW Average Sodium Oxide Loading - DBVS, } \\
\text { BVS, East STP, West STP }\end{array}$ & - & $\sim 21 \%$ \\
\hline
\end{tabular}

Notes: Assumptions and inputs are shown with bold blue text; notable results are shown in bold red text.

* Reported quantities include those from hot commissioning.

**Evaporator capacity is required through the end of SST retrieval to meet sodium concentration specifications for WTP LAW feed.

$\begin{array}{lll}\text { BVS } & & \text { Bulk Vitrification System. } \\ \text { CH-TRU } & \text { contact handled transuranic waste. } \\ \text { CSB } & = & \text { Canister Storage Building. } \\ \text { CY } & = & \text { calendar year. } \\ \text { DBVS } & = & \text { Demonstration Bulk Vitrification } \\ & & \text { System. } \\ \text { DOE }= & \text { U.S. Department of Energy. } \\ \text { DST }= & \text { double-shell tank. } \\ \text { GPM }= & \text { Glass Property Model. } \\ \text { DF }= & \text { Integrated Disposal Facility. }\end{array}$

$\begin{array}{lll}\text { IHLW } & & \text { immobilized high-level waste. } \\ \text { IAW } & \text { immobilized low-activity waste. } \\ \text { IMUST } & \text { inactive miscellaneous underground storage } \\ & & \text { tank. } \\ \text { IPS } & \text { Interim Pretreatment System } \\ \text { MT }= & \text { metric tons } \\ \text { MTG } & \text { metric tons of glass. } \\ \text { RH-TRU } & \text { remote handled transuranic waste. } \\ \text { SST } & \text { single-shell tank. } \\ \text { STP }= & \text { Supplemental Treatment Plant. } \\ \text { WTP }= & \text { Waste Treatment and Immobilization Plant. }\end{array}$


ORP-11242, Rev 3A

\section{Kev Issues and Uncertainties}

The Reference Case projects single value estimates for key mission metrics such as the treatment end date and the quantity of glass produced. A number of sensitivity studies were performed to evaluate how these projected results might be impacted by differing assumptions. These estimates are shown in Table 4-1, Ranges on Key Mission Parameters. An abridged version of those results is presented in Table ES-2, Ranges on Key Mission Parameters, Abridged. Note that these ranges are not necessarily bounding and do not address the likelihood of any particular result. The three variables with the greatest overall impact on the treatment mission are the need to add additional sodium hydroxide during pretreatment, the need for supplemental LAW treatment capacity beyond that which is provided by a single WTP LAW Vitrification Facility, and the ability to retrieve the SSTs quickly while minimizing the amounts of water needed.

Some of the assumptions used for the Reference Case present issues and uncertainties that need to be successfully addressed to further reduce ORP's risk of achieving the desired performance for the mission. These challenges are discussed in more detail together with potential mitigating actions in Table 4-2, Key Issues and Uncertainties for the Reference Case, located in $\S 4.3$. The issues and uncertainties identified for the Reference Case will assist ORP in the management of the programmatic and technical risks associated with the waste treatment mission. 
Table ES-2. Ranges on Key Mission Parameters, Abridged.

\begin{tabular}{|c|c|c|c|c|c|}
\hline Parameter & $\begin{array}{c}\text { Selected Estimates Lower than I } \\
\text { Case }\end{array}$ & ference & $\begin{array}{l}\text { Reference } \\
\text { Case }\end{array}$ & Sele & $\begin{array}{l}\text { ed Estimates Higher than } \\
\text { Reference Case }\end{array}$ \\
\hline & & & & 2060 & $34,000 \mathrm{MT}$ additional Sodium \\
\hline $\begin{array}{l}\text { Treatment End Date } \\
\text { (Calendar Year) }\end{array}$ & Total blend; HLW drives duration & 2035 & 2049 & 2072 & $\begin{array}{l}\text { No Supplemental LAW } \\
\text { Treatment \& only one WTP } \\
\text { ILAW Facility }\end{array}$ \\
\hline & & & & 14,363 & TRU sent to WTP \\
\hline $\begin{array}{l}\text { HLW Glass } \\
\text { (Canisters) }\end{array}$ & Total Blend & 8,944 & 12,513 & 15,237 & $\begin{array}{l}\text { Similar to WTP baseline HLW } \\
\text { glass formulation model }\end{array}$ \\
\hline $\begin{array}{l}\text { Retrieval End Date } \\
\text { (Calendar Year) }\end{array}$ & Enhanced SST Retrieval & 2040 & 2047 & 2062 & $\begin{array}{c}\text { Ecology Case } \\
\text { (mainly risk-based retrieval } \\
\text { sequence) }\end{array}$ \\
\hline $\begin{array}{l}\text { Total LAW Glass } \\
\text { (MTG) }\end{array}$ & Not evaluated & -- & 384,200 & 617,000 & $34,000 \mathrm{MT}$ additional Sodium \\
\hline $\begin{array}{l}\text { CH-TRU to WIPP } \\
\text { (55-gallon drums) }\end{array}$ & CH-TRU sent to WTP & 0 & 7,678 & -- & Not evaluated \\
\hline $\begin{array}{c}\text { RH-TRU to WIPP } \\
\text { (RH-TRU Waste Canisters) }\end{array}$ & RH-TRU sent to WTP & 0 & 2,723 & 3,513 & $\begin{array}{c}\text { Similar to FY } 2008 \text { IPABS } \\
\text { submittal }\end{array}$ \\
\hline
\end{tabular}


ORP-11242, Rev 3

This page intentionally left blank.

ES-10 


\section{CONTENTS}

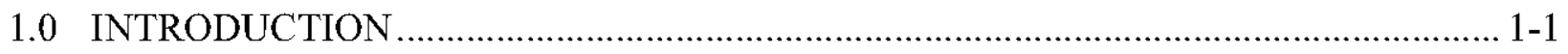

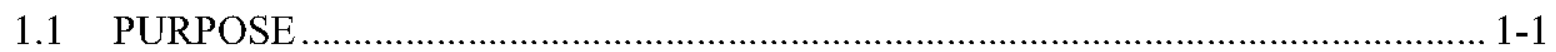

1.2 ORGANIZATION OF DOCUMENT ….......................................................... 1-2

1.3 OVERVIEW OF THE WASTE TREATMENT COMPLEX …........................... 1-2

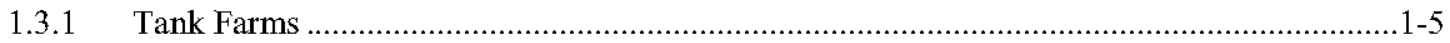

1.3.1.1 Single-Shell Tanks...............................................................................

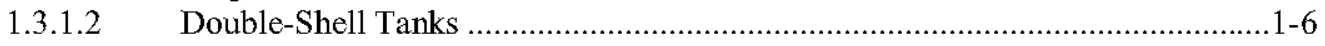

1.3.1.3 Miscellaneous Underground Storage Tanks ................................................1-11

1.3.1.4 Waste Retrieval from Single-Shell Tanks.....................................................1-12

1.3.1.5 Waste Retrieval from Double-Shell Tanks ..................................................1-16

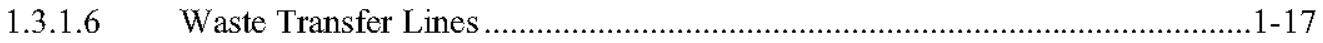

1.3.1.7 Tank Farm Waste Evaporator (242-A) .....................................................1-17

1.3.2 Waste Treatment and Immobilization Plant..............................................................

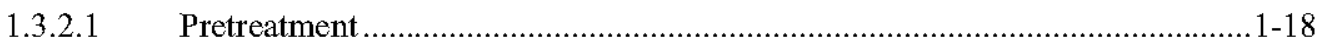

1.3.2.2 High-Level Waste Vitrification .........................................................1-19

1.3.2.3 Low-Level Waste Vitrification ..............................................................

1.3.2.4 Waste Treatment and Immobilization Plant Analytical Laboratory ..................1-21

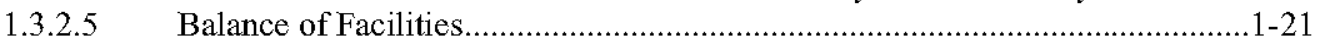

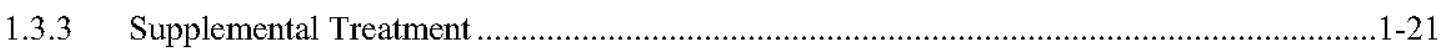

1.3.3.1 Demonstration Bulk Vitrification System.............................................1-22

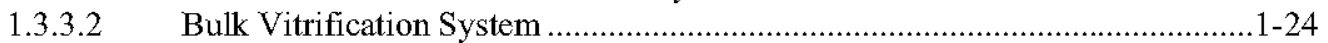

1.3.3.3 East Supplemental LAW Treatment Plant ....................................................1-24

1.3.3.4 Interim Pretreatment System...................................................................

1.3.3.5 West Supplemental Treatment Facility ...................................................1-25

1.3.3.6 Supplemental Transuranic Waste Treatment System.......................................1-25

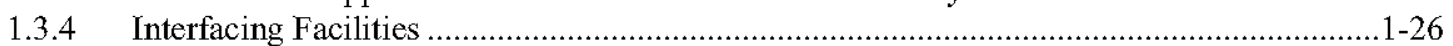

1.3.4.1 Liquid Effluent Retention Facility and Effluent Treatment Facility ................1-26

1.3.4.2 Central Waste Complex .............................................................................

1.3.4.3 Canister Storage Building / Hanford Shipping Facility ...................................1-28

1.3.4.4 Integrated Disposal Facility .................................................................. 28

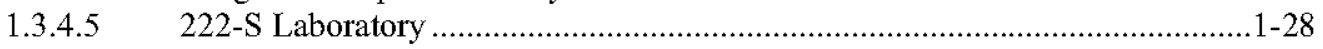

1.3.4.6 Other Hanford Site Facilities .........................................................1-29

1.3.4.7 Waste Encapsulation and Storage Facility …..............................................1-29

1.3.4.8 State Approved Land Disposal Site .........................................................1-30

1.3.4.9 200 Area Treated Effluent Disposal Facility ...............................................1-30

1.3.4.10 Offsite Geologic Repository …................................................................

1.3.4.11 Waste Isolation Pilot Plant...........................................................................

1.4 OPTIONS UNDER CONSIDERATION …................................................. 1-31

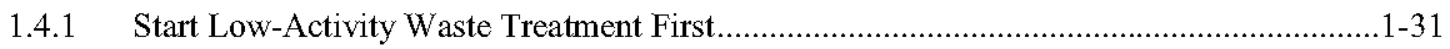

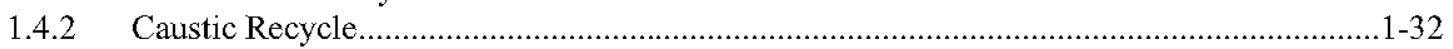

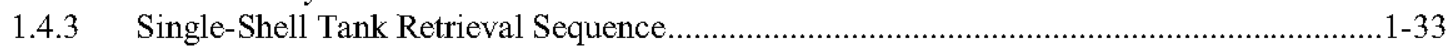

1.4.4 Supplemental Treatment vs. Second Waste Treatment and Immobilization Plant

Immobilized Low-Activity Waste Facility ...................................................................

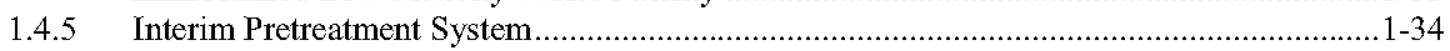

2.0 RESULTS AND DISCUSSION OF REFERENCE CASE ……..................................... 2-1

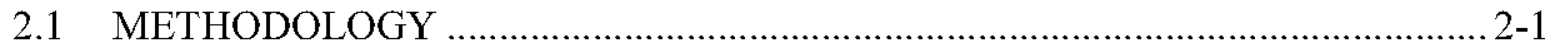

2.2 KEY FEATURES AND RESULTS ............................................................... 2-2 


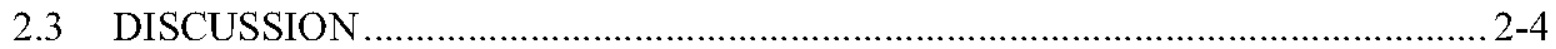

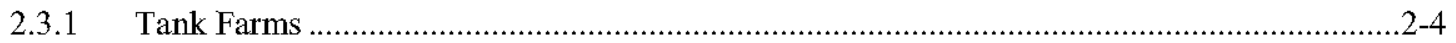

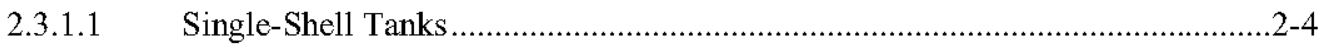

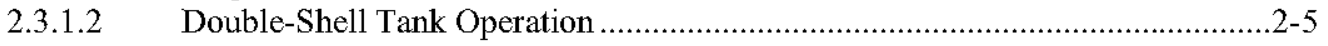

2.3.1.3 Inactive Miscellaneous Underground Storage Tanks......................................2-7

2.3.1.4 Waste Retrieval from Single-Shell Tanks .......................................................

2.3.1.5 Waste Retrieval from Double-Shell Tanks ................................................2-13

2.3.1.6 Waste Transfers ...................................................................................

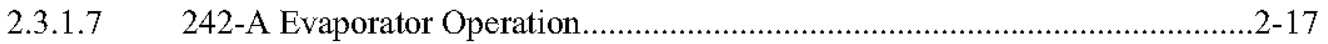

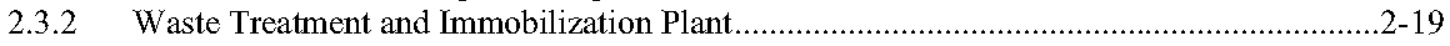

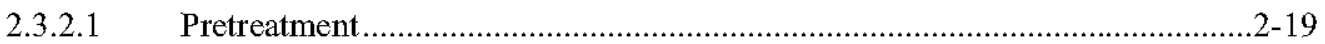

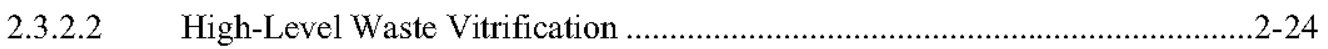

2.3.2.3 Low-Activity Waste Vitrification ........................................................2-25

2.3.2.4 Waste Treatment and Immobilization Plant Analytical Laboratory..................2-25

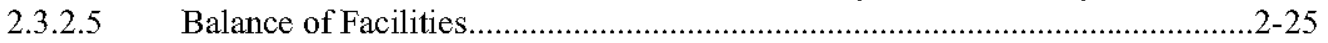

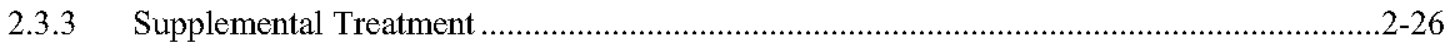

2.3.3.1 Demonstration Bulk Vitrification System.................................................2-26

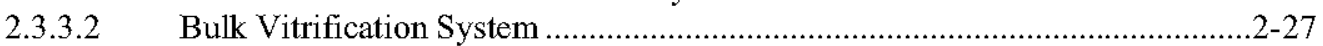

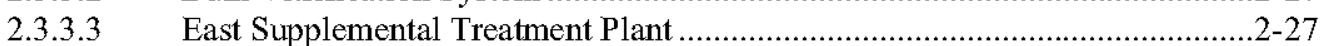

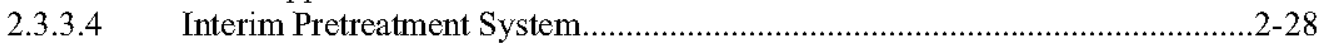

2.3.3.5 West Supplemental Treatment Plant .........................................................2-28

2.3.3.6 Supplemental Transuranic Waste Treatment System......................................2-29

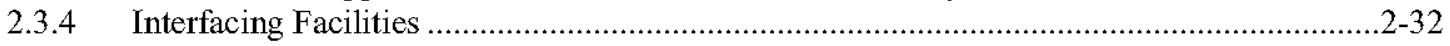

2.3.4.1 Liquid Effluent Retention Facility and Effluent Treatment Facility ................2-32

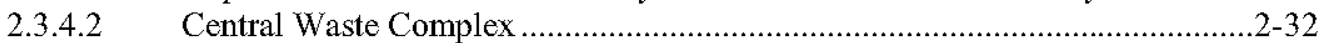

2.3.4.3 Canister Storage Building / Hanford Shipping Facility ...................................2-33

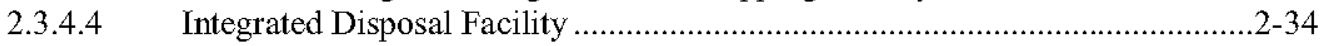

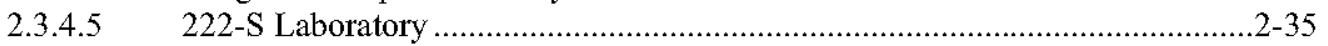

2.3.4.6 Other Hanford Site Facilities ................................................................... $2-35$

2.3.4.7 Waste Encapsulation and Storage Facility .................................................. $2-35$

2.3.4.8 State Approved Land Disposal Site …............................................................

2.3.4.9 200 Area Treated Effluent Disposal Facility ….........................................2-35

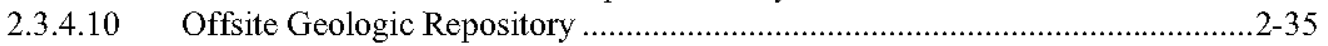

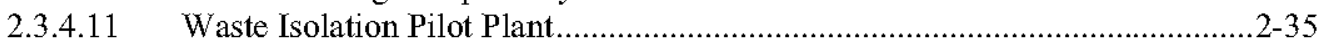

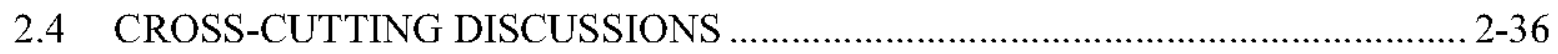

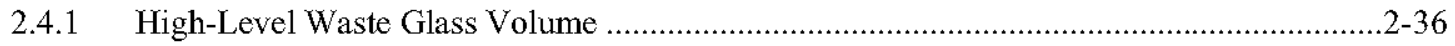

2.4.1.1 Waste Composition and Quantity ……...............................................................

2.4.1.2 Solubility During Retrieval and Staging ...................................................

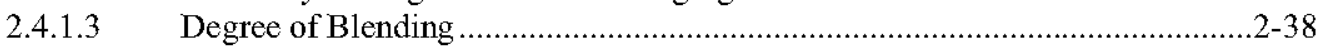

2.4.1.4 Partitioning During Pretreatment .......................................................

2.4.1.5 Glass Formulation Model .....................................................................

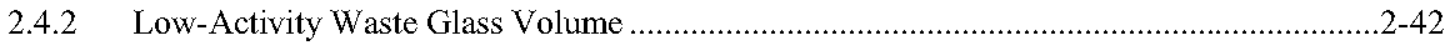

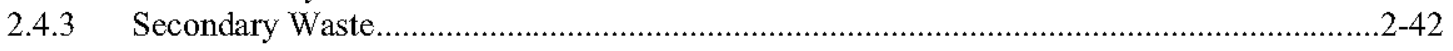

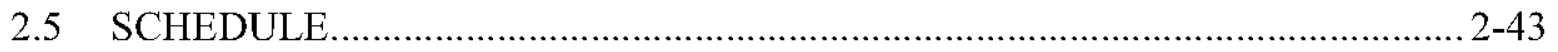

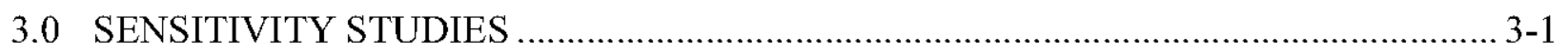

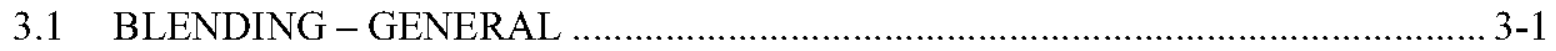

3.2 BLENDING - RETRIEVAL CONSTRAINTS ………...................................... 3-3

3.3 TRANSURANIC WASTE DISPOSITION ………..........................................

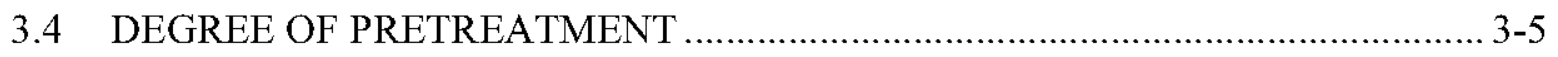

3.5 LEACH CAUSTIC …………… 3-6 


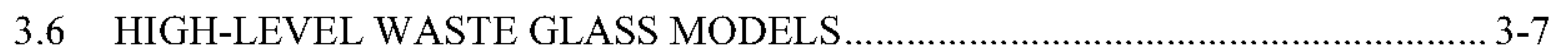

3.7 SUPPLEMENTAL LOW-ACTIVITY WASTE TREATMENT ……..................... 3-8

3.8 ENHANCED SINGLE-SHELL TANK RETRIEVAL ……................................. 3-10

3.9 RISK-BASED RETRIEVAL SEQUENCE …….............................................

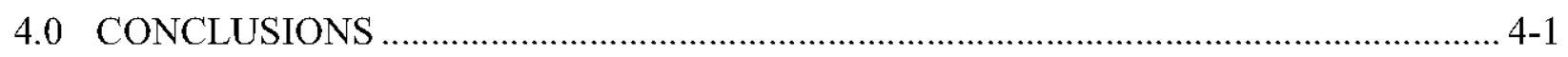

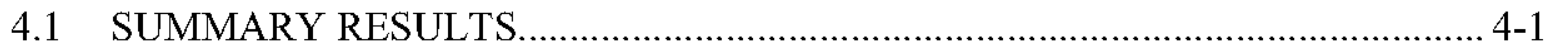

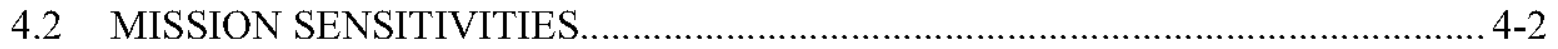

4.3 KEY ISSUES AND UNCERTAINTIES ………................................................

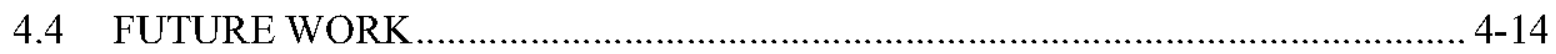

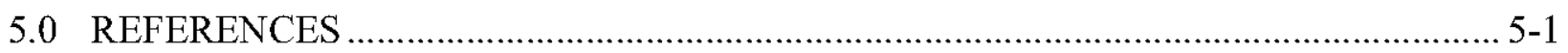

\section{APPENDICES}

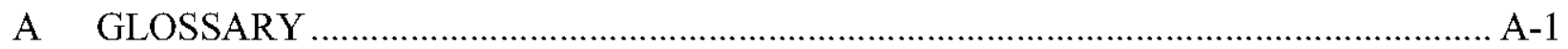

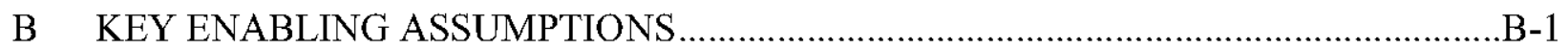

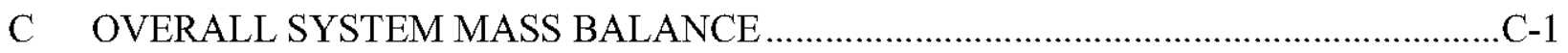

\section{FIGURES}

Figure 1-1. River Protection Project Simplified Process Flow Diagram................................... 1-3

Figure 1-2. Waste Transfer System Overview.................................................................... 1-7

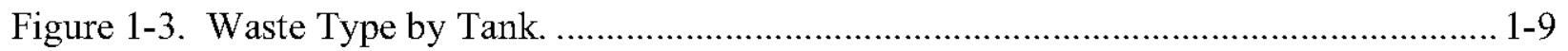

Figure 2-1. Projected Single-Shell Tank Retrieval Progress. .................................................. 2-4

Figure 2-2. Cumulative Volume Transferred to the Double-Shell Tanks from the Single-Shell

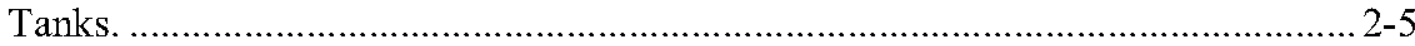

Figure 2-3. Total Double-Shell Tank Space Utilization. ……............................................... 2-7

Figure 2-4. Projected Single-Shell Tank Retrieval Sequence and Schedule. ............................. 2-9

Figure 2-5. Approach Used to Sequence Single-Shell Tank Retrievals................................... 2-11

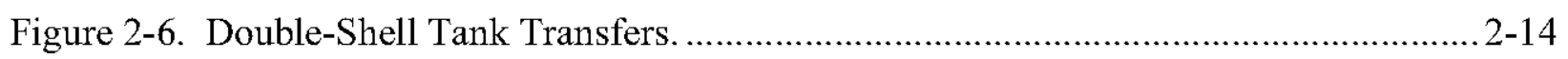

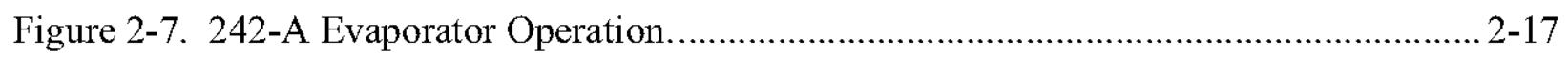


Figure 2-8. Sodium Concentration in Delivered Waste Treatment and Immobilization Plant Feed.

Figure 2-9. Cumulative Volume of the Feed Delivered to the Waste Treatment and Immobilization Plant.

Figure 2-10. Cumulative Sodium in the Feed Delivered to the Waste Treatment and Immobilization Plant.

Figure 2-11. Solids Concentration Distribution in Feed Delivered to the Waste Treatment and Immobilization Plant.

Figure 2-12. Waste Treatment and Immobilization Plant High-Level Waste Glass Production. $2-24$

Figure 2-13. Waste Treatment Plant Low-Activity Waste Glass Production. $2-25$

Figure 2-14. Demonstration Bulk Vitrification System and Bulk Vitrification System LowActivity Waste Glass Production.

Figure 2-15. East Supplemental Treatment Plant Low-Activity Waste Glass Production.......2-27

Figure 2-16. West Supplemental Treatment Plant Low-Activity Waste Glass Production...... 2-28

Figure 2-17. Contact-Handled Transuranic Packaged Waste Production. 2-29

Figure 2-18. Remote-Handled Transuranic Packaged Waste Production. $2-30$

Figure 2-19. Projected Demand on the Liquid Effluent Retention Facility and Effluent Treatment Facility. $2-32$

Figure 2-20. High-Level Waste Glass Interim Storage and Shipping. 2-33

Figure 2-21. Conceptual Model for Estimating High-Level Waste Glass Mass. ................... 2-36

Figure 2-22. RPP Operating Schedule for the Reference Case. ..........................................2-44

Figure 3-1. Comparison of High-Level Waste Glass Mass Ranges for Selected Cases. 3-2

Figure 3-2. High-Level Waste Glass Production for the Enhanced Single-Shell Tank Retrieval Sensitivity Case.

\section{TABLES}

Table 2-1. Key Features of the Reference Case..... 2-3

Table 2-2. Feed Controls Assumed for the Reference Case ................................................2-16

Table 2-3. Supplemental Transuranic Waste Product Inventory for Selected Constituents.....2-31

Table 2-4. Integrated Disposal Facility Inventory for Selected Constituents.......................2-34

Table 2-5. Summary of Reference Case High-Level Waste Glass Drivers. ........................... 2-41

Table 3-1. Effects of Constraining Blend Pairs. ............................................................... 3-3 
Table 3-2. Sensitivity of Mission to Transuranic Waste Disposition. ........................................ 3-5

Table 3-3. Sensitivity of Mission to Degree-of-Pretreatment............................................... 3-6

Table 3-4. High-Level Waste Glass Formulation Constraints and Limits.................................. 3-9

Table 4-1. Ranges on Key Mission Parameters............................................................... 4-3

Table 4-2. Key Issues and Uncertainties for the Reference Case............................................... 4-5 
ORP-11242, Rev 3

This page intentionally left blank. 
ORP-11242, Rev 3

\section{TERMS}

$200 \mathrm{E}$

$200 \mathrm{~W}$

BBI

BDGRE

BNI

BOF

BVS

$\mathrm{CC}$

$\mathrm{CH}$

CH-TRU

CH2M HILL

CID

CSS

CSB

CWC

DBVS

DCRT

DOE

DSS

DSSF

DST

East STP

EFRT

EIS

EM

ERP

ETF

FY

GFM

GPM

HDW

HEPA

HGR

HLW

HSF

HTWOS

$\mathrm{ICV}^{\mathrm{TM}}$

IDF

IHLW

ILAW

IMUST

IPABS

IPS
200 East Area

200 West Area

Best-Basis Inventory

Buoyant-Displacement Gas Release Event

Bechtel National, Inc.

balance of facilities

Bulk Vitrification System

concentrated-complexed (waste)

contact handled

contact-handled transuranic mixed waste (sometimes called

CH-TRUM)

CH2M HILL Hanford Group, Inc.

Central Internet Database

central storage and shipping

Canister Storage Building

Central Waste Complex

Demonstration Bulk Vitrification System

double-contained receiver tank

U.S. Department of Energy

double-shell slurry

double-shell slurry feed

double-shell tank

East Supplemental Treatment Plant

External Flowsheet Review Team

Environmental Impact Statement

U.S. Department of Energy, Office of Environmental Management

Expert Review Panel

Effluent Treatment Facility

fiscal year

glass-forming mineral

Glass Property Model

Hanford Defined Waste (Model)

high-efficiency particulate air

hydrogen generation rate

high-level waste

Hanford Shipping Facility

Hanford Tank Waste Operations Simulator

In-Container Vitrification $^{\text {TM }}$

Integrated Disposal Facility

immobilized high-level waste

immobilized low-activity waste

inactive miscellaneous underground storage tank

Integrated Planning, Accountability and Budgeting System

Interim Pretreatment System 
IS

ITV

LAW

LERF

LLW

$\underline{M}$

MRS

MS

MTG

MUST

NEPA

NRC

NWPA

ORP

PNNL

PT

PUREX

REDOX

RCRA

$\mathrm{RH}$

RH-TRU

RL

ROD

RPP

SALDS

SNF

SST

SWP

TC\&WM

TEDF

TFC

TFCOUP

TPA

TRU

TRUPACT-II

TWINS

UFP

VRS

WAC

WESF

West STP

WIPP

WIPP-WAC

WRF

WTP
Interim Storage (Facility)

in-tank vehicle

low-activity waste

Liquid Effluent Retention Facility

low-level waste

molarity (moles per liter)

Mobile Retrieval System

modified sluicing

metric tons of glass

miscellaneous underground storage tank

National Environmental Policy Act of 1969

U. S. Nuclear Regulatory Commission

Nuclear Waste Policy Amendments Act of 1987

U.S. Department of Energy, Office of River Protection

Pacific Northwest National Laboratory

Pretreatment (Facility)

Plutonium-Uranium Extraction (Plant)

Reduction and Oxidation Facility (S-Plant)

Resource Conservation and Recovery Act

remote handled

remote-handled transuranic mixed waste (sometimes called

RH-TRUM)

U.S. Department of Energy, Richland Operations Office

Record of Decision

River Protection Project

State Approved Land Disposal Site

Spent Nuclear Fuel

single-shell tank

special work permit (protective clothing)

Tank Closure and Waste Management

Treated Effluent Disposal Facility

Tank Farm Contractor (also Tank Farm Contract)

Tank Farm Contractor Operation and Utilization Plan

Tri-Party Agreement (Hanford Federal Facility Agreement and

Consent Order)

transuranic

Transuranic Package Transporter-II

Tank Waste Information Network System

ultrafiltration process

Vacuum Retrieval System

Waste Acceptance Criteria

Waste Encapsulation and Storage Facility

West Supplemental Treatment Plant

Waste Isolation Pilot Plant

Waste Isolation Pilot Plant - Waste Acceptance Criteria

Waste Retrieval Facility

Waste Treatment and Immobilization Plant 
ORP-11242, Rev 3

This page intentionally left blank. 
ORP-11242, Rev 3

\subsection{INTRODUCTION}

\subsection{PURPOSE}

The U.S. Department of Energy, Office of River Protection (ORP) manages the River Protection Project (RPP). The RPP mission is to retrieve and treat the Hanford Site's tank waste and close the tank farms to protect the Columbia River. As a result, the ORP is responsible for the retrieval, treatment, and disposal of approximately $57^{6}$ million gallons (Mgal) of highly radioactive and hazardous waste contained in 177 Hanford Site waste tanks and closure of all the tanks and associated facilities. The tanks contain materials from years of World-War-II and post-war weapons material production, accounting for $60 \%$ by volume of the nation's stored radioactive tank waste. These tanks contain both high-level and transuranic (TRU) wastes and are approximately 10 miles from the Columbia River and within a 50-mile radius of more than 200,000 people.

There have been a number of changes to the tank waste treatment plans since the last revision of this document. Since 2003, the ORP has conducted over 30 design oversight assessments ${ }^{7}$ of the Waste Treatment and Immobilization Plant (WTP). The estimated cost at completion has increased and the schedule for construction and commissioning of the WTP has been extended. The U.S. Department of Energy, Office of Environmental Management (EM), directed a comprehensive review ${ }^{8}$ of the WTP flowsheet, focusing on throughput.

In addition to the WTP-specific changes, there have been compensatory changes in the tank farms' strategy and plans, affecting both near-term retrieval plans and the assumed implementation of Supplemental Low-Activity Waste (LAW) Treatment and Supplemental TRU waste Treatment.

This version of the System Plan establishes a Reference Case that will be used to provide a description of how the mission could play out, and communicate the potential mission impacts of key issues and uncertainties on the mission. The Reference Case demonstrates how ORP could use the WTP with supplemental LAW and supplemental TRU treatment to complete the treatment and disposal of Hanford tank waste in a reasonable time frame. This case assumes that the WTP being constructed by Bechtel National, Inc. (BNI) will perform better than the minimum contractual performance requirements. Key assumptions have been adjusted to result in a more realistic scenario for this System Plan revision, without undue optimism or pessimism.

The Reference Case approximates the key features of the current baseline and underlying technical basis; it not an exact depiction of the current baseline, a budget request, nor contractual or regulatory commitment on behalf of any party.

\footnotetext{
${ }^{6}$ This is the total volume of waste in the tanks as January 2007 . The volume varies depending on how much water is added during waste retrieval and how much of that water has been removed by the waste evaporator.

${ }^{7}$ One of the key assessments deals with the HLW pretreatment capacity of the WTP Pretreatment Facility. See D-03-DESIGN-005, 2004, HLW Feed Preparation System: Ultra-Filtration Process System, ORP WTP Engineering Division, for more details. Nota bene - this document number was also used for a different report issued in 2003.

8 "Comprehensive Review of the Hanford Waste Treatment Plant Flowsheet and Throughput, Assessment Conducted by an Independent Team of External Experts," March 2006, transmitted under cover of letter CCN: 132846.
} 
The Reference Case continues the alignment of the baseline plan for waste feed delivery, singleshell tank (SST) retrieval, and supplemental treatment with the hot commissioning and ramp up plans for the WTP. Identification of those areas that might benefit from resolution of issues and uncertainties allows the ORP to hone its risk mitigating strategy.

\subsection{ORGANIZATION OF DOCUMENT}

Chapter 1 explains the purpose of this version of the System Plan. An overview of the waste treatment complex (the Hanford Site facilities supporting the storage, retrieval, treatment, and disposal of the tank waste) is provided in $\$ 1.3$; a brief discussion of several potential major changes to the treatment mission is provided in $\$ 1.4$.

Chapter 2 provides a description of how the Reference Case could play out, based on a dynamic simulation of the mission using the Hanford Tank Waste Operations Simulator (HTWOS). The description includes the projected operations and products from the various processes and facilities. Discussions of several cross-cutting topics, while not strictly model results, are provided in $\$ 2.4$.

Chapter 3 discusses the impact of selected parameters upon key aspects of the mission scenario described by the Reference Case.

Chapter 4 provides the overall conclusions, including summaries of key results $(\$ 4.1)$, the mission sensitivities from Chapter $3(\$ 4.2)$, and the key issues and uncertainties that potentially drive the mission $(\$ 4.3)$.

References are located in Chapter 5.

This document also contains three appendices. A glossary of terms is provided in Appendix A. Appendix B summarizes the assumptions used in developing and modeling the Reference Case. Appendix C presents the overall system mass balances for several key constituents.

The detailed HTWOS modeling assumptions used for the Reference Case will be documented in RPP-RPT-33214, HTWOS Model Data Package for the RPP System, Rev. 3 Case. This report will also include references to more detailed model results, such as spreadsheets containing the overall system mass balances.

For traceability purposes, the HTWOS model run depicting the Reference Case is called "System Plan Rev 3(1-12-2008)-8.3r1-WC91778."

\subsection{OVERVIEW OF THE WASTE TREATMENT COMPLEX}

The proposed configuration of the RPP systems and interfaces are described in this section and shown in Figure 1-1. Final decisions concerning the configuration of the Waste Treatment Complex will be made after analysis of environmental impacts have been conducted, and will be included in a record of decision using the National Environmental Policy Act of 1969 (NEPA) process. 
Figure 1-1. River Protection Project Simplified Process Flow Diagram.

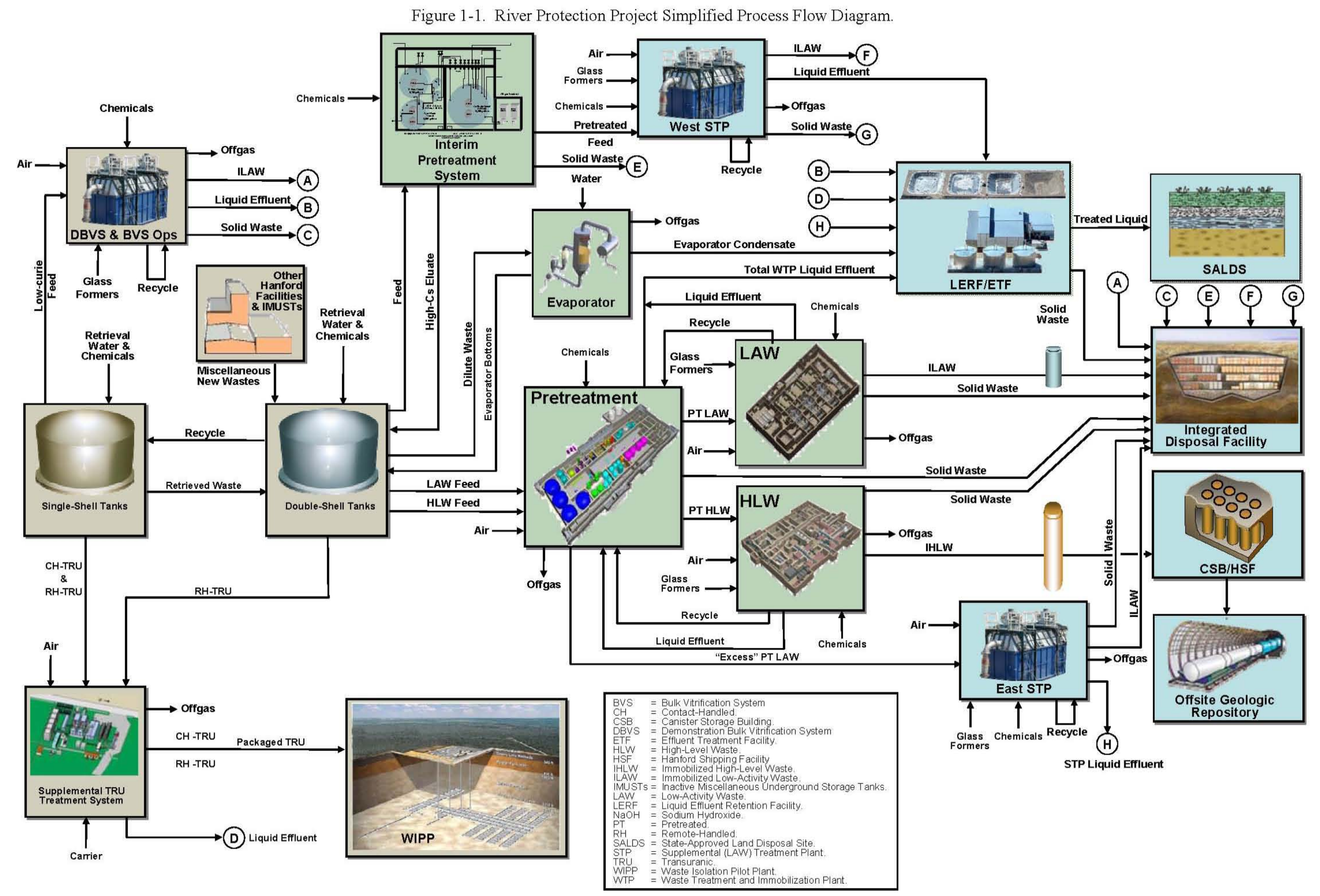




\subsubsection{Tank Farms}

In the 200 East (200 E) and 200 West (200 W) Areas of the Hanford Site, 177 waste storage tanks were built in 18 groups called tank farms. Each tank farm contains from 2 to 18 tanks and holds varying amounts of waste. Twelve of the farms contain SSTs and six contain double-shell tanks (DST). At the time the assumptions were established for this revision of the System Plan, the ORP was responsible for these tank farms and for a number of miscellaneous underground storage tanks distributed throughout the $200 \mathrm{E}$ and $200 \mathrm{~W}$ Areas that contain a small total quantity of waste (HNF-EP-0182, Rev 225).

Figure 1-2 provides an overview of the SSTs and DSTs along with the principal existing and planned transfer systems. The DST System will be used to receive new wastes generated by miscellaneous Hanford Site facilities, to receive wastes retrieved from the SSTs, and to stage wastes for delivery to various pretreatment and treatment facilities.

The tank waste is a complex mixture of multiple waste streams (often called waste types), produced from various facilities using flowsheets and feed stock that evolved over time. Figure 1-3 shows the complex distribution of waste types over the 177 SSTs and DSTs.

The Best-Basis Inventory (BBI) is the official database for tank waste inventory estimates at the Hanford Site, providing waste composition data for safety analyses; risk assessments; and waste retrieval, treatment, and disposal operations. The estimates, comprising 25 chemical and 46 radionuclide components, are based on the "best" available information to describe in-tank waste contents. This includes sample-based information, when available, process knowledge calculations, and waste type templates based on sample data and Hanford Defined Waste (HDW) Model $^{9}$ estimates. The development and maintenance of the BBI is an ongoing effort. The inventories for tanks are updated as a result of new sample data, waste transfers into or out of tanks, and advances in process knowledge or application of available data. Over 100 additional analytes (called supplemental analytes), generally obtained on an opportunistic basis, are tracked and reported via Tank Waste Information Network System (TWINS) when available (RPP-7625, Best-Basis Inventory Process Requirements).

\subsubsection{Single-Shell Tanks}

There are 149 SSTs on the Hanford Site, which were built from 1943 to 1964 to hold radioactive waste created by the production and separation of plutonium and other radionuclides. The SSTs are underground, reinforced-concrete structures (i.e., a concrete tank with a concrete dome) with a carbon steel liner covering the concrete base and walls. They are grouped into 12 tank farms containing between 4 and 18 tanks each. Of the 149 SSTs, 133 are large-capacity tanks with a 75-ft internal diameter (called "100-Series" tanks) and 16 are smaller-capacity tanks (called "200-Series" tanks) with a 20-ft internal diameter. All of the SSTs were removed from active service as waste receivers as of November 1980 (RPP-10435, Single-Shell Tank System Integrity Assessment Report).

\footnotetext{
${ }^{9}$ RPP-19822, Hanford Defined Waste Model, Revision 5.0
} 
The number and capacities of the SSTs follow:

- 16 have a 55,000-gal capacity,

- 60 have a 530,000-gal capacity,

- 48 have a 758,000-gal capacity, and

- 25 have a 1,000,000-gal capacity.

The total holding capacity of the SSTs is about $94 \mathrm{Mgal}$. As of January 2007, the effective date of the starting tank inventory used in this analysis, the SSTs contained approximately $30 \mathrm{Mgal}$ of mixed radioactive and hazardous waste and $95 \mathrm{MCi}$ of radioactivity. ${ }^{10}$ These tanks contain mixtures of varying amounts of saltcake and sludge. Most of their free liquids were evaporated or transferred to the newer DSTs to lessen the chance of leakage.

Since 1959, a total of 67 SSTs have been assumed to have leaked and between 1979 and 2005, all of the SSTs have been "Interim Stabilized" (HNF-EP-0182, Rev 225). The interim stabilization program reduced the liquid content of the SSTs to the greatest extent technically and economically feasible in order to minimize the risk associated with loss of tank integrity (HNF-SD-RE-TI-178, Single-Shell Tank Interim Stabilization Record).

As of April 2007, seven SSTs (C-103, C-106, C-201, C-202, C-203, C-204 and S-112) have been retrieved and two SSTs (C-108 and S-102) were being retrieved.

\subsubsection{Double-Shell Tanks}

The DSTs are Resource Conservation and Recovery Act (RCRA) compliant, double-contained underground storage tanks whose primary function is to safely store the tank waste until it can be transferred to an appropriate treatment system. The DSTs consist of a primary and secondary carbon steel tank within an outer reinforced concrete structure. There are 28 DSTs on the Hanford Site, all built between 1968 and 1986. Their nominal capacities vary:

- 4 have $1,000,000$ gal capacity,

- 16 have $1,120,000$ gal to $1,160,000$ gal capacity, and

- 8 have $1,250,000$ gal capacity. ${ }^{11}$

The DSTs have a total holding capacity of about $32 \mathrm{Mgal}$. As of January 2007, the effective date of the starting tank inventory used in this analysis, the DSTs contain approximately $27 \mathrm{Mgal}$ of mixed radioactive and hazardous waste and $99 \mathrm{MCi}$ of radioactivity. Generally, the tanks contain liquids and settled solids (either salts or sludge).

\footnotetext{
${ }^{10}$ Throughout this report, activity is reported with a January 1,2004 , decay date unless stated otherwise and includes daughter products.

${ }^{11}$ Recently, the allowable waste levels for the eight DSTs in AP-Farm were revaluated to allow for more effective use of existing DST space. The evaluation determined that the levels could be increased from $1.235 \mathrm{Mgal}$ to 1.2465 Mgal after certain prerequisites are met.
} 
Figure 1-2. Waste Transfer System Overview.

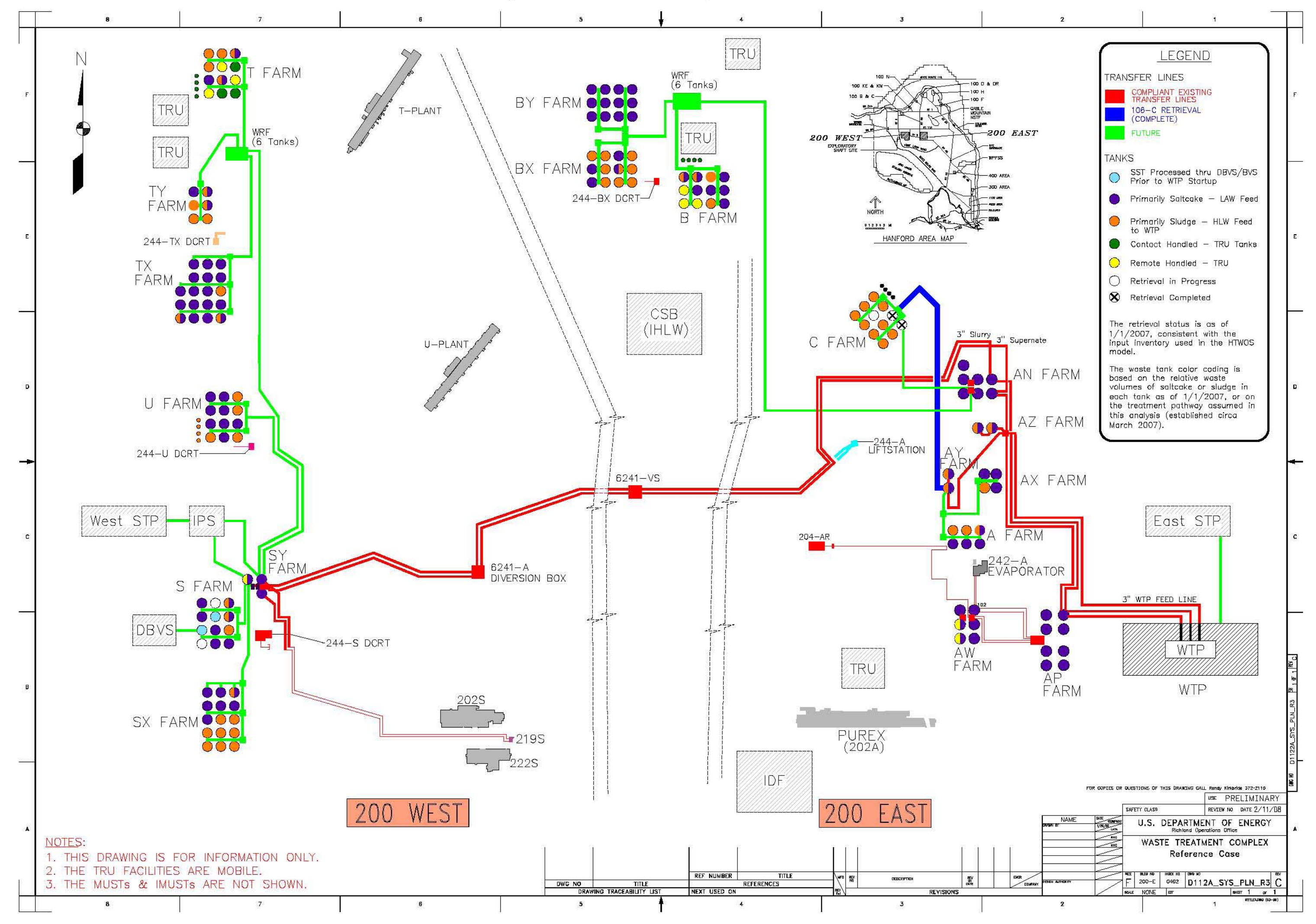


Figure 1-3. Waste Type by Tank.

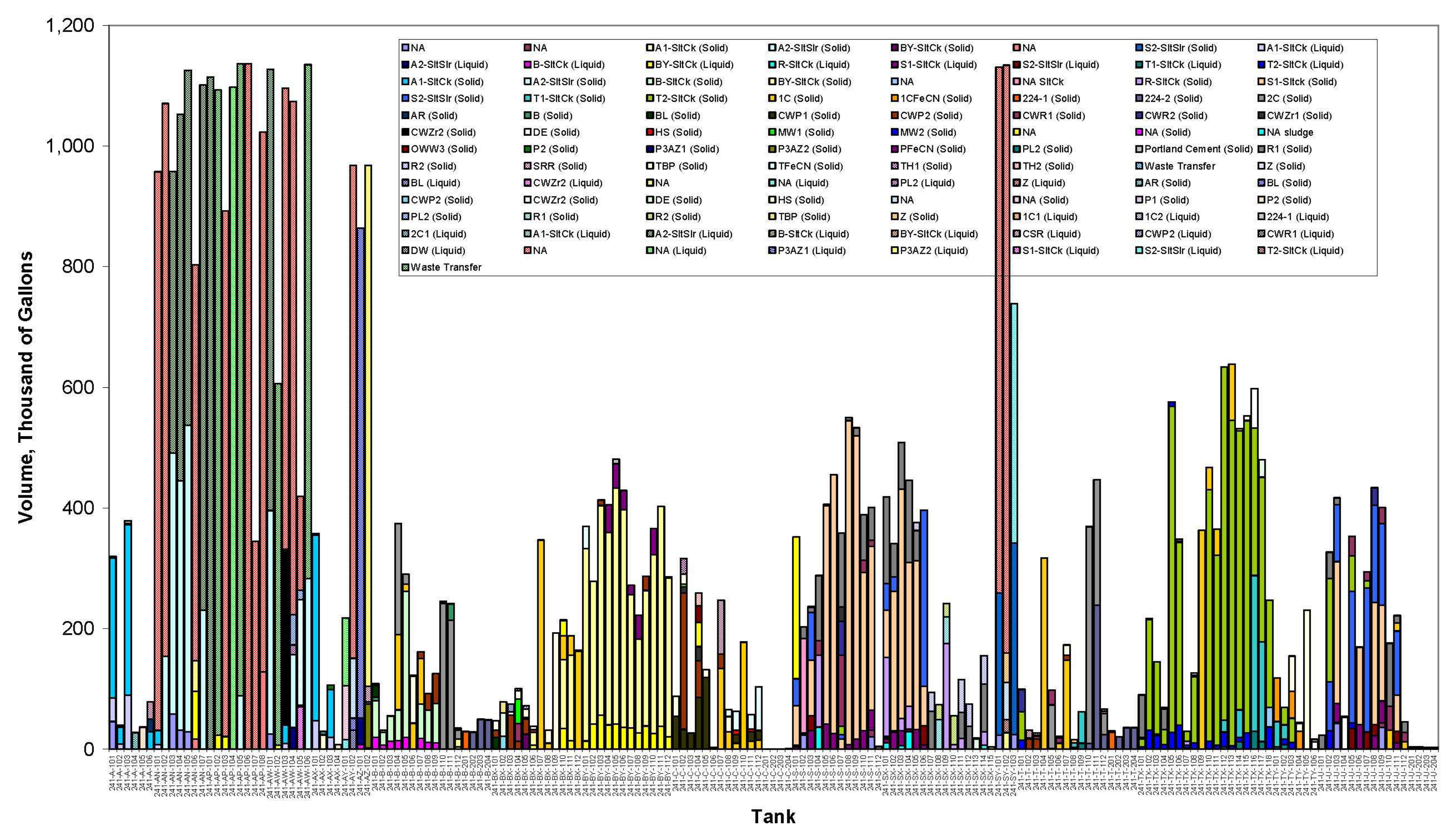


One of the considerations in operating the DSTs is managing the solids and liquids in the DSTs to avoid buoyant-displacement gas release events (BDGRE) and to avoid tank bumps (RPP-RPT-24887, The Long-Term Management of Tank Waste at Hanford). A BDGRE is the rapid release of gas ${ }^{12}$ that may be retained in a settled solids layer resulting in temporary creation of a flammable mixture in the headspace of the tank (RPP-7771, Flammable Gas Safety Issue Resolution). A tank bump is the rapid release of gas, mostly water vapor, causing the tank headspace to pressurize as a result of local superheated liquid vaporization (RPP-6213, Hanford Waste Tank Bump Accident and Consequence Analysis). The controls to prevent each of these events directly or indirectly limit the depth of the solids in the tank, the depth of the supernate, and/or the heat load from radioactive decay. This requires careful coordination with SST retrieval plans to allow effective use of the DSTs before waste treatment processes are on-line.

Another consideration in operating the DSTs is managing waste containing high concentrations of phosphates. Wastes containing phosphates pose a high risk of solids precipitation and/or gelling during transfer, after evaporation and cooling, or during mixing with the waste in the receiver tank. This could (and has in the past) lead to formation of plugs in waste transfer lines or could cause significant difficulties during evaporator operations. It is asserted that a tank containing phosphate gel might retain flammable gases leading to a gas release event of a different mechanism than a BDGRE (RPP-23584). Because of these issues, controls for the transfer of phosphate wastes are provided by HNF-SD-WM-OCD-015, Tank Farms Waste Transfer Compatibility Program. These phosphate waste transfer controls are not currently explicitly modeled for life-cycle mission modeling purposes.

The current baseline assumes that all DSTs will remain in service without failure until the treatment mission has been completed and that no new DSTs will be built. While none of the DSTs have leaked, many are approaching their design lifetimes. The continued integrity of the DSTs is maintained by an ongoing Double-Shell Tank Integrity Program, described in RPP-7574, Double-Shell Integrity Program Plan. This program consists of visual and ultrasonic inspections of the DSTs, corrosion monitoring probes installed in tanks of particular interest, well-defined waste chemistry limits, and structural analysis (RPP-RPT-24887).

\subsubsection{Miscellaneous Underground Storage Tanks}

The ORP is currently responsible for 70 miscellaneous underground storage tanks that comprise 42 inactive miscellaneous underground storage tanks (IMUST) and 28 miscellaneous underground storage tanks (MUST). The distinction between IMUSTs and MUSTs is regulatory: the IMUSTs were removed from service before RCRA permitting and therefore not included in the RCRA operating permit for the tank farm facilities, while the MUSTs are permitted under either RCRA SST Part A or RCRA DST Part A. All will be closed under RCRA provisions per the Hanford Federal Facility Agreement and Consent Order (Tri-Party Agreement or TPA) (Ecology et al. 1989).

The number of miscellaneous underground storage tanks under ORP management changes over time as the status of waste sites and operable units is better understood and as memorandum of agreements between ORP and RL are adjusted. The Reference Case assumed that ORP was

\footnotetext{
${ }^{12}$ Tank waste generates flammable gases through the radiolysis of water and organic compounds, thermolytic decomposition of organic compounds, and corrosion of a tank's carbon steel walls.
} 
responsible for 60 miscellaneous underground storage tanks that comprise 43 IMUSTs and 17 MUSTs. The list of these tanks, their waste volumes, and their status assumed by the Reference Case is provided by HNF-EP-0182, Rev. $215^{13}$ while the FY 2007 Tank Farm Contract (TFC) Baseline ${ }^{14}$ identified 63 (45 IMUSTs and 18 MUSTs).

In any case, decisions regarding the retrieval of any remaining liquid or sludge from these tanks have not yet been made. Therefore, for the purposes of this System Plan, it was assumed that the waste from the IMUSTs and MUSTs would be retrieved circa 2020-2030 into the DST System and treated with the rest of the waste. The combined inventory of the IMUSTs and MUSTs is not well known and was estimated from an engineering study circa 1994 (WHC-SD-EN-ES-040, Engineering Study of 50 Miscellaneous Inactive Underground Radioactive Waste Tanks Located at the Hanford Site, Washington). This should be acceptable for mission modeling purposes because the waste in the IMUSTs and MUSTs comprises only a small fraction of the total tank waste.

\subsubsection{Waste Retrieval from Single-Shell Tanks}

Waste from the SSTs is retrieved to reduce the risk to the public and environment. Although the tank waste is currently managed as high-level waste, the disposition of the waste depends on whether it satisfies criteria as LAW feed, low-curie LAW feed, contact-handled transuranic (CH-TRU) sludge, remote-handled transuranic (RH-TRU) sludge, or high-level waste (HLW).

- Most of the tank waste is candidate LAW feed and is comprised primarily of soluble salts. LAW feed ${ }^{15}$ is material that will require pretreatment to remove some of the isotopes (primarily ${ }^{137} \mathrm{Cs}$ ) and entrained solids so that it can be treated and disposed as immobilized low-activity waste (ILAW) by either the WTP or by Supplemental Treatment. The type of pretreatment depends upon the specific waste - for example, the feed to the Demonstration Bulk Vitrification System (DBVS) and Bulk Vitrification System (BVS) may only require selective dissolution and solid/liquid separation, while the bulk of the waste will require solid/liquid separation and cesium removal.

- Some of the sludge in the SSTs may meet the criteria for definition as CH-TRU waste. The CH-TRU sludge is candidate material for drying, packaging, and disposal at the Waste Isolation Pilot Plant (WIPP). This waste can be retrieved directly to the Supplemental TRU Treatment System.

- Some sludge in SSTs and DSTs may meet the criteria for definition as RH-TRU waste. The RH-TRU sludge is candidate material for drying, packaging, and disposal at WIPP after water-washing to remove soluble salts and to reduce the dose rate by removal of soluble radionuclides. Even after water-washing, the dose rate of this material is expected to exceed allowable limits for CH-TRU.

\footnotetext{
${ }^{13}$ Tables 5.1, 5.2 and 5.3 of HNF-EP-0182, Rev 215.

${ }^{14}$ Baseline Change Request, RPP-06-003, Rev 1, Appendix A, WBS 5.08.05.10, MUST/IMUST Retrieval and Closure.

${ }^{15}$ The terms "LAW Feed" and "HLW Feed" refer to liquid feed (containing mostly soluble salts and a small amount of entrained solids) and slurry feed (containing mostly insoluble solids mixed with liquid feed), respectively. In this context, they are used without regulatory connotation.
} 
- Most of the sludge in the SSTs and DSTs is likely to be classified as HLW, which will be transferred to the WTP for pretreatment and immobilization as HLW glass. The resulting HLW glass is planned for disposal in the geologic repository at Yucca Mountain.

Wastes are planned to be retrieved from the SSTs by using one of three primary retrieval technologies: modified sluicing (MS), a Mobile Retrieval System (MRS), or a Vacuum Retrieval System (VRS). The choice of retrieval system depends on the nature of the waste retrieved and the condition of the SSTs (i.e., whether the SST is a sound tank or assumed to have leaked previously). The selected retrieval techniques for each SST, along with the associated minimum retrieval durations and as-retrieved volumes, are part of the key enabling assumptions (See Appendix B, §B2.2.3.3 ). Special retrieval systems may be developed to deal with specific waste retrieval issues (e.g., the removal of hard heels).

Note that the minimum retrieval durations and as-retrieved volumes assumed for the Reference Case reflect our current understanding of retrieval system performance based on very limited field experience and do not take credit for possible improvements in how a given technology is actually applied, or other improvements resulting from the deployment of other new technologies. See \$2.3.1.4, Waste Retrieval from Single-Shell Tanks, for a discussion on the sensitivity of the treatment end date to these assumptions.

Retrieval of each SST requires a pathway or route to a DST, a Waste Retrieval Facility (WRF), or a processing facility. The route is typically provided by a combination of underground and above ground transfer lines (See §1.3.1.6). Because of the distance of tanks in the northwest (T-, TX-, and TY-Farms) and northeast (B-, BX-, and BY-Farms) quadrants from the DST system, waste will be initially retrieved into WRFs. WRFs will provide the necessary tanks ${ }^{16}$ and pumps to support retrieval and conditioning of the waste before transfer to the DST System. The B-Complex WRF is assumed to be available for use in June 2018; the T-Complex WRF one year later. The eleven B- and T-Farm SSTs containing CH-TRU waste are assumed to be retrieved directly to the Supplemental TRU Treatment System without requiring a WRF or impacting the DST system.

A small amount of "residual" tank waste may remain in each SST after retrieval has been completed. TPA Milestone M-045-00 requires “...retrieval of as much tank waste as technically possible, with tank waste residues not to exceed 360 cubic feet (cu. ft.) in each of the 100 series tanks, $30 \mathrm{cu}$. ft. in each of the 200 series tanks, or the limit of waste retrieval technology capability, whichever is less."

After retrieval of an SST is completed, the tank residuals are established and reported in the BBI. For the $\operatorname{six}^{17}$ of the seven SSTs that had been retrieved, the Reference Case used the BBI inventory for the amount and composition of the tank residuals. For the tanks that have not yet been retrieved, the Reference Case assumed that the residuals would be no better than the maximum allowable volume to attempt to provide a conservative estimate of the tank residuals for potential use in risk assessments. The detailed residual assumptions are provided in Appendix B, §B2.2.3.9 .

\footnotetext{
${ }^{16}$ Each WRF was assumed to contain 6 tanks, each with a working volume of $150 \mathrm{Kgal}$.

${ }^{17}$ Only six of the seven SSTs were retrieved in time to have their residual inventory reported in the download of the $\mathrm{BBI}$ used as input to the Reference Case.
} 


\subsection{Modified Sluicing}

The MS technology uses a liquid spray to dissolve, dislodge, and mobilize SST wastes for retrieval. The sluicing system typically consists of two sluicers, a slurry pump, and one or more cameras installed in the tank, and a control trailer located near the tank. Water is added to a SST to dissolve and mobilize the waste, or recycled supernate from a DST or a WRF may be used as the motive fluid. The mobilized waste solutions and slurries will be pumped from the SST to a DST receiver, or to a WRF tank and then to a DST. The system is referred to as MS because of design improvements that improve or maintain waste retrieval efficiencies (compared to past retrieval efforts using sluicing) while reducing the amount of water or recycled liquid required to retrieve the waste (HNF-SD-WM-SP-012, Tank Farm Contractor Operation and Utilization Plan).

\subsection{Mobile Retrieval System}

The MRS is a vacuum-based waste retrieval system that consists of an articulated mast installed near the center of a tank along with an in-tank vehicle (ITV) designed to move waste toward the center of the tank where it can be removed with the mast. The articulating arm on the mast has a vacuum head that can be moved around the central region of the tank with an effective horizontal reach of approximately $16 \mathrm{ft}$. Air or water can be injected at the vacuum head to assist in mobilizing the waste. If needed, a series of five scarifying, high-pressure, low-volume water jets located around the outside of the vacuum head can be used to dislodge the waste. Both the central mast and the ITV have the ability to use low-pressure water (approximately $125 \mathrm{psi}$ ) and high-pressure water (approximately 1,500 psi) to mobilize waste. The waste is moved to a batch vessel located above grade in the vessel/pump skid where load cells and a level gauge indicate the waste batch volume. The batch vessel has a working volume of about $400 \mathrm{gal}$

(HNF-SD-WM-SP-012).

The ITV is an adaptation of a commercially available tracked vehicle. The ITV has the ability to push waste via a low-pressure water cannon to wash down tank walls and equipment and a three-nozzle scarifier system that can be used to dislodge and mobilize waste, if necessary. The ITV may be deployed at any time during waste retrieval operations to push or jet waste to the center of the tank where it can be removed with the vacuum system. Water and hydraulic lines are routed to the ITV through an umbilical line (HNF-SD-WM-SP-012).

During retrieval operations, the batch vessel is placed under a vacuum (created by the vacuum skid), which draws waste from the SST into the batch vessel. The waste is separated from the gas stream, which continues to the vacuum skid. When the batch vessel is full $(\sim 400 \mathrm{gal})$, the vacuum is broken and the waste is combined with supernate before transfer to the pump skid. A booster pump located on the pump skid draws waste from the batch tank through an ultrasonic de-agglomeration unit to reduce the particle size before transfer to the DST (HNF-SD-WM-SP-012).

The MRS technology was developed to retrieve waste from those SSTs assumed to have leaked. As such, the volume of liquid added to the SST at any point in time is kept to a minimum. Additionally, water is used as a motive fluid rather than recycled supernate to avoid increasing the source term that could leak from the tank during retrieval. 


\subsection{Vacuum Retrieval System}

The VRS uses the same articulated mast described in the MRS system above installed near the center of a 200-Series tank. The articulated mast has a vacuum head, which can be moved along the bottom of the tank with an effective horizontal reach of approximately $16 \mathrm{ft}$, which is sufficient to retrieve waste from the 12 remaining small-volume 200-Series tanks, avoiding the need to deploy an ITV. Air or water can be injected at the vacuum head to assist in mobilizing the waste. If needed, a series of five scarifying, high-pressure, low-volume water jets located around the outside of the vacuum head can be used to dislodge the waste. The central mast has the ability to use low-pressure water (approximately $125 \mathrm{psi}$ ) or high-pressure water (approximately 1,500 psi) to mobilize waste. The waste is moved to a batch vessel located above grade in the vessel/pump skid where load cells and a level gauge indicate the waste batch volume. The batch vessel has a working volume of about $400 \mathrm{gal}$.

During retrieval operations, the batch vessel is placed under a vacuum (created by the vacuum skid), which draws waste from the SST into the batch vessel. The waste is separated from the gas stream, which continues to the vacuum skid. When the batch vessel is full ( $\sim 400$ gal), the vacuum is broken, and the waste is combined with supernatant before transfer to the pump skid. A booster pump located on the pump skid draws waste from the batch tank through an ultrasonic de-agglomeration unit to reduce the particle size before transfer to the DST.

\subsection{Secondary Retrieval Technologies}

A number of secondary retrieval technologies also have been developed to help with the removal of heels projected to remain after the retrieval of certain SSTs using one of the primary retrieval technologies. These include:

- A remote water lance (a.k.a. Salt Mantis), which directs a thin stream of high-pressure (30,000 psi), low-volume (6 gpm) water to break up and mobilize hardened material;

- A mobile retrieval tool (a.k.a. Sand Mantis), which combines a remote water lance with a VRS;

- A high-pressure water mixer (a.k.a. Rotary Viper), which allows a focused stream of water to be directed at problematic waste in the tank to assist with mobilization and dissolution;

- A remotely-controlled in-tank tracked vehicle (a.k.a. Foldtrack ${ }^{\circledR}$ ) capable of being deployed through a $12 \mathrm{in}$. riser that can be fitted with several tools, including a water cannon and scarifying bars, to aid retrieval operations.

\subsection{Chemical Addition}

Varying amounts of recycled supernate, water, or other chemicals may be added to the waste to support retrieval depending on the nature of the waste, the selected retrieval technology, and the destination tank.

Recycled supernate can be used to mobilize the waste and to transport the waste through pipelines as slurry. 
Water can also be used to mobilize waste and has the added benefit of dissolving a portion of the water soluble fraction of the waste. Water may also be added during installation and startup of retrieval equipment and for flushing equipment or pipelines.

Chemicals such as sodium hydroxide may be added to the waste to facilitate dissolution of aluminum compounds (similar to caustic leaching) or to ensure that the composition of the retrieved waste remains within the DST chemistry controls to limit corrosion of the tank. Oxalic acid was added to C-106 to break down the large clumps of solids which could not be retrieved by the installed sluicing system. Generally, it is desired to minimize the use of oxalic acid to the tank waste due to the limited solubility of its sodium salt.

In the modeling of the retrieval and feed staging processes, sufficient water is assumed to be added during retrieval to dissolve salts and other material in the waste to the extent defined by the water wash factors (see \$2.4.1.2). This assumption is important in estimating the fraction of the soluble salts that dissolve prior to delivery to the WTP. If they are not dissolved during retrieval and feed staging, they will need to be dissolved in the WTP Pretreatment (PT) Facility during the caustic and oxidative leaching process, potentially reducing the facility's throughput. The applicability of this assumption may require revisiting for future modeling efforts due to the increasing use of recycled supernate rather than water during retrievals to limit demands on DST tank space.

\subsubsection{Waste Retrieval from Double-Shell Tanks}

DST waste retrieval uses combinations of 300-hp mixer pumps, fixed or variable inlet height transfer pumps, and the ability to add diluent to the waste. The transfer pumps are used to pump waste from one DST to another DST, to the 242-A Evaporator, and to deliver feed to the various treatment facilities. Variable inlet height transfer pumps provide the capability to decant supernate from above a layer of settled solids. The mixer pumps will be used to mobilize sludge for transfer between DSTs, to the WTP, or to the RH-TRU system and for blending of solids; for dissolution of settled salts in the DSTs; and for mixing staged feed before sampling and delivery.

In 2000, a full-scale mixer pump test using actual tank waste demonstrated that mixer pumps could be used to mobilize essentially all of the settled solids in DST AZ-101. This test was performed with a solids depth of about 18 in. (RPP-6548, Test Report, 241-AZ-101 Mixer Pump Test ). However, the baseline requires that up to $200-$ in. deep layers of sludge be mobilized. The ability to mobilize, maintain in suspension, and transfer such quantities of sludge has not yet been demonstrated at Hanford. ${ }^{18}$ As a risk mitigating measure, the baseline includes the performance of related engineering research and studies, small-scale demonstration tests, and limited full-scale demonstration tests, starting in fiscal year (FY) 2012. The baseline also contains risk mitigating measures to improve the ability to sample the staged feed.

The retrieval of waste from the DSTs containing double-shell slurry feed (DSSF) or double-shell slurry (DSS) is complicated by the settled salts and retained gas in those tanks. Each of these tanks contains a large layer of settled salts with retained gas and a layer of saturated supernate with a floating crust on the surface. These tanks (AN-103, AN-104, AN-105, and AW-101) are all designated as "Waste Group A" tanks because of their potential for BDGREs. The strategy

\footnotetext{
${ }^{18}$ Both the West Valley Demonstration Project and the Savannah River Site have successfully used mixer pumps to recover waste sludge for feed to their respective vitrification facilities.
} 
selected for retrieving this waste comprises the following key operational steps (HNF-4669, Decision Document for the Low-Activity Waste Retrieval Strategy for Tanks 241-AN-103, 241-AN-104, 241-AN-105, and 241-AW-101):

- Slowly decant the supernate from the source tank to another DST while adding water to the pump inlet to dissolve any entrained salts and dilute the waste. This step may need to be performed gradually because it will likely induce BDGREs as the hydrostatic head in the tank is reduced. The decant transfer may be paused if flammable gas concentrations in the vapor space exceed allowable limits.

- Add dilution water to the source tank and install and operate a mixer-pump to dissolve the majority of the settled salts and release any remaining gas.

- Stage, sample, and deliver the diluted supernate and the dissolved salts to the WTP as LAW feed.

There are several issues related to the retrieval and staging of the DSSF/DSS tanks. First, the authorization basis for the tank farms will need to be amended before this waste can be retrieved. Second, the retrieval of each of these tanks temporarily ties up two DSTs because of the large volumes of dilution water required to dissolve the solids. Third, Tank AN-104 needs to be retrieved early in the mission to open up the route for cross-site transfer of solids from $200 \mathrm{~W}$ to $200 \mathrm{E}$ because this slurry pipeline is hard piped into AN-104; alternatively, the slurry pipeline could be rerouted to allow the transfer of waste cross-site into any $200 \mathrm{E}$ Area DST.

\subsubsection{Waste Transfer Lines}

The tank farms contain underground piping so the waste can be pumped between tanks, between tank farms, to and from the different facilities, and between the $200 \mathrm{E}$ and $200 \mathrm{~W}$ Areas. These farms also contain equipment, such as diversion boxes and valve pits, that are used to route the waste. For safety and environmental protection, the pipelines generally have a double-wall design with sensors to monitor for leaks. Above-ground hose-in-hose transfer lines will also be used directly or in combination with existing transfer routes to permit more rapid deployment, reduce costs, and provide additional flexibility. See Figure 1-2 for an overview of the waste transfer system.

\subsubsection{Tank Farm Waste Evaporator (242-A)}

The 242-A Evaporator, located in the $200 \mathrm{E}$ Area just north of the AW-Tank Farm, was constructed from 1974 through 1977 and began operating in 1977. The design life of the 242-A Evaporator as originally constructed was 10 years. Portions of the 242-A Evaporator were expanded and upgraded in 1983, and life-extension upgrades were made between 1989 and 1993 to extend its life through 2000. Since then, additional upgrades have either been made or are planned to extend the life of the 242-A Evaporator through 2019. This System Plan assumes that the 242-A Evaporator will be available as needed, except during a series of maintenance outages planned for FYs 2008 - 2012 (HNF-14755, Documented Safety Analysis for the 242-A Evaporator).

The purpose of the 242-A Evaporator is to reduce waste volume so that waste, primarily from retrieval of the SSTs, can be stored within the existing DST system. The process uses a conventional, forced circulation, vacuum evaporator operating at low pressure (approximately 
60 torr) and low temperature (approximately $50^{\circ} \mathrm{C}\left[122^{\circ} \mathrm{F}\right]$ ) to concentrate the waste and reduce its volume by removing some of the water (HNF-14755).

The waste feed is pumped from feed Tank AW-102, through an underground encased transfer line to the 242-A Evaporator and subsequently into the recirculation loop. The waste feed passed through the tube of the reboiler and heated with steam on the shell side. A portion of the water in the waste flashes in the main vessel, creating product slurry and water vapor. The slurry is generally transferred from the 242-A Evaporator through underground encased piping to Tank AW-106, but can be routed to other DSTs in the 200 E Area. Process off-gas and the water vapor are passed through one primary and two secondary condensers, creating process condensate and a gaseous effluent. Gaseous effluents are filtered and released to the environment from the vessel ventilation exhaust system. Process condensate is collected in the condensate collection tank and pumped directly to the Liquid Effluent Retention Facility (LERF) or is used in the process condensate recycle system. Cooling water from the process vapor condensers and the steam condensate stream is discharged to the 200 Area Treated Effluent Disposal Facility (TEDF) Pump Station 3 (HNF-14755).

\subsubsection{Waste Treatment and Immobilization Plant}

The WTP will pretreat and immobilize by vitrification to borosilicate glass about half of the waste now stored in underground tanks at the Hanford Site. The WTP consists of three individual waste treatment facilities (Pretreatment, HLW Vitrification, and LAW Vitrification), a stand-alone analytical and radiochemical laboratory, and the balance of facilities (BOF). These facilities are described in the following subsections.

\subsubsection{Pretreatment}

The WTP PT separates waste feed from the tank farms into an HLW fraction and LAW fraction for subsequent treatment by either vitrification or a separate supplemental process. The WTP PT Facility consists of a series of process vessels located in process cells and a hot cell. The PT Facility includes systems to support the following activities:

- Receive and store waste feed from the tank farm DST System;

- Concentrate waste feed, recycle streams, and treated LAW product to facilitate WTP processing;

- Precipitate strontium and TRU from selected waste for incorporation into HLW feed; ${ }^{19}$

- Mix appropriate amounts of HLW feed with LAW feed for use as feed to the ultrafilter process (UFP) system;

- Use the UFP system to concentrate solids, caustic and oxidative leach solids, and water wash solids;

- $\quad$ Store pretreated HLW solids for HLW vitrification feed;

\footnotetext{
${ }^{19}$ This capability is not used in this mission scenario since this is assumed to be performed in the Tank Farms for the waste currently in tanks AN-102 and AN-107.
} 
- After removal of solids, strontium, TRU, and cesium, transfer the remaining process stream to the LAW Vitrification Facility and/or the East Supplemental Treatment Plant (East STP); and

- Blend pretreated HLW feed with the separated cesium, strontium, and TRU material and then transfer it to the HLW Vitrification Facility.

The technical and programmatic assumptions for the PT Facility are included in Appendix B, $\S \mathrm{B} 2.3 .1$ and $\S \mathrm{B} 2.3 .2$.

Between 2003 and 2006, the ORP and an Expert Flowsheet Review Team ${ }^{20}$ extensively reviewed the WTP flowsheet, focusing on sustaining plant throughput. Collectively, these reviews identified a number of issues requiring optimization of the WTP Pretreatment Facility flowsheet. These optimizations will result in future evolution of the ultrafiltration process system and associated leaching process and minor changes to the ion exchange system. Testing to address these issues is well underway and is scheduled to be completed in 2009. It is anticipated that after resolution of these issues the WTP Pretreatment Facility performance will be reasonably aligned with that assumed by the Reference Case presented in this report with one exception: the quantity of caustic that will be required to leach alumina from HLW solids and keep the resulting aluminate in solution will be significantly higher than the Reference Case. The potential impact from the additional sodium added with the caustic addition is addressed as a sensitivity study in $\S 3.5$, Leach Caustic.

\subsubsection{High-Level Waste Vitrification}

The HLW Vitrification Facility provides the final treatment for the HLW portion of the tank waste comprising the pretreated HLW feed (sludge) and the separated cesium, strontium, and TRU. The waste is blended with various glass-forming materials and is fed into two ceramiclined joule-heated melters where the mixture is processed into molten borosilicate glass. This glass contains and is called immobilized high-level waste (IHLW). The glass is poured into large canisters [0.61 m (24 in.) diameter x $4.5 \mathrm{~m}$ (177 in.) long], cooled, sealed, decontaminated, and staged for interim storage at the Canister Storage Building (CSB) for final disposal at an offsite geologic repository.

The HLW Vitrification Facility also provides temporary storage for up to 48 canisters of IHLW, allocated equally between canister cooling and buffer capacity.

The Reference Case assumes that the two HLW melters will each support a 3 metric tons of glass per day (MTG/d) nameplate capacity, with $70 \%$ availability, yielding a net $4.2 \mathrm{MTG} / \mathrm{d}$ vitrification capacity. This is consistent with the contract capacity of 480 canisters per year for the HLW Vitrification Facility which equates to $4.2 \mathrm{MTG} / \mathrm{d}$ net production capacity and with the Basis of Design (24590-WTP-DB-ENG-01-001). ${ }^{21}$

\footnotetext{
20 "Comprehensive Review of the Hanford Waste Treatment Plant Flowsheet and Throughput, Assessment Conducted by an Independent Team of External Experts," March 2006, transmitted under cover of letter CCN: 132846.

${ }^{21}$ The Basis of Design provides a couple of capacity calculations, keeping only two significant figures: Calculation $1-(480$ canisters / year $) *\left(1.16 \mathrm{~m}^{3} /\right.$ canister $) *\left(2.7 \mathrm{MTG} / \mathrm{m}^{3}\right) /(365 \mathrm{~d} /$ year $)=4.1 \mathrm{MTG} / \mathrm{d}$ Calculation $2-(480$ canisters / year $) *(3.2 \mathrm{MTG} /$ canister $) /(365 \mathrm{~d} /$ year $)=4.2 \mathrm{MTG} / \mathrm{d}$.
} 
The Reference Case also assumes that after about 5 years of operation, these melters are replaced with second generation melters, each supporting a $3.75 \mathrm{MTG} / \mathrm{d}$ nameplate capacity, with a $70 \%$ availability, yielding a net $5.25 \mathrm{MTG} / \mathrm{d}$ vitrification capacity. This is consistent with the Basis of Design which requires the HLW Vitrification Facility to be capable of supporting a production capacity of up to $7.5 \mathrm{MTG} / \mathrm{d}$. The High Level Waste Vitrification Plant Capacity Enhancement Study (24590-HLW-RPT-PE-07-001) concluded that the HLW Vitrification Facility should be capable of supporting production of $7.5 \mathrm{MTG} / \mathrm{d}$ with relatively minor design changes.

Modification M083 to the WTP Contract (DE-AC27-01RV14136) now requires that the HLW Vitrification Facility be designed to support this increased capacity.

The technical and programmatic assumptions for the HLW Vitrification Facility are included in Appendix B, §B2.3.1 and §B2.3.3.

\subsubsection{Low-Level Waste Vitrification}

The LAW Vitrification Facility provides the final treatment for the LAW portion of the tank waste comprising the pretreated LAW feed (supernate) and leachate from pretreatment of the HLW sludge after removal of the cesium, strontium, and TRU. The waste is blended with various glass-forming materials and is fed into two ceramic-lined joule-heated melters where the mixture is processed into molten borosilicate glass. This glass contains and is called ILAW. The glass is poured into large packages [1.22 m (48 in.) diameter by $2.286 \mathrm{~m}$ (90 in.) height], cooled, sealed, decontaminated, and staged for onsite disposal at the Integrated Disposal Facility (IDF).

The Reference Case assumes that the two LAW melter lines will each support $15 \mathrm{MTG} / \mathrm{d}$ nameplate capacity, with $70 \%$ availability, yielding a net $21 \mathrm{MTG} / \mathrm{d}$ vitrification capacity. This is consistent with the contract capacity to treat (vitrify) an average of 733 units of sodium per year, yielding a net $20 \mathrm{MTG} / \mathrm{d}$ vitrification capacity ${ }^{22}$. Design oversight report, D-03-DESIGN-002, Waste Treatment Plant LAW Melter Support System Capacities, concluded that the LAW Vitrification Facility would support up to $32 \mathrm{MTG} / \mathrm{d}$ nameplate capacity (23 MTG/d net). If the most limiting systems were upgraded, the LAW Vitrification Facility would support about $45 \mathrm{MTG} / \mathrm{d}$ nameplate capacity (32 MTG/d net).

The contract requires that the design of the LAW vitrification facility allow for future expansion to support treatment of 1100 units of sodium per year, equivalent to a net $30 \mathrm{MTG} / \mathrm{d}$ vitrification capacity. The expanded capacity could be provided by either installation of a melter in the third melter cell for a total of three melters, or the use of two second generation melters. In either case, changes to the LAW Vitrification Facility would be required to take advantage of this expansion capability (D-03-DESIGN-002, 24590-WTP-DB-ENG-01-001). These changes would likely require a one-year outage of the LAW Vitrification Facility to implement. Assumptions established for the Reference Case did not take credit for this potential future expanded LAW vitrification capacity. Instead, additional LAW vitrification capacity was provided through the supplemental LAW treatment facilities.

\footnotetext{
${ }^{22}$ The conversion of units of sodium per year to net MTG/d assumes Envelope A waste, non-waste sodium additions of $3.5 \%$, and a $14-w t \%$ sodium oxide loading in the glass:

$(733$ units/year)*(1 MT Na/unit)*(1.035)/(0.7419 kg Na/ kg Na2O) / (0.14) / (365 d / year) $=20 \mathrm{MTG} / \mathrm{d}$ net.
} 
The technical and programmatic assumptions for the LAW Vitrification Facility are included in Appendix B, §B2.3.1 and $\S \mathrm{B} 2.3 .4$.

\subsubsection{Waste Treatment and Immobilization Plant Analytical Laboratory}

A stand-alone analytical and radiochemical laboratory will support efficient WTP operations and meet permitting, process control, authorization basis, and waste form qualification requirements. The laboratory will also support the investigation of operational anomalies or process upsets, process improvements, analytical methods optimization, and qualification of new instruments.

\subsubsection{Balance of Facilities}

The WTP includes 20 support facilities, collectively referred to as the BOF, which consist of seven functional groups (D-05-DESIGN-019, Design Oversight Report, Review of Balance of Facilities (BOF) Equipment, System and Facility Preservation Lay-Up and Turnover):

- Power Group - three switch gear buildings and a diesel generator facility.

- Steam Group - a steam plant and a fuel oil facility.

- Water Group - cooling towers, water treatment facility, chiller/compressor facility, and firewater facility.

- Air Group - chiller/compressor facility.

- Process Support Group - glass former storage facility, wet chemical storage facility, and anhydrous ammonia storage and supply facility.

- Waste Facility Group - spent melter staging pad and the non-dangerous non-radioactive effluent facility.

- Miscellaneous Support Facility Group - administration building, simulator facility, warehouse, and Site infrastructure (roads, grading, lights, sanitary waste, storm drains, etc.).

\subsubsection{Supplemental Treatment}

The WTP, as currently scoped, was not intended to process all of the tank waste. The U.S. Department of Energy (DOE) has pursued a variety of strategies to obtain the needed treatment capacity, either by parallel plant construction by two private vendors, or phased approach in which a smaller plant is followed by the construction of a second, larger plant. As the development and design of WTP has progressed, DOE has been able to increase the capacity of the HLW system to support completion of the HLW treatment mission in 25-35 years. However, the capacity improvements implemented on the LAW side provide only about $50 \%$ of the capacity needed to complete the mission in a similar timeframe. As a result, using only the WTP, the mission duration is driven by the available LAW treatment capacity and the amount of LAW that would need to be treated. The current strategy is to shorten the overall treatment schedule by roughly balancing the overall HLW and LAW treatment durations. This is done by basing the mission duration on the available HLW treatment capacity and the amount of HLW that would need to be treated. Then the WTP will be augmented with additional LAW treatment capacity so that LAW treatment completes about the same time as the HLW treatment completes. 
Therefore, the baseline assumes that the treatment capability being provided by the WTP will be augmented in order to reduce the overall duration of the treatment mission. This augmented capability, collectively called "Supplemental Treatment," refers to any primary waste treatment capabilities beyond those provided by the WTP. Supplemental Treatment includes both Supplemental LAW Treatment and Supplemental TRU Treatment. Supplemental LAW Treatment includes the DBVS, the BVS, the East STP, the Interim Pretreatment System (IPS), and the West Supplemental Treatment Plant (West STP). Each of these will be discussed in the remainder of this section.

Previous technology evaluations have recommended that bulk vitrification, steam reforming, and a cementatious waste form called cast stone be developed as potential alternative technologies to the LAW vitrification process used at the WTP (CH2M-0303565, "CH2M HILL Hanford Group, Inc. Recommendation for Further Testing of Supplemental Technologies”). While a supplemental treatment technology has not been selected, the DBVS is planned to demonstrate the viability of one of these proposed supplemental treatment technologies to treat actual Hanford Site waste.

The decision as to which technologies (bulk vitrification, steam reformer, cast stone, or a second WTP LAW facility) will be used to provide supplemental LAW treatment capability will be made as part of TPA Milestones M-62-08 and M-62-11. Key information supporting that decision will be obtained by the DBVS project at the Hanford Site and the Steam Reformer testing being performed at the Idaho National Laboratory and at Hazen Research in Golden, Colorado. Meanwhile, the System Plan assumes that the eventual outcome of those decisions will be to provide supplemental LAW treatment capability using bulk vitrification instead of building a second WTP LAW vitrification facility. Final decisions concerning the use of supplemental treatment will be made after analysis of environmental impacts have been conducted, and will be included in a record of decision using the National Environmental Policy Act of 1969 (NEPA) process.

A new concept under consideration for supporting the M-62-08 and M-62-11 Milestones and for providing the needed supplemental treatment capacity is discussed in $\S 1.4 .4$, Supplemental Treatment vs. Second Waste Treatment and Immobilization Plant Immobilized Low-Activity Waste Facility.

\subsubsection{Demonstration Bulk Vitrification System}

The DBVS, to be located in $200 \mathrm{~W}$ Area west of S-Farm, is a single-line, full-scale test facility that will treat LAW from Tank S-109 in order to support a decision as to how to provide supplemental LAW treatment capacity. A portion of the waste from S-109 is selectively dissolved and the low-curie fraction is used as feed for DBVS after separation of any entrained solids. The Tank S-109 waste retrieval will be controlled to ensure that the feed meets the U.S. Nuclear Regulatory Commission (NRC) definition of LAW and to limit the total activity in the retrieved waste to reduce the dose rate and allow the use of a partially shielded demonstration facility.

The retrieved LAW is mixed with glass-forming minerals (GFM) in a rotary mixer-dryer and heated to about $60^{\circ} \mathrm{C}\left(140^{\circ} \mathrm{F}\right)$ under a vacuum of about 26 in. mercury (660 torr) to remove most of the water. The resulting mixture (dried waste and GFMs with $1-3 \mathrm{wt} \%$ residual moisture) is fed in several batches to a large, refractory-lined, steel box, similar to a roll-off container, and melted by application of an electric current between two electrodes using the In-Container 
Vitrification $^{\mathrm{TM}}\left(\mathrm{ICV}^{\mathrm{TM}}\right)$ technology available from AMEC Earth and Environmental, Inc. The maximum melt temperatures will range from 1300 to $1500^{\circ} \mathrm{C}$. When the $\mathrm{ICV}^{\mathrm{TM}}$ container is nearly full, it is topped off with clean GFMs (no waste) or gypsum from the Off-gas Treatment System, allowed to cool, and interim stored until they are transferred to the IDF for disposal onsite.

Off-gases from the melt are vented from the container and directed to the Off-gas Treatment System. The Off-gas Treatment System consists of multiple stages of particulate filtration, NOx removal, scrubbing, and high-efficiency particulate air (HEPA) filtration systems and off-gas sampling and monitoring systems. Liquid secondary wastes (condensate from the mixer-dryer and liquid effluent from the Off-gas Treatment System) are sent to the LERF for treatment at the Effluent Treatment Facility (ETF).

The DBVS is constructed using process modules, comprised of process equipment mounted on mobile skids, and associated process structures (the buildings, skids, and trailers that house the processing equipment). The process systems include:

- Clean Soil System (supplies the GFM);

- Waste Receipt System;

- Waste Mixer-Dryer and Condensate Recovery Systems;

- Dried Waste Handling System;

- In-Container Vitrification ${ }^{\mathrm{TM}}$ System;

- Off-Gas Treatment System; and

- Secondary Waste Storage System.

The technical and programmatic assumptions for the DBVS are included in Appendix B, $\S \mathrm{B} 2.4 .1$.

An Expert Review Panel (ERP) was chartered to review the current status of the DBVS project, focusing on mission integration; the overall process flowsheet; vitrification and product qualification; equipment design, including operations and maintenance; and safety. The ERP identified a number of technical issues, concerns, and suggestions (RPP-31314, $A$ Comprehensive Technical Review of the Demonstration Bulk Vitrification System, Technical Assessment Conducted by an Independent and External Team of Experts, September 28, 2006,) which are being resolved as described in RPP-PLAN-32249, Demonstration Bulk Vitrification System Project Implementation Plan, Response to the Demonstration Bulk Vitrification System Expert Review Panel Final Report.

Recently, a full-scale integrated dryer melter test called FS-38D (AMEC07.02, "RE: Test and Analytical Results from IDMT"; 30686-RT-0003, Demonstration Bulk Vitrification System, Series 38 Full-Scale Testing) was conducted using cold feed at the Horn Rapids Test Site. The test results demonstrated that the three primary test objectives to (1) demonstrate integrated dryer and melt system operations, (2) demonstrate resolution to the molten ionic salt issue, and (3) demonstrate acceptable glass product were successfully met. The average $\mathrm{Na}_{2} \mathrm{O}$ loading in the glass from the full-scale test was $17.7 \mathrm{wt} \%$ (the test targeted $18.18 \mathrm{wt} \%$ ).

An earlier engineering scale test called ES-30K (30686-RT-0001) demonstrated successful glass formulation using GFMs at $20.80 \mathrm{wt} \% \mathrm{Na}_{2} \mathrm{O}$ loading as compared to the $21.24 \mathrm{wt} \% \mathrm{Na}_{2} \mathrm{O}$ 
loading assumed by the Reference Case and targeted by that test. The slightly lower $\mathrm{Na}_{2} \mathrm{O}$ loading was due to formulating the glass using approximate compositions for the GFMs and is not believed to reflect a real constraint.

\subsubsection{Bulk Vitrification System}

After it completes its initial mission, the DBVS is assumed to be shut down, refurbished, re-permitted, and operated to process additional low-curie feed. In this new role, the refurbished system is called the BVS. The feed will comprise the portion of low-curie waste from Tank S-109 that was not treated by the DBVS, plus low-curie feed obtained by selective dissolution and solid-liquid separation of the waste in Tank S-105. The BVS will operate as long as low-curie feed is available from tanks S-109 and S-105.

The technical and programmatic assumptions for the BVS are included in Appendix B, $\S \mathrm{B} 2.4 .2$.

\subsubsection{East Supplemental LAW Treatment Plant}

The underlying capacity requirements for the WTP PT Facility are to provide enough pretreated HLW feed to support the HLW Vitrification Facility and enough pretreated LAW feed to support about twice the capacity of the LAW Vitrification Facility. The East STP is designed and sized to process the "excess" pretreated LAW feed beyond that which the LAW Vitrification Facility can process.

The East STP is a production scale supplemental LAW treatment facility, located in $200 \mathrm{E}$, northeast of the WTP PT Facility, on the plot of land originally reserved for the second LAW Vitrification Facility. For planning purposes, the East STP is assumed to be a four-line bulk vitrification facility using the same technology and process flowsheet as the DBVS and BVS.

The technical and programmatic assumptions for the East STP are included in Appendix B, $\S \mathrm{B} 2.4 .3$.

\subsubsection{Interim Pretreatment System}

The term "Interim Pretreatment System" is used in two different contexts in this System Plan:

- The Reference Case uses the term "Interim Pretreatment System" to refer to the West Supplemental Pretreatment Facility provided by the baseline, and is discussed in this section.

- The term "Interim Pretreatment System" also refers to a new project that may eventually supplant the "West Supplemental Pretreatment" and is discussed as an option under consideration in $\$ 1.4 .5$.

The Reference Case assumes that the IPS will be used to pretreat a portion of the supernate generated from retrieval of $200 \mathrm{~W}$ Area SSTs to provided pretreated LAW for treatment in the West STP.

For the Reference Case, the IPS is assumed to be installed in two new vaults located near SY-Farm consistent with the current approved baseline for the West Supplemental Pretreatment system. Rotary micro-filtration units located in Tank SY-101 are assumed to remove entrained solids, and a regenerable ion exchange system located in one of the vaults will remove cesium 
from the supernate. Pretreated supernate will be temporarily stored in a pair of double-contained receiver tanks (DCRT) located in the second vault. After sampling, the staged pretreated supernate from the DCRTs will be transferred to the West STP for vitrification.

The technical and programmatic assumptions for the IPS are included in Appendix B, §B2.4.4.

\subsubsection{West Supplemental Treatment Facility}

The West STP, to be located near SY-Farm and the IPS, is assumed to be functionally identical to the East STP. However, it will treat pretreated supernate from the IPS rather than from the WTP PT Facility.

One of the features of the current TFC baseline is that the total supplemental LAW treatment capacity is split between 200 E Area and $200 \mathrm{~W}$ Area to reduce the demand on the WTP PT Facility to prepare pretreated LAW feed, to reduce the volume of waste that must be transferred cross site from the $200 \mathrm{~W}$ to $200 \mathrm{E}$ Areas, and to partially decouple West Area SST retrievals from the WTP schedule.

The technical and programmatic assumptions for the West STP are included in Appendix B, $\S \mathrm{B} 2.4 .5$.

\subsubsection{Supplemental Transuranic Waste Treatment System}

As many as 20 tanks (17 SSTs and 3 DSTs) contain waste that is classified as TRU and might qualify for disposal at the WIPP. However, questions remain as to how much, if any, of the waste will meet all of the conditions ${ }^{23}$ for disposal at WIPP, and the outcome of the Tank Closure and Waste Management (TC\&WM) Environmental Impact Statement (EIS) Record of Decision (ROD). If the decision is to not dispose of this waste as TRU, then this TRU waste would probably be processed in the WTP along with the HLW.

The purpose of the Supplemental TRU Treatment System is to prepare the TRU tank waste for shipment and disposal at WIPP. Doing so will avoid the increase in HLW glass mass, and treatment and disposal costs that would result if this TRU waste were immobilized in the WTP along with the HLW.

Supplemental TRU treatment comprises both contact-handled transuranic mixed waste (CH-TRU) and remote-handled transuranic mixed waste (RH-TRU) processes. Eleven of the tanks are projected to yield a low-dose, contact-handled product meeting WIPP waste acceptance criteria (WAC); the remaining nine tanks are projected to yield a higher-dose, remote-handled product. WIPP has recently received a RH-TRU permit and has established waste acceptance criteria for remote-handled waste. A Class 3 RCRA permit modification would be required as a precursor to acceptance of the Hanford TRU tank waste at WIPP.

The CH-TRU process will use mobile, skid-mounted process equipment. The facility will be first located adjacent to B-Farm, the tank farm supplying the initial CH-TRU waste feed, and then be relocated to T-Farm, which supplies the remaining CH-TRU feed.

\footnotetext{
${ }^{23}$ A decision for disposal at the Waste Isolation Pilot Plant (WIPP) will not be made until (1) the waste meets the WIPP Waste Acceptance Criteria, with special emphasis on the waste determination as delineated in the WIPP recertification decision by the Environmental Protection Agency in March 2006; and (2) it meets the regulatory eligibility requirements for disposal as described in the WIPP Hazardous Waste Facility Permit.
} 
The TRU treatment system uses a rotary dryer-mixer similar in design to that being used for the bulk vitrification processes to remove water from the TRU sludge. A flowability agent (vermiculite) is added during startup of the dryer, and a scouring agent (sand) is added during steady-state operation. The dried product, consisting of approximately $10 \mathrm{wt} \%$ water, $10 \mathrm{wt} \%$ sand, with the remainder dried TRU sludge, is packaged in 55-gal drums for eventual disposal at WIPP. Condensate from the mixer-dryer is filtered and then discharged to LERF/ETF via a tank truck or reused to retrieve and transport additional TRU sludge. Off-gas is HEPA filtered and then discharged to the atmosphere.

The RH-TRU process is assumed to be the same as the CH-TRU process; however, the RH-TRU sludge will be water washed to remove soluble high-level waste components before drying. The RH-TRU from the DSTs will be water-washed in AW-Farm; the RH-TRU from B-Farm and T-Farm will be water-washed in the adjacent WRF. The facility will also include provisions such as shielding to handle the higher dose rate expected from the RH-TRU sludge. The RH-TRU is assumed to be directly packaged into a RH-TRU waste canister.

The RH-TRU Facility will be located adjacent to AW-Farm, which will supply the initial water-washed RH-TRU waste feed, and then be relocated near the B-Complex WRF to treat sludge from B-Farm, and finally near the T-Complex WRF to treat sludge from T-Farm.

An Interim Storage (IS) Facility will be provided adjacent to each CH-TRU or RH-TRU facility site to enable packaged wastes to be staged pending accumulation of sufficient quantity for shipment to a central storage and shipping (CSS) facility or the Central Waste Complex (CWC) for CH-TRU waste or direct to WIPP for RH-TRU waste (WBS 5.09.02.02.04.04, CH-TRU CSS WIPP Waste Facilities Cost Estimating Input Sheet; WBS 5.09.02.02.05.04. RH-TRU CSS WIPP Waste Facilities Cost Estimating Input Sheet).

Shipping is discussed in $\$ 1.3 .4 .11$, Waste Isolation Pilot Plant.

The technical and programmatic assumptions for the Supplemental TRU Treatment System are included in Appendix B, §B2.4.6.

\subsubsection{Interfacing Facilities}

\subsubsection{Liquid Effluent Retention Facility and Effluent Treatment Facility}

The LERF is designed to store 242-A Evaporator process condensate and other dilute liquid waste streams for treatment at the 200 E Area ETF. ${ }^{24}$ The LERF is located in 200 E Area, approximately $1.2 \mathrm{~km}(0.75$ mile $)$ north of the 242-A Evaporator. The LERF consists of three $7.8 \mathrm{Mgal}$ basins, each equipped with primary and secondary liners, leachate detection, collection and removal systems, and a floating cover, capable of storing up to $23.4 \mathrm{Mgal}$ of waste. The LERF also includes transfer piping and pumps connecting it to the 242-A Evaporator and the ETF. A life extension upgrade is planned for the LERF in FY 2015 to extend its 20-year design life (HNF-SD-WM-SAD-040, LERF Final Hazard Category Determination).

The ETF provides for the collection, treatment and storage of low-level mixed wastes as well as the disposal of the treated wastes meeting applicable state and federal permit requirements. The ETF is located in the northeast corner of 200 East Area, near the LERF, approximately $1.6 \mathrm{~km}$

\footnotetext{
${ }^{24}$ Throughout this document, ETF refers specifically to the 200 Area ETF.
} 
(1 mile) north of the 242-A Evaporator (HNF-SD-ETF-ASA-001, 200 Area Effluent Treatment Facility Auditable Safety Analysis Report). The ETF began operation in 1995 and has an operating design life of 30 years (HNF-26914, Conceptual Design Report for Effluent Treatment Facility Solidification Treatment Unit).

Together, the LERF and ETF are assumed to provide the necessary storage and treatment capability for the radioactive liquid effluents generated by the Waste Treatment Complex over the waste treatment mission. An engineering study was conducted to ensure that the ETF has sufficient capacity and produces a secondary waste product that would meet future disposal requirements. Due to uncertainties in the projected inventory of mobile radionuclides to be disposed in this stream, and potential issues with the performance of the existing powder waste form, the study recommended that the secondary waste from ETF be stabilized in a cement-based waste form. The cement-based waste form can be tailored to meet the final WAC for the disposal of waste at the IDF once they have been defined (HNF-23142). Project W-601, Effluent Treatment Facility Solidification Treatment Unit (HNF-26914), is assumed to provide the ETF with the recommended cement-based stabilization method.

This Plan assumes that the LERF and ETF will support the needs of the waste treatment mission.

The technical and programmatic assumptions for the LERF and ETF are included in Appendix B, §B2.5.1.

The DOE Richland Operations Office (RL) is currently responsible for the management of the LERF and the ETF. These facilities will be transitioned to the ORP as part of the new contracting scheme for the Hanford Site. Under the solicitation for the Tank Operations Contract (DE-RP27-07RV14800), the Tank Operations Contractor will assume responsibility for the ETF and LERF, and complete upgrade designs and permitting, perform facility upgrades, and operate the ETF and LERF.

\subsubsection{Central Waste Complex}

The CWC in the $200 \mathrm{~W}$ Area provides compliant interim storage for containerized low-level waste (LLW) and mixed LLW on the Hanford Site, and TRU waste awaiting treatment and final disposal at the WIPP. The CWC began waste management operations in August 1988. Treatment available at the CWC includes the absorption and solidification of free liquids, neutralization of corrosive materials, and stabilization and encapsulation of solid waste matrices (WA7890008967, "Dangerous Waste Permit Application, Central Waste Complex").

The CWC receives, stores, and distributes solid radioactive and non-radioactive waste in a safe and environmentally compliant manner. The CWC consists of multiple storage structures that provide interim storage for solid waste awaiting appropriate treatment and final disposal. The solid waste is received from both onsite and offsite generators. Low level, mixed low level, and mixed TRU waste are all stored at the CWC (SWIFT-CWC 2007, Solid Waste Integrated Forecast Technical [SWIFT] Report).

The CWC is not modeled. It is assumed to provide, to the extent practical, permitted waste storage and characterization for the CH-TRU waste packaged by the Supplemental TRU Treatment System (WBS 5.09.02.02.04.07, CH-TRU CSS Onsite Waste Storage Cost Estimating Input Sheet). 


\subsubsection{Canister Storage Building / Hanford Shipping Facility}

The CSB, also known as Building $212 \mathrm{H}$, is located in the $200 \mathrm{E}$ Area. The CSB consists of three below-grade concrete vaults along with common superstructure, operating deck, utilities and a support building. Project W-379, Spent Nuclear Fuel (SNF) Canister Storage Building, completed construction of the CSB and outfitted Vault 1 . Vault 1 is being used by the SNF Program managed by RL. Vaults 2 and 3 will be transitioned to the ORP and retrofitted under Project W-464 for the interim storage of up to 880 IHLW glass canisters before shipping to the Offsite Geologic Repository. Project W-464 will also provide for the onsite transportation of IHLW canisters from the WTP to the CSB and then to the Hanford Shipping Facility (HSF) (RPP-7507, Design Requirements Document for Immobilized High-Level Waste Interim Storage Facility, Project $W-464)$.

The HSF will receive, package, and stage the IHLW canisters from the ORP and SNF multi-canister overpacks and SNF standard canisters from RL; load the canisters and overpacks into casks, and dispatch the loaded casks to transport to the Offsite Geologic Repository for permanent disposal. The HSF will have a 40-year design life; its location has not yet been determined. The HSF is specified to receive up to two canisters per day. The System Plan assumes that this entire capacity will be available for the ORP mission (RPP-20270, Hanford Shipping Facility System Specification).

The technical and programmatic assumptions for the CSB and HSF are included in Appendix B, $\S \mathrm{B} 2.5 .3$.

\subsubsection{Integrated Disposal Facility}

The IDF will provide onsite disposal of ILAW from the WTP; mixed waste generated through waste operations; other LLW; offsite generated mixed and LLW; alternative ILAW forms such as those generated from bulk vitrification or the ETF; and spent or failed LAW and HLW melters from the WTP. The IDF also provides for the transport of spent or failed melters and ILAW packages from the WTP to the IDF. The initial phase of the IDF has been constructed (RPP-15833, System Specification for the Integrated Disposal Facility).

The IDF is located in the 200 E Area, southwest of the Plutonium-Uranium Extraction Plant (PUREX). The IDF consists of a single landfill with two separate, expandable cells that will be expanded if and when the additional capacity is needed. One cell (Cell 1) is permitted as an RCRA Subtitle C landfill system and designed in accordance with Washington Dangerous Waste Regulations; this cell may receive dangerous and/or hazardous waste, specifically mixed LLW. This includes the ILAW from WTP and bulk vitrification, the spent or failed melters, and ETF secondary waste. The other cell (Cell 2) will not receive dangerous and/or hazardous waste, it will receive only LLW. Both cells include a double liner system, leachate collection and removal systems, and a leak-detection system (RPP-15479, Project Definition Criteria for the Integrated Disposal Facility).

The technical and programmatic assumptions for the IDF are included in Appendix B, §B2.5.5.

\subsubsection{222-S Laboratory}

The 222-S Laboratory provides key analytical support for the operation (primarily waste compatibility analysis, 242-A Evaporator campaign planning, and SST retrieval) of the tank farms. Approximately $10 \mathrm{Kgal} /$ year of liquid waste is returned to the tank farms. 
The 222-S Laboratory is not shown on the Simplified Process Flow Diagram or explicitly modeled. However, the detailed modeling assumptions account for the waste stream from the 222-S Laboratory to the tank farms.

The programmatic assumptions for the 222-S Laboratory are included in Appendix B, §B2.5.6.

\subsubsection{Other Hanford Site Facilities}

Radioactive waste receipts from other Hanford Site facilities are largely completed, and this plan assumes that they will handle their own deactivation waste, except for a small volume of liquid waste from T-Plant (18 Kgal) and the -PUREX Plant $(17 \mathrm{Kgal})$ that is assumed to be transferred to the tank farms circa 2025. T-Plant and PUREX are managed by RL.

\subsubsection{Waste Encapsulation and Storage Facility}

The Waste Encapsulation and Storage Facility (WESF), adjacent to the west end of B-Plant, was constructed in 1974 to encapsulate and store cesium and strontium that were separated from the Hanford Site's tank waste (DOE/RL-2006-35, Hanford Facility Dangerous Waste Permit Application, Waste Encapsulation and Storage Facility). The cesium waste is stored as a chloride salt in double-contained 316L stainless steel capsules with maximum outer dimensions of about $53 \mathrm{~cm}(21 \mathrm{in}$.) long by about $8 \mathrm{~cm}$ ( $3 \mathrm{in}$.) in diameter. The strontium waste is stored as a fluoride salt in double contained Hastelloy ${ }^{\mathrm{TM}} \mathrm{C}-276$ capsules with maximum outer dimensions of about $51 \mathrm{~cm}$ (20.1 in.) long by about $6.7 \mathrm{~cm}$ (2.625 in.) in diameter (HNF-22687, WESF Capsule Data Book).

Approximately one third of the cesium and strontium contained in the original tank waste was previously removed and incorporated into capsules that are now stored in water pools located in WESF pending final disposition. WESF provides safe storage and monitoring of the capsules, which contain radioactive cesium chloride salt and strontium fluoride powder. The current inventory consists of 1,335 cesium capsules and 601 strontium capsules. The capsules contain some $130 \mathrm{MCi}$ of radioactivity ${ }^{25}$ (HNF-SD-WM-TI-733, Supporting Calculations and Assumptions for Use in WESF Safety Analysis).

The management of the WESF and the disposition of the cesium and strontium capsules is the responsibility of RL and, therefore, is not a part of this plan. Current plans assume that the capsules will be transferred for direct disposal at the Offsite Geological Repository starting in FY 2018 and that WESF will be deactivated by FY 2022. However, the current WTP contract provides for the ability to receive and vitrify the contents of the capsules, after appropriate conditioning, as HLW if direct disposal is determined to be infeasible.

A recent study (EDF-NSNF-072, Hanford Cs-Sr Repository Disposal Performance Analysis Using the TSPA-FEIS Model) has shown that direct disposal of the capsules at the Offsite Geologic Repository at Yucca Mountain appears viable. A decision as to the continuing viability of direct disposal will be made under TPA Milestone M-092-05 circa 2017. This allows sufficient time for ORP to make the necessary changes to the WTP to receive and vitrify the contents of the capsules (M-92-07-01, Modification of Hanford Federal Facility Agreement and Consent Order (Tri-Party Agreement) M-92-05).

\footnotetext{
${ }^{25}$ Nota bene - the decay date for this activity is January 1, 2002.
} 
The WESF is not shown on the Simplified Process Flow Diagram nor is the treatment of the capsule contents modeled.

The programmatic assumptions for the WESF are included in Appendix B, §B2.5.7.

\subsubsection{State Approved Land Disposal Site}

The State Approved Land Disposal Site (SALDS) is located north of the $200 \mathrm{~W}$ Area. Treated effluent from the ETF is transferred via pipeline to the SALDS where it is discharged to the ground (HNF-SD-ETF-ASA-001).

The SALDS is not explicitly modeled, although the predicted demand on the SALDS from the ETF resulting from the retrieval and treatment of tank waste is calculated.

The programmatic assumptions for the SALDS are included in Appendix B, §B2.5.1.

\subsubsection{200 Area Treated Effluent Disposal Facility}

The 200 Area TEDF began operations in 1995 and collects, transports, and disposes of treated or unregulated liquid effluents from facilities and systems in the $200 \mathrm{E}$ and $200 \mathrm{~W}$ Areas. The TEDF consists of about 11 miles of pipeline, three pumping stations, one disposal sampling station (Building 6653) and two five-acre disposal ponds (HNF-SD-W049H-ICD-001, 200 Area Treated Effluent Disposal Facility Interface Control Document).

Project W-519-P1 provided a pipeline for future WTP non-radioactive, non-dangerous liquid effluents from the WTP site boundary to the 200 Area TEDF (24590-WTP-ICD-MG-01-005, ICD 05 - Interface Control Document for Nonradioactive, Nondangerous Liquid Effluents).

The 200 Area TEDF is not modeled or shown on the Simplified Process Flow Diagram.

The technical and programmatic assumptions for the 200 Area TEDF are included in Appendix B, §B2.5.1.

\subsubsection{Offsite Geologic Repository}

The IHLW glass canisters are assumed to be disposed at an Offsite Geologic Repository, designed to isolate the IHLW from the environment for tens or hundreds of thousands of years. The Nuclear Waste Policy Amendments Act of 1987 (NWPA) lists Yucca Mountain, Nevada, as the only site to be studied as a candidate for a deep geologic repository (42 USC 10172). In 2002, President Bush signed House Joint Resolution 87, designating the Yucca Mountain site for development as a repository for the disposal of SNF and HLW.

The final decision on whether DOE is allowed to construct the repository and given a license for its operation is under the jurisdiction of the NRC as the licensing and enforcement agency (DOEYMP01111, Regulatory Licensing Overview - Fact Sheet). As of July 2006, the earliest date that the Yucca Mountain Repository could begin receiving waste was projected as March 2017, based solely on factors within DOE's control (DOE OCRM, 2007, "Yucca Mountain Repository -- About the Project").

This System Plan assumes that the Yucca Mountain Repository will be ready to accept IHLW from Hanford in April 2019. However, until such a repository is ready for receipt of the IHLW canisters, they will have to be stored and monitored on an interim basis at the CSB, and if necessary, additional storage facilities of similar design would be constructed. 


\subsubsection{Waste Isolation Pilot Plant}

The WIPP, located in the Chihuahuan Desert, 26 miles southeast of Carlsbad, New Mexico, is the world's first underground repository that is licensed to safely and permanently dispose of TRU radioactive waste left from the research and production of nuclear weapons. The WIPP is designated to receive and safely dispose of this defense-related TRU waste from the DOE complex in an ancient salt bed approximately 2,150 ft underground (WIPP 2007a, "Why WIPP?")

The WIPP began accepting CH-TRU waste in March 1999 and RH-TRU waste in January 2007 (WIPP 2007b, "WIPP Chronology"). The baseline described in DOE/NTP-96-1204, National TRU Waste Management Plan, (shows that disposal phase activities are currently scheduled through FY 2034. WIPP acceleration initiatives ${ }^{26}$ show the completion of shipping to WIPP from Hanford of CH-TRU by FY 2015 and RH-TRU by FY 2028.

CH-TRU sludge from the tank farms is assumed to be retrieved, packaged to meet WIPP WAC, and transported to the WIPP for disposal. A shipment comprises up to fourteen 55-gal drums of packaged CH-TRU in a Transuranic Package Transporter-II (TRUPACT-II) shipping container, three TRUPACT-IIs in a shipment, for a maximum of 42 drums per shipment. However, actual shipments will contain approximately 30 drums each due to a variety of shipping-related constraints (RPP-36870, Rough Estimate of TRU Drums per Shipment to WIPP). The drums are planned to be disposed of in the WIPP; the TRUPACT-II shipping containers will be reused.

RH-TRU sludge from the tank farms is assumed to be water-washed, retrieved, packaged to meet WIPP WAC, and transported to the WIPP for disposal. The plans are to directly package the RH-TRU into an RH-TRU waste canister which will be shipped to WIPP in an RH-72B shipping package, one RH-72B per shipment. The RH-TRU waste canister will be emplaced at WIPP with its contents; the $\mathrm{RH}-72 \mathrm{~B}$ shipping package is reused.

\subsection{OPTIONS UNDER CONSIDERATION}

There are a number of major options under consideration that may significantly change the overall mission. These are briefly discussed in the following subsections.

\subsubsection{Start Low-Activity Waste Treatment First}

One change under consideration is to allow the WTP LAW Facility to begin vitrifying pretreated tank waste before the projected completion of WTP hot startup. This would require early startup of the WTP LAW, BOF, and Laboratory facilities and implementation of a tank farm based pretreatment system. Additional modifications to the WTP LAW Facility or the 200 Area ETF may also be necessary to accommodate secondary waste streams that would otherwise be recycled back to the WTP PT Facility. The operational WTP facilities would need to be isolated from the WTP facilities still under construction, namely the WTP PT and WTP HLW Facilities (RPP-29981, Evaluation of Starting the Waste Treatment and Immobilization Plant (WTP) Low Activity Waste (LAW) Facility First).

\footnotetext{
${ }^{26}$ Per Tables 5.0-1 and 5.0-2 of "Transuranic Waste Performance Management Plan," U.S. Department of Energy, Carlsbad Field Office, August 2002.
} 
The ORP has made provisions for the Start LAW First option in its recent request for proposal for the Tank Operating Contract (DE-RP27-07RV14800).

At ORP's request, a potential scenario for implementing the Start LAW First option was developed and evaluated (RPP-29981). The option includes a new PT Facility located in the tank farms tailored to pretreat selected tank waste to the extent necessary to directly feed the WTP LAW Facility. The study suggests that LAW treatment could begin as early as mid-2014 with WTP LAW treatment running for about five years in advance of the 2019 operational date for the entire WTP complex. Some of the more important benefits and programmatic risks include:

- Benefits:

- Treats a portion of the tank waste, producing approximately $32,000 \mathrm{MTG}$ that incorporates approximately 4,600 MT Na.

- Frees up about $4.7 \mathrm{Mgal}$ of DST space to support accelerated SST retrieval.

- Lessons learned during the WTP LAW startup could be applied to the startup of the WTP PT and WTP HLW Facilities.

- Experience from the operation of the WTP LAW Facility could be considered in supporting supplemental LAW treatment decisions.

- Programmatic Risks:

- The Tank Farm and WTP baselines do not address the additional operational and Interim Pretreatment System costs associated with starting the LAW facility earlier than assumed in the Reference Case.

- The tank farm PT Facility would need to be covered under either the TC\&WM EIS or a separate NEPA analysis.

- The potential shift of some of the ${ }^{99} \mathrm{Tc}$ and ${ }^{129} \mathrm{I}$ from the LAW glass to the solidified secondary waste form from ETF would need to be evaluated and mitigated, if necessary.

- Operation of the WTP LAW Facility, the WTP Laboratory, and the BOF within an active construction site will result in complex logistical and security issues.

- The technology selected for solid-liquid separation has not been tested at full scale, nor has the assumed cesium ion exchange technology been operated recently in the tank farms.

\subsubsection{Caustic Recycle}

One of the emerging changes to the WTP flowsheet is the need to add hydroxide ion (from sodium hydroxide) to the waste, beyond that assumed in this System Plan, to maintain aluminum that has been leached or otherwise predicted to report to the liquid phase, in solution. This is discussed in more detail in $\$ 3.5$, Leach Caustic. Most of the sodium added to the waste eventually reports to the LAW glass, significantly increasing the mass of LAW glass and potentially driving the mission duration. 
One of the options to mitigate this increase in LAW glass volume is the recycle of caustic from the pretreated LAW stream back to either the WTP PT Facility or the tank farms. ORP is exploring potential caustic management techniques, such as caustic recycle, in conjunction with technology development efforts under the DOE Environmental Management (EM) program.

\subsubsection{Single-Shell Tank Retrieval Sequence}

The SST retrieval sequence needs to balance a number of competing, interdependent considerations. The primary considerations include:

- Maximizing the reduction of short-term and long-term risk to human health and the environment; and

- Optimizing waste feed ${ }^{27}$ to maintain efficient WTP operations.

Additional considerations include:

- Worker safety;

- Supporting the completion of waste management area closures;

- Optimization of DST space utilization considering resource leveling and waste transfer infrastructure; and

- Waste retrieval and closure requirements for associated ancillary equipment.

While this version of the System Plan focuses optimizing the waste feed and DST space utilization, the SST retrieval sequence will continue to change as the treatment mission evolves.

\subsubsection{Supplemental Treatment vs. Second Waste Treatment and Immobilization Plant Immobilized Low-Activity Waste Facility}

As discussed in $\$ 1.3 .3$, Supplemental Treatment, the WTP as currently scoped was not intended to process all of the tank waste; additional capacity, to be constructed at a later date, was always planned. Using only the WTP, the mission duration is driven by the available LAW treatment capacity and the amount of LAW that would need to be treated. Alternatives for providing some or all of the needed supplemental treatment capacity include the addition of a third LAW melter to the existing WTP LAW Facility or the replacement of the LAW melters with higher-capacity second-generation melters. Final decisions concerning the use of supplemental treatment, including which technologies (bulk vitrification, steam reformer, cast stone, or a second WTP LAW facility) will be used to provide supplemental LAW treatment capability, will be made after analysis of environmental impacts have been conducted, and will be included in a record of decision using the National Envirommental Policy Act of 1969 (NEPA) process.

A new concept is being considered for supporting the supplemental treatment decision that would avoid the need for the DBVS facility. This "Cold Test" concept would continue the development of integrated tests performed at the Hom Rapids Test Site by incorporating a

\footnotetext{
${ }^{27}$ This comprises feed to DBVS/BVS, West STP, East STP, CH-TRU and RH-TRU packaging, and the WTP. Two of the key challenges are to allow for reasonable degree of incidental and/or intentional blending to reduce the resulting volume of HLW glass and to maintain the appropriate balance of HLW feed (primarily solids) and LAW feed (primarily liquids) to the WTP to minimize the overall treatment mission duration.
} 
prototypical off gas treatment system. Additional full scale testing that extends the latest system performance tests over the range of expected LAW feed compositions would provide sufficient information to select a supplemental treatment technology, avoiding the need to build and test the DBVS on a narrow range of selected hot feed from a single source.

A production-scale STP using BV technology would probably be located in $200 \mathrm{E}$ Area to treat both the "excess" pretreated LAW from the WTP Pretreatment Facility and the pretreated LAW from the IPS. This STP would be constructed in phases to manage risk. The phased construction and operation would first focus on demonstrating the performance of a single-line BV facility based largely on an optimized version of the existing DBVS design. The facility would then be expanded to include multiple BV lines as needed to support the RPP mission throughput objectives. This concept would be a more cost effective method of obtaining sufficient information to support the supplemental treatment decision and ensures that the location and capability of a future STP is integrated with and supportive of the overall RPP mission objectives.

\subsubsection{Interim Pretreatment System}

As discussed in $§ 1.3 .3 .4$, the term IPS is used in two different contexts in this System Plan. In that context, IPS was assumed to be the West Supplemental Pretreatment system. For the other context, discussed in the remainder of this section, it refers to a recently chartered project on which ORP has directed the TFC (CORR-2008-0024, "Contract No. DE-AC27-99RL14047 Prepare Baseline Change Requests (BCR) to: 1) Develop an Integrity Program for Single-Shell Tanks (SST), and 2) Support Mission Analysis and Preliminary Conceptual Design for Interim Pretreatment System") to initiate work.

ORP's goal for the IPS is to begin providing pretreated waste to the WTP LAW Vitrification facility about 5 years before the WTP Pretreatment Facility is hot commissioned (see $\$ 1.4 .1$, Start Low-Activity Waste Treatment First). After the WTP Pretreatment Facility begins operation, the IPS would provide back-up or supplemental pretreatment capacity and could be used to feed the WTP LAW Vitrification Facility and/or a STP. The IPS is targeted for start-up in FY 2014.

A mission analysis will evaluate alternatives for siting, technology selection, feed selection, system size, preliminary mass balances, cost estimate, and strategies for secondary waste management. Conceptual design development activities include detailed siting study and geophysical survey, development of the process flowsheet, development of functions and requirements and safety design strategy, plus a number of related activities (CORR-2008-0024).

The IPS is time-sensitive since its initial goal is to provide pretreated LAW feed for LAW treatment (either Early LAW or STP) before the WTP Pretreatment Facility has completed hot commissioning. 
ORP-11242, Rev 3

\subsection{RESULTS AND DISCUSSION OF REFERENCE CASE}

This chapter provides a description of the Reference Case based on a dynamic simulation of the mission using the HTWOS:

- $\$ 2.1$ briefly discusses the modeling methodology;

- $\$ 2.2$ summarizes the key features and results for the Reference Case;

- $\$ 2.3$ is a more detailed discussion of the projected operations and products from the various processes and facilities;

- A discussion of several cross-cutting topics, while not strictly model results, is provided in $\$ 2.4$; and

- A summary level schedule depicting key operational activities is provided in $\$ 2.5$.

\subsection{METHODOLOGY}

This revision of the System Plan uses the most recent release of the HTWOS model to simulate the waste storage, retrieval, feed staging, and treatment processes to provide a Reference Case for implementing the RPP mission. The HTWOS model is a dynamic flowsheet mass balance that tracks and predicts the movement of waste over the full RPP mission. It establishes the timing of key process steps and the life-cycle system mass balance using a well-defined set of assumptions. The various processes are modeled in sufficient detail to estimate the overall timing of each process and the quantities and composition of the primary and secondary waste streams, taking into account the interactions, including recycle, between the various processes and unit operations.

The assumptions used to establish the Reference Case were developed after reviewing existing assumptions from the previous RPP System Plan, the WTP contract, ${ }^{28}$ and the HTWOS model run $^{29}$ supporting the TFC baseline submittal, ${ }^{30}$ along with considerations of the findings of two relatively recent reviews ${ }^{31,32}$ of the WTP. These assumptions, documented in Appendix B, were then used in conjunction with lower-level technical and programmatic assumptions to prepare the more detailed modeling assumptions that were used to configure the HTWOS model. These more detailed HTWOS modeling assumptions are documented in RPP-RPT-33214.

In simulating the waste treatment mission, the HTWOS model addresses mixing of waste streams, partitioning of streams (evaporators, ion exchange, solid-liquid separation, wash and leach factors or decontamination factors, and a strontium solubility correlation) and certain

\footnotetext{
${ }^{28}$ DE-AC27-01RV14136, Through Modification Number M051, 2006, WTP Contract.

${ }^{29}$ HNF-SD-WM-SP-012, 2007, Tank Farm Contractor Operation and Utilization Plan, Rev. 6, CH2M HILL Hanford Group, Inc., Richland, Washington.

${ }^{30}$ Baseline Change Request RPP-06-003, Rev. 1, "Alignment of TFC Lifecycle Baseline," November 2006.

31 "Comprehensive Review of the Hanford Waste Treatment Plant Flowsheet and Throughput, Assessment Conducted by an Independent Team of External Experts," March 2006, transmitted under cover of letter CCN: 132846.

${ }^{32}$ D-03-DESIGN-005, 2004, "HLW Feed Preparation System: Ultra-Filtration Process System", ORP WTP Engineering Division. NB - this document number was also used for a different report issued in 2003.
} 
chemical reactions. The simulation proceeds subject to a variety of constraints such as tank space, vessel volume, production rates, dwell time, and simultaneous retrieval limitations. The model doesn't explicitly address reaction kinetics, waste speciation, solid-liquid equilibria, heat transfer, equipment reliability, and certain flowsheet details.

\subsection{KEY FEATURES AND RESULTS}

The key distinguishing features and summary level results of the Reference Case are presented in Table 2-1. The mission scenario depicted in this version of the System Plan is not compliant with several key TPA milestone dates. This non-compliance results primarily from a series of mission delays. The scenario depicted by this Reference Case is not intended to be used as the basis for renegotiated milestone dates. 
Table 2-1. Key Features of the Reference Case.

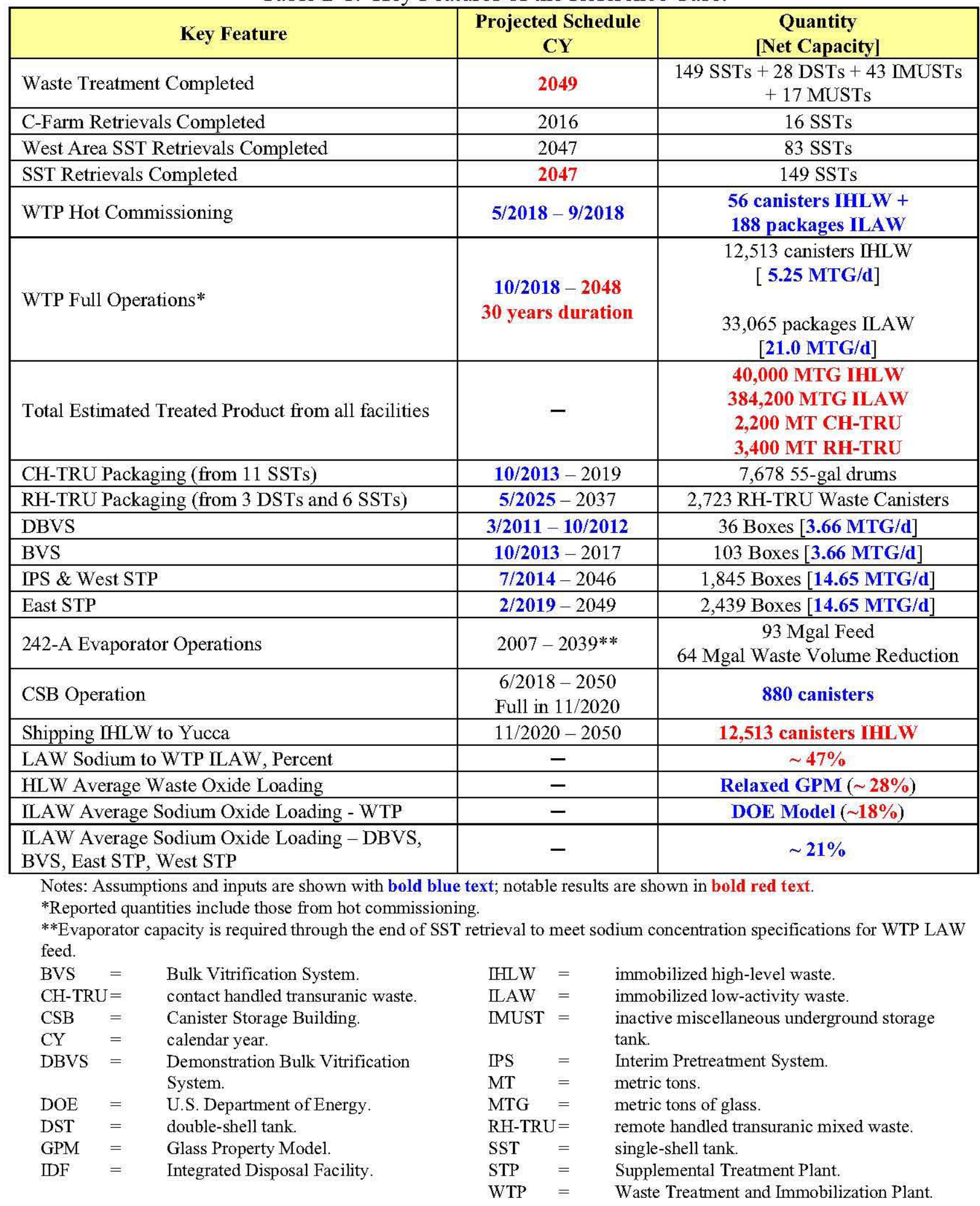




\subsection{DISCUSSION}

The discussion of the mission scenario depicted by the Reference Case is generally organized according to Figure 1-1, River Protection Project Simplified Process Flow Diagram.

The overall mass balance for the Reference Case for selected constituents is provided in Appendix C; the full mass balance is provided as a spreadsheet in SVF-1431, Balance_Graphic_System Plan Rev 3(1-12-2008)-8.3r1-WC91778_M4.xls.

\subsubsection{Tank Farms}

\subsubsection{Single-Shell Tanks}

The SSTs are projected to be retrieved by March 2047, with the C-Farm retrievals completing in November 2016. Figure 2-1 shows the projected SST retrieval progress as measured by the approximate volume of waste remaining in the SSTs as a function of time (SVF-1360, SST_Retrieval_File_System Plan Rev 3(1-12-2008)-8.3r2-WC91778_M3.xls).

Figure 2-1. Projected Single-Shell Tank Retrieval Progress.

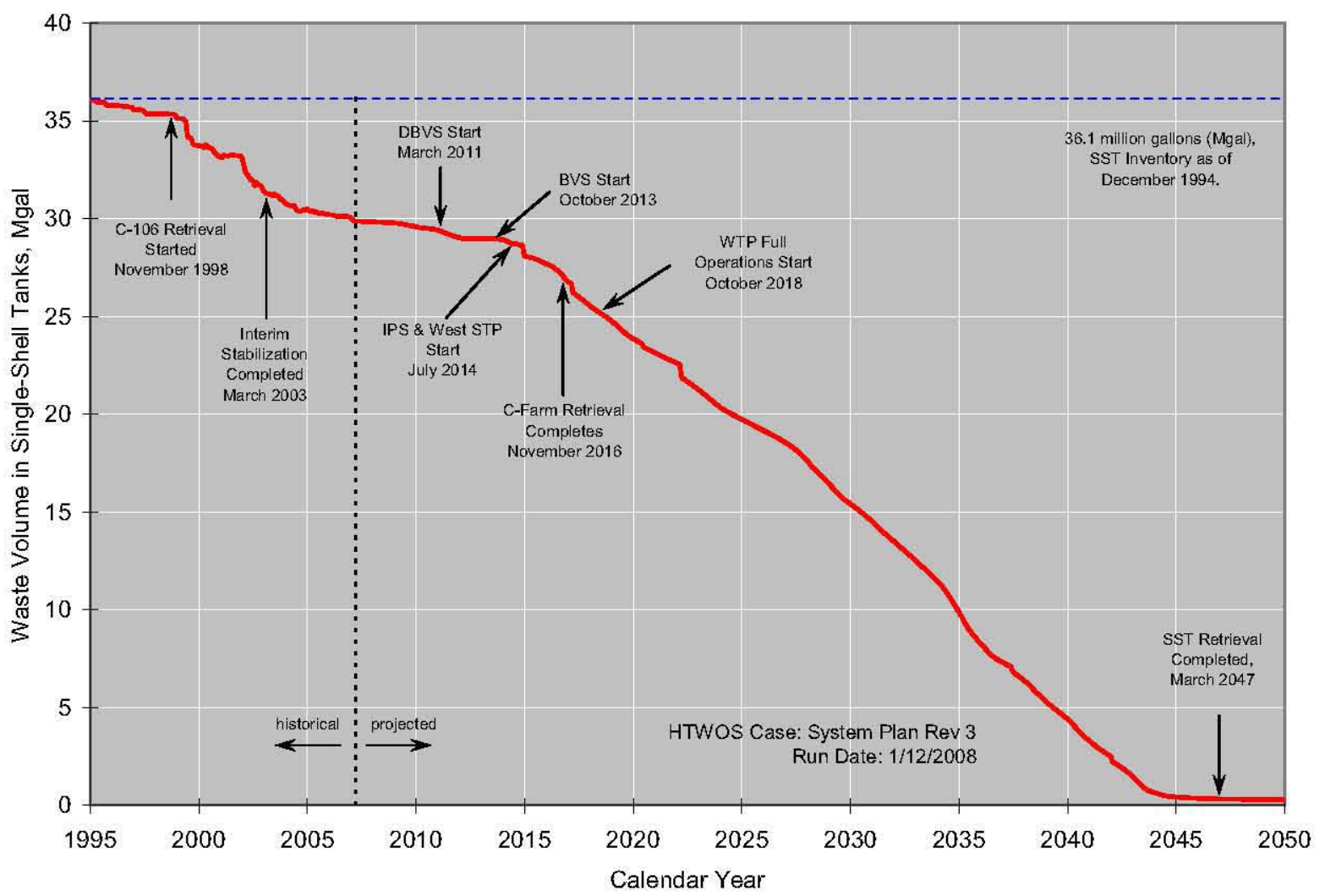

Approximately 300,000 gal of residual waste are projected to remain in the SSTs, comprising approximately $3 \mathrm{MCi}$ of total activity or $1.6 \%$ of the total starting tank inventory. As discussed in $\$ 1.3 .1 .4$, Waste Retrieval from Single-Shell Tanks, this is intentionally based on assumptions that provide a conservative (high) estimate of the tank residuals for potential use in risk assessments and therefore does not represent the most-likely estimate of these residuals. 
The volume of waste transferred into the DST System as a result of SST retrievals is shown in Figure 2-2. The volumes are on an "as-retrieved" basis - this is the net increase in waste in the DST System for the retrievals after accounting for any supernate recycle and water additions, but before the waste is re-concentrated through the 242-A Evaporator. The average retrieval rate on an as-retrieved basis is shown between each pair of black points (SVF-1360).

Figure 2-2. Cumulative Volume Transferred to the Double-Shell Tanks from the Single-Shell Tanks.

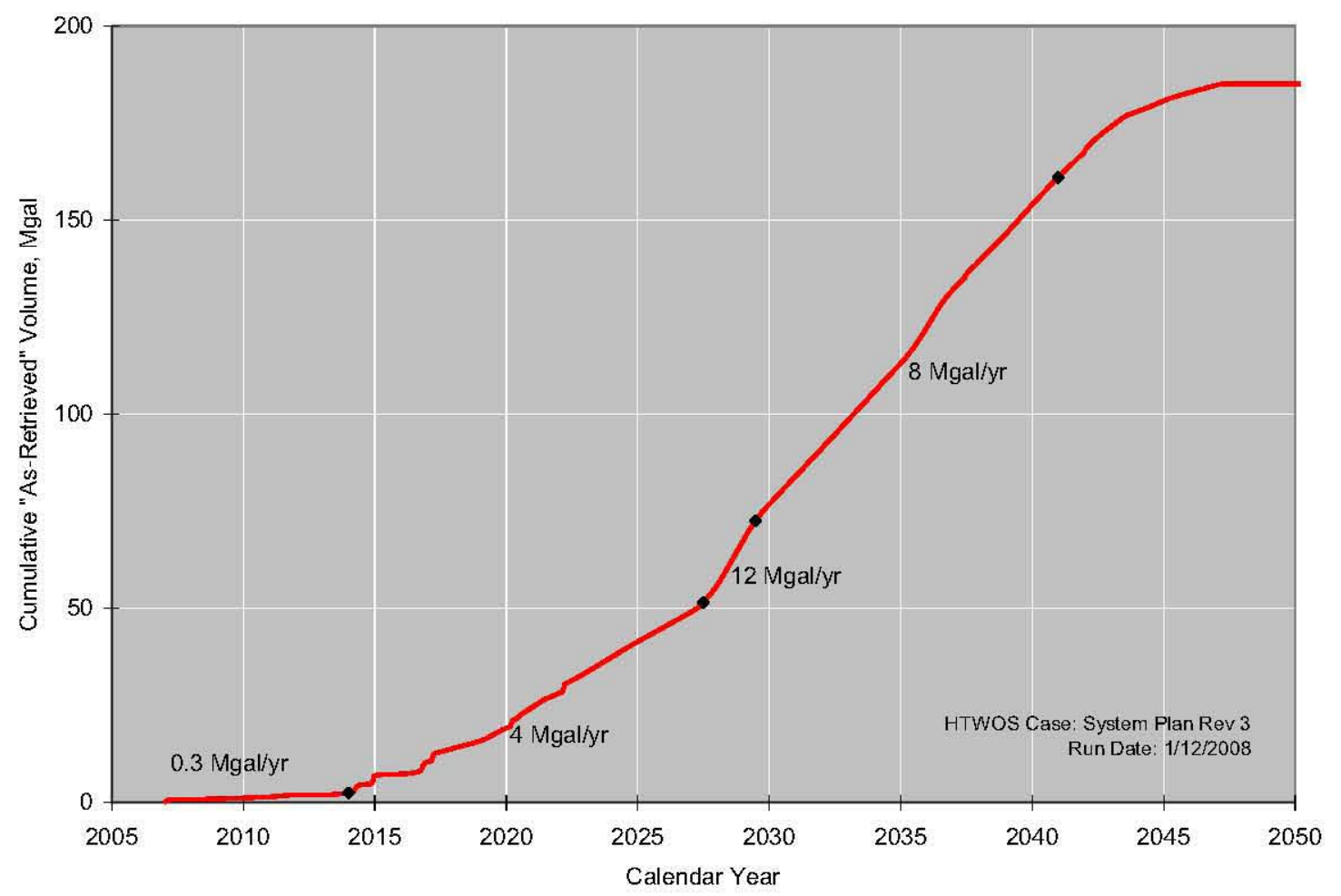

More details on the timing and sequence of individual retrievals are presented in $\$ 2.3 .1 .4$, Waste Retrieval from Single-Shell Tanks.

\subsubsection{Double-Shell Tank Operation}

The 28 DSTs are used to support a number of different functions, which include:

- Storing of waste currently in the DST System, including segregation of the RH-TRU, concentrated-complexed (CC) wastes, and DSSF/DSS wastes;

- Receiving and storing waste to be retrieved from the SSTs, especially near-term retrievals;

- Sending and receiving waste (both slurry and supernate) cross-site from $200 \mathrm{West}$ to 200 East Area;

- $\quad$ Staging slurry for delivery as HLW feed for WTP;

- $\quad$ Staging supernate for delivery as LAW feed for WTP;

- $\quad$ Staging supernate for LAW feed for IPS and West STP; 
- Receiving high-cesium eluate from the IPS;

- Water washing of some of the RH-TRU waste;

- Staging dilute waste for 242-A Evaporator feed;

- Storing concentrated waste from 242-A Evaporator operation;

- Precipitating the strontium and TRU in the CC waste currently stored in $\mathrm{AN}-102$ and AN-107;

- Reserving storage space for emergency purposes; and

- Incidental and intentional waste blending, including segregation of incompatible wastes.

The allocation of specific DSTs to each of these functions varies as the mission progresses and involves a number of implicit and explicit trade-offs that are dependent on the overall configuration of the Waste Treatment Complex and the associated mission scenario. The specific assignments used for the Reference Case should be considered as placeholders that can serve as a starting point for further analysis as the configuration of the Waste Treatment Complex evolves.

Figure 2-3 shows the overall utilization of the DSTs over time. Both the volume of actual waste projected to be stored in the DSTs and a series of head-space allocations for designated purposes are shown. The head-space allocations reflect that portion of the DST space that is not useable for storing waste for the indicated reasons. One example is "Safety-Basis Tank Headspace," which refers to those tanks into which additional waste may not be transferred because of BDGRE concerns - this restriction is removed once the underlying concern is resolved as part of the feed staging activities. Another example is "WTP Feed Tank Headspace," which refers to those tanks containing staged and sampled LAW or HLW for the WTP. Until this waste has been completely delivered to the WTP, no additional waste may be transferred into the tank of staged feed. The total waste inventory plus the allocated DST space should remain less than or equal to the maximum total DST capacity. Both the allocation of DSTs to functions and the head-space allocations vary with time. Keep in mind that as the maximum total DST capacity is approached, the operation of the DST System becomes more and more difficult because of the large number of constraints and lack of free space for the transfer of waste.

A number of specific waste blending activities are assumed to take place in the DST System beyond incidental blending. These specific blending activities originate from the Feed Control List discussed in \$2.3.1.6, Waste Transfers, and listed in Table 2-2, Feed Controls Assumed for the Reference Case. The current baseline includes the blending of the solids from three pairs of tanks as a placeholder for potential future intentional blending activities - these placeholders were not included in the Reference Case since they were speculative. 
Figure 2-3. Total Double-Shell Tank Space Utilization.

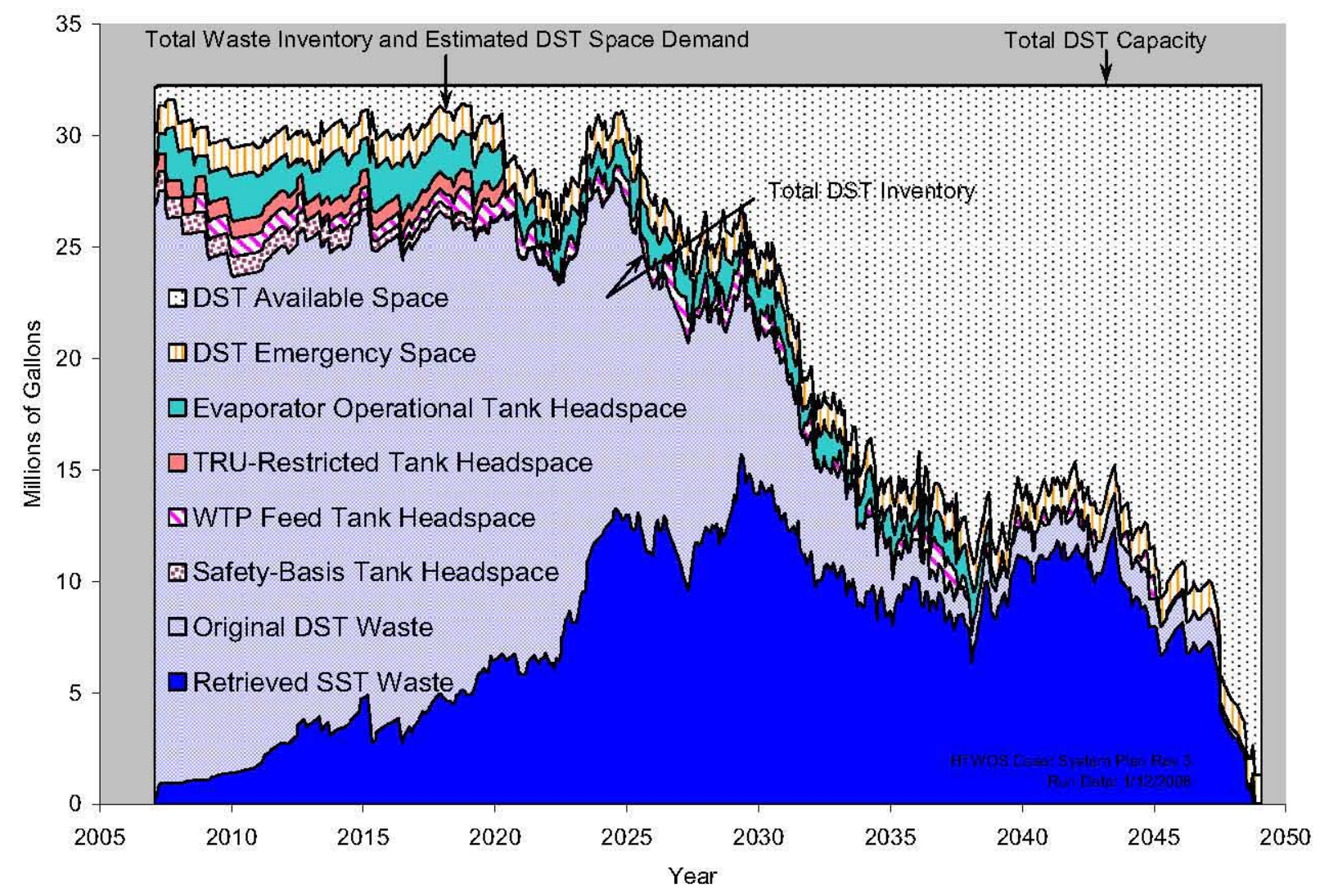

Another set of activities assumed to be performed in the DST System is the precipitation of the

${ }^{90} \mathrm{Sr}$ and TRU from the CC waste currently stored in tanks AN-102 and AN-107. The detailed assumptions for these activities are described in Appendix A of RPP-RPT-33214. First, an in-tank demonstration on about $50 \mathrm{Kgal}$ of waste from AN-107 is performed in Tank AP-102 in 2020. Assuming the demonstration is successful, the ${ }^{90} \mathrm{Sr}$ and TRU will be removed from the remainder of the waste from AN-107 in 2020 and from AN-102 in 2022. If the demonstration is not successful, the $\mathrm{CC}$ in $\mathrm{AN}-102$ and $\mathrm{AN}-107$ will continue to be segregated and delivered to the WTP as Envelope $\mathrm{C}$ feed for removal of the ${ }^{90} \mathrm{Sr}$ and TRU during pretreatment; the WTP is required to maintain the capability for this contingency.

\subsubsection{Inactive Miscellaneous Underground Storage Tanks}

The 43 IMUSTs and 17 MUSTs were projected to be retrieved from October 2019 through October 2031. A total of 550,000 gal of waste (liquid and solid) were projected to be transferred to the DSTs during this period comprising about $0.04 \%$ of the total starting tank (SSTs and DSTs) activity.

\subsubsection{Waste Retrieval from Single-Shell Tanks}

Figure 2-4 shows the SST retrieval sequence and schedule for the Reference Case. The retrievals are sorted in order of increasing retrieval start dates and the total length of each bar shows the modeled retrieval duration. The figure contains both historical and projected information; the 
date which demarcates the historical from the projected retrievals is April 1,2007. As of that date, CH2M HILL Hanford Group, Inc. (CH2M HILL) has completed retrievals of seven SSTs (shown with green bars), namely C-106, C-203, C-202, C-201, C-103, C-204 and S-112.

The projected retrievals are shown with black and yellow bars. The black portion of the bar shows the assumed minimum retrieval duration. The yellow portion of the bar shows the increase in projected retrieval duration beyond the minimum duration due to bottlenecks in the DST System.

The retrieval sequence projected for the Reference Case was established using methodology described in Section 2.1 of "Single-Shell Tank Retrieval Selection and Sequence" (RPP-21216, Single-Shell Tank Retrieval Selection and Sequence). The basic approach was to group the SSTs in four subsets of tanks, with each subset addressing different retrieval drivers. As the HTWOS model simulates the mission, it attempts to honor each of these retrieval drivers, subject to DST space and logistical considerations, simultaneous retrieval constraints, and programmatic assumptions related to the timing and sequencing of tanks within some of the subsets. ${ }^{33}$

Figure 2-5 shows the overall timing of the retrievals supporting each of these drivers and how they are consolidated into the overall projected sequence. The four groups of drivers, Committed Tanks, TRU Treatment, West Area LAW Feed, and Balance WTP Feed, are summarized below:

- Committed Tanks: The Committed Tanks group is comprised of S-102, S-112 and all of the C-Farm SSTs - these tanks are referred to as "committed" because their retrieval directly supports near term TPA milestones. The projected timing of the In-Progress and Planned tanks is determined by near-term DST space availability, operation of the 242-A Evaporator, operational logistics, and the programmatic assumptions for the relative order and destination DST for the retrievals.

${ }^{33}$ Section 2.3, "Single-Shell Tank Retrieval Sequence Development" of RPP-21216 describes this in more detail. 


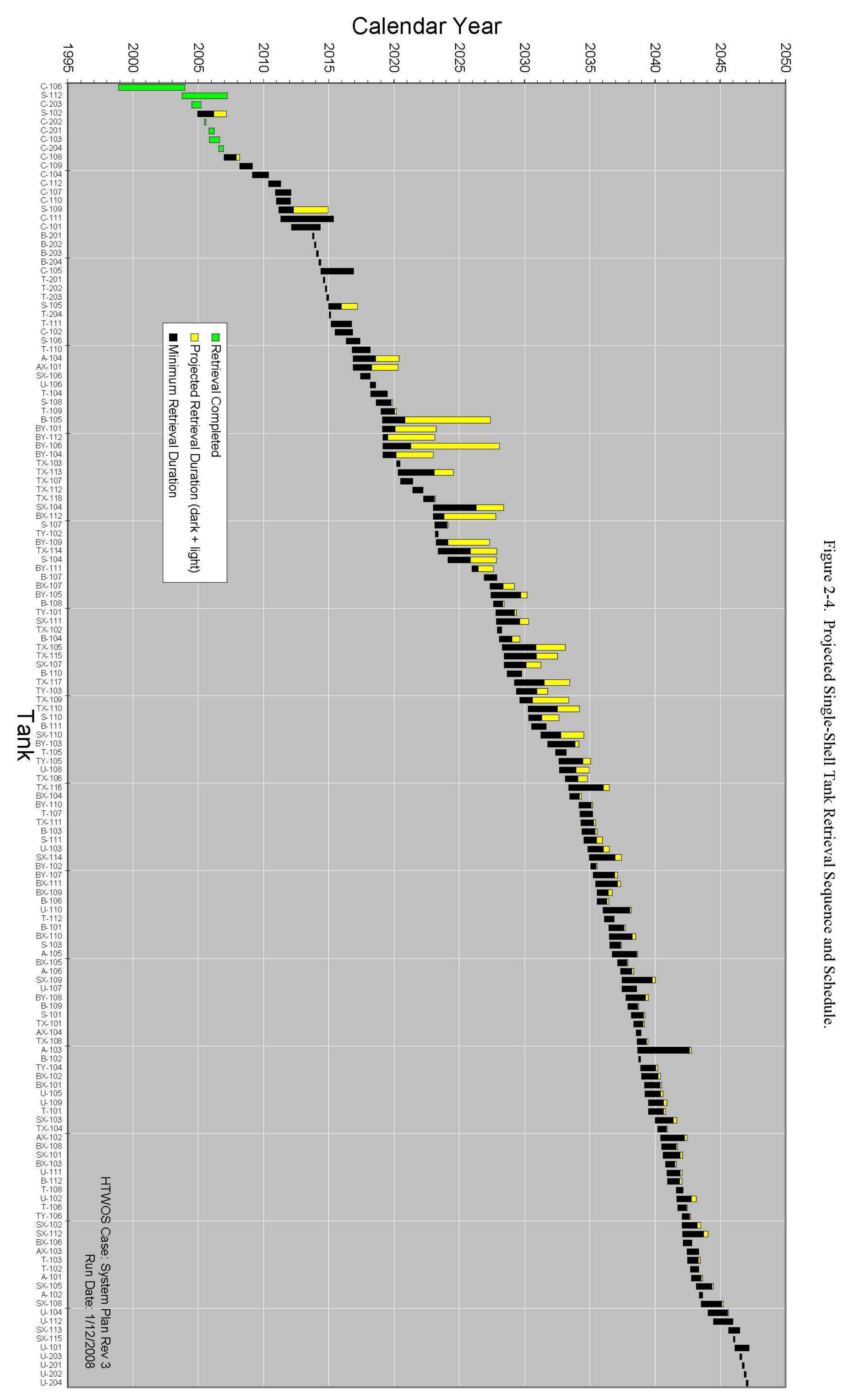


ORP-11242, Rev 3

Figure 2-5. Approach Used to Sequence Single-Shell Tank Retrievals.

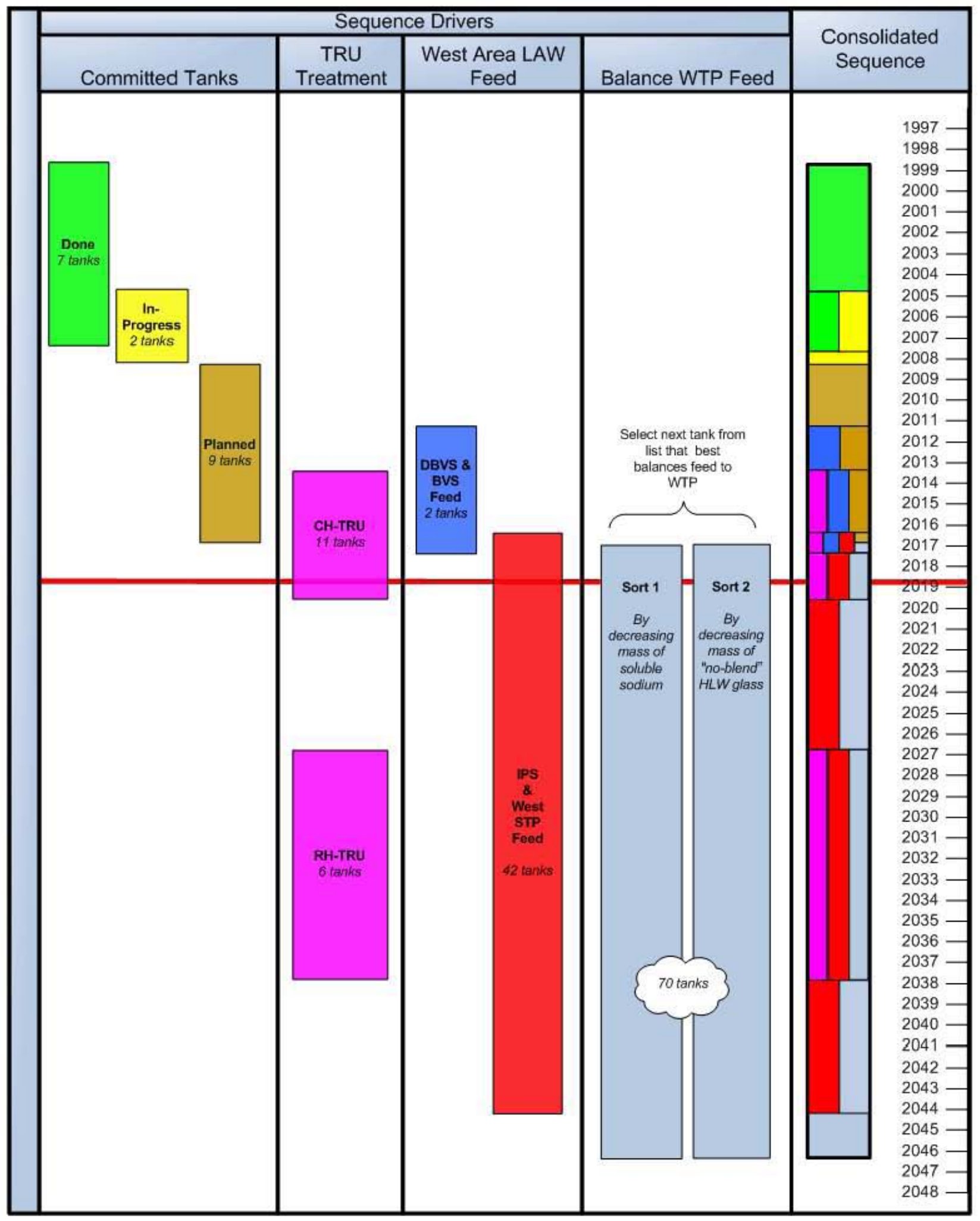


- TRU Treatment: The TRU Treatment group is comprised of both CH-TRU and RH-TRU drivers (see Appendix B, §B2.4.6, Supplemental TRU Sludge Treatment, for details):

- The desired start date and general sequence of the retrieval of the CH-TRU tanks is established by the baseline, while the projected timing of the individual retrievals is established by the interplay of the SST retrieval durations and volumes and the assumed TRU Packaging System slurry treatment rate. ${ }^{34}$ There is a 10-day outage between tanks and a 60 -day outage between farms. DST tank space is not a factor because these tanks are retrieved directly to the CH-TRU Treatment System.

- The early availability date for the RH-TRU Treatment System and the sequence of SSTs to be used for its feed was established by the baseline. The projected availability date of the RH-TRU Treatment System for packaging SST waste was determined from when the packaging of the RH-TRU from DSTs AW-103, AW-105, and SY-102 was completed. The projected timing of the individual retrievals is established by the interplay of the SST retrieval durations and volumes, the time needed to water-wash the retrieved sludge in the WRFs, the availability of space in the DST System to receive the wash water, and the assumed TRU Packaging System slurry treatment rate.

- West Area LAW Feed: The West Area LAW Feed group is comprised of both DBVS / BVS Feed and IPS / West STP Feed drivers:

- The desired start date and sequence of the retrieval of S-109 and S-105 to feed DBVS and BVS is set by the baseline. The pace of these retrievals is limited by the assumed treatment (vitrification rate) and the one-year outage to allow for the refurbishment and re-permitting of the DBVS facility as the BVS facility.

- The start date for the operation of the IPS and West STP and the treatment (vitrification) capacity were established by the baseline. Forty-two SSTs, containing mostly salt-cake, were selected to provide feed to the IPS and West STP facilities. Before the T-Complex WRF was assumed to be available (June 2019), retrievals were further restricted to a twenty-three SST subset of that forty-two tank group. The timing of the individual retrievals was determined by the interplay of the SST retrieval durations and volumes, simultaneous retrieval constraints, the assumed West STP treatment rate, and the availability of DST space for receipt of the high-cesium eluent from the IPS and for settled solids from the retrieved waste.

- Balance WTP Feed: The SSTs in this subset comprise the seventy SSTs not explicitly included in the other three groups. The early start date for retrieving tanks from this group is set by the projected completion date of the Committed Tanks. The subgroup is sorted two different ways - "Sort 1" is by decreasing mass of soluble sodium in each SST and "Sort 2" is by decreasing mass of "no-blend" HLW glass

${ }^{34}$ The current baseline assumes that TRU treatment is limited by the shipping rate of packaged TRU wastes, while this system plan is limited by the capacity of the treatment. 
that would be made after pretreating the waste in each SST. The HTWOS model determines which SST to retrieve next by keeping track of the relative balance of sodium and solids retrieved from all of the SSTs to date. Starting from the top of both lists, the model finds the first SST that best maintains the balance of retrieved sodium (provides LAW feed) and solids (provides HLW feed) and that satisfies the simultaneous retrieval constraints. The selection is biased toward retrieving additional HLW feed whenever the number of DSTs containing staged HLW feed drops below three.

Using the Reference Case assumptions, the SST retrieval assumptions are now the primary driver in the overall mission duration. The outages on the production plots for West STP (see $\$ 2.3 .3 .5$ ) and HLW vitrification (see \$2.3.2.2) suggest that feed is not being retrieved and/or staged fast enough to keep up with the assumed capacity of these facilities.

A simple sensitivity study was performed to confirm that the outages on the production plots were caused by the assumed SST retrieval performance. See §3.8, Enhanced Single-Shell Tank Retrieval, for more details.

\subsubsection{Waste Retrieval from Double-Shell Tanks}

As discussed in $\$ 1.3 .1 .5$, Waste Retrieval from Double-Shell Tanks, the timing of the initial retrieval of the DSSF in AN-104 is key to enabling cross-site transfers of solids from West Area to East Area. In the Reference Case, Tank AN-104 was decanted to AY-102 ${ }^{35}$ in 2019 , immediately after all of the hot commissioning feed was delivered from AY-102. After retrieval of AN-104 was completed, the initial cross-site transfer of solids from West to East Area was projected to occur.

It may be prudent to revisit the decision to hard-pipe the slurry cross-site transfer line directly into AN-104 and provide multiple destinations (receivers) for the cross-site transfers of slurry from West to East Area. This would eliminate potential bottlenecks through AN-104 and the additional flexibility might also simplify the operation of the DST System as a whole. The original rationale behind having a single, hard-piped, receiver was to avoid potential problems with exceeding the transfer line pressure ratings for the interconnected portions of the transfer system.

\subsubsection{Waste Transfers}

The detailed list of all waste transfers that are projected to occur in the tank farms has been captured from the model results and is available for further analysis (SVF-1292, Transfer_File_Formatted_System Plan Rev 3(1-12-2008)-8.3r1-WC91778_M1.xls). Cursory analysis of this list has shown that the dynamic allocation of individual DSTs to process functions (early SST waste storage, SST receivers, HLW staging, LAW staging, cross-site receivers, RH-TRU washing, evaporator feed staging and bottoms receivers, AN-102/107 $\mathrm{Sr} / \mathrm{TRU}$ precipitation, etc.) can likely be improved.

\footnotetext{
${ }^{35}$ To simply programming of the HTWOS model, AY-102 was used to receive and stage the decanted supernate from the DSSF/DSS-containing tanks. However, since AY-102 will be configured as a HLW staging tank, it may be beneficial to use another DST with fewer equipment upgrades for staging the supernate from the DSSF/DSScontaining tanks.
} 
Figure 2-6 shows the cumulative number of transfers involving ${ }^{36}$ the DSTs, with the exception that the SST retrieval transfers are intentionally ${ }^{37}$ not included in this plot. This figure provides a representation of the general level of activities in the DST System as projected for the Reference Case over the life-cycle mission; it is not intended to be used for near-term operational planning. There are approximately 15 DST transfers per year through 2020, increasing to about 50 transfers per year for the remainder of the mission. The corresponding transfer volumes are about $8 \mathrm{Mgal}$ per year and $20 \mathrm{Mgal}$ per year respectively, for a total of $600 \mathrm{Mgal}$ of waste transferred (SVF-1429, Transfer_Plots_System Plan Rev 3(1-12-2008)-8.3r1-WC91778.xls).

Figure 2-6. Double-Shell Tank Transfers.

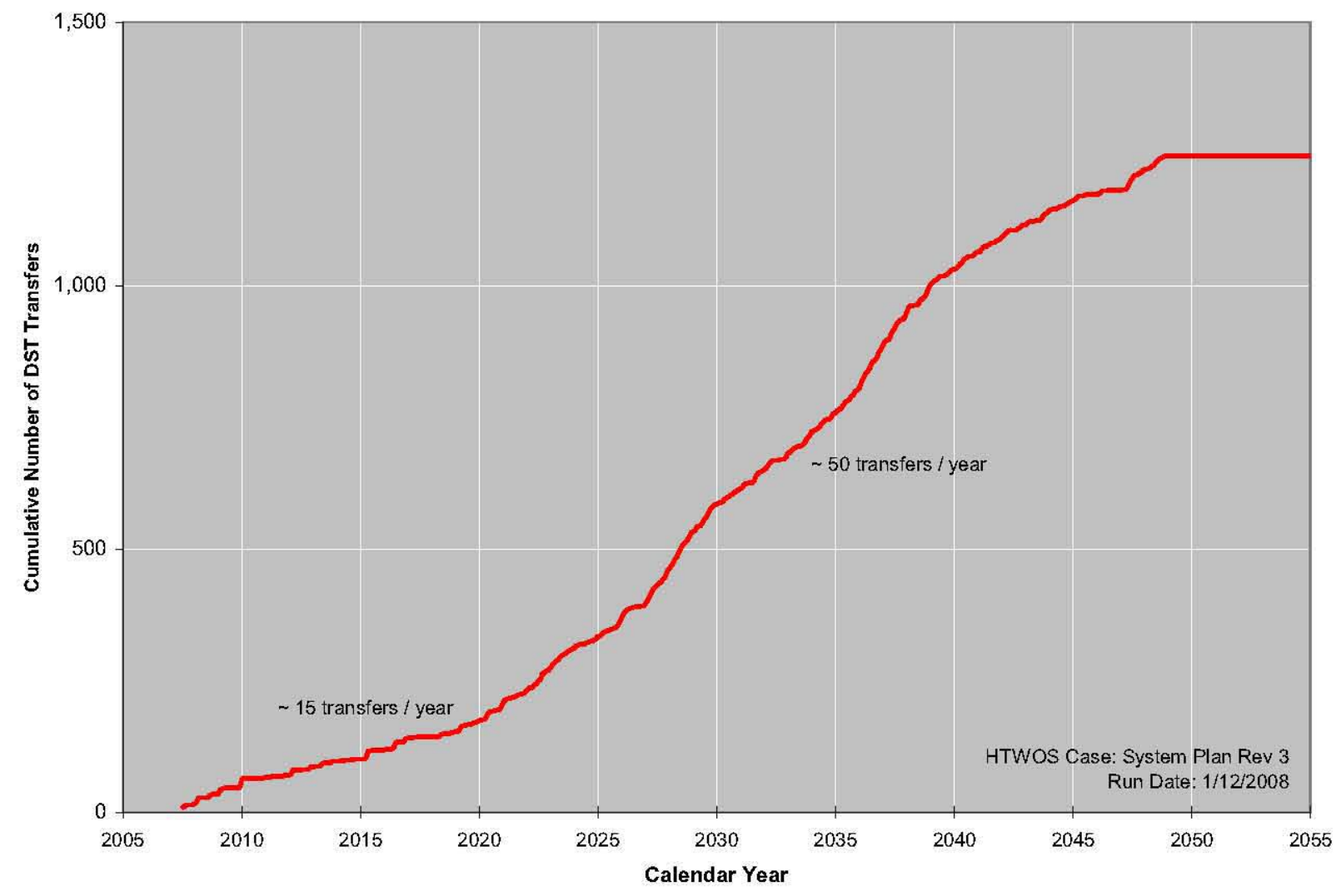

The waste transfers (and retrievals) projected for the Reference Case are for strategic planning purposes only. Near-term operational planning considerations often preempt specific activities projected by modeling, while supporting the same overall mission goals and objectives. In any case, proposed waste transfers or chemical additions into or between the waste tanks are subject to the evaluation rules documented in the Tank Farm Waste Compatibility Program (HNF-SD-WM-OCD-015) before being performed. The waste compatibility program is a safety

\footnotetext{
${ }^{36}$ These transfers include DST to DST transfers, cross-site transfers (a sub-set of DST to DST transfers), and transfers of feed from a DST to a treatment facility.

${ }^{37}$ The individual SST retrieval transfers are significantly more complicated (run as semi-continuous processes, often with recycle) than transfers within the DST system and thus a simple comparison with discrete DST transfers would be misleading.
} 
management program whose primary purpose is to prevent the formation of incompatible mixtures as a result of waster transfer operations.

The compatibility program also includes programmatic controls over the feed planned for the various treatment facilities. These programmatic controls are called the "Feed Control List." A summary of these feed controls, incorporating the revisions assumed by Appendix B, $\S \mathrm{B} 2.2 .2 .6$, are presented in Table 2-2. These assumed revisions include both housekeeping changes and changes needed to align the controls with the other Reference Case assumptions. 
Table 2-2. Feed Controls Assumed for the Reference Case.

\begin{tabular}{|c|c|}
\hline Concern & Summary of Feed Control ${ }^{*}$ \\
\hline Blend off high-sulfate supernate & $\begin{array}{l}\text { Decant and blend the } \mathrm{AZ}-102 \text { supernate with supernate containing lower } \\
\text { sulfate }\left(\mathrm{SO}_{4}\right) \text { concentrations to reduce the }\left[\mathrm{SO}_{4}\right]:[\mathrm{Na}] \text { ratio in } \mathrm{AZ}-102 \text { and in } \\
\text { any other tank receiving significant quantities of this supernate. }\end{array}$ \\
\hline Blend off high ${ }^{233} \mathrm{U}$ solids & $\begin{array}{l}\text { Blend the solids from } \mathrm{C}-104 \text { with the solids from } \mathrm{C}-111 \text { and } \mathrm{C}-112 \text { in } \\
\mathrm{AN}-101 \text { so that the resulting }\left(\left[\mathrm{U}_{\text {fissile }}\right] /\left[\mathrm{U}_{\text {total }}\right]\right) \text { ratio is less than a target level of } \\
\text { 9.4. Alignment: follow assumed path forward for blending the C-104 waste. }\end{array}$ \\
\hline $\begin{array}{l}\text { Prepare and protect hot } \\
\text { commissioning feed }\end{array}$ & $\begin{array}{l}\text { The HLW and LAW hot commissioning feeds have already been } \\
\text { consolidated in AY-102 as of January } 2007 \text { - do nothing to compromise this } \\
\text { feed. Housekeeping: AP-101 no longer contains hot commissioning feed. }\end{array}$ \\
\hline Segregate Envelope C & $\begin{array}{l}\text { Segregate the waste in } \mathrm{AN}-102 \text { and } \mathrm{AN}-107 \text { from all other wastes until it has } \\
\text { been partially pretreated in DSTs. Alignment: this waste assumed to be } \\
\text { partially pretreated in the DSTs rather than the WTP. }\end{array}$ \\
\hline $\begin{array}{l}\text { Segregate TRU sludge from } \\
\text { complexed waste }\end{array}$ & $\begin{array}{l}\text { Do not add complexed waste to insoluble solids currently stored in AW-103, } \\
\text { AW-105, or SY-102. }\end{array}$ \\
\hline $\begin{array}{l}\text { Reduce WTP hydrogen } \\
\text { generation rate by blending }\end{array}$ & $\begin{array}{l}\text { Blend the HLW solids in C- } 102 \text { with the solids in } \mathrm{AZ}-101 \text { to reduce the } \mathrm{H}_{2} \\
\text { generation rate. }\end{array}$ \\
\hline $\begin{array}{l}\text { Segregate waste destined for } \\
\text { TRU or LLW packaging }\end{array}$ & $\begin{array}{l}\text { Do not add to or store additional waste with the insoluble solids currently in } \\
\text { AW-103 and AW } 105 \text {, with the exception that the addition of remote-handled } \\
\text { TRU from SY- } 102 \text { to either tank is permitted. Control the addition of wastes } \\
\text { to SY-102 to avoid mixing the TRU solids in SY- } 102 \text { with additional solids. } \\
\text { Additional solids may be settled on top of the TRU solids in SY-102 as long } \\
\text { as they are not mixed with the SY-102 solids and the transfer of wastes } \\
\text { through SY-102 is controlled to avoid disturbing the TRU sludge layer. Do } \\
\text { not transfer contact-handled TRU waste into the DST system. Segregate the } \\
\text { remote-handled TRU waste from insoluble non-TRU solids. }\end{array}$ \\
\hline $\begin{array}{l}\text { Segregate low-cesium SST } \\
\text { waste for supplemental } \\
\text { treatment }\end{array}$ & $\begin{array}{l}\text { Manage the low-curie waste (less than } 0.05 \mathrm{Ci} / \text { liter }{ }^{137} \mathrm{Cs} \text { when normalized to } \\
7 \mathrm{M} \text { Na) retrieved from tanks } \mathrm{S}-109 \text { and } \mathrm{S}-105 \text { to maximize the amount of } \\
\text { low-cesium feed that can be made available to supplemental treatment } \\
\text { (DBVS \& BVS). Keep the low-cesium fraction designated for feed separate } \\
\text { from any high-cesium waste. Alignment: IPS removes the need to segregate } \\
\text { all low-cesium SST waste. }\end{array}$ \\
\hline
\end{tabular}

*This is a summary only and includes assumed revisions per Appendix B, $\S \mathrm{B} 2.2 .2 .6$ see most current version of HNF-SD-WM-OCD-015 for the actual controls. Changes from the current controls, if any, are explained in italics. BVS $=$ Bulk Vitrification System. IPS $=$ Interim Pretreatment System

DBVS $=$ Demonstration Bulk Vitrification LAW $=$ low-activity waste.

DST $=\quad \begin{aligned} & \text { System. } \\ & \text { double-shell tank }\end{aligned}$

HLW $=$ high-level waste.

$\mathrm{LLW}=$ low-level waste.

SST $=$ single-shell tank.

TRU $=$ transuranic (waste).

$\mathrm{WTP}=$ Waste Treatment and Immobilization Plant 


\subsubsection{242-A Evaporator Operation}

Figure 2-7 shows the projected demand on the 242-A Evaporator over the treatment mission. The figure shows the cumulative volumes of feed to the evaporator, bottoms (concentrated waste) returned to the DSTs, condensate sent to LERF/ETF, and the waste volume reduction (the decrease in storage waste volume resulting from evaporator operation).

Around 2027, there is a sharp increase in the demand on the evaporator that begins (with a slight lag) when the $12 \mathrm{Mgal} /$ year retrieval rate shown on Figure 2-2, "Cumulative Volume Transferred to the Double-Shell Tanks from the Single-Shell Tanks" and continues through the $8 \mathrm{Mgal} /$ year retrieval rate period.

Figure 2-7. 242-A Evaporator Operation.

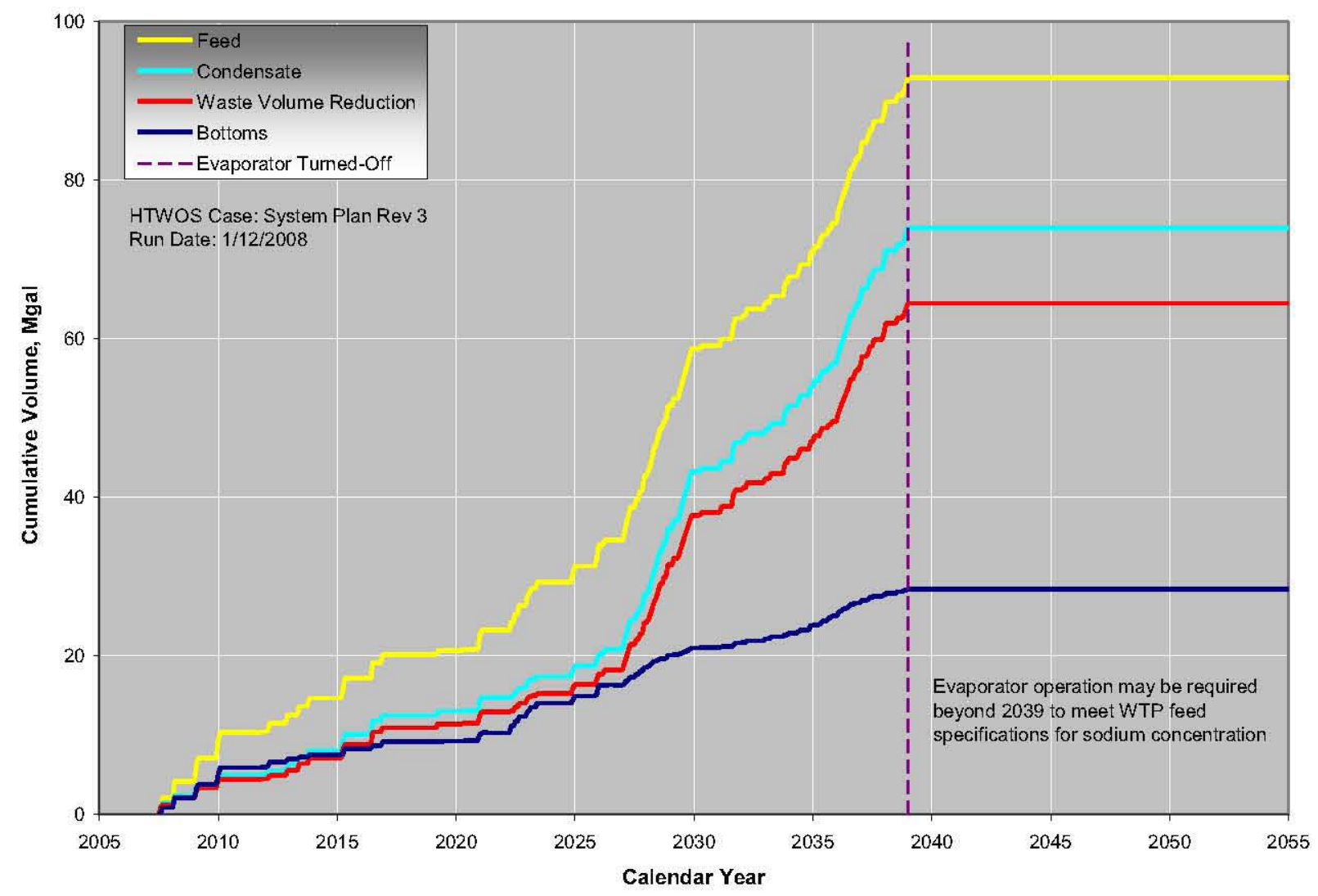


At the start of $2039,{ }^{38}$ the 242-A Evaporator was turned off in the model to see what impacts might result. The impacts can be seen on Figure 2-8, which shows a drop ${ }^{39}$ in delivered sodium concentration in WTP feed corresponding to the date on which the evaporator was turned off (SVF-1423, Specification_7_Assessment_System Plan Rev 3(1-12-2008)-8.3r1WC91778.xls_MI). Continued availability of evaporator capability will likely be required to both assist with the management of the large volumes of water added during the retrieval of the SSTs and with meeting the sodium concentration specifications for WTP feed. It might be possible to provide some of this capacity by using some of the WTP's spare feed evaporator capacity.

On Figure 2-8, the five LAW batches projected to exceed the upper sodium concentration limit are modeling artifacts. For two of the batches, the dilution water was not added during the decanting of supernate from the DSSF/DSS tanks (see $\S 1.3 .1 .5$, Waste Retrieval from Double-Shell Tanks). For the remaining batches, waste concentrated by the 242-A Evaporator to the target specific gravity of 1.43 required the addition of dilution water before delivery to the WTP.

Figure 2-8. Sodium Concentration in Delivered Waste Treatment and Immobilization Plant Feed.

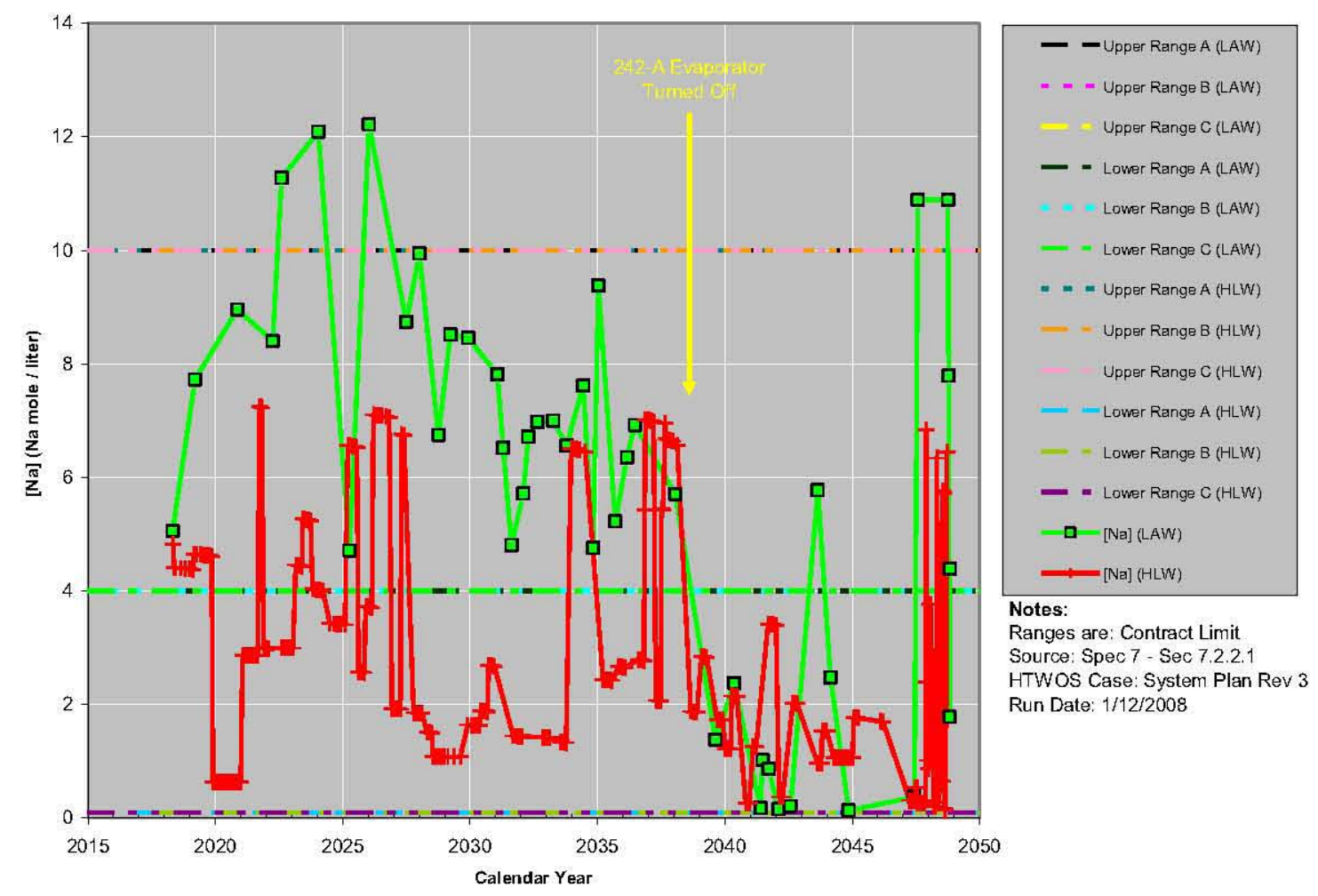

\footnotetext{
${ }^{38}$ This date was selected because it was originally thought to extend beyond the end of the waste treatment mission.

${ }^{39}$ The spike in sodium concentration after 2047 is a modeling artifact of how the DSTs are cleaned out near the end of the mission. Lacking detailed assumptions for tank cleanout, the waste was simply transferred to the WTP to ensure that all of the waste, other than the tank residuals, was properly dispositioned.
} 


\subsubsection{Waste Treatment and Immobilization Plant}

\subsubsection{Pretreatment}

Figure 2-9 shows the cumulative volume of feed delivered to the WTP PT Facility over time. The amounts delivered to the HLW and LAW feed receipt systems are shown separately, along with the volume (on a dry solids particle basis) of the solids in those streams (SVF-1423).

Figure 2-9. Cumulative Volume of the Feed Delivered to the Waste Treatment and Immobilization Plant.

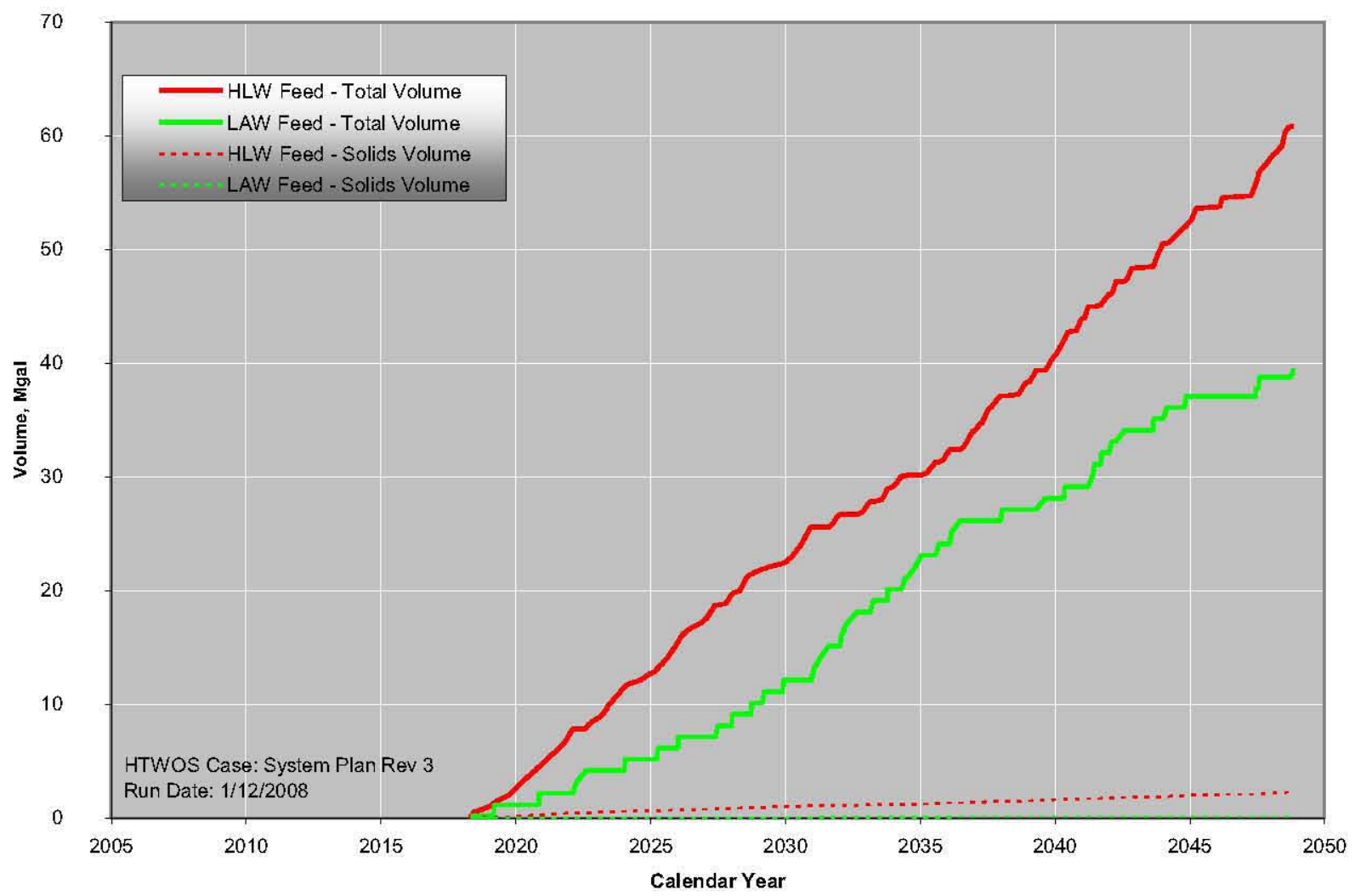


Figure 2-10 shows the cumulative mass of sodium in the feed projected to be delivered to the WTP PT Facility over time. The amounts delivered via the HLW and LAW feed receipt systems are shown separately for comparison (SVF-1423).

Figure 2-10. Cumulative Sodium in the Feed Delivered to the Waste Treatment and Immobilization Plant.

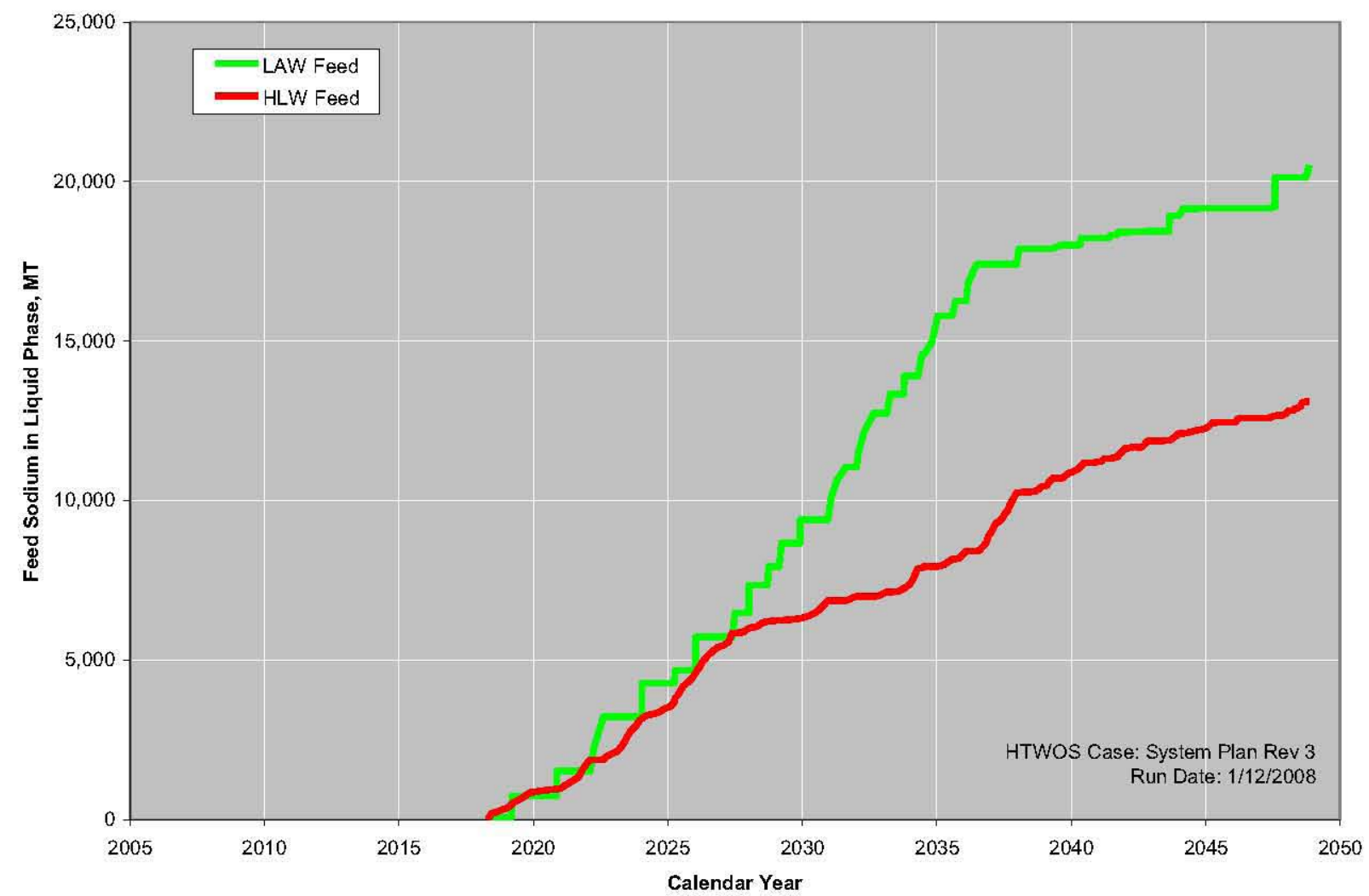

The WTP Contract, Section C, Specification 8, Paragraph 8.2.2.1, establishes the range of acceptable solids concentration in the delivered HLW feed as between 10 and $200 \mathrm{~g} / \mathrm{l}$. This version of the System Plan attempted to target a nominal $8 \mathrm{wt} \%$ solid concentration to facilitate more efficient WTP operations. Depending on the supernate density, $8 \mathrm{wt} \%$ corresponds to about $85-120 \mathrm{~g} / 1$ solids in the delivered feed. A simple feed staging approach was used, namely routing waste with more than $3 \mathrm{wt} \%$ solids towards DSTs assigned as HLW feed staging tanks and waste with less than or equal to $3 \mathrm{wt} \%$ solids towards DSTs assigned as LAW feed staging tanks. The $3 \mathrm{wt} \%$ breakpoint was selected to be slightly below the $3.8 \mathrm{wt} \%$ upper limit for the concentration of solids in the LAW feed. The distribution plots in Figure 2-11 shows that all of the HLW feed was above the $3 \mathrm{wt} \%$ breakpoint, while about half of the HLW feed is below the $8 \mathrm{wt} \%$ target.

A settle-decant process could be used in one or more DSTs to provide better control of the solids concentration in both the delivered HLW and LAW feed batches. Waste with solids concentrations above the target value would simply be transferred directly to a HLW staging tank. Waste with a solids concentration less than the target would be allowed to settle in an "accumulator" DST equipped with two mixer pumps and a transfer pump with a properly 
positioned inlet (either variable height or a fixed, raised height). The clarified supernate would be decanted and transferred towards DSTs assigned as LAW feed staging tanks. Additional waste would be transferred into the "accumulator" DST and the settle-decant process repeated until the desired solids concentration was reached. The waste in the "accumulator" DST would then be transferred to a HLW staging tank, sampled, and delivered to the WTP. Additional modeling would be needed to determine in which DSTs to conduct the settle-decant operation and if those DSTs could also serve as the HLW staging tanks.

Figure 2-11. Solids Concentration Distribution in Feed Delivered to the Waste Treatment and Immobilization Plant.

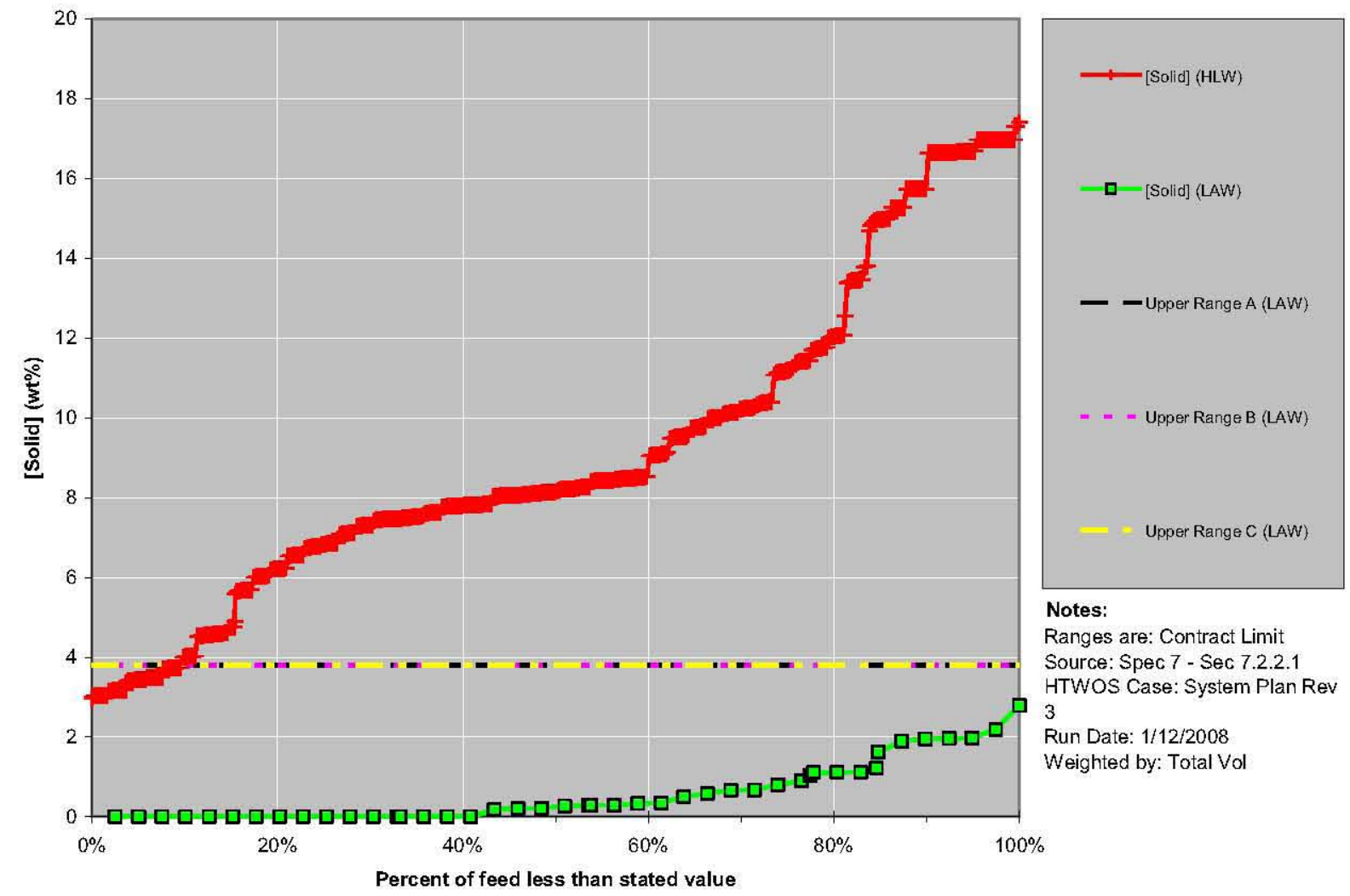

The waste projected to be delivered to the WTP PT Facility was screened against the WTP contract feed specifications (Specifications 7 and 8), ${ }^{40}$ and the directed hydrogen generation rate (HGR) limits. The detailed results of these screenings are documented in SVF-1423; SVF-1422, Specification_8_Assessment_System Plan Rev 3(1-12-2008)-8.3r1-WC91778.xls; and SVF-1420, HGR_Feed_Assessment_System Plan Rev 3(1-12-2008)-8.3r1-WC91778.xls, respectively, on both batch-by-batch and mission aggregate basis. While a full assessment of the results of this

\footnotetext{
${ }^{40}$ Specification 7 primarily applies to the feed delivered to the WTP LAW feed receipt tanks, plus the liquid phase of the feed delivered to the WTP HLW feed receipt tanks. Specification 8 primarily applies to the solids in the feed delivered to the WTP HLW feed receipt tanks.
} 
screening is beyond the scope of the System Plan and typically is handled as follow-on work, some of the major observations follow:

- All of the waste was projected to meet the HGR screening criteria, with the exception of a batch group of HLW feed that exceeded the upper limit by less than $10 \%$. The waste in this batch group includes a mix of waste originally from AN-102 and AN-107. This waste may benefit from intentional blending with other waste after the removal of the ${ }^{90} \mathrm{Sr}$ and TRU and before delivery to the WTP to mitigate the high HGR.

- Most of the feed was projected to satisfy Specification 7; however, four limits were projected to be exceeded in the Reference Case by more than $1 \%$ of the delivered waste, weighted by mass of delivered sodium. These were sodium concentration, bulk density, mercury to sodium ratio, and TRU to sodium ratio.

- The batches with high sodium concentration and bulk density result from the modeling artifacts discussed in \$2.3.1.7, 242-A Evaporator Operation.

- The high TRU batches result from an unrealistically high (75\%) wash factor for Tank C-105 for ${ }^{241} \mathrm{Am}$. The $75 \%$ value is based on experimental results from 1986, too old to investigate further. Newer experimental data from 1997 suggests a more realistic upper bound of about $0.3 \%$. The basis for this factor has been reviewed and the factor has since been updated.

- The cause of the high mercury batches has been traced to the inventory and wash factor (unity) for A-106. The basis for the A-106 inventory and wash factor were evaluated to determine that the current mercury wash factor is too high. The current wash factor was derived using a much smaller mercury inventory for A-106 and mercury is not expected to be soluble in high $\mathrm{pH}$ solutions. The A-106 mercury wash factor was revised in the BBI to a value of 0.293 based on the behavior of cadmium as a chemical analog. Application of the revised wash factor would resolve the out-of-specification batches.

- Specification 8 includes feed component concentration limits that will be used to provide the basis for certification that the HLW feed is within specification limits (certification limits) and component concentration limits that will be used to support product and process qualification but will not be used as a basis for determining if the feed meets specification requirements (qualification limits). Of the certification limits, four limits were projected to be exceeded in the Reference Case by more than $1 \%$ of the delivered waste, weighted by mass of delivered solids. These include the strontium, vanadium, total organic carbon and ${ }^{233} \mathrm{U}$, all as ratios to mass of non-volatile oxides. The causes (modeling artifacts, data issues, or real) and potential impacts of these have not been evaluated. Also, about one-third of the qualification limits are projected to be exceeded by more than $1 \%$ of the delivered waste.

A comprehensive evaluation of the processability of the tank waste through the WTP was performed as part of the follow-on actions from the External Flowsheet Review Team (24590-WTP-RPT-PE-07-001, WTP Waste Feed Analysis and Definition - EFRT M4 Final Report). This review was based upon the feed projected to be delivered to the WTP according to then current tank farm technical baseline documented in the Tank Farm Contractor Operations and Utilization Plan (HNF-SD-WM-SP-012). From an overall mission perspective, this feed 
should be similar in composition to the Reference Case, although the distribution of components among the individual feed batches will vary. The evaluation found that "All of the TFCOUP $\{$ Tank Farm Contractor Operation and Utilization Plan\} Rev. 6 batches appear processable by the WTP. However, some batches will hamper WTP operations and result in reduce $\{\mathrm{sic}\}$ production rates and/or require reduction in waste loading to accommodate."

The "feed vector" is a data file that contains a listing of all of the feed batches projected to be delivered to the WTP for a specific mission scenario, including the type (HLW or LAW) of feed; the projected delivery date; liquid and solid volumes and density; weight percent solids; liquid and solid phase composition; residual water wash factors (if any); and the caustic leach factors. The water wash factors and caustic leach factors are zero-order approximations of the complex solid-liquid equilibrium that occurs in the waste. They assume that process conditions will support the stated factors and that sufficient reactants are present to support the assumed stoichiometry. The waste composition data input to the HTWOS model are not fully speciated. Currently, leach factors for only ten analytes (plus their isotopes) are being tracked. These were selected because of their potential impact on the mass of HLW glass.

The feed vector ${ }^{41}$ specific to the underlying technical and programmatic assumptions used by the Reference Case is available for further analysis. However, because of the limitations described above, the feed vector may require adjustments for charge balance, solid-liquid equilibrium, free and bound hydroxide, speciation of key analytes such as aluminum, and other parameters important to the end user. These considerations are important in understanding the performance of the UFP system and the caustic and oxidative leach operations.

The WTP PT assumptions (namely, the ultrafilter permeate rate and associated operating cycles) did not appear to drive the mission duration for the Reference Case based on cursory examination of the model execution and its results.

\footnotetext{
${ }^{41}$ The feed vector for this Reference Case is named "batches-to-wtp-fully-water-washed.csv" and is kept with the raw data from the Reference Case: "System Plan Rev 3(1-12-2008)-8.3r1-WC91778."
} 


\subsubsection{High-Level Waste Vitrification}

In the Reference Case, about 12,513 canisters of HLW are projected to be produced by the WTP HLW Vitrification Facility by November 2048. The average waste oxide loading of the HLW glass was approximately $28.4 \mathrm{wt} \%$ and ranged from 10 - to $55 \mathrm{wt} \%$ for most of the projected melter batches.

Figure 2-12 is a plot of cumulative WTP HLW glass production versus time, overlaid with the cumulative production capacity based on the assumed ramp-up of HLW Vitrification Facility. The production closely follows the assumed capacity through 2032 , at which time production is limited by the ability to retrieve SSTs fast enough to provide a continual supply of HLW feed to the WTP pretreatment facility. The cumulative outage represents an increase in treatment mission length of about 8 years beyond the date at which the 12,513 canisters would have been produced had there been a continual supply of feed. Had there been no outages, the HLW vitrification could have completed by 2041. As discussed in $\$ 2.3 .1 .4$, most of this cumulative outage results from not being able to retrieve waste from the SSTs fast enough.

Figure 2-12. Waste Treatment and Immobilization Plant High-Level Waste Glass Production.

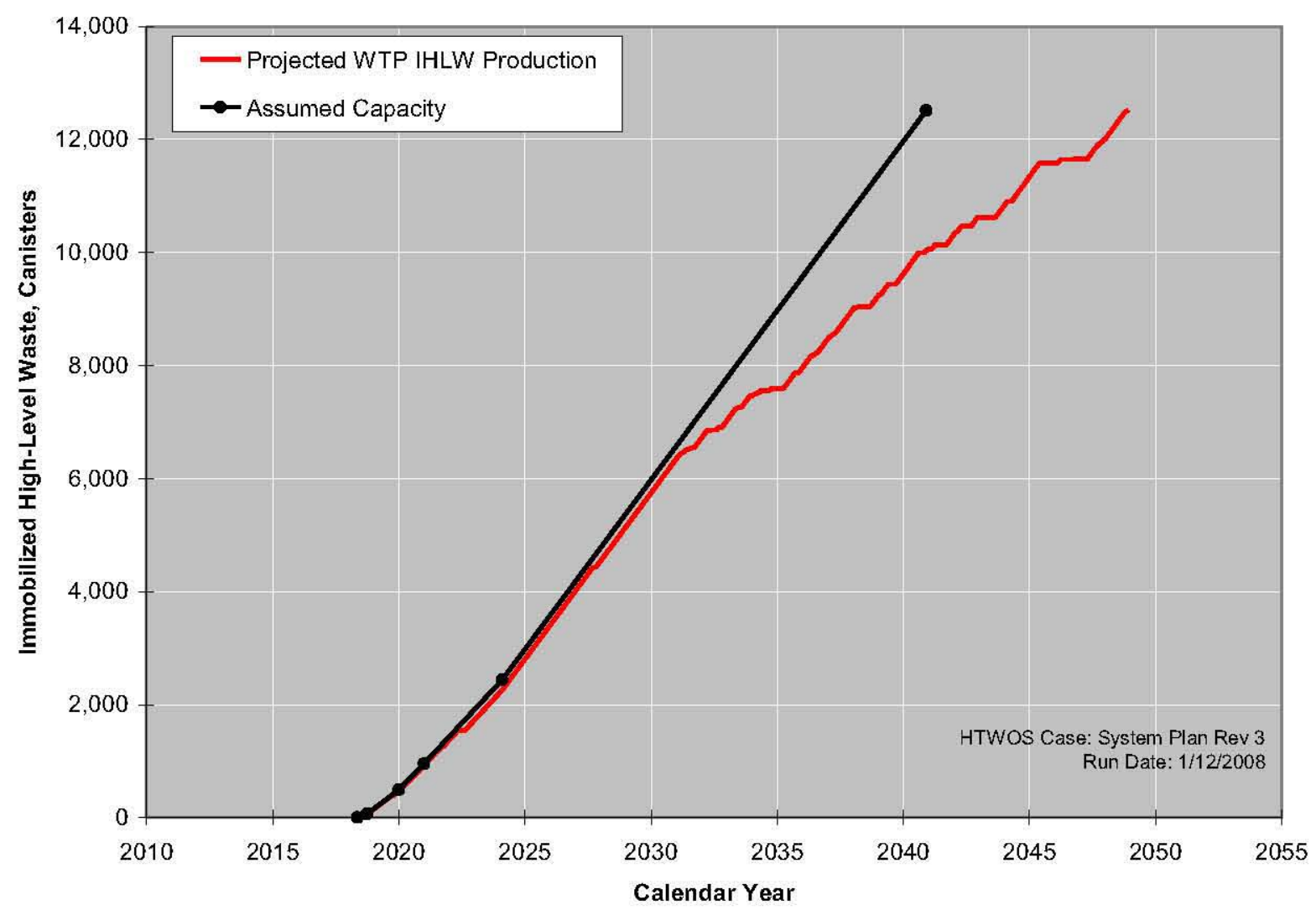




\subsubsection{Low-Activity Waste Vitrification}

In the Reference Case, about 33,065 packages of ILAW are projected to be produced by the WTP LAW Vitrification Facility by December 2048. The average sodium oxide loading of the glass is about $18.1 \mathrm{wt} \%$. The total activity incorporated in the WTP LAW glass is about $1.4 \mathrm{MCi}$ or about $0.7 \%$ of the starting tank inventory.

Figure 2-13 is a plot of cumulative WTP LAW glass production versus time, overlaid with the cumulative production capacity based on the assumed ramp-up of LAW Vitrification Facility. The production closely follows the assumed capacity through 2039 , at which time production is limited by the ability to retrieve SSTs fast enough to provide enough sodium-bearing feed to the WTP PT Facility. The cumulative outages represent an increase in treatment mission length of about 4 years beyond the date at which the 33,065 packages would have been produced had there been an unrestricted supply of feed.

Figure 2-13. Waste Treatment Plant Low-Activity Waste Glass Production.

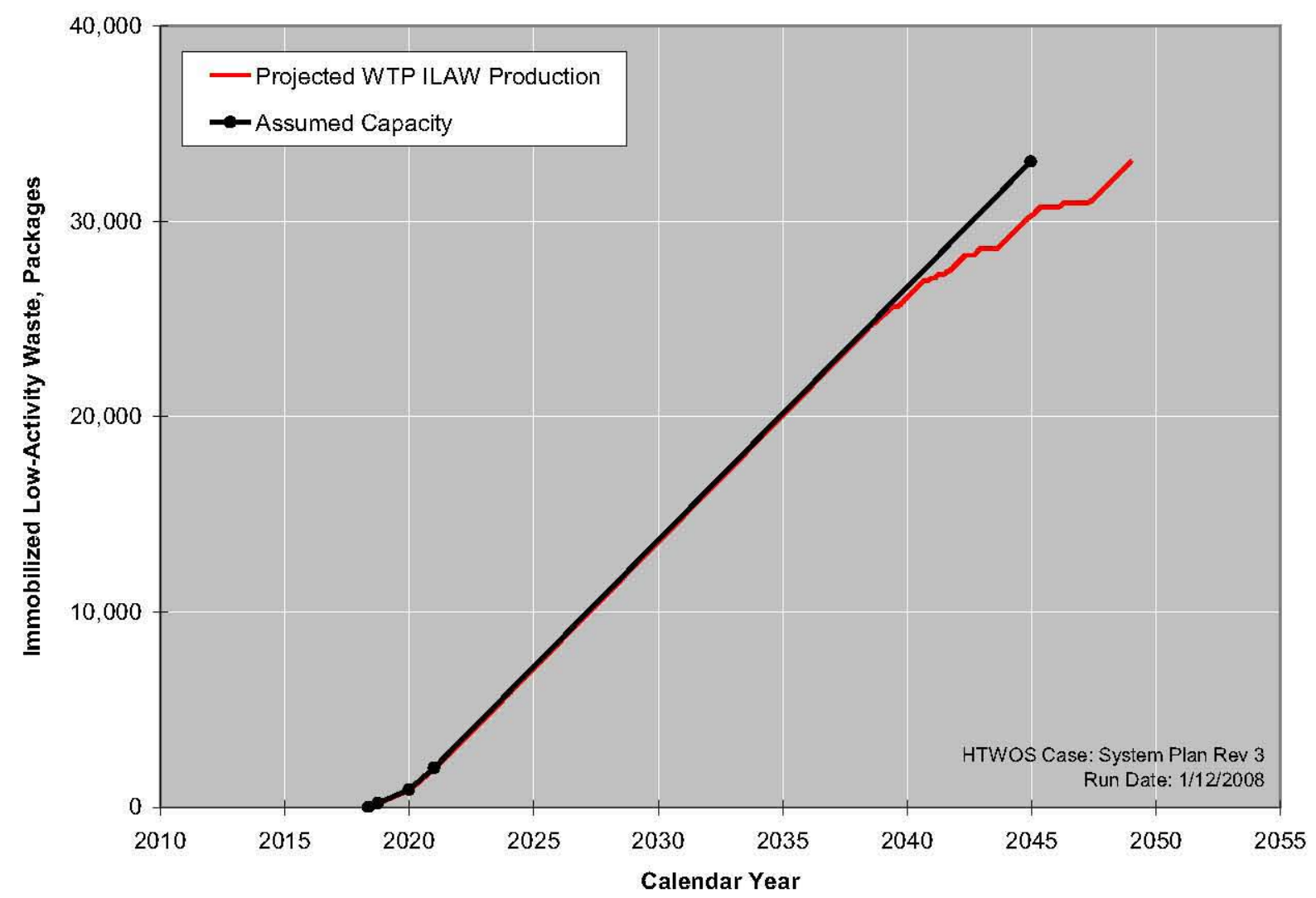

\subsubsection{Waste Treatment and Immobilization Plant Analytical Laboratory}

Reserved for future use - not modeled or evaluated.

\subsubsection{Balance of Facilities}

Reserved for future use - not modeled or evaluated. 


\subsubsection{Supplemental Treatment}

The following subsections provide projected production metrics for each of the Supplemental LAW Treatment processes and for the Supplemental TRU Treatment processes.

\subsubsection{Demonstration Bulk Vitrification System}

The DBVS was projected to produce about $36 \mathrm{ICV}^{\mathrm{TM}}$ containers (a.k.a., boxes) of vitrified LAW by October 2012, treating approximately 242 MT of LAW sodium, at the assumed sodium oxide loading of $21.24 \mathrm{wt} \%$. This is slightly less than the 260 MT of LAW sodium ( 39 boxes) in the key enabling assumptions because of modeling artifacts. ${ }^{42}$ Figure 2-14 shows the projected production over time.

Together, the total activity incorporated in to the DBVS and BVS glass is about $0.09 \mathrm{MCi}$ or about $0.05 \%$ of the starting tank inventory.

Figure 2-14. Demonstration Bulk Vitrification System and Bulk Vitrification System LowActivity Waste Glass Production.

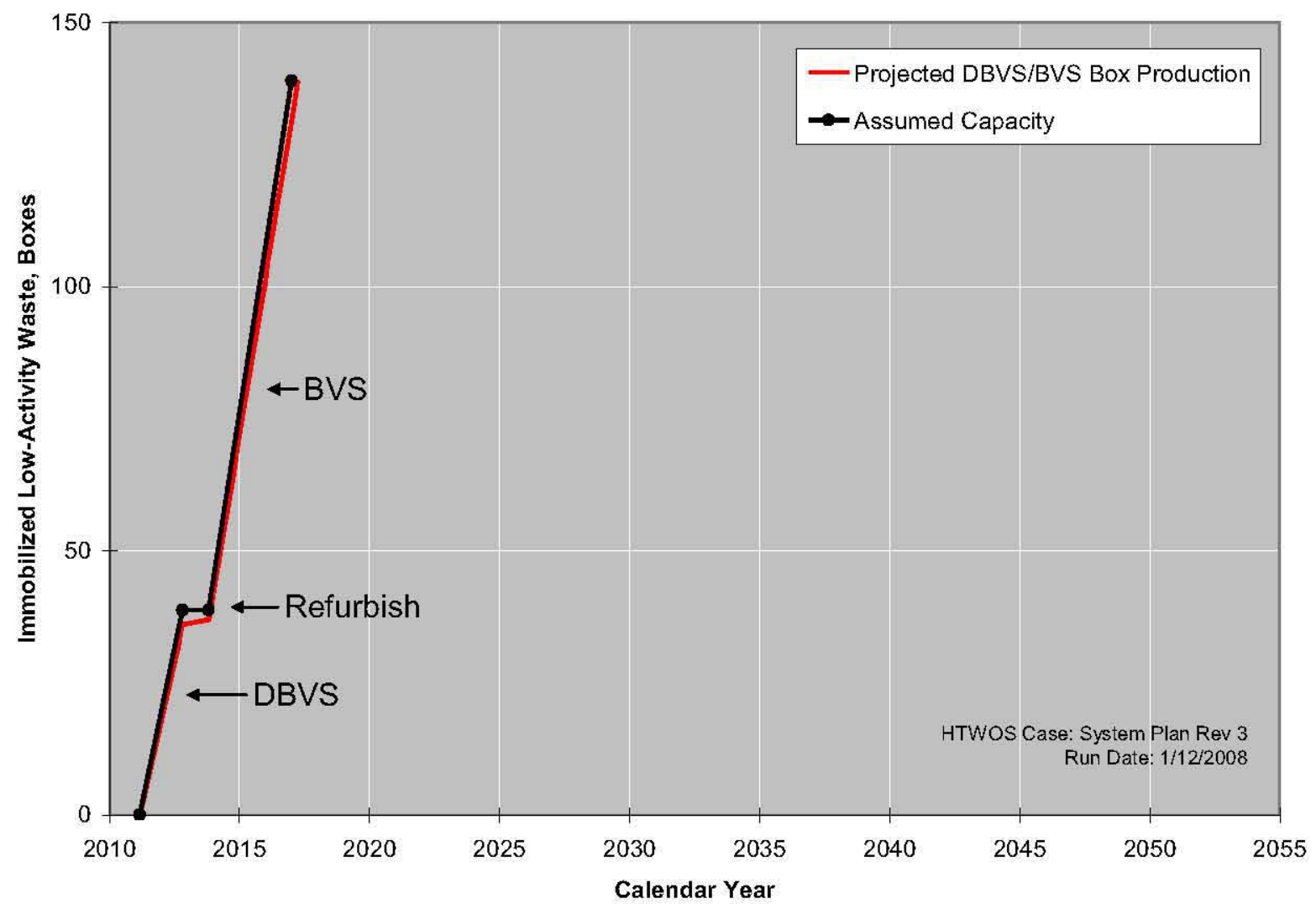

\footnotetext{
${ }^{42}$ These artifacts were (1) the last partially full box and the waste present in the DBVS at the end date for the DBVS operation was attributed to BVS, and (2) the holdup in the DBVS feed tank and dryer was not addressed when selecting the melter production rate.
} 


\subsubsection{Bulk Vitrification System}

The BVS was projected to produce about $103 \mathrm{ICV}^{\mathrm{TM}}$ containers (boxes) of vitrified LAW by March 2017, treating approximately 692 MT of LAW sodium at the assumed sodium oxide loading of $21.24 \mathrm{wt} \%$. Figure 2-14 shows the projected production over time.

Together, the total activity incorporated in to the DBVS and BVS glass is about $0.09 \mathrm{MCi}$ or about $0.05 \%$ of the starting tank inventory.

\subsubsection{East Supplemental Treatment Plant}

The East STP was projected to produce about 2,439 $\mathrm{ICV}^{\mathrm{TM}}$ containers (boxes) of vitrified LAW by February 2049, treating approximately 16,376 MT of LAW sodium at the DBVS sodium oxide loading of $21.24 \mathrm{wt} \%$. The total activity incorporated in to the East STP glass is about $0.9 \mathrm{MCi}$ or about $0.5 \%$ of the starting tank inventory.

Figure 2-15 shows the projected production over time. The outages after 2039 are a result of the SST retrieval assumptions driving the mission duration as previously discussed in $\S 3.8$, Enhanced Single-Shell Tank Retrieval.

Figure 2-15. East Supplemental Treatment Plant Low-Activity Waste Glass Production.

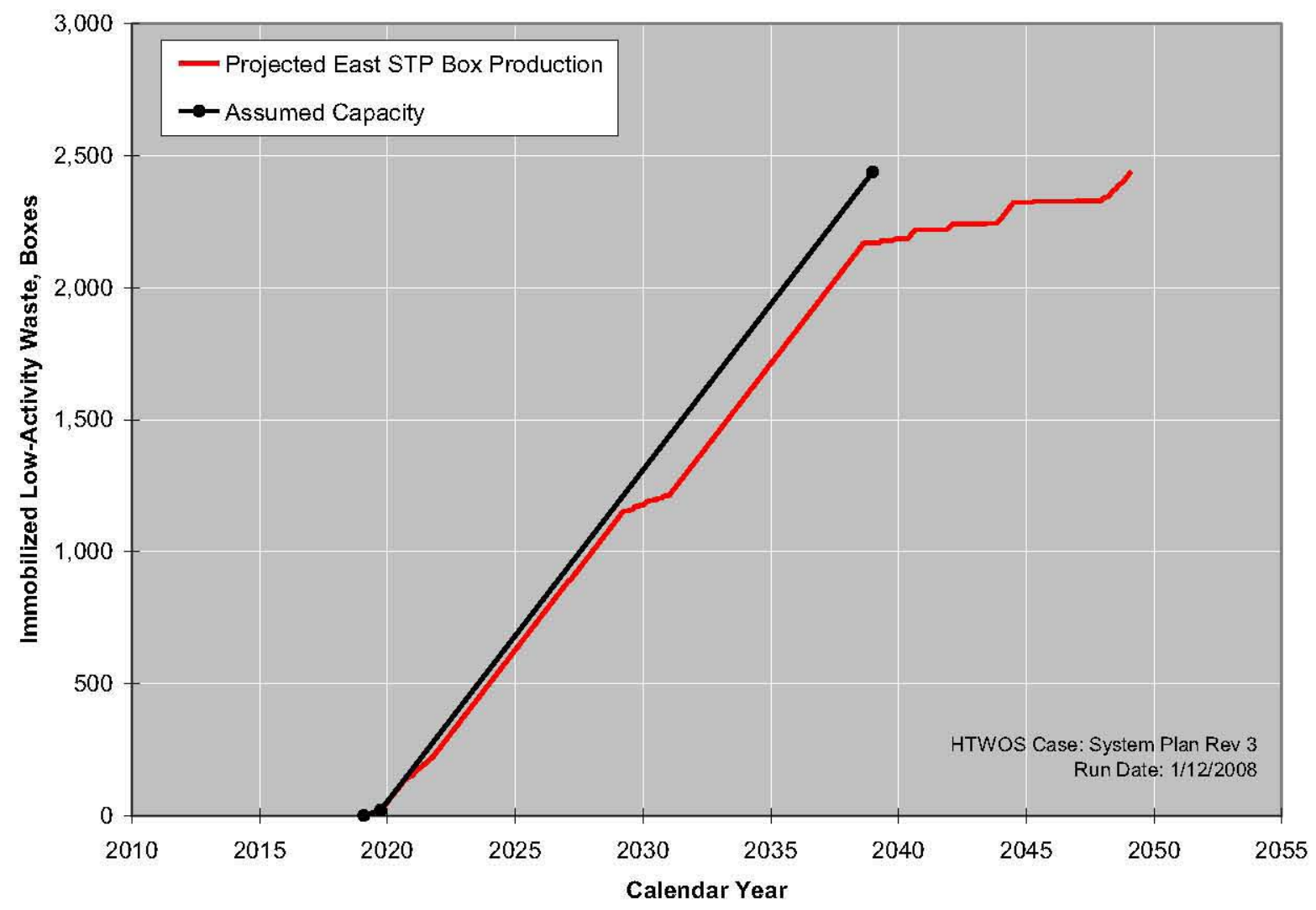




\subsubsection{Interim Pretreatment System}

The capacity of the IPS was assumed to exceed the capacity of the West STP per Appendix B, $\S \mathrm{B} 2.4 .4 .4$; therefore, production curves specific to IPS are not reported.

The modeled capacity of the IPS was set slightly lower than intended and at times slightly restricted feed to the West STP. This can be seen as the curved part of the production curve on Figure 2-16 between 2028 and 2035. An HTWOS model run ${ }^{43}$ demonstrated that this had no impact on the West STP production since the West STP production was driven by the SST Retrieval assumptions - basically, the curved segments of the production curve became straight lines parallel to the assumed capacity while the treatment end date stays the same and the individual outages attributed to the SST Retrieval Assumptions shuffled around (SVF-1460, Production_Plots_System Plan Rev 3(1-14-2008)-8.3r1-WC91778_M1.xls).

Figure 2-16. West Supplemental Treatment Plant Low-Activity Waste Glass Production.

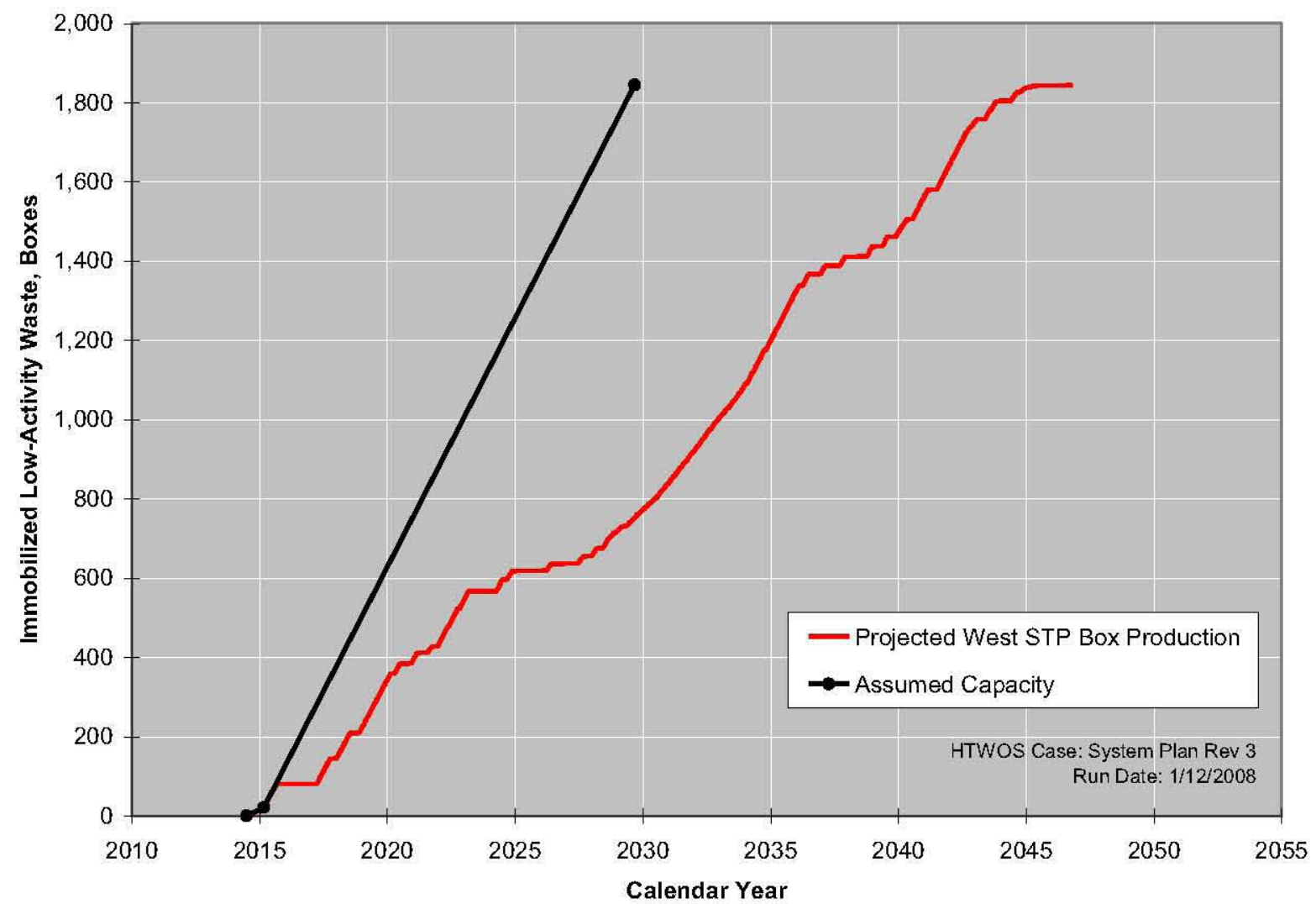

\subsubsection{West Supplemental Treatment Plant}

The West STP was projected to produce about 1,845 ICV ${ }^{\mathrm{TM}}$ containers (a.k.a., boxes) of vitrified LAW by October 2046, treating approximately 12,395 MT of LAW sodium, at the assumed

\footnotetext{
${ }^{43}$ HTWOS model run: System Plan Rev 3(1-14-2008)-8.3r1-WC91778.
} 
sodium oxide loading of $21.24 \mathrm{wt} \%$. The total activity incorporated in to the West STP glass is about $0.7 \mathrm{MCi}$ or about $0.4 \%$ of the starting tank inventory.

Figure 2-16 shows the projected production over time. The pervasive cumulative outages are a result of the SST retrieval assumptions driving the mission duration as previously discussed in $\S 3.8$, Enhanced Single-Shell Tank Retrieval.

\subsubsection{Supplemental Transuranic Waste Treatment System}

The Supplemental TRU Treatment System is comprised of both CH-TRU and RH-TRU processes.

Between October 2013 and June 2019, the contact-handled portion of Supplemental TRU Treatment System was projected to produce about 7,678 55-gal drums, each containing about $620 \mathrm{lb}$ of dried CH-TRU waste. The projected production over time is shown in Figure 2-17. The outage in 2014 is the assumed 60-day outage needed to relocate the contact-handled system from B-Farm to T-Farm. The ten-day outages assumed between tanks in a given farm are not visible.

Figure 2-17. Contact-Handled Transuranic Packaged Waste Production.

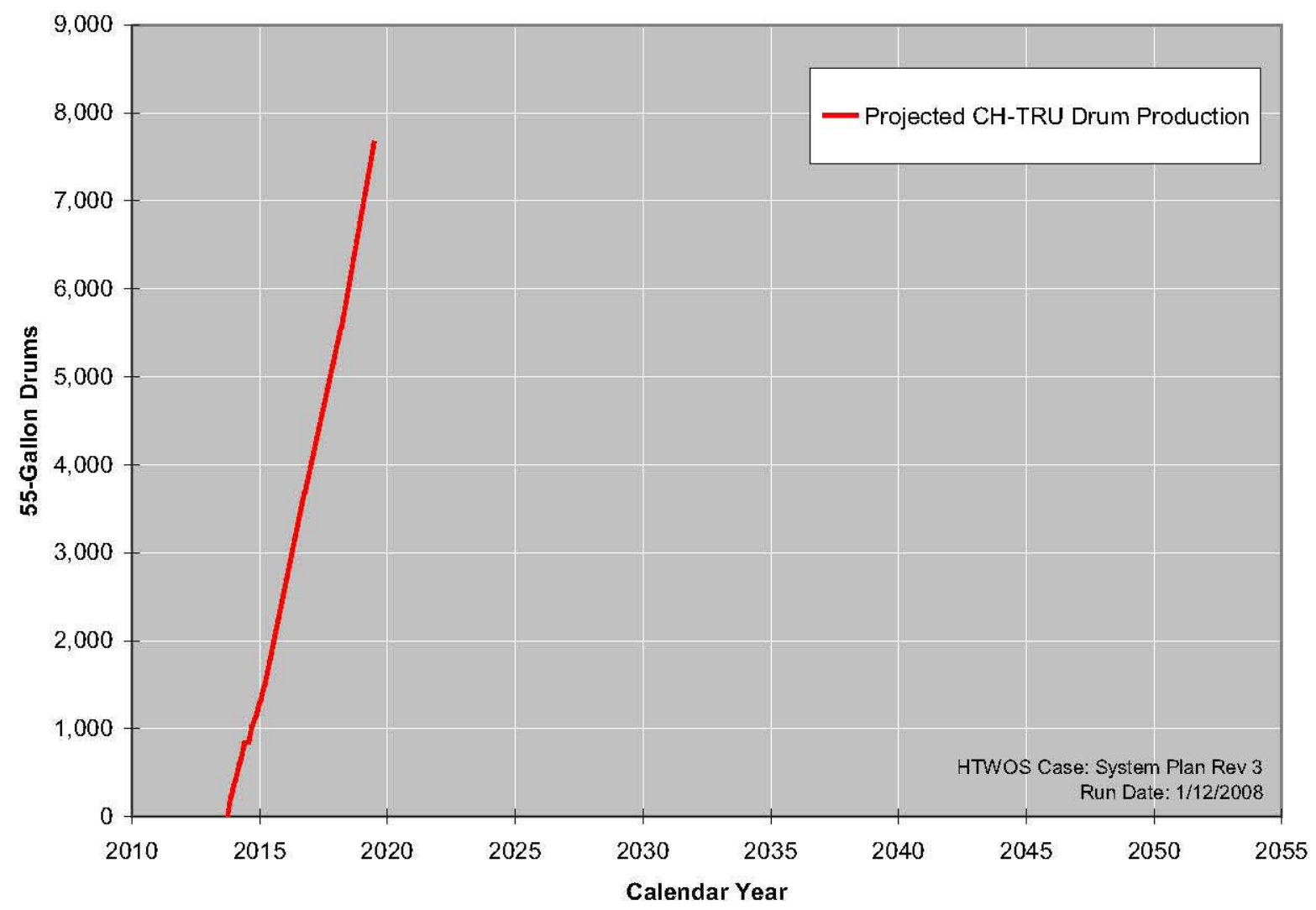


Between May 2025 and June 2037, the remote-handled portion of the Supplemental TRU Treatment System was projected to produce about 2,723 RH-TRU waste canisters, each containing about $2,825 \mathrm{lb}$ of dried, RH-TRU waste. The projected production over time is shown in Figure 2-18. The outages correspond to changes in feed source: the first outage is the transition from AW-103 to AW-105/SY-102, the remaining outages comprise the time assumed to retrieve and water wash the six RH-TRU containing SSTs in a single WRF tank.

Figure 2-18. Remote-Handled Transuranic Packaged Waste Production.

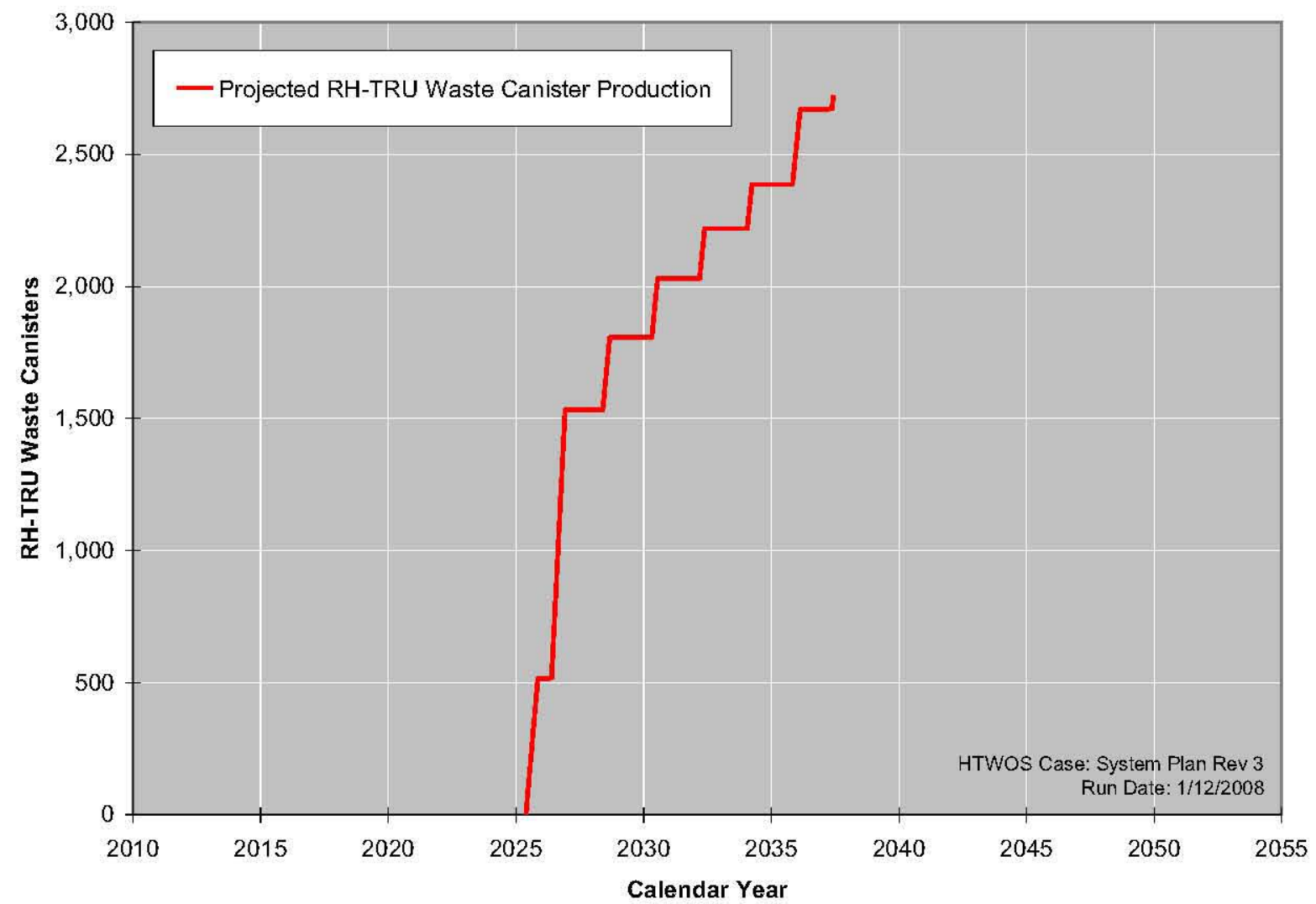

ORP provides the official estimates of the CH-TRU and RH-TRU projected to be shipped to WIPP via the Central Internet Database (CID) and the Integrated Planning, Accountability and Budgeting System (IPABS). The IPABS submittal is the official estimate while the Reference Case is one of a series of projections based on evolving flowsheet assumptions:

- The Reference Case projections for the number of CH-TRU drums agrees well with the FY 2008 IPABS submittal $^{44}$ within about $4 \%$.

- The amount of packaged RH-TRU waste projected by the Reference Case is about $20 \%$ less than the submittal. ${ }^{45}$ This is due primarily to different dried product

\footnotetext{
${ }^{44}$ The submittal to the IPABS (IDMS 87687537) reports that the projected CH-TRU has a $1,555 \mathrm{~m}^{3}$ disposed volume. Using $0.21 \mathrm{~m}^{3}$ disposed volume per 55-gal drum implies 7,405 drums.

${ }^{45}$ The submittal to the IPABS (IDMS 87687537) reports that the projected RH-TRU disposed volume is $3,864 \mathrm{~m}^{3}$. Using $1.1 \mathrm{~m}^{3}$ disposed volume per RH-TRU waste canister implies 3,513 canisters. The end-users may have also
} 
densities and tank heels. The Reference Case assumed a bulk density of $1.60 \mathrm{~kg} / \mathrm{l}$ as used by the CH-TRU flowsheet while the IPABS assumed $1.37 \mathrm{~kg} / \mathrm{l}$. In the Reference Case, about $30 \%$ of the RH-TRU from SY-102 is left behind in tank heels as that material is transferred cross-site to AW-103/AW-105 for water washing and ends up being treated by the WTP.

Table 2-3 provides the projected inventory of selected constituents in the packaged TRU waste from the CH-TRU and RH-TRU treatment systems that is assumed to be disposed of at WIPP.

Table 2-3. Supplemental Transuranic Waste Product Inventory for Selected Constituents.

\begin{tabular}{|l|c|c|c|c|}
\hline \multirow{2}{*}{\multicolumn{2}{|c|}{ Source }} & \multicolumn{4}{|c|}{ Percentage of Starting Tank Inventory } \\
\cline { 2 - 5 } & Total Activity & ${ }^{99} \mathbf{T c}$ & ${ }^{\mathbf{1 2 9}} \mathbf{I}$ & $\mathbf{H g}$ \\
\hline CH-TRU & 0.01 & 0.1 & $\sim 0$ & 0.4 \\
\hline RH-TRU & 1.3 & 0.6 & 0.5 & 1.3 \\
\hline Total to WIPP & & 0.7 & 0.5 & 1.7 \\
\hline & 1.3 & \multicolumn{4}{|c|}{ Starting Tank Inventory, units as stated } \\
\hline Starting Tank Inventory & $194.1 \mathrm{MCi}$ & $26,930 \mathrm{Ci}$ & $30.38 \mathrm{Ci}$ & $1,987 \mathrm{Kg}$ \\
\hline
\end{tabular}

${ }^{a}$ Discrepancies in the Total are caused by rounding and unreported system holdup.

$\mathrm{CH}-\mathrm{TRU}=$ contact-handled transuranic waste.

RH-TRU $=$ remote-handled transuranic mixed waste.

$\mathrm{WLPP}=$ Waste Isolation Pilot Plant.

incorrectly increased the submittal to account for a $90 \%$-fill. However, the submittal already included this adjustment. 


\subsubsection{Interfacing Facilities}

\subsubsection{Liquid Effluent Retention Facility and Effluent Treatment Facility}

The total demand on the LERF and ETF is approximately $386 \mathrm{Mgal}$ of secondary liquid waste from the Waste Treatment Complex over the duration of the waste treatment mission.

Figure 2-19 shows this demand on the LERF and ETF over time, delineating the contributions from the various treatment processes.

Approximately $1,500 \mathrm{Ci}$ of total activity and 1,592 MT of solids are projected to be removed by ETF while treating the $386 \mathrm{Mgal}$ of secondary liquid waste. This solid waste stream is assumed to be stabilized to meet the IDF WAC, even if this requires improved stabilization beyond the current baseline assumptions used in the performance or risk assessments.

Figure 2-19. Projected Demand on the Liquid Effluent Retention Facility and Effluent Treatment Facility.

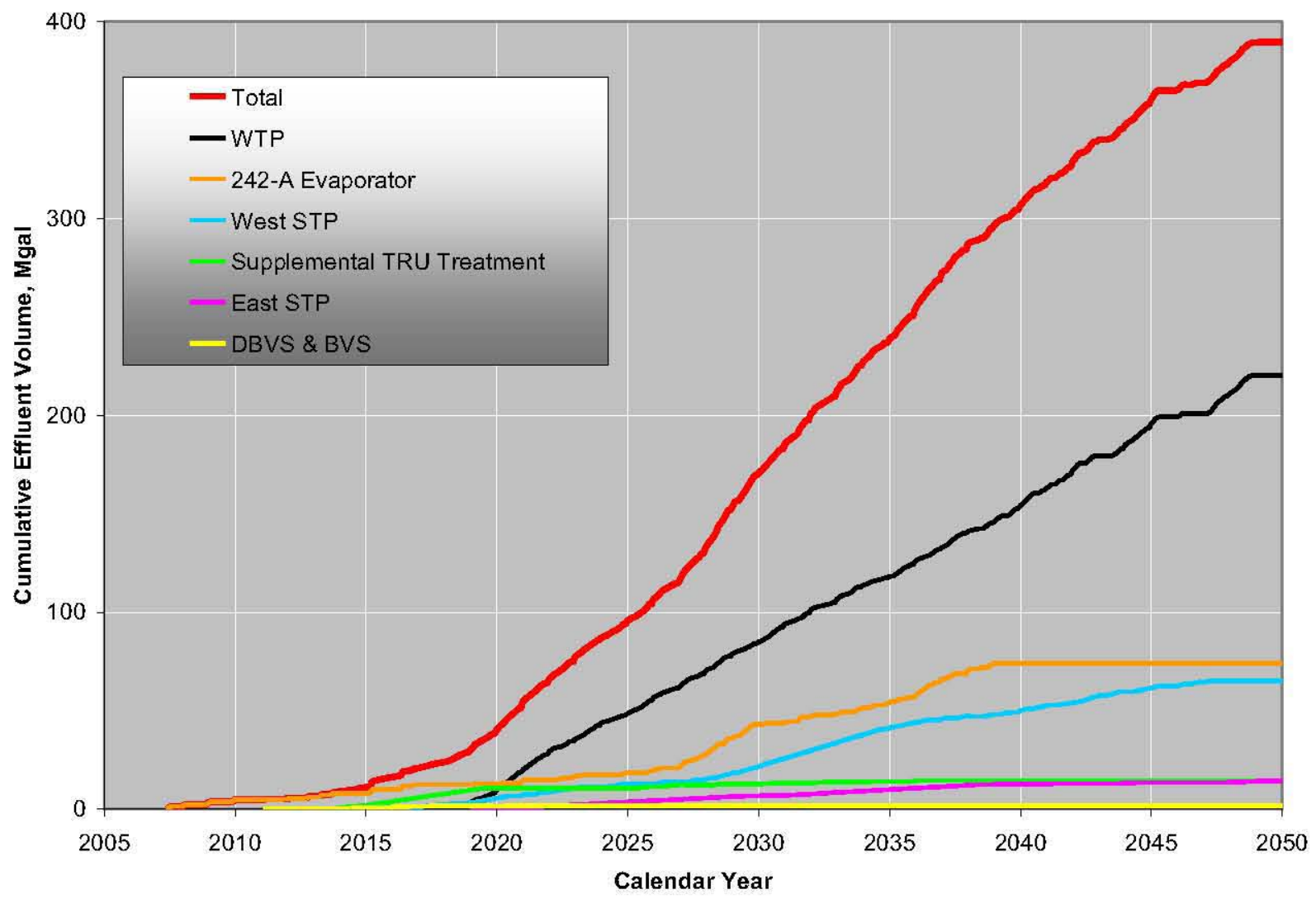

\subsubsection{Central Waste Complex}

Reserved for future use - not modeled or evaluated. 


\subsubsection{Canister Storage Building / Hanford Shipping Facility}

Figure 2-20 shows the relationships between the HLW glass production, the amount of HLW stored in the CSB, and the amount of HLW glass shipped to the Offsite Repository at Yucca Mountain.

The first canister of HLW is projected to be received by the CSB in June 2018. The full use of the assumed CSB capacity of 880 canisters delays the start of shipping of HLW glass to Yucca to November 2020. Shipping continues at a rate not to exceed two canisters per day until February 2050.

Figure 2-20. High-Level Waste Glass Interim Storage and Shipping.

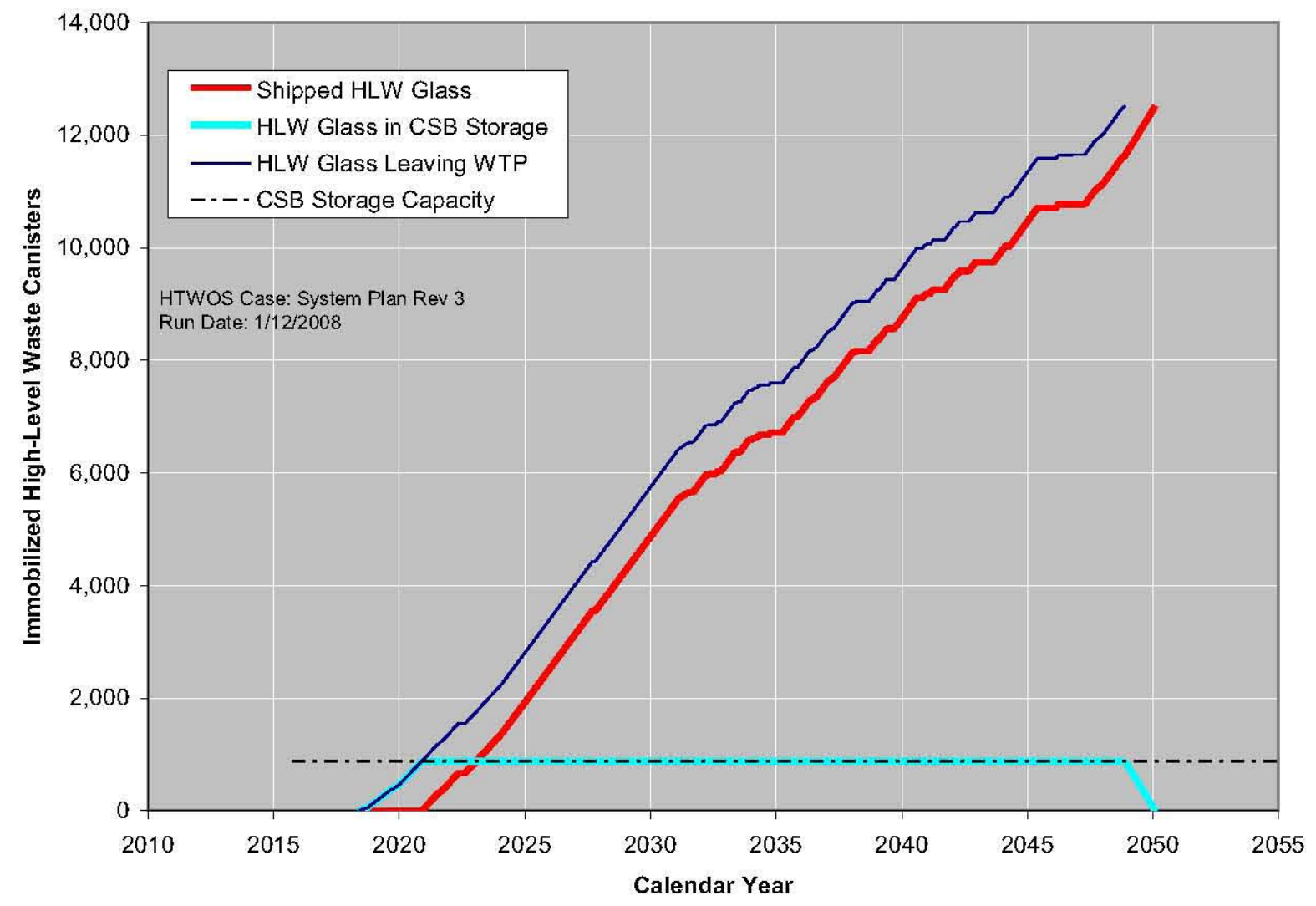




\subsubsection{Integrated Disposal Facility}

Table 2-4 shows the total activity and inventory for three selected constituents of concern for the primary and secondary waste projected to be disposed of at the IDF. A more detailed breakdown of the primary and secondary waste streams is provided in Appendix C for those selected constituents and in SVF-1431 for all tracked constituents.

Table 2-4. Integrated Disposal Facility Inventory for Selected Constituents.

\begin{tabular}{|c|c|c|c|c|}
\hline \multirow{2}{*}{ Source } & \multicolumn{4}{|c|}{ Percentage of Starting Tank Inventory } \\
\hline & Total Activity & ${ }^{99} \mathrm{Te}$ & ${ }^{129} \mathrm{I}$ & $\mathrm{Hg}$ \\
\hline WTP ILAW & 0.73 & 28.90 & 12.20 & 0.00 \\
\hline $\begin{array}{l}\text { DBVS, BVS, West STP, and } \\
\text { East STP ILAW }\end{array}$ & 0.86 & 63.32 & 14.54 & 0.00 \\
\hline Primary Waste Subtotal & 1.59 & 92.22 & 26.74 & 0.00 \\
\hline Spent WTP melters & 0.32 & 0.16 & 0.06 & 0.00 \\
\hline WTP via ETF & 0.00 & 0.18 & 0.37 & 0.07 \\
\hline $242-\mathrm{A}$ via $\mathrm{ETF}$ & 0.00 & 0.00 & 0.00 & 0.20 \\
\hline WTP Solid Waste & 0.01 & 0.14 & 27.44 & 75.26 \\
\hline $\begin{array}{l}\text { DBVS, BVS, West STP, and } \\
\text { East STP non-glass }\end{array}$ & 0.00 & 0.29 & 0.00 & 0.00 \\
\hline $\begin{array}{l}\text { DBVS, BVS, West STP, and } \\
\text { East STP Solid Waste }\end{array}$ & 0.00 & 0.00 & 26.89 & 0.21 \\
\hline $\begin{array}{l}\text { DBVS, BVS, West STP, and } \\
\text { East STP via ETF }\end{array}$ & 0.00 & 0.07 & 15.02 & 20.49 \\
\hline IPS Solid Waste & 0.00 & 0.00 & 0.00 & 0.00 \\
\hline Secondary Waste Subtotal & 0.33 & 0.84 & 69.78 & 96.23 \\
\hline \multirow[t]{3}{*}{ Total $^{\mathrm{a}}$} & 1.91 & 93.06 & 96.59 & 96.23 \\
\hline & \multicolumn{4}{|c|}{ Starting Tank Inventory } \\
\hline & $\mathrm{MCi}$ & $\mathrm{Ci}$ & $\mathrm{Ci}$ & $\mathrm{Kg}$ \\
\hline Starting Tank Inventory & $194.2 \mathrm{MCi}$ & $26,930 \mathrm{Ci}$ & $30.38 \mathrm{Ci}$ & $1,987 \mathrm{Kg}$ \\
\hline \multicolumn{5}{|c|}{$\begin{array}{l}\text { aiscrepancies in the Total are caused by rounding. Slight differences from Appendix C are due to unreported system holdu } \\
\text { BVS }=\text { Bulk Vitrification System. }\end{array} \begin{array}{ll}\text { IPS }=\text { Interim Pretreatment System. } \\
\text { DBVS }=\text { Demonstration Bulk Vitrification System. }\end{array}$} \\
\hline
\end{tabular}




\subsubsection{222-S Laboratory}

A small volume of dilute waste is assumed to be transferred each year to the DSTs from the operation of the 222-S Laboratory through the end of the waste treatment mission. For modeling purposes, these were assumed to be $6.1 \mathrm{Kgal} /$ year before FY 2018 and $12.2 \mathrm{Kgal} / \mathrm{year}$ thereafter.

\subsubsection{Other Hanford Site Facilities}

A small volume of dilute waste was assumed to be transferred to the DSTs from the decommissioning of T-Plant $(18.3 \mathrm{Kgal})$ and PUREX $(16.5 \mathrm{Kgal})$. For modeling purposes, these two transfers were assumed to occur in 2025.

\subsubsection{Waste Encapsulation and Storage Facility}

The cesium and strontium capsules are assumed to be dispositioned outside of the Waste Treatment Complex and therefore are not modeled or evaluated.

\subsubsection{State Approved Land Disposal Site}

The total volume of treated effluent from the Waste Treatment Complex projected to be disposed at the SALDS is $386 \mathrm{Mgal}$.

\subsubsection{200 Area Treated Effluent Disposal Facility}

Reserved for future use - not modeled.

\subsubsection{Offsite Geologic Repository}

The Offsite Geologic Repository is assumed to be located at Yucca Mountain. The first canister of IHLW is projected to be shipped to Yucca by November 2020. Shipping continues at a rate not to exceed two canisters per day until February 2050. The number of canisters projected to be shipped to Yucca Mountain over time is shown in Figure 2-20, High-Level Waste Glass Interim Storage and Shipping.

\subsubsection{Waste Isolation Pilot Plant}

The projected production and therefore the earliest shipping schedules for the CH-TRU (2013 - 2019) and RH-TRU (2025 - 2037) are not fully aligned with the WIPP Baseline and initiatives. The baseline described in DOE/NTP-96-1204, National TRU Waste Management Plan, Corporate Board Annual Report shows that disposal phase activities are currently scheduled through FY 2034. WIPP acceleration initiatives ${ }^{46}$ show the completion of shipping to WIPP from Hanford of CH-TRU by FY 2015 and RH-TRU by FY 2028. These schedule mismatches will continue to be monitored and resolved.

The schedule for shipping packaged TRU waste from the Supplemental TRU Treatment System to WIPP may be slightly delayed from the production schedule depending upon the size of the two IS Facilities discussed in $\$ 1.3 .3 .6$, Supplemental Transuranic Waste Treatment System. In any case, the schedule can be no earlier than the projected production for packaged CH-TRU

\footnotetext{
${ }^{46}$ Per Tables 5.0-1 and 5.0-2 of "Transuranic Waste Performance Management Plan," U.S. Department of Energy, Carlsbad Field Office, August 2002.
} 
drums and RH-TRU canisters discussed in 2.3.3.6, Supplemental Transuranic Waste Treatment System.

\subsection{CROSS-CUTTING DISCUSSIONS}

There are three cross-cutting topics (HLW Glass Volume, LAW Glass Volume, and Secondary Waste) that, while not strictly results, are best discussed along with the results.

\subsubsection{High-Level Waste Glass Volume}

In many previous mission scenarios, the projected treatment end date is driven by the predicted total mass of HLW glass produced given adequate LAW and TRU treatment capacity and feed availability. Although in this Reference Case HLW glass no longer drives the treatment duration, the mission can be no shorter than the time it takes to treat the HLW. Additionally, the HLW glass produced eventually will incur disposal costs. The predicted quantity of HLW glass depends on the waste composition and quantity, solubility during retrieval and staging, degree of blending, partitioning during pretreatment, and the glass formulation model and constraints as shown by the simplified conceptual model in Figure 2-21. These factors are briefly discussed in the following sections.

Figure 2-21. Conceptual Model for Estimating High-Level Waste Glass Mass.

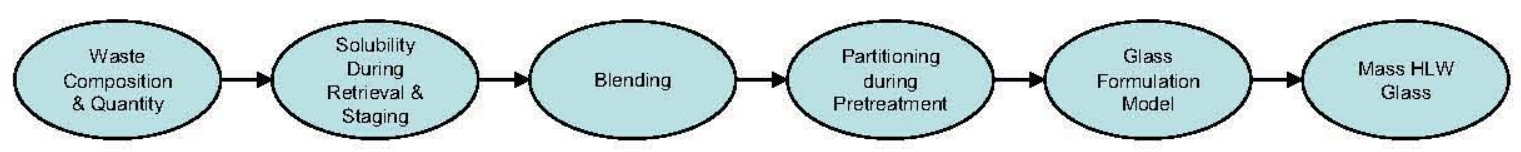

\subsubsection{Waste Composition and Quantity}

The BBI, together with selected supplemental analytes from TWINS, provides the starting estimated composition and quantity of waste in the DSTs and SSTs. Although many of these supplemental analytes ${ }^{47}$ are included in the Reference Case mass balances, they may be systematically underestimated because any missing values are treated as zeros.

The composition and quantity of waste from the MUSTs and IMUSTs are not well known as already discussed in $\$ 1.3 .1 .3$, Miscellaneous Underground Storage Tanks.

A portion of the insoluble solids (sludge) has been provisionally identified for packaging and disposal as CH-TRU or RH-TRU waste and, therefore, does not contribute to the HLW glass mass in the Reference Case. The sensitivity study in $\$ 3.3$, Transuranic Waste Disposition, estimates the impacts of incorporating this TRU waste into the HLW glass.

A what-if analysis documented in RPP-21216 Rev 3 demonstrated how addition of SST retrieval sequence constraints can impact the degree of incidental blending and resulting mass of HLW glass. This what-if case, called the "Ecology Case," used both farm-by-farm and by-area SST retrieval sequence constraints, with the order of the farms based on risk considerations. The

\footnotetext{
${ }^{47}$ In addition to the 25 chemical and 46 radionuclide components tracked by the BBI, about 32 of the supplemental analytes are used as input to the Reference Case mass balances.
} 
resulting HLW glass mass was about $11 \%$ greater than the Reference Case, after backing-out the TRU waste from the Ecology Case estimates, corresponding to about 88 percent-of-span. As discussed in $\$ 3.1$, Blending - General, the Reference Case achieved a HLW glass mass corresponding to 64 percent-of-span.

Uncertainty estimates associated with the standard BBI analytes for all 177 SSTs and DSTs are quantified and summarized in PNNL-12003, Summary of Uncertainty Estimation Results for Hanford Tank Chemical and Radionuclide Inventories.

Qualitatively, there are known uncertainties in and limitations of the BBI that may affect the HLW (and LAW) glass estimates. For example, the composition of certain waste in TX-Farm is based on only a few samples, increasing the uncertainty in the sulfate inventory. Also, there are only a few samples of REDOX (Reduction and Oxidation Facility (S-Plant)) sludge that have been analyzed, which increases the uncertainty about aluminum dissolution (wash and leach factors). Another limitation of the BBI is that the inventory is not fully speciated ${ }^{48}$ nor is the bound hydroxide (mostly associated with aluminum) measured. This causes difficulties in both estimating the total hydroxide and in reconciling and maintaining the charge balance of the waste. Uncertainties in the accounting of hydroxide (both free and bound) in the feed delivered to the WTP will result in uncertainties in determining the amount of sodium hydroxide that needs to be added to the waste during pretreatment.

\subsubsection{Solubility During Retrieval and Staging}

The solubility of tank waste during retrieval and staging is an important factor in determining both the quantity of solids and overall composition of the feed delivered to the WTP for pretreatment. This chemistry is approximated using water wash factors which describe the solubility of the tank waste when contacted with large quantities of water. They define both how much saltcake is predicted to dissolve during retrieval and staging and how much slightly soluble material is predicted to be removed from sludge when water-washed in the PT Facility.

One limitation of water wash factors is that they are a zero-order approximation that applies only to the specific set of conditions used when they were developed; they cannot accurately reflect complex changes in solid-liquid equilibrium that occur as varying amounts of water are used during retrieval, that occur when mixing different wastes, or that occur from concentration (removal of water) in the 242-A Evaporator or in the WTP. This solubility approximation allows the simulation of the retrieval and staging of all the tank waste in reasonable amount of computer time.

The water wash factors were originally developed to help estimate the quantity of HLW glass that would result from treating all of the Hanford tank waste before the decision was made include caustic and oxidative leaching as one of the pretreatment processes. The factors were generally estimated by contacting solids with large quantities of water and measuring the composition of the liquid phase. Engineering judgment was used to estimate the wash factors for waste that lacked direct measurements.

\footnotetext{
48 The phrase "not fully speciated" means that not all of the chemical compounds or their constituent species have been identified.
} 
Over the past several years, the water wash factors for $\mathrm{Cr}, \mathrm{Al}, \mathrm{SO}_{4}, \mathrm{PO}_{4},{ }^{99} \mathrm{Tc}$ were reviewed and updated because previous analysis suggested there were biases or errors that required correction. The factors actually used in the Reference Case are cited in Appendix B, §B2.6.3.

\subsubsection{Degree of Blending}

One of the major drivers for predicting the HLW glass mass is the degree of blending that occurs before vitrification of the waste. Blending (or its intentional absence, called segregation) influences the HLW glass mass by influencing the composition and variability of the pretreated HLW feed batches, thus increasing or decreasing the overall amount of glass formers that must be added to the waste during vitrification.

Previous work (RPP-20003, Sensitivity of Hanford Immobilized High-level Waste Glass Mass to Chromium and Aluminum Partitioning Assumptions, and RPP-RPT-26040, Pairwise Blending of High-Level Waste) has shown that the degree of blending can change the predicted mass of HLW by about a factor of two between two bounding cases, the Total-Blend and the No-Blend cases. Under current assumptions for the Reference Case, the HLW glass mass for the No-Blend case is nominally twice that of the Total-Blend case; see the sensitivity study discussed in $\S 3.1$, Blending - General, for more details.

Like many previous mission scenarios, the Reference Case relies primarily on "Incidental Blending" - that which occurs during the retrieval, staging, storage, and delivery of feed without any special effort other than SST sequencing. The degree of incidental blending in recent mission scenarios has typically resulted in a projected HLW glass mass about half-way between the Total-Blend and No-Blend cases, with the exception of the TFCOUP Rev 6, which overestimated the degree of incidental blending. The degree of incidental blending is sensitive to the configuration (most notably how tank systems are connected) of the retrieval, transfer, and staging systems; the amount of solids that are allowed to accumulate in the DST System; and the SST retrieval sequence.

In addition to incidental blending, the Reference Case incorporates several intentional blends supporting WTP safety and operational considerations; these were discussed in the Feed Control List discussion in $\$ 2.3 .1 .6$, Waste Transfers.

Intentional blending can also be used to reduce the mass of HLW glass. However, there are many operational and logistical considerations that constrain the degree of blending that can be achieved and the difficulty and cost thereof. Section 2.4 of the RPP-RPT-26040 discusses some of the ways in which intentional blending could be implemented.

\subsubsection{Partitioning During Pretreatment}

The purpose of the WTP PT Facility is to partition (separate) the tank waste into two streams. One stream, containing the LAW fraction of the waste, will be sent to either the WTP LAW Vitrification Facility or to the East STP for treatment (immobilization in glass) and on-site disposal in the IDF. The other stream, containing the HLW faction of the waste and separated fission products, will be sent to the WTP HLW Vitrification Facility for treatment (immobilization in glass) and eventual disposal at the HLW Geologic Repository.

The WTP PT Facility contains several unit operations that influence the partitioning of waste into pretreated LAW and HLW. These are briefly discussed below and include feed concentration, caustic leaching, oxidative leaching, post-leach wash, Sr/TRU precipitation, and 
cesium removal. The sensitivity study in $\$ 3.4$, Degree of Pretreatment, demonstrates the importance of both caustic and oxidative leaching on the resulting mass of HLW glass.

A vacuum evaporator is used to concentrate liquid feed to a target sodium concentration (nominally $5 \underline{\mathrm{M}}$ ) when needed. The solid liquid equilibrium that takes place during this concentration step has not been defined in the WTP Dynamic (G2) Model Design Document (24590-WTP-MDD-PR-01-002) nor modeled in HTWOS.

The UFP system is used to remove any remaining water-soluble components, caustic-soluble (primarily aluminum and chromium) components, and additional removal of chromium (oxidative leaching) from the solids. The water wash factors have already been "applied" during the retrieval and staging of the feed to the WTP PT Facility; little or no additional dissolution from washing is assumed here.

The caustic-soluble components are removed by contacting the solids with hydroxide ion from a sodium hydroxide solution. The amount of material removed from the solids is approximated using the caustic leach factors, which, like water wash factors, are a zero-order approximation. Sufficient excess hydroxide must remain to keep the removed material (mostly aluminum) in solution in the subsequent processing steps. The caustic leach factors used by the Reference Case are cited in Appendix B, §B2.6.4. The Reference Case assumes that the amount of caustic needed to achieve a $3 \underline{\mathrm{M}}$ free $\mathrm{OH}^{-}$concentration after caustic leaching will be sufficient to keep the aluminum in solution. However, recent WTP flowsheet calculations predict that additional caustic will be required. See the sensitivity study in $\S 3.5$, Leach Caustic, for more details.

It has been assumed that additional chromium can be removed during the ultrafilter operating cycles by oxidizing the chromium to a soluble valance by adding sodium permanganate to the waste after caustic leaching and water rinsing is completed.

The final step in the pretreatment of solids in the UFP system is a post-leach wash in which the interstitial liquid containing the leached (dissolved) solids is physically diluted and removed from the insoluble solids. The post-leach wash effectiveness depends primarily on the operating modes and parameters selected for the operation of the UFP system.

Envelope C waste from tanks AN-102 and AN-107 requires the removal of complexed strontium and TRU from the liquid phase in order for the resulting ILAW to be disposed on site. Although the Reference Case assumes that this removal will occur in the tank farms, the WTP is retaining that capability. If performed in the WTP, the UFP system is used to effect this separation by precipitating the TRU with sodium permanganate and precipitating the strontium using isotopic dilution with $\mathrm{Sr}\left(\mathrm{NO}_{3}\right)_{2}$. This potential operation has little impact on the total HLW glass mass but reduces the rate at which waste can be pretreated and introduces some process inefficiencies in the management and blending of the precipitate, both of which in turn impacts the overall glass production.

\subsubsection{Glass Formulation Model}

A glass formulation model is a mathematical model that estimates the composition of the glass resulting from the vitrification of a specified (in this case pretreated HLW) feed. It is generally stated as a non-linear programming problem in which the object (the objective function) is to minimize the mass or volume of the resulting glass subject to a set of constraints on acceptable glass properties and allowable glass composition. In theory, and depending on the goal, different objective functions or constraints could be used to account for uncertainties in properties, 
composition or limits; maximize rate of incorporation of feed into the glass; increase melter lifespan; or increase the robustness of the formulation.

The method currently used to formulate the HLW glass in both the WTP's G2 model and the HTWOS model directly bases the glass formulation on the composition of the pretreated HLW. The pretreated HLW is comprised of the water- and caustic-insoluble solids, the separated cesium, the precipitated strontium and TRU, and any dissolved solids remaining in the liquid phase, less any chromium removed by oxidative leaching. In the WTP HLW Vitrification Facility, the pretreated HLW is combined with glass forming chemicals, converted to oxides, and incorporated into glass in the HLW melters. The mass and composition of the glass-forming chemicals is adjusted to produce the minimum mass of HLW for that specific batch of pretreated HLW, and is subject to a number of constraints on glass properties and composition. The resulting mass of HLW glass depends on the specific glass properties models (i.e., empirical property-composition correlations) being used, the allowable ranges for each property, the model domain (region of model validity), allowances for uncertainties, and any other limits on glass composition. One of the main objectives of blending is to level out the various glass-limiting components to reduce the total quantity of glass formers needed to produce an acceptable glass and thus minimize the total mass of HLW glass produced.

The Reference Case uses a glass formulation model often referred to as the "Relaxed Glass Property Model (GPM)," which was developed using experimental data available before 1996. The details of the model are restated in Appendix B, §B2.3.3.6, for convenience. While this model is more aggressive than the WTP's baseline model, it is thought to estimate improvements expected in HLW loading after additional technology development. Pacific Northwest National Laboratory (PNNL) is developing an updated glass formulation model for the ORP using data available through 2007 to improve the accuracy and expand the region of validity of the model. The sensitivity study in 2.4.1.5, Glass Formulation Model, compares the HLW glass mass projected by the Reference Case to that projected by a model similar to WTP's current baseline model.

The 2,000-plus projected melter feed batches (individual melter feed preparation vessel batches of pretreated HLW sent to the HLW melters) for the Reference Case were reviewed and the limiting constraints were identified. Table 2-5 summarizes the glass drivers; three constraints ( $\mathrm{SO}_{3}, \mathrm{Al}_{2} \mathrm{O}_{3}$, and Spinel liquidus temperature) determine about $94 \%$ of the glass mass. This assumes that water washing and caustic leaching removes much of the aluminum; that oxidative leaching is effective in removing the chromium; that the components removed by leaching do not re-precipitate; and that the relaxed glass properties model applies. For similar technical assumptions, but different degrees of blending and older tank inventory, a previous analysis (RPP-RPT-26040) identified $\mathrm{Fe}_{2} \mathrm{O}_{3}$ and $\mathrm{P}_{2} \mathrm{O}_{5}$ as limiting constraints in addition to those identified for the Reference Case. 
Table 2-5. Summary of Reference Case High-Level Waste Glass Drivers.

\begin{tabular}{|c|c|c|c|c|c|c|c|c|}
\hline \multicolumn{3}{|c|}{ Constraints $^{1}$} & \multirow{2}{*}{$\begin{array}{c}\text { Number of waste } \\
\text { feed batches }\end{array}$} & \multirow{2}{*}{$\begin{array}{c}\begin{array}{c}\text { Waste oxide } \\
\text { mass }^{2} \text { (MT) }\end{array} \\
5,738\end{array}$} & \multirow{2}{*}{$\begin{array}{r}\begin{array}{r}\text { Glass } \\
\text { mass } \\
\text { (MT) }\end{array} \\
22,645\end{array}$} & \multirow{2}{*}{$\begin{array}{c}\begin{array}{c}\text { Average waste } \\
\text { loading in glass }\end{array} \\
0.253\end{array}$} & \multirow{2}{*}{$\begin{array}{c}\begin{array}{c}\text { Percent of waste } \\
\text { oxide mass }\end{array} \\
46.8 \%\end{array}$} & \multirow{2}{*}{$\begin{array}{c}\begin{array}{l}\text { Percent of } \\
\text { glass mass }\end{array} \\
56.1 \%\end{array}$} \\
\hline \multirow{10}{*}{$\begin{array}{c}\text { Glass } \\
\text { composition } \\
\text { constraints }\end{array}$} & \multirow{4}{*}{$\begin{array}{l}\text { Solubility } \\
\text { limited }\end{array}$} & $\mathrm{SO}_{3}$ & & & & & & \\
\hline & & $\mathrm{P}_{2} \mathrm{O}_{5}$ & 0 & 0 & 0 & $\mathrm{n} / \mathrm{a}$ & $0.0 \%$ & $0.0 \%$ \\
\hline & & $\mathrm{Cr}_{2} \mathrm{O}_{3}$ & 0 & 0 & 0 & $\mathrm{n} / \mathrm{a}$ & $0.0 \%$ & $0.0 \%$ \\
\hline & & Subtotal & 960 & 5,738 & 22,645 & 0.253 & $46.8 \%$ & $56.1 \%$ \\
\hline & \multirow{5}{*}{$\begin{array}{l}\text { Model } \\
\text { validity } \\
\text { limited }\end{array}$} & $\mathrm{Al}_{2} \mathrm{O}_{3}$ & 298 & 1,829 & 5,871 & 0.312 & $14.9 \%$ & $14.5 \%$ \\
\hline & & $\mathrm{Fe}_{2} \mathrm{O}_{3}$ & 57 & 362 & 933 & 0.388 & $3.0 \%$ & $2.3 \%$ \\
\hline & & $\mathrm{Na}_{2} \mathrm{O}$ & 81 & 449 & 1,291 & 0.348 & $3.7 \%$ & $3.2 \%$ \\
\hline & & $\mathrm{SiO}_{2}$ & 0 & 0 & 0 & $\mathrm{n} / \mathrm{a}$ & $0.0 \%$ & $0.0 \%$ \\
\hline & & Subtotal & 436 & 2,640 & 8,096 & 0.326 & $21.5 \%$ & $20.1 \%$ \\
\hline & \multicolumn{2}{|c|}{$\begin{array}{l}\text { Glass composition constraints } \\
\text { subtotal }\end{array}$} & 1,396 & 8,378 & 30,740 & 0.273 & $68.4 \%$ & $76.2 \%$ \\
\hline \multirow{3}{*}{$\begin{array}{l}\text { Glass property } \\
\text { constraints }\end{array}$} & \multicolumn{2}{|c|}{ Spinel $T_{\mathrm{L}}$ involved } & 615 & 3,712 & 9,289 & 0.400 & $30.3 \%$ & $23.0 \%$ \\
\hline & \multicolumn{2}{|c|}{ Spinel $T_{\mathrm{L}}$ NOT involved } & 33 & 164 & 336 & 0.488 & $1.3 \%$ & $0.8 \%$ \\
\hline & \multicolumn{2}{|c|}{$\begin{array}{l}\text { Glass property constraints } \\
\text { subtotal }\end{array}$} & 648 & 3,876 & 9,626 & 0.403 & $31.6 \%$ & $23.8 \%$ \\
\hline \multicolumn{3}{|c|}{ Reference Case Realized Blend total } & 2,044 & 12,254 & 40,366 & 0.304 & $100.0 \%$ & $100.0 \%$ \\
\hline
\end{tabular}

Notes:

${ }^{1}$ The shaded cells indicate the major constraints that drive the HLW glass mass. This analysis of glass drivers is performed for glass formulated before the application of melter DFs. No credit is taken for volatility of constraining components.

${ }^{2}$ In this table, waste oxides refer to the fully pretreated $\mathrm{HLW}$, on an oxide basis.

${ }^{3}$ Represents the weighted average waste loading from the glasses produced from melter feed batches that are limited by the same (or same group) of constraints. Units are mass fraction. 


\subsubsection{Low-Activity Waste Glass Volume}

The main factors that control the mass of LAW glass are the total mass of LAW sodium and the achievable sodium oxide loading.

The total mass of soluble sodium comprises the soluble portion of the tank waste, the sodium present in the sodium hydroxide and sodium nitrite added for DST corrosion control, and the sodium from sodium hydroxide added by the WTP PT process. In the Reference Case, about 55,900 MT of LAW sodium are incorporated into LAW glass from the WTP, DBVS, BVS, West STP, and East STP. Of that amount, approximately 1,500 MT were added for tank corrosion chemistry controls and 8,770 MT were added by the WTP for caustic leaching and other process reasons. The sensitivity study in $\$ 3.5$, Leach Caustic, explains that up to $34,000 \mathrm{MT}$ additional leach caustic might be required to be added by the WTP flowsheet.

The achievable sodium oxide loading is driven primarily by the amount of $\mathrm{SO}_{4}$ from the LAW supernate that can be incorporated into the glass as $\mathrm{SO}_{3}$.

- For the facilities using the ICV ${ }^{\mathrm{TM}}$ process (DBVS, BVS, West STP and East STP), a fixed sodium oxide loading of $21.24 \mathrm{wt} \%$ is used pending flowsheet revision after completion of the crucible-scale glass formulation work and the full scale tests.

- For the WTP, the DOE Model is used to estimate the sodium oxide loading. In this model, the LAW glass is formulated around two constraints: $\left[\mathrm{Na}_{2} \mathrm{O}\right] \leq 20 \mathrm{wt} \%$ and $\left[\mathrm{SO}_{3}\right] \leq 0.8 \mathrm{wt} \%$. For the Reference Case, this results in about an $18.1 \mathrm{wt} \%$ sodium oxide loading.

- The DOE Model assumes that LAW glass can be formulated to incorporate more $\mathrm{SO}_{3}$ than the baseline LAW glass formulation model (24590-LAW-RTP-RT-04-0003, "Preliminary ILAW Formulation Algorithm Description") currently in use at the WTP. Use of the baseline model with the other Reference Case assumptions would reduce the sodium oxide loading to around $13 \mathrm{wt} \%$. Use of the WTP baseline model with the addition of $34,000 \mathrm{MT}$ of additional caustic would likely dilute the $\mathrm{SO}_{3}$ sufficiently so that the sodium oxide loading would be similar to that achieved by the DOE Model.

\subsubsection{Secondary Waste}

Table 2-4 shows the total activity and inventory for three selected constituents of concern for the secondary waste streams projected to be disposed of at the IDF. A more detailed breakdown of the secondary waste streams is provided in Appendix $\mathrm{C}$ for those selected constituents and in SVF-1431 for all tracked constituents. As discussed in \$2.3.4.4, Integrated Disposal Facility, only process-related waste streams generated by the Waste Treatment Complex are reported, not the overall mass and volume (e.g., the total waste inventory on the HEPA filters is estimated, but not the number of filters or their mass and volume). Miscellaneous LLW such as shoe covers and SWPs (protective clothing requiring special work permits) are not estimated or reported, nor is waste that will be generated from the decommissioning of the various facilities addressed.

The secondary waste estimates are strongly affected by the overall system configuration (i.e., how the various facilities are interconnected); the assumptions impacting the internal recycles within each facility, particularly the phase of the recycled material; and the numerous split factor 
assumptions used to partition the mass at each unit operation. Like wash and leach factors, split factors (and decontamination factors) are a zero-order approximation to the partitioning that is expected to occur in each unit operation. The basis for each of the individual split factors run the gamut from engineering estimates to partial- and full-scale testing of simulants, analogs, or actual waste.

An implicit assumption is that whatever inventory is projected to report to IDF as secondary waste, it will meet IDF performance goals through either better stabilization at ETF, or better control at the treatment facility (West STP, East STP, or WTP), more optimal system design (e.g., recycle management, interfaces between WTP and supplemental pretreatment and/or supplemental treatment), or through refined estimates of the behaviors of each unit operation.

Because of the importance of the secondary waste in the successful treatment of the tank waste, the ORP is developing a secondary waste management strategy that focuses on the key constituents of concern and addresses the basis for the secondary waste estimates, the acceptability of those estimates to their ultimate disposal at the IDF, and the ability of the ETF to support the treatment mission.

\subsection{SCHEDULE}

Figure 2-22 depicts the schedule for the key operational activities for the RPP Mission as estimated by the Reference Case. The overall mission, including closure and decontamination and decommissioning activities, extends to FY 2055. Only key operational activities are shown activities such as design, construction, permitting and testing are not shown. The schedule for activities not addressed by the HTWOS model, such as closure and decontamination and decommissioning, were estimated by shifting the baseline schedule to be consistent with the projected dates for the modeled activities. 
Figure 2-22. RPP Operating Schedule for the Reference Case.

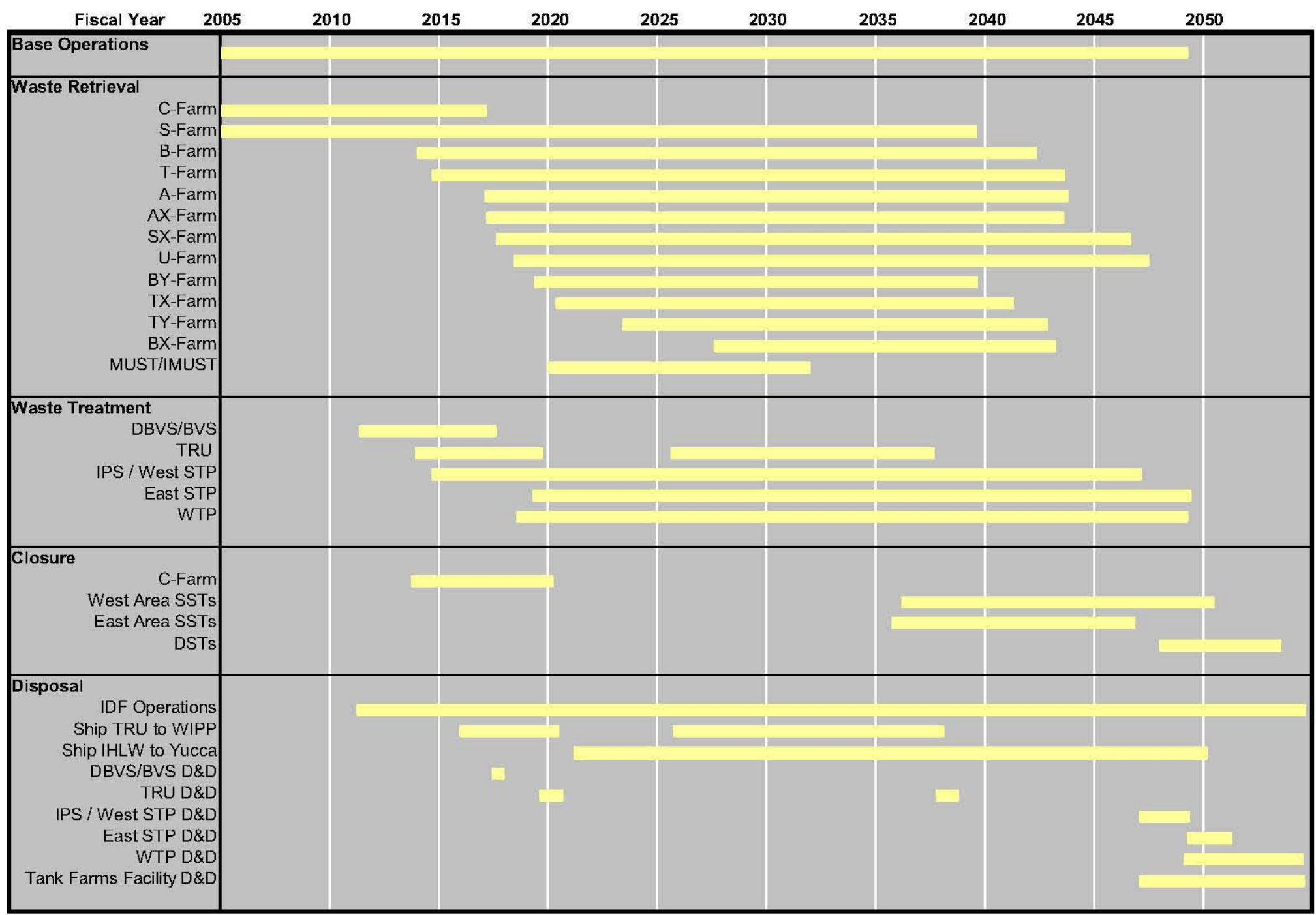




\subsection{SENSITIVITY STUDIES}

This section discusses the impact of selected parameters upon key aspects of the Reference Case mission scenario. This section is organized according to study and each study is independent of the others. These studies are meant to provide a representation of the key sensitivities; they are not meant to be comprehensive, rigorous, sensitivity analyses that capture all uncertainties and interactions.

$\S 4.2$, Mission Sensitivities, will summarize the results by providing projected ranges on key mission parameters.

\subsection{BLENDING - GENERAL}

As discussed in $\$ 2.4 .1 .3$, one of the factors that influences the mass of HLW glass is the degree of blending. The impact that blending may have upon the mass of HLW glass can be assessed by comparing the mass of glass that would result if all of the tank waste solids were mixed together before treatment versus that which would result if the solids from each tank were treated separately and the resulting glass totaled. This analysis uses many of the same assumptions as the Reference Case, namely, the tank inventory, disposition of TRU tanks, water wash and caustic leach factors, oxidative leaching, and the glass formulation model and associated limits.

For the Reference Case assumptions, the mass of HLW glass could range from 28,620 MTG (8,944 canisters) to 46,514 MTG (14,536 canisters). The mass of HLW glass resulting from the degree of blending realized in the mission scenario underpinning the Reference Case was 40,042 MTG (12,513 canisters). This is 64 percent-of-span between the Total-Blend and the No-Blend. The percent-of-span is the percent of the way the projected glass mass falls between the Total Blend and the No Blend glass mass. For example, 0 percent of span corresponds to the Total Blend, while 50 percent of span corresponds to halfway between the Total Blend and No Blend." These glass masses are shown on Figure 3-1 as "Case 16 (SP3 Ref)."49 (SVF-1397, SP3_Total-Blend_No-Blend_v_2.xls).

The potential change in mission duration relative to the Realized Blend can be estimated for the Total-Blend and No-Blend by assuming that HLW drives the mission at the assumed net HLW vitrification rate of 5.25 MTG/d. If the Total-Blend were achieved, the length of the mission would be reduced by about 6 years; if the No-Blend were achieved, the length would increase by about 3 years. In practice, other constraints such as SST retrieval durations or LAW treatment capacity may limit reductions in mission length.

The Realized Blend for the Reference Case is about $34 \%$ larger $^{50}$ than the System Plan Revision 2 (SP2). Most of this increase is due to increases in the Total Blend and No Blend in response to updated waste inventories and wash and leach factors. So of the increase is due to a lesser degree of incidental blending as evidenced by an increased percent-of-span for the Reference Case.

\footnotetext{
${ }^{49}$ The case numbering on Figure 3-1 begins at Case 16 in order to maintain continuity with the numbering used in RPP-RTP-26040 and RPP-20003.

${ }^{50}$ The $24 \%$ increase shown on Figure 3-1 applies to the average increase in the Total Blend and No Blend. The $34 \%$ increase applies to the increase in the Realized Blend.
} 
Figure 3-1. Comparison of High-Level Waste Glass Mass Ranges for Selected Cases.

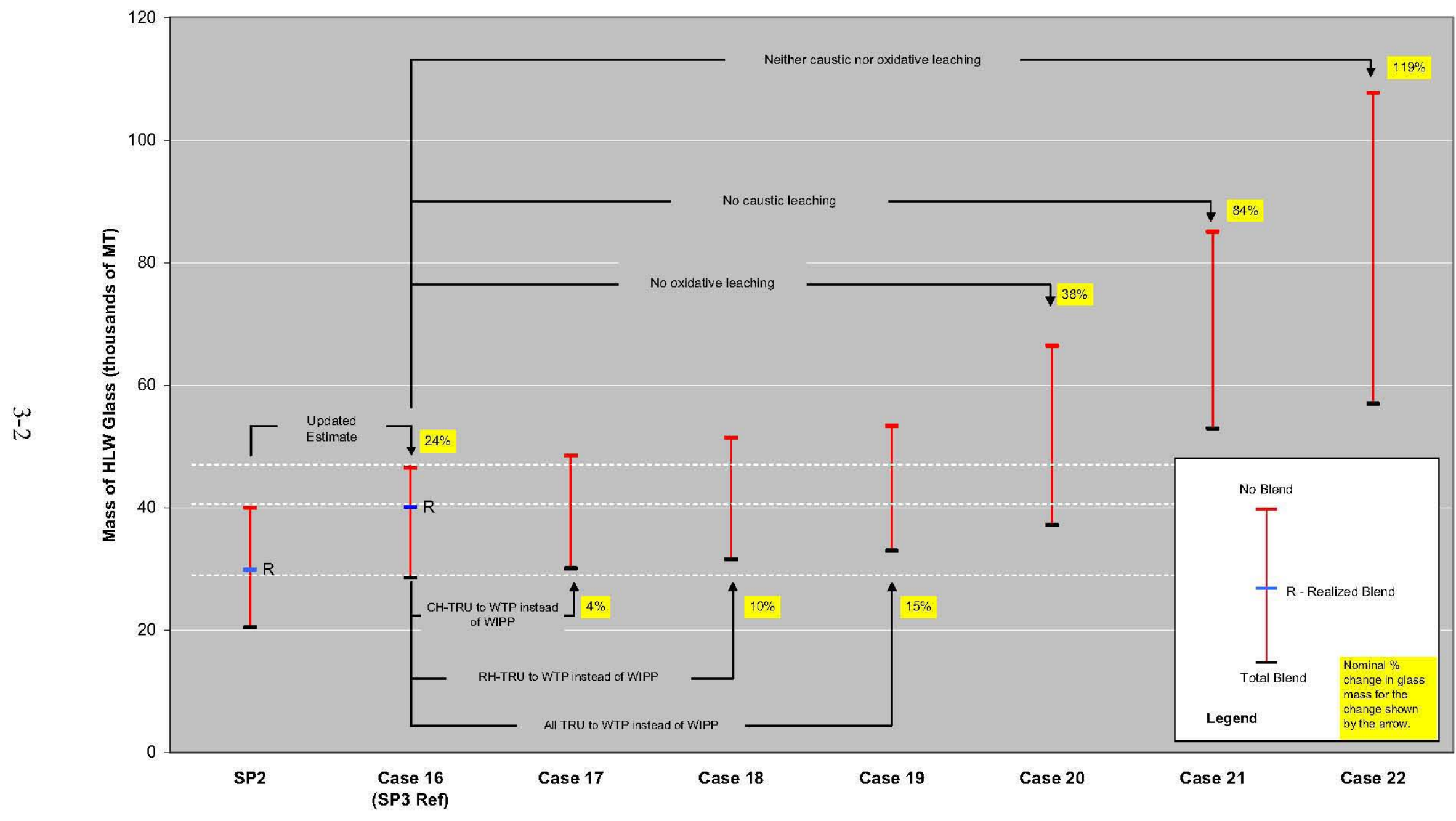




\subsection{BLENDING - RETRIEVAL CONSTRAINTS}

Addition of operational or logistical constraints tends to reduce the degree of blending and increase the mass of HLW glass. The study "Pairwise blending of High-Level Waste," RPP-RPT-26040, has demonstrated this for the hypothetical situation in which tanks are blended by pairs, with no additional blending beyond the blend pairs. Although the Reference Case does not use this pairwise blending approach, the general trends are still valid. This analysis uses many of the same assumptions as the Reference Case, namely, the tank inventory, disposition of TRU tanks, water wash and caustic leach factors, oxidative leaching, and the glass formulation model and associated limits. This kind of analysis has previously assumed perfect solid-liquid separation after pretreatment and will continue to do so.

The sensitivity study compared the potential improvements in HLW glass mass relative to the Total-Blend and No-Blend Cases for a series of blend pair cases, each imposing additional constraints on which blends are permissible:

- No constraints (any of the 156 tanks $^{51}$ can be blended with any other tank)

- Area Constrained (200 E tanks can only be blended with $200 \mathrm{E}$ tanks; $200 \mathrm{~W}$ with $200 \mathrm{~W})$

- Quadrant Constrained (tanks can only be blended with other tanks from the same quadrant)

- Farm Constrained (tanks can only be blended with other tanks from the same farm).

The results are reported in Table 3-1 as "percent-of-span," which is the percent of the way the projected glass mass falls between the Total-Blend and the No-Blend glass mass. For example, 0 percent-of-span corresponds to the Total-Blend, while 50 percent-of-span corresponds to halfway between the Total-Blend and No-Blend." The resulting HLW glass mass increases significantly as the severity of the constraints imposed on the blend pairs is increased.

Table 3-1. Effects of Constraining Blend Pairs.

\begin{tabular}{|l|c|}
\hline \multicolumn{1}{|c|}{ Constraints on Blend Pairs } & $\begin{array}{c}\text { HLW Glass, } \\
\text { Percent-of-Span }\end{array}$ \\
\hline Unconstrained & 4 \\
\hline By Area (200E / 200W) & 18 \\
\hline By Quadrant (NE / NW/ SE / SW) & 34 \\
\hline By Farm & 61 \\
\hline
\end{tabular}

A what-if analysis documented in RPP-21216 Rev 3 demonstrated how addition of SST retrieval sequence constraints can impact the degree of incidental blending and resulting mass of HLW

\footnotetext{
${ }^{51}$ The pairwise blending sensitivity study examined the blending of 156 tanks. The 20 tanks containing TRU assumed to be sent to WIPP were excluded, which left an odd number of tanks $(177-20=157)$. To ensure an even number of tanks for blending by pairs, one nearly empty tank was also excluded, yielding 156 tanks.
} 
glass. This what-if case, called the "Ecology Case," used both farm-by-farm and by-area SST retrieval sequence constraints, with the order of the farms based on risk considerations. The resulting HLW glass mass was about $11 \%$ greater than the Reference Case, after backing-out ${ }^{52}$ the TRU waste from the Ecology Case estimates, corresponding to about 88 percent-of-span. As discussed in $\$ 3.1$, Blending - General, the Reference Case achieved a HLW glass mass corresponding to 64 percent-of-span.

\subsection{TRANSURANIC WASTE DISPOSITION}

The Reference Case assumes that the TRU sludge present in 20 tanks will be packaged and shipped to WIPP for disposal. The impact to HLW glass mass from treating this TRU sludge in the WTP instead disposal at WIPP was estimated by comparing the Total-Blend / No-Blend for the Reference Case against those for three different dispositions. This analysis uses many of the same assumptions as the Reference Case, namely, the tank inventory, water wash and caustic leach factors, oxidative leaching, and the glass formulation model and associated limits. This kind of analysis has previously assumed perfect solid-liquid separation after pretreatment and will continue to do so.

Case 17 on Figure 3-1 shows that the impact of treating the CH-TRU in the WTP rather than disposal at WIPP is an increase in the Total-Blend and No-Blend HLW glass of about 4\% relative to the Reference Case - Case 16 (Reference Case). Case 18 shows about a 10\% increase for RH-TRU. Case 19 shows about a 15\% increase for both CH-TRU and RH-TRU (SVF-1397).

\footnotetext{
${ }^{52}$ In the Ecology Case, the TRU waste was assumed to be treated at the WTP. The Ecology Case HLW glass mass was therefore adjusted by a factor of $1 / 1.15$ to account for the increase in glass mass due solely to the TRU disposition. This adjusted glass mass can then be directly compared to that from the Reference Case - the difference is due to changes in blending as a result of the changed SST retrieval sequence.
} 
The increase in the realized blend can be estimated assuming that the same degree of blending (or more specifically, constant percent-of-span) is maintained after the TRU is blended with the HLW. These are shown in Table 3-2 below along with an estimate of the increase in HLW treatment duration, based on the assumed 5.25 MTG/d production rate and an assumption that the HLW glass production drives the mission duration. Some of the increase in HLW glass mass may be used to "fill-in" HLW melter outages, partially mitigating the increase in mission duration.

Table 3-2. Sensitivity of Mission to Transuranic Waste Disposition.

\begin{tabular}{|l|c|c|c|}
\hline \multirow{2}{*}{ Case } & \multicolumn{3}{|c|}{ Increase Relative to Case 16 (Reference Case) } \\
\cline { 2 - 4 } & Percent & $\begin{array}{c}\text { HLW Glass } \\
\text { (MTG) }\end{array}$ & $\begin{array}{c}\text { Treatment Duration } \\
\text { (Months) }\end{array}$ \\
\hline 16 (Reference Case) & 0 & 0 & 0 \\
\hline 17 (CH-TRU to WTP) & 4 & 1,755 & 11 \\
\hline 18 (RH-TRU to WTP) & 10 & 4,165 & 26 \\
\hline 19 (All TRU to WTP) & 15 & 5,920 & 37 \\
\hline
\end{tabular}

${ }^{1}$ This is the estimated increase in treatment duration assuming that $\mathrm{HLW}$ production drives the duration. HLW $=$ high-level waste.

$\mathrm{MTG}=$ metric tons of glass.

TRU $=$ transuranic.

WTP $=$ Waste Treatment and Immobilization Plant

\subsection{DEGREE OF PRETREATMENT}

The Reference Case assumes that all solids delivered to the WTP will undergo caustic and oxidative leaching. This sensitivity study looks at how the Total-Blend / No-Blend HLW glass mass varies as a function of degree of pretreatment. Four degrees of pretreatment were evaluated: water wash only, water wash + caustic leach, water wash + oxidative leach and water wash + caustic leach + oxidative leach. For a given case all tanks are assumed to receive the same degree of pretreatment. This analysis uses many of the same assumptions as the Reference Case, namely, the tank inventory, disposition of TRU tanks, water wash factors, caustic leach factors (when applicable), oxidative leach endpoint (when applicable), and the HLW glass formulation model and associated limits.

The results are shown graphically on Figure 3-1 and organized according to increasing impact relative to the Reference Case - Case 16 (Reference Case). The glass mass range for Case 20 (No oxidative leach $=$ water wash + caustic leach) is about $38 \%$ larger than the Reference Case; Case 21 (No caustic leaching = water wash + oxidative leach) is about 84\% larger; and Case 22 (Neither caustic nor oxidative leaching = water wash only) is about 119\% larger (SVF-1397). 
The increase in the realized blend can be estimated assuming that the same degree of blending (or more precisely, a constant percent-of-span) is maintained was achieved in the Reference Case. These are shown in Table 3-3 along with an estimate of the increase in HLW treatment duration, based on the assumed 5.25 MTG/d production rate.

Table 3-3. Sensitivity of Mission to Degree-of-Pretreatment.

\begin{tabular}{|l|c|c|c|}
\hline \multirow{2}{*}{ Case } & \multicolumn{2}{|c|}{ Increase Relative to Case 16 (Reference Case) } \\
\cline { 2 - 4 } & Percent & $\begin{array}{c}\text { HLW Glass } \\
\text { (MTG) }\end{array}$ & $\begin{array}{c}\text { Treatment } \\
\text { Duration } \\
\text { (years) }\end{array}$ \\
\hline 16 (Reference Case) & 0 & 0 & 0 \\
\hline 20 (No oxidative leach) & 38 & 15,777 & 8 \\
\hline 21 (No caustic leach) & 84 & 33,370 & 17 \\
\hline 22 (No oxidative or caustic leaching) & 119 & 49,329 & 26 \\
\hline
\end{tabular}

${ }^{1}$ This is the estimated increase in treatment duration assuming that $\mathrm{HLW}$ production drives the duration. $\mathrm{HLW}=$ high-level waste.

$\mathrm{MTG}=$ metric tons of glass.

Another previously published study (RPP-20003) looked at which tanks contain waste that would benefit from the different degrees of pretreatment. Tanks were screened by comparing tank-by-tank glass masses under different pretreatment assumptions: water wash only; water wash plus caustic leach; water wash, caustic leach, and oxidative leach; and water wash plus oxidative leach. The degree of pretreatment was assumed to be the least amount of pretreatment that yields a glass mass not significantly different from the minimum glass mass for each specific tank.

The study concluded that the majority of the tanks (about 75\%) require caustic leaching, either with or without oxidative leaching, and that oxidative leaching provides a significant benefit when used in conjunction with caustic leaching. It may be difficult to take advantage of the differing degrees of pretreatment because of the extensive amount of incidental blending that occurs. For example, it may be impractical or even counterproductive to retrieve and deliver the $25 \%$ of tanks that do not require caustic leaching without any blending with tanks that do require caustic leaching. Specific decisions about tailoring the degree of pretreatment need to consider the composition of the delivered feed, not just the composition of the waste as it sits in the source tanks; those considerations were not addressed in RPP-20003.

\subsection{LEACH CAUSTIC}

In 2004, ORP conducted a design oversight of the UFP system process in the WTP PT Facility. The design oversight, transmitted under cover of Letter 04-WED-024, "Summary and Actions from the U.S. Department of Energy, Office of River Protection (ORP) Oversight of Pretreatment (PT) Plant Ultrafiltration Process (UFP) System," identified that the then-current WTP process flowsheet would not support effective aluminum dissolution and significantly underestimated the caustic required to be added to the system.

In 2005, BNI assembled a team of leading experts from industry, national laboratories and universities (referred to as the External Flowsheet Review Team [EFRT]) to conduct a review of 
the process flowsheet. In response to this review, BNI performed a study to determine the impact of eight proposed modifications to the WTP PT processes. This study included the process flowsheet changes (aluminum solubility relationships) needed to complete the caustic leaching process and maintain the aluminum in solution through the cesium ion-exchange process. Based on the recommended modifications and updated aluminum solubility relationships from this study, up to $34,000 \mathrm{MT}$ of additional sodium ${ }^{53}$ may be required to be added during caustic leaching. (24590-WTP-RPT-PO-07-002, Dynamic (G2) Flowsheet Assessment of the Effect of M-12 Modifications on Pretreatment Capacity)

The sensitivity study in this section estimates the impact upon the mission if the additional 34,000 MT of sodium were incorporated into the WTP PT flowsheet. The impacts were estimated in two ways:

- Given a fixed LAW treatment capacity (WTP LAW Vitrification + East STP), estimate the increase in mission duration.

- Given a fixed mission duration, estimate the needed East STP capacity.

In both of the above cases, the West Area LAW treatment (DBVS, BVS, and West STP) production was held constant. The production of the WTP LAW Vitrification facility and the East STP were assumed to follow their ramp-up curves in the key enabling assumptions (i.e., any production outages were removed to decouple this study from SST retrieval limitations). The results of the study (SVF-1412, Caustic_Sensitivity_v1.xls) are discussed below; the mission durations and end dates have been adjusted to remove production outages in the Reference Case.

- Given a fixed LAW treatment capacity (WTP LAW Vitrification + East STP), estimate the increase in mission duration: An additional 15 years would be required to treat the additional sodium resulting in a treatment end date of about 2060 as compared to the no-outage date of 2045 for the Reference Case.

- Given a fixed mission duration, estimate the needed East STP capacity: The East STP would require approximately $35 \mathrm{MTG} / \mathrm{d}$ net production capacity to maintain the treatment end date as compared to about $14.65 \mathrm{MTG} / \mathrm{d}$ for the Reference Case. This is over twice the Reference Case capacity for East STP.

In either of the above cases, the total mass of projected LAW glass will be about $617,000 \mathrm{MTG}$ as compared to $384,200 \mathrm{MTG}$ for the Reference Case, an increase of about 61 percent, assuming the average $\mathrm{Na} 2 \mathrm{O}$ loadings discussion in $\$ 2.4 .2$, Low-Activity Waste Glass Volume, are maintained.

\subsection{HIGH-LEVEL WASTE GLASS MODELS}

As discussed in $\$ 2.4 .1 .5$, one of the factors that influences the mass of HLW glass is the glass formulation model. This sensitivity study estimated the impact of using a different glass formulation model. The study compares the glass mass projected by the Reference Case versus that projected by a Sensitivity Case that is generally aligned with the glass formulation

\footnotetext{
${ }^{53}$ The cited study estimated 40,600 MT sodium for leaching and maintaining aluminum solubility when using recommended modifications and updated aluminum solubility relationships. The base case for the cited study used only $6,600 \mathrm{MT}$ sodium. The difference $(40,600-6,600=34,000)$ is the incremental or additional sodium assumed by the Leach Caustic sensitivity study.
} 
constraints and limits implicit in the WTP flowsheet. In this study, the composition of each of the two thousand plus batches of pretreated HLW is kept constant between the two cases to eliminate blending or pretreatment related influences. Table 3-4 compares the constraints and limits for both cases used in this study.

The impact of changing from the Reference Case to the Sensitivity Case HLW glass constraints and limits is an increase in HLW glass mass of about 21\% (SVF-1427, SP3_HLW_Glass_Limit_Sensitivity.xls). A sub-study changed only the $\mathrm{Al}_{2} \mathrm{O}_{3}$ limit to the Sensitivity Case value, leaving the other constraints and limits at the Reference Case values. This sub-study found that over half of this glass mass increase is solely a result of the reduction of the $\mathrm{Al}_{2} \mathrm{O}_{3}$ upper limit from $17 \mathrm{wt} \%$ to $11 \mathrm{wt} \%$.

\subsection{SUPPLEMENTAL LOW-ACTIVITY WASTE TREATMENT}

As discussed in $\$ 1.3 .3$ and $\$ 1.4 .4$, the WTP as currently scoped was not intended to treat all of the tank waste; the Reference Case assumes additional (supplemental) LAW treatment capability will be provided in order to maintain a reasonable duration for the treatment mission. This study demonstrates the need for supplemental LAW treatment by estimating the treatment mission duration and end date if there were no supplemental LAW treatment other than the small amount provided by DBVS and BVS. In this study, the WTP LAW Vitrification capacity is held constant at the Reference Case assumptions and all production outages are removed to decouple this study from the SST retrieval limitations.

The results of this study (SVF-1412) indicate that the treatment mission would end around 2072 without the treatment capacity provided by East STP and West STP, for approximately 54 years of WTP full operations. This simple calculation assumes that the $18.1 \mathrm{wt} \%$ average $\mathrm{Na}_{2} \mathrm{O}$ loading for the WTP LAW Facility projected for the Reference Case is maintained. However, since the overall $\mathrm{SO}_{4}: \mathrm{Na}$ ratio for the combined feed (East STP, West STP, and WTP LAW) is slightly higher ${ }^{54}$ than the Reference Case's WTP LAW ratio, the resulting $\mathrm{Na}_{2} \mathrm{O}$ loading may be smaller and the treatment end date later than estimated here.

A sub-study examined this same question, but added in the 34,000 MT of additional sodium that might be required for leaching solids and maintaining aluminum in solution, as discussed in $\$ 3.5$. If this additional sodium were treated with the WTP LAW Vitrification Facility, without East STP or West STP, the treatment mission would end around 2105, for approximately 87 years of full WTP operations.

\footnotetext{
54 The "excess pretreated LAW" from the WTP is enriched in $\mathrm{SO}_{4}$ because there is more excess pretreated waste whenever the $\mathrm{Na}_{2} \mathrm{O}$ loading in the LAW glass is lower.
} 
ORP-11242, Rev 3

Table 3-4. High-Level Waste Glass Formulation Constraints and Limits.

\begin{tabular}{|c|c|c|c|c|c|}
\hline \multirow[b]{2}{*}{ Constraints } & \multirow[b]{2}{*}{ Units } & \multicolumn{2}{|c|}{ Sensitivity Case } & \multicolumn{2}{|c|}{ Reference Case } \\
\hline & & $\begin{array}{l}\text { Lower } \\
\text { Limit }\end{array}$ & $\begin{array}{c}\text { Upper } \\
\text { Limit }\end{array}$ & $\begin{array}{c}\text { Lower } \\
\text { Limit }\end{array}$ & $\begin{array}{l}\text { Upper } \\
\text { Limit }\end{array}$ \\
\hline $\mathrm{Al}_{2} \mathrm{O}_{3} *$ & $\mathrm{wt} \%$ & & 11 & & 17 \\
\hline $\mathrm{B}_{2} \mathrm{O}_{3} *$ & $\mathrm{wt} \%$ & 0 & & 5 & 20 \\
\hline $\mathrm{Bi}_{2} \mathrm{O}_{3}$ & $\mathrm{wt} \%$ & & 2 & & \\
\hline $\mathrm{CaO}$ & $\mathrm{wt} \%$ & & 7 & & 10 \\
\hline $\mathrm{Cr}_{2} \mathrm{O}_{3}$ & $\mathrm{wt} \%$ & & 0.5 & & 1.0 \\
\hline F- & $\mathrm{wt} \%$ & & 1.7 & & \\
\hline $\mathrm{Fe}_{2} \mathrm{O}_{3} *$ & $\mathrm{wt} \%$ & 0 & 14 & 2 & 15 \\
\hline $\mathrm{Li}_{2} \mathrm{O}^{*}$ & $\mathrm{wt} \%$ & 0 & & & 4 \\
\hline $\mathrm{MgO}$ & $\mathrm{wt} \%$ & & & & 8 \\
\hline $\mathrm{MnO}_{2}$ & $\mathrm{wt} \%$ & & & & \\
\hline $\mathrm{Na}_{2} \mathrm{O}^{*}$ & $\mathrm{wt} \%$ & 0 & & & 20 \\
\hline $\mathrm{P}_{2} \mathrm{O}_{5}$ & $\mathrm{wt} \%$ & & 3 & & 3 \\
\hline $\mathrm{PbO}$ & $\mathrm{wt} \%$ & & 1 & & \\
\hline $\mathrm{SiO}_{2} *$ & $\mathrm{wt} \%$ & & & & 57 \\
\hline $\mathrm{SO}_{3}$ & $\mathrm{wt} \%$ & & 0.5 & & 0.5 \\
\hline $\mathrm{SrO}$ & $\mathrm{wt} \%$ & & 8 & & \\
\hline $\mathrm{ThO}_{2}$ & $\mathrm{wt} \%$ & & 4 & & \\
\hline $\mathrm{U}_{3} \mathrm{O}_{8}$ & $w t \%$ & & 8.05 & & \\
\hline $\mathrm{ZrO}_{2}$ & $w t \%$ & & 10 & & 15 \\
\hline $\mathrm{Rh}_{2} \mathrm{O}_{3}+\mathrm{Ru}_{2} \mathrm{O}_{3}$ & $w t \%$ & & & & 0.25 \\
\hline $\mathrm{Al}_{2} \mathrm{O}_{3}+\mathrm{ZrO}_{2}$ & $\mathrm{wt} \%$ & & 14 & & \\
\hline $\mathrm{Al}_{2} \mathrm{O}_{3}+\mathrm{ZrO}_{2}+\mathrm{Fe}_{2} \mathrm{O}_{3}$ & $\mathrm{wt} \%$ & & 21 & & \\
\hline $\mathrm{Na}_{2} \mathrm{O}+\mathrm{K}_{2} \mathrm{O}$ & $\mathrm{wt} \%$ & & 15 & & \\
\hline $\mathrm{T}_{\mathrm{L}}$ (Spinel) & ${ }^{\circ} \mathrm{C}$ & 850 & 1,050 & 850 & 1,100 \\
\hline $\mathrm{T}_{\mathrm{L}}$ (Zircon) & ${ }^{\circ} \mathrm{C}$ & & 1,050 & & 1,050 \\
\hline PCT $r_{B}$ & $\mathrm{~g} / \mathrm{m} 2$ & & 16.7 & & 2.0 \\
\hline $\mathrm{PCT} \mathrm{r}_{\mathrm{Li}}$ & $\mathrm{g} / \mathrm{m} 2$ & & 13.3 & & 2.0 \\
\hline PCT $r_{\mathrm{Na}}$ & $\mathrm{g} / \mathrm{m} 2$ & & 9.6 & & 2.0 \\
\hline Melt viscosity & $\mathrm{Pa} \cdot \mathrm{S}$ & 2.0 & 8.0 & 4.5 & 10.0 \\
\hline Nepheline rule & $\mathrm{wt} \%$ & 62 & & 62 & \\
\hline
\end{tabular}

* These are the glass forming chemicals used in formulating the glass. 


\subsection{ENHANCED SINGLE-SHELL TANK RETRIEVAL}

As mentioned in $\$ 2.3 .1 .4$, Waste Retrieval from Single-Shell Tanks, the outages in the production plots for West STP and HLW Vitrification suggest that feed is not being retrieved and/or staged fast enough to keep up with the assumed capacities of these facilities. Examination of the detailed model results for the Reference case revealed:

- The SSTs providing West Area LAW Feed are first retrieved into Tank SY-103. The liquids in Tank SY-103 are decanted into Tank SY-101, which then provides feed to the IPS. The IPS returns the separated cesium to SY-102 and sends the pretreated feed to the West STP. Tank utilization data (SVF-1361, DST_Space_File_System Plan Rev 3(1-12-2008)-8.3r1-WC91778_M3.xls) shows that SY-101 is emptied by the IPS faster than SY-103 is refilled with retrieved SST waste. Although the majority of the seventeen-year cumulative West STP outage was related to the SST retrieval assumptions, a couple of years was due to waiting for the high-solids cross-site receiver (AN-104) to be available so that it could receive the settled solids accumulated in SY-103.

- Around the time that the HLW production curve begins to deviate from the assumed capacity (2031), the volume of waste in the DSTs begins to decrease. This suggests that the SSTs are not being retrieved fast enough to replenish the supply of HLW feed.

This was confirmed by performing a simple sensitivity study ${ }^{55}$ in which the SST retrieval volumes and durations of the SSTs assumed to be retrieved using the MRS technology (these tend to be the tanks with high as-retrieved volumes and long minimum retrieval durations) were replaced with volumes and durations similar to using MS technology, which is generally much more efficient. The rationale behind selecting this more optimistic assumption is that the retrieval systems supporting the MRS tanks might be reconfigured to include both "at-tank" recycle of supernate to reduce the addition of water to the SST during retrieval and recycle of supernate from the DST System to reduce the addition of water to slurry the retrieved waste to the DST System.

The results of this simple study show (SVF-1437, Transfer_File_Formatted_System Plan Rev 3(1-30-2008)-8.3r1-WC91778_M1.xls SVF-1438, DST_Space_File_System Plan Rev 3 (1-30-2008)-8.3r1-WC91778_M1.xls; SVF-1439, Production_Plots_System Plan Rev 3(1-30-2008)-8.3r1-WC91778_M1.xls):

- The cumulative outage in the HLW production curve (Figure 3-2) is reduced to about 3 years versus the 8 years seen in the Reference Case. Much of this remaining outage is now a result of the East Area LAW treatment capacity (WTP LAW Vitrification + East STP) driving the treatment end date.

- There are no outages in the WTP LAW Vitrification and only a 3-year cumulative outage in East STP. The cause of this residual outage had not been positively identified, but may be related to the balance of HLW and LAW feed projected to be delivered to the WTP around 2025 - 2027 and the assumed WTP ultrafilter permeate rate.

\footnotetext{
${ }^{55}$ HTWOS Model Run: “System Plan Rev 3(1-30-2008)-8.3r1-WC91778”.
} 
Figure 3-2. High-Level Waste Glass Production for the Enhanced Single-Shell Tank Retrieval Sensitivity Case.

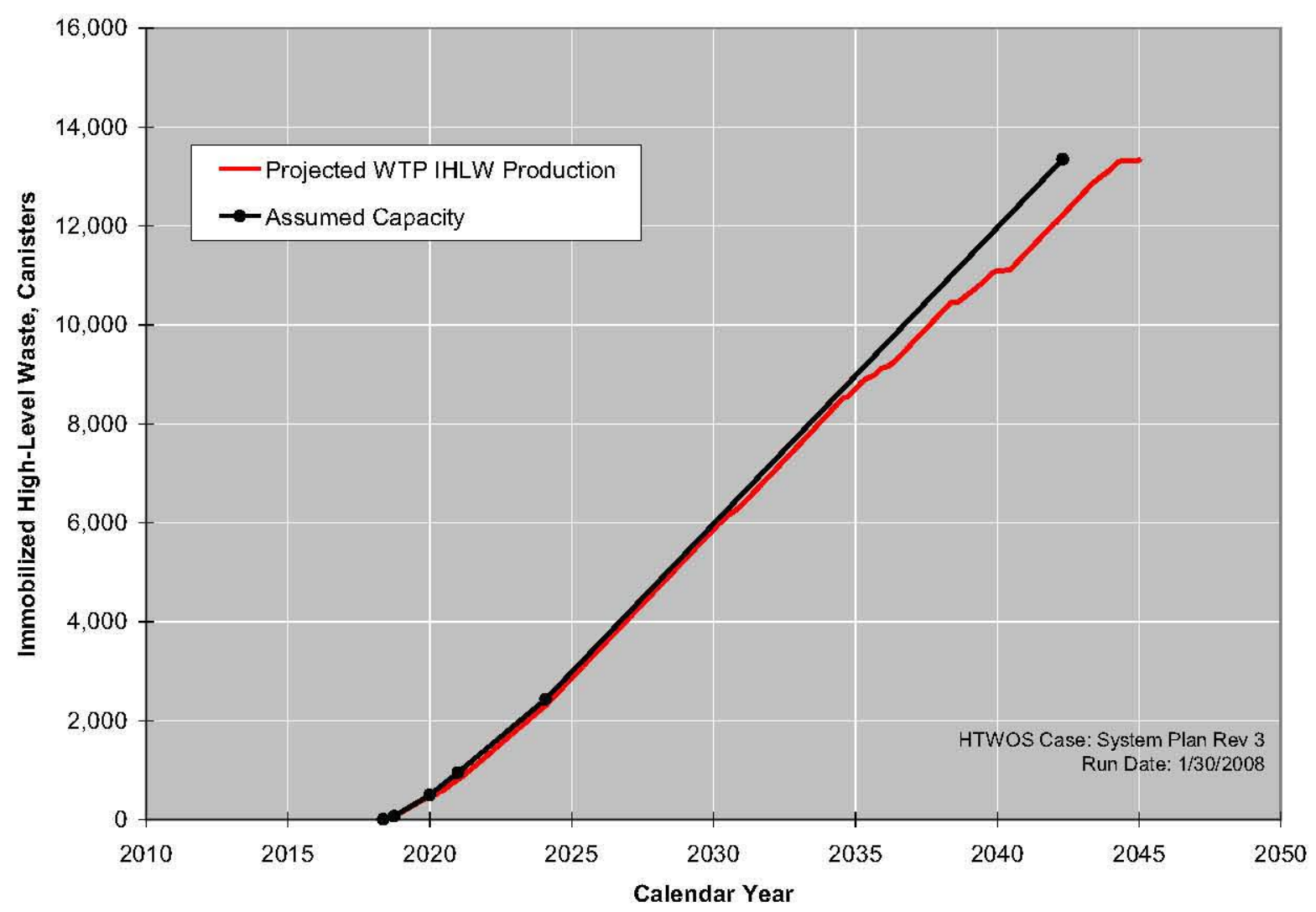

- West STP still incurred about 10 years of outages because the retrieval and cross-site transfer of the sludge needed to maintain the WTP HLW production was performed using the supernate that would have otherwise been used as feed to the IPS and West STP.

- The completion date for the SST retrievals is about 2040 versus the 2047 projected by the Reference Case.

- The DST system is operated closer to the modeled capacity (Figure 3-3).

A similar sensitivity study for a different mission scenario (the "Ecology Case" in RPP-21216) demonstrated that both number of simultaneous retrievals and the SST retrieval volumes and durations can drive the overall mission duration. See $\$ 3.9$, Risk-Based Retrieval Sequence, for more details. 
Figure 3-3. Total Double-Shell Tank Space Utilization for the Enhanced Single-Shell Tank Retrieval Sensitivity Case.

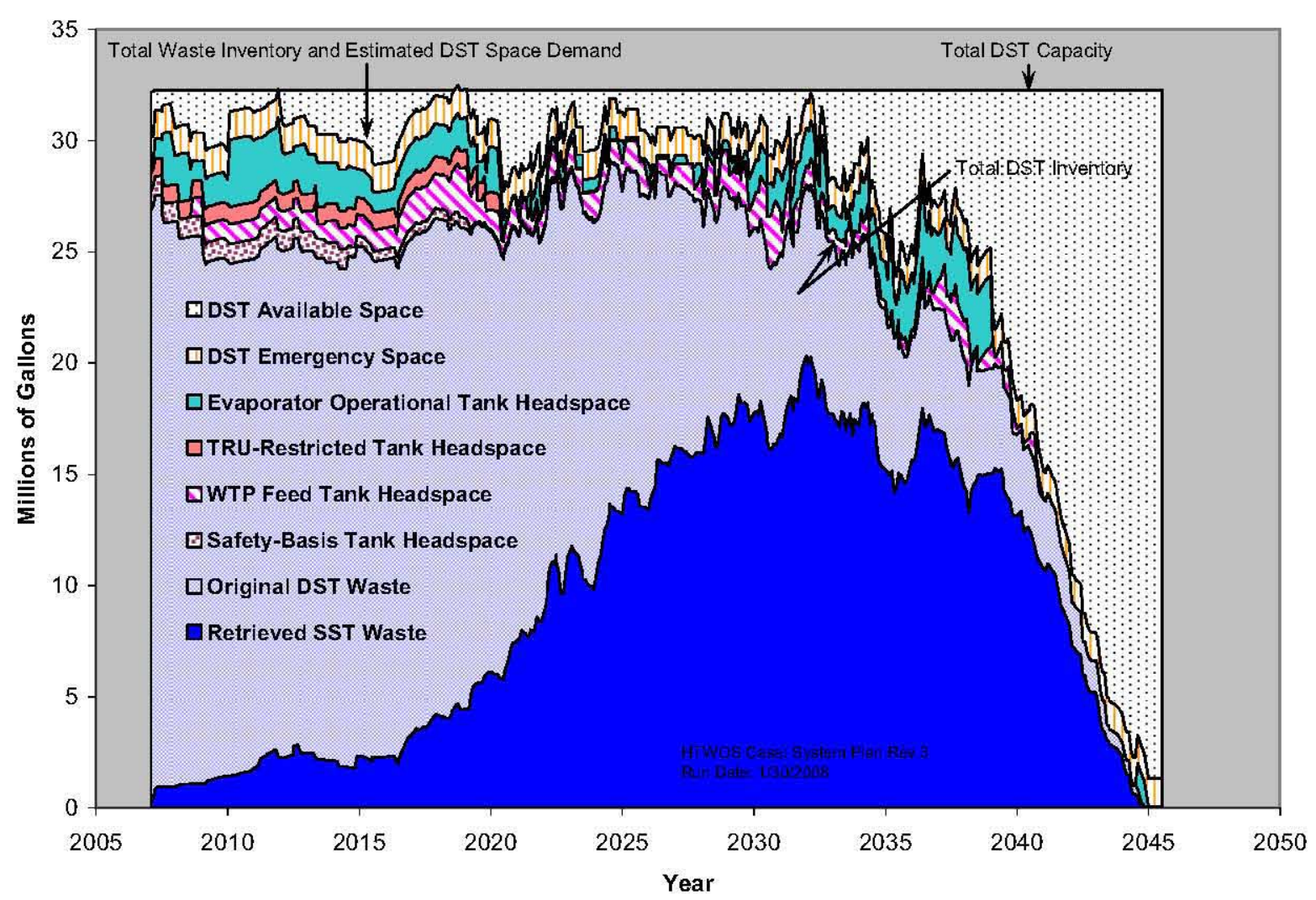

\subsection{RISK-BASED RETRIEVAL SEQUENCE}

A recent analysis (RPP-21216) compared the Reference Case from this System Plan with an alternative case, called the "Ecology Case." The Ecology Case was requested by Ecology to examine the potential for sequencing single-shell tank retrievals to accelerate environmental risk reduction, and to understand the impacts of changes to ORP's plans. Three sensitivity studies against the Ecology Case were also performed.

The Ecology Case differs from the Reference Case as follows:

- There will be no TRU waste packaging. This change was requested to understand the impacts of ORP not obtaining regulatory authority to ship packaged transuranic waste to the Waste Isolation Pilot Plant.

- Supplementary low-activity waste treatment using bulk vitrification will be limited to the DVBS. There will be no extended operation as the BVS and no West Area Supplemental Treatment Plant. This change was requested to assess the impact on the RPP mission if technical issues for bulk vitrification cannot be resolved.

- Supplementary LAW treatment in the East Area will be performed in a second WTP LAW facility, which will receive pretreated LAW feed from the WTP Pretreatment Facility. 
- The maximum WTP HLW melter capacity was reduced from 5.25 MTG/d to 4.2 MTG/d. This change was requested to understand the impact if ORP is not able to achieve higher HLW melter production rates than those currently specified in the Dangerous Waste Permit.

- The near-term schedule for the retrieval of SST wastes from C-Farm, from tanks S$102, \mathrm{~S}-109$, and S-112, and from the A and AX Farms will be accelerated.

- Risk reduction, including a desire for early closure of waste management areas, was the primary consideration used to prioritize the sequencing of the remaining SSTs for retrieval. This was implemented by sequencing the remaining retrievals first by area (200 West before 200 East) and then by farm within each area. Retrievals from different areas and different farms were allowed a reasonable overlap. Within each farm, the tanks were ordered to attempt to provide balanced feed to the WTP within the few remaining degrees of freedom. The order of the farms was selected by Ecology based on risk considerations described in RPP-21216.

The Ecology Case projected that the treatment mission would be completed in 2066 ( 2049 for Reference Case), SST Retrievals would be completed in 2062 (2047 for Reference Case), and approximately 15,921 canisters of HLW glass (12,513 for Reference Case) would be produced.

The increase in HLW glass mass had two drivers. First, treating the TRU waste at the WTP accounted for a $15 \%$ increase in HLW glass as compared to the Reference Case. This is consistent with the results in $\S 3.3$, Transuranic Waste Disposition. Second, the reduction in incidental blending increased the HLW glass mass by an additional 11\%. In the Ecology Case, the degree of incidental blending is reduced because the retrieved waste did not have an opportunity to be accumulated and blended in the DSTs before delivery to the WTP and because the tanks in a given tank farms often contain waste that would produce HLW glass limited by the same components.

A sensitivity case around the Ecology Case increased the net HLW and LAW vitrification capacity so that waste treatment could be finished by 2047 if vitrification capacity were the only constraint. The treatment end date (2065) and SST retrieval end date (2062) were about the same as the Ecology Case. Increasing the vitrification capacities did not significantly reduce the mission length because the SST retrieval assumptions constrain the mission and not the processing rates through the WTP.

Two other sensitivity studies around the Ecology Case explored how improvements in SST retrieval could affect the mission. One study, similar to that discussed in §3.8, Enhanced SingleShell Tank Retrieval, demonstrated that the mission could be shortened by about 8 years if the performance of SST Retrieval could be increased. The other study demonstrated that an increase in the number of simultaneous retrievals that could be supported in the south-west quadrant (S, SX, and U-Farms) would provide a similar benefit. 
ORP-11242, Rev 3

This page intentionally left blank. 


\subsection{CONCLUSIONS}

\subsection{SUMMARY RESULTS}

This version of the System Plan establishes a Reference Case that provides a description of how the mission could play out, generally aligned with the FY 2007 baseline. The Reference Case demonstrates how ORP could use the WTP, together with Supplemental LAW Treatment and Supplemental Treatment and Packaging of TRU waste to complete the treatment and disposal of Hanford tank waste in a reasonable time frame. The key issues and uncertainties identified for the Reference Case will assist ORP in the management of the programmatic and technical risks associated with the waste treatment mission.

The Reference Case demonstrates a mission scenario in which the Hanford tank waste is retrieved by 2047 and treated by 2049. The projected primary waste production comprises:

- 12,513 canisters of HLW glass for disposal at Yucca

- 384,200 MT of LAW glass for disposal at the IDF

- 33,065 packages of LAW glass from WTP

- 4,423 ICV ${ }^{\mathrm{TM}}$ boxes of LAW glass total:

- 36 from DBVS

- 103 from BVS

- 1,845 from West STP

- 2,439 from East STP

- 5,582 MT of packaged TRU waste for disposal at WIPP

- 7,678 55-gal drums of CH-TRU

- 2,723 RH-TRU canisters of RH-TRU

The Reference Case is based on an extensive set of technical and programmatic inputs and assumptions. Although the results projected by the Reference Case are presented as single values, there are issues and uncertainties that will result in a range of possible values for the key mission metrics such as duration and product quantities; these are tabulated in $\$ 4.2$, Mission Sensitivities.

Under the assumptions and inputs for the Reference Case, the mission duration is now being driven by the SST retrieval capabilities, followed by total (WTP and supplemental) LAW vitrification capacity and HLW vitrification capacity. Since 2003 , the original planning assumptions for the SST retrieval were replaced with more detailed assumptions that reflect recent field experience in terms of overall retrieval durations and water additions. The significantly longer retrieval durations and water usage for 67 of the SSTs assumed to have leaked resulted in delays in delivery of HLW feed to the WTP. Also, since 2003, the projected HLW glass mass has increased by about 34 percent, primarily because of updates in the estimated tank inventory and the water-wash and caustic-leach factors. Revision 2 of the System Plan assumed that supplemental LAW treatment capacity was available simply "as-needed" to treat the desired quantities of feed. The current plan assumes the deployment of a specified 
number of melter-lines, each using the flowsheet and testing for the DBVS as the basis for its available capacity.

The Reference Case also developed overall system mass balances for the Waste Treatment Complex. Estimates of secondary waste were found to be sensitive to the overall configuration of the Waste Treatment Complex, the process splits for each unit operation, and the process-specific internal recycles.

\subsection{MISSION SENSITIVITIES}

Based on the discussions in $\S 1.3$, Overview of the Waste Treatment Complex, the Reference Case Results presented in $\$ 2.0$, Results and Discussion of Reference Case, and the sensitivities studies in $\$ 3.0$, Sensitivity Studies, the waste retrieval and treatment mission is sensitive to the following broad categories of process assumptions:

- Leach caustic requirements;

- $\quad$ SST retrieval capabilities;

- STP capacity;

- WTP capacity (pretreatment, LAW vitrification, and HLW vitrification);

- Overall configuration of the Waste Treatment Complex;

- Glass formulation models and limits;

- Degree of blending;

- TRU disposition;

- Process splits and recycle configuration;

- Tank waste inventory.

In order to help understand some of the technical and programmatic uncertainty in the Reference Case, Table 4-1 presents multiple estimates of several key mission parameters. The estimates include values lower and higher than the point estimate for the Reference Case when available and a brief explaination of the source of the estimates. A more comprehensive analysis, such as a Monte Carlo-based sensitivity analysis with input distributions provided by a Delphi study, or perhaps a series of well-crafted parametric studies, would be required to provide more definitive ranges. 
Table 4-1. Ranges on Key Mission Parameters.

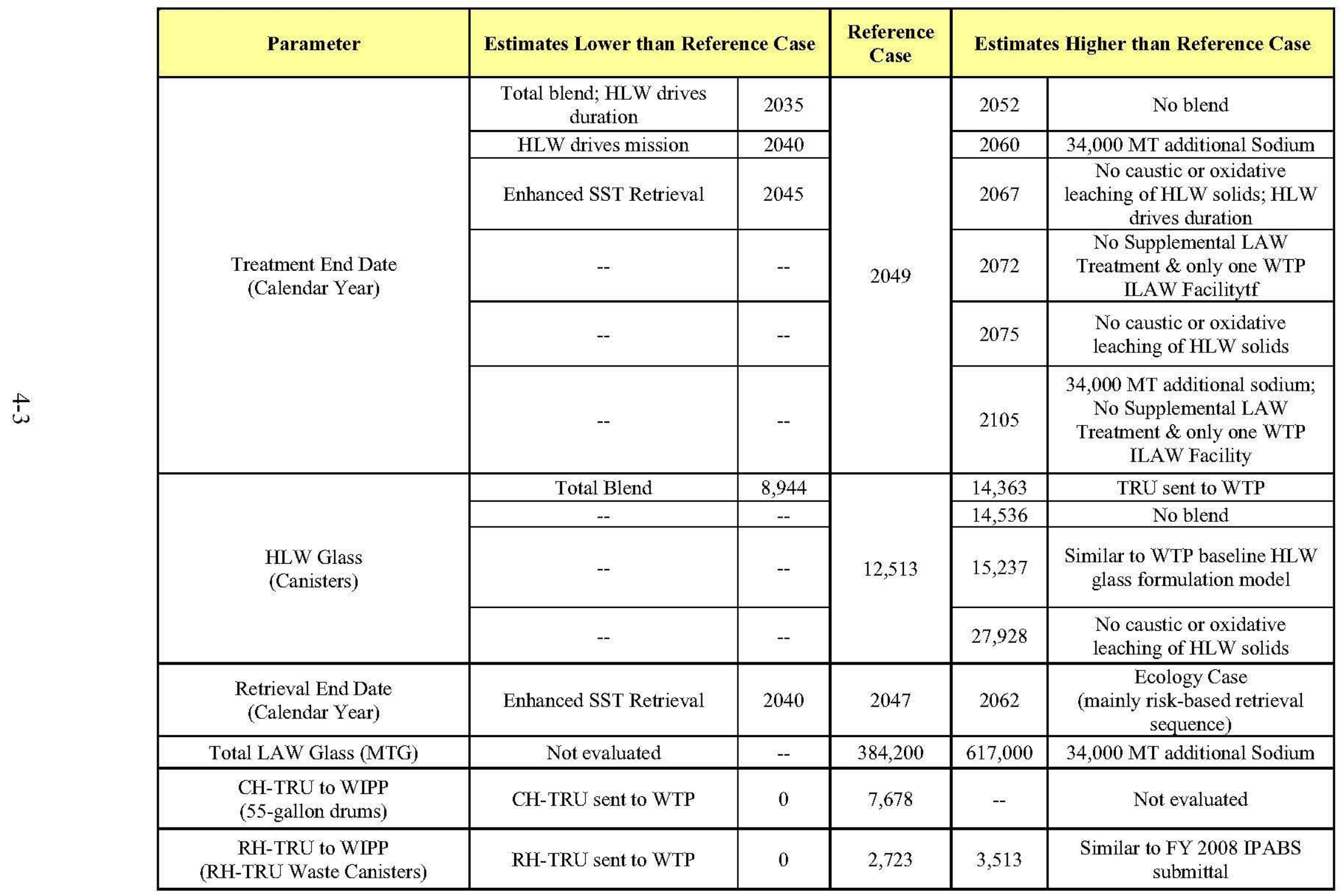




\subsection{KEY ISSUES AND UNCERTAINTIES}

The mission scenario depicted by the Reference Case includes a number of challenges that need to be successfully addressed to reach the desired performance for the mission. These challenges are summarized along with potential mitigating actions in Table 4-2, "Key Issues and Uncertainties for the Reference Case."

The key issues and uncertainties were developed using a top-down, qualitative, approach that examined the challenges presented by the key enabling assumptions or other assertions or from the key features or other observations from the simulation of the Reference Case. The key issues and uncertainties identified in Table 4-2 are grouped by summary-level assumptions and are intended to reflect mission driving issues and uncertainties only. Programmatic risks, such as labor shortfalls, and lower-level issues and uncertainties are addressed in RPP risk management plans and associated data.

Information sources included the RPP System Plan Key Enabling Assumptions (Appendix B) of ORP M 413.3-1d, River Protection Project Federal Risk Management Plan; TFC-PLN-39, Risk Management Plan; ( and 24590-WTP-RPT-PR-01-006, Risk Assessment Report, supporting the WTP Technical and Programmatic Risk Analysis.

The baseline has evolved and continues to evolve since the assumptions for the Reference Case were established. Therefore, some of the assumptions and key features of the Reference Case are different than the current baseline and the associated issues and uncertainties may not be fully consistent with the critical risks addressed in current ORP and contractor critical risk lists. An overall update of RPP risk data has been initiated and is targeted for completion in 2008. 
Table 4-2. Key Issues and Uncertainties for the Reference Case. (9 pages)

\begin{tabular}{|c|c|c|c|}
\hline Item & Assumption / Assertion & Key Issues and Uncertainties & Potential Mitigating Actions \\
\hline \multirow[t]{2}{*}{1} & \multirow[t]{2}{*}{$\begin{array}{l}\text { WTP hot commissioning will start May } \\
\text { 2018. WTP production operations will start } \\
\text { October } 2018 \text {. The net LAW treatment rate } \\
\text { will ramp up to } 21.0 \mathrm{MTG} / \text { day by January } \\
\text { 2021. The net HLW treatment rate will } \\
\text { ramp up to } 5.25 \mathrm{MTG} / \text { day by February } \\
\text { 2024. WTP Pretreatment Facility achieves } \\
15.6 \text { gpm permeate rate per ultrafilter train. }\end{array}$} & $\begin{array}{l}\text { Experience at other sites indicates startup and } \\
\text { readiness at complex facilities is uncertain. } \\
\text { Should the start of operations be delayed, or the } \\
\text { capacity of the WTP is lower than projected, the } \\
\text { duration of the treatment mission may increase. } \\
\text { And depending on the current mission duration } \\
\text { driver, more waste may have to be processed } \\
\text { through supplemental treatment. }\end{array}$ & $\begin{array}{l}\text { Continue execution of the DBVS, Interim } \\
\text { Pretreatment System, and Supplemental } \\
\text { Treatment baseline work scope. Continue to } \\
\text { identify WTP construction, startup and process } \\
\text { throughput uncertainties and complete } \\
\text { appropriate risk mitigation actions. }\end{array}$ \\
\hline & & $\begin{array}{l}\text { The WTP Pretreatment Facility, LAW } \\
\text { Vitrification Facility, or HLW Vitrification } \\
\text { Facility may not achieve the assumed net } \\
\text { capacities. }\end{array}$ & $\begin{array}{l}\text { Continue to monitor WTP design capacities and } \\
\text { predicted availabilities. Consider future } \\
\text { improvements in design, flowsheet, and } \\
\text { operating modes and strategies. }\end{array}$ \\
\hline 2 & $\begin{array}{l}\text { The Richland Operations Office (RL) will } \\
\text { dispose of Waste Encapsulation and } \\
\text { Storage Facility (WESF) Cs and Sr capsules } \\
\text { independent of the WTP or Tank Farms. }\end{array}$ & $\begin{array}{l}\text { If the viability of direct disposal of Waste } \\
\text { Encapsulation and Storage Facility (WESF) Cs } \\
\text { and Sr capsules at Yucca Mountain changes then } \\
\text { vitrification at WTP could be required. }\end{array}$ & $\begin{array}{l}\text { Monitor RL progress on direct disposal of WESF } \\
\text { capsules at Yucca Mountain. }\end{array}$ \\
\hline \multirow[t]{4}{*}{3} & \multirow[t]{4}{*}{$\begin{array}{l}\text { Waste feed delivery (specifically, the } \\
\text { staging of feed within the DSTs and } \\
\text { delivery to the WTP) will support WTP } \\
\text { treatment rates. }\end{array}$} & \multirow[t]{2}{*}{$\begin{array}{l}\text { Waste feed delivery system rates and reliability } \\
\text { have not been demonstrated. }\end{array}$} & $\begin{array}{l}\text { Include technology development activities in the } \\
\text { baseline to address mixer pump performance and } \\
\text { feed sampling capabilities. Include indexing or } \\
\text { incremental insertion systems for the mixer } \\
\text { pumps in deep sludge tanks. }\end{array}$ \\
\hline & & & $\begin{array}{l}\text { Develop a spare parts management plan for } \\
\text { critical components. Develop and implement } \\
\text { feed delivery system maintenance plans and } \\
\text { procedures. }\end{array}$ \\
\hline & & \multirow{2}{*}{$\begin{array}{l}\text { The number and identities of the DSTs required } \\
\text { to stage LAW Feed and HLW Feed to the WTP } \\
\text { have not yet been finalized. Too few tanks may } \\
\text { lead to failure to deliver feed on time. Too } \\
\text { many tanks may impact other activities that } \\
\text { require the use of the DSTs. }\end{array}$} & $\begin{array}{l}\text { Plan feed delivery so that a backup tank is } \\
\text { readied before the WTP could run out of waste } \\
\text { feed. }\end{array}$ \\
\hline & & & Update the Waste Feed Delivery Plan. \\
\hline
\end{tabular}


Table 4-2. Key Issues and Uncertainties for the Reference Case. (9 pages)

\begin{tabular}{|c|c|c|c|}
\hline Item & Assumption / Assertion & Key Issues and Uncertainties & Potential Mitigating Actions \\
\hline \multirow[t]{2}{*}{4} & \multirow[t]{2}{*}{$\begin{array}{l}\text { Physical properties and composition of feed } \\
\text { delivered to the WTP are assumed to be } \\
\text { compatible with WTP design calculations } \\
\text { and safety analyses. The WTP design basis } \\
\text { makes assumptions that place feed } \\
\text { constraints on rheology, particle size, } \\
\text { particle density, particle } \\
\text { hardness/abrasivity, criticality, hydrogen } \\
\text { generation, and potentially other } \\
\text { parameters. }\end{array}$} & $\begin{array}{l}\text { Additional conditioning or processing schemes } \\
\text { may be required because a portion of the WTP } \\
\text { feed is projected to fall outside of these } \\
\text { parameters. }\end{array}$ & $\begin{array}{l}\text { Continue maintenance of the feed interface } \\
\text { control document (ICD-19) using existing } \\
\text { interface management procedures. } \\
\text { Implement the recommendations of a recent } \\
\text { assessment of proposed changes to ICD-19 to } \\
\text { address these parameters ( } 24590 \text {-WTP-ES-PET- } \\
01-001 \text { rev 1). }\end{array}$ \\
\hline & & $\begin{array}{l}\text { A portion of the WTP feed is projected to fall } \\
\text { outside of the feed envelopes documented in the } \\
\text { WTP contract. Additionally, the WTP could be } \\
\text { operated more efficiently if the solids content of } \\
\text { the HLW and LAW feed batches were better } \\
\text { controlled. }\end{array}$ & $\begin{array}{l}\text { Assess the projections to identify and correct any } \\
\text { assumption or modeling artifacts that may be } \\
\text { driving these projections. } \\
\text { Consider implementing a settle-decant operation } \\
\text { in the DSTs to better control the solids content of } \\
\text { the delivered HLW and LAW feed batches. }\end{array}$ \\
\hline
\end{tabular}


Table 4-2. Key Issues and Uncertainties for the Reference Case. (9 pages)

\begin{tabular}{|c|c|c|c|}
\hline Item & Assumption / Assertion & Key Issues and Uncertainties & Potential Mitigating Actions \\
\hline \multirow[t]{4}{*}{5} & \multirow{4}{*}{$\begin{array}{l}\text { Composition and waste oxide loading of } \\
\text { HLW glass will be as estimated by the } \\
\text { PNNL Relaxed } 1996 \text { Glass Properties } \\
\text { Model for HLW. Three glass property } \\
\text { model constraints, glass viscosity, } \\
\text { chromium oxide }\left(\mathrm{Cr}_{2} \mathrm{O}_{3} \text { ) glass solubility, }\right. \\
\text { and spinel liquidus temperature were } \\
\text { relaxed. The maximum allowable viscosity } \\
\text { was increased from } 5.5 \text { Pascal-seconds } \\
(\mathrm{Pa} \cdot \mathrm{s}) \text { to } 10 \mathrm{~Pa} \cdot \mathrm{s} \text {. The maximum allowable } \\
\text { chrome oxide loading was increased from } \\
0.5 \text { wt } \% \text { to } 1.0 \text { wt } \% \text {. The maximum spinel } \\
\text { liquidus temperature }\left(\mathrm{T}_{\mathrm{L}} \text { ) was increased }\right. \\
\text { from } 1050^{\circ} \mathrm{C} \text { to } 1100^{\circ} \mathrm{C} \text { (see Appendix B, } \\
\text { Key Enabling Assumption B2.3.3.6). }\end{array}$} & $\begin{array}{l}\text { HLW glass formulation assumptions have not } \\
\text { been demonstrated for all Hanford waste } \\
\text { compositions. Incorrect assumptions could } \\
\text { impact expected waste loading per unit of glass, } \\
\text { number of IHLW canisters and mission } \\
\text { duration. }\end{array}$ & $\begin{array}{l}\text { Further HLW glass development is underway at } \\
\text { the Vitreous State Laboratory (Catholic } \\
\text { University, Maryland) with DOE (EM-21) } \\
\text { funding. } \\
\text { An effort to update the HLW glass formulation } \\
\text { model using currently available glass data is } \\
\text { underway at PNNL. }\end{array}$ \\
\hline & & $\begin{array}{l}\text { Projected number of IHLW canisters generated } \\
\text { is uncertain. HLW glass mass is sensitive to the } \\
\text { degree-of-blending (both incidental and } \\
\text { intentional) achieved during the retrieval, } \\
\text { storage and delivery of feed. }\end{array}$ & $\begin{array}{l}\text { Continue to evaluate options for blending, } \\
\text { caustic and oxidative leaching, and improving } \\
\text { the HLW glass formulations. Evaluate impact } \\
\text { that other assumption changes and operational } \\
\text { constraints have upon blending and the resulting } \\
\text { HLW glass mass. } \\
\text { Sample, characterize, and test leaching } \\
\text { performance of DSTs containing SST waste after } \\
\text { near-term SST retrievals are complete to reduce } \\
\text { uncertainty. } \\
\text { If the disposition of the TRU waste is not } \\
\text { disposal at WIPP, then evaluate the need for } \\
\text { blending with HLW before treatment at the } \\
\text { WTP. }\end{array}$ \\
\hline & & $\begin{array}{l}\text { Projected number of ILAW packages from the } \\
\text { WTP is uncertain. }\end{array}$ & $\begin{array}{l}\text { Adopt the recently updated ILAW glass } \\
\text { formulation model for future planning in lieu of } \\
\text { the DOE glass model. } \\
\text { Continue to evaluate options for filtering and ion } \\
\text { exchange at higher temperature, caustic recycle, } \\
\text { potential segregation of high Al batches and } \\
\text { special treatment to minimize caustic additions. }\end{array}$ \\
\hline & & $\begin{array}{l}\text { Projected number of ILAW boxes from } \\
\text { Supplemental LAW treatment is uncertain. }\end{array}$ & $\begin{array}{l}\text { Continue the testing and development effort } \\
\text { supporting the DBVS. }\end{array}$ \\
\hline
\end{tabular}


Table 4-2. Key Issues and Uncertainties for the Reference Case. (9 pages)

\begin{tabular}{|c|c|c|c|}
\hline Item & Assumption / Assertion & Key Issues and Uncertainties & Potential Mitigating Actions \\
\hline 6 & $\begin{array}{l}\text { The amount of caustic projected for caustic } \\
\text { leaching is adequate to leach } \mathrm{Al} \text { and keep } \\
\mathrm{Al} \text { soluble through } \mathrm{Cs} \text { ion exchange. }\end{array}$ & $\begin{array}{l}\text { The current WTP design will result in the need } \\
\text { for the addition of caustic beyond current } \\
\text { projections in order to leach Al and keep the Al } \\
\text { soluble. The result is the addition of up to } \\
34,000 \text { MT Na beyond that projected by this } \\
\text { System Plan, which increases the total LAW } \\
\text { sodium requiring treatment by about } 60 \% \text {. }\end{array}$ & $\begin{array}{l}\text { Evaluate caustic recycle after pretreatment or } \\
\text { other caustic management strategies. } \\
\text { Maintaining the leachate at higher temperature } \\
\left(\sim 45^{\circ} \mathrm{C}\right) \text { through Cs ion exchange system was } \\
\text { not recommended as a mitigating action due to } \\
\text { the high design change costs. } \\
\text { Develop refined LAW glass formulation models } \\
\text { to increase sodium oxide loading and consider } \\
\text { ways to increase total LAW treatment capacity. }\end{array}$ \\
\hline 7 & $\begin{array}{l}\text { One spent LAW melter (full) will be } \\
\text { replaced every } 2.5 \text { years. One spent HLW } \\
\text { melter (partially emptied) will be replaced } \\
\text { every } 2.5 \text { years. }\end{array}$ & $\begin{array}{l}\text { Melters are expendable - their replacement } \\
\text { frequency is uncertain. Spent melter disposal } \\
\text { pathways and associated potential issues are not } \\
\text { fully defined. }\end{array}$ & $\begin{array}{l}\text { Develop a spent melter disposal strategy and the } \\
\text { associated planning. }\end{array}$ \\
\hline 8 & $\begin{array}{l}\text { HHLW canisters will be shipped to the } \\
\text { Offsite Geologic Repository at Yucca } \\
\text { Mountain in } 2020 \text { at a rate that does not } \\
\text { require construction of additional interim } \\
\text { storage beyond planned CSB modifications. }\end{array}$ & $\begin{array}{l}\text { The Yucca Mountain Repository may } \\
\text { experience delays. The WTP will start } \\
\text { producing glass potentially before Yucca is } \\
\text { ready to accept the IHLW. Depending on } \\
\text { production capability and timing, the WTP } \\
\text { could produce more IHLW than can be stored } \\
\text { onsite awaiting opening of Yucca requiring the } \\
\text { construction of additional interim storage. }\end{array}$ & $\begin{array}{l}\text { Monitor Yucca Mountain Repository } \\
\text { developments. Continue to Integrate the WTP } \\
\text { and TFC schedules with projected startup and } \\
\text { operating schedules for Yucca. Evaluate impacts } \\
\text { of Yucca Mountain Repository delays on } \\
\text { planned onsite interim storage on an annual } \\
\text { basis. }\end{array}$ \\
\hline 9 & $\begin{array}{l}\text { The Canister Storage Building (CSB) will } \\
\text { be filled prior to shipments to the Yucca } \\
\text { Mountain Repository. }\end{array}$ & $\begin{array}{l}\text { Uncertainty associated with onsite interim } \\
\text { storage and preparation for shipment of IHLW } \\
\text { canisters may result in the need for construction } \\
\text { of additional interim storage to support WTP } \\
\text { treatment rates. }\end{array}$ & $\begin{array}{l}\text { Evaluate handling operations and identify } \\
\text { potential system issues. }\end{array}$ \\
\hline
\end{tabular}


Table 4-2. Key Issues and Uncertainties for the Reference Case. (9 pages)

\begin{tabular}{|c|c|c|c|}
\hline Item & Assumption / Assertion & Key Issues and Uncertainties & Potential Mitigating Actions \\
\hline 10 & $\begin{array}{l}\text { The current strategy to comply with the } \\
\text { OCRWM waste acceptance criteria is } \\
\text { described in "IHLW Waste Form } \\
\text { Compliance Plan for the Hanford Tank } \\
\text { Waste Treatment and Immobilization Plant" } \\
\text { (24590-HLW-PL-RT-07-0001 Rev 1). It is } \\
\text { assumed that the strategy will be acceptable } \\
\text { to OCRWM. }\end{array}$ & $\begin{array}{l}\text { There is a potential that the waste acceptance } \\
\text { strategy will not be acceptable to OCRWM for } \\
\text { the RW/WASRD IHLW product requirements. }\end{array}$ & $\begin{array}{l}\text { The waste compliance plan will be updated as } \\
\text { the waste form qualification process evolves. It } \\
\text { includes actions for ensuring that the strategy } \\
\text { will meet waste form specifications and } \\
\text { requirements. }\end{array}$ \\
\hline \multirow[t]{3}{*}{11} & \multirow[t]{3}{*}{$\begin{array}{l}\text { DBVS operations will start March } 2011 . \\
\text { BVS operations will start October } 2013 \text {. } \\
\text { The net DBVS and BVS treatment capacity } \\
\text { will be } 3.66 \mathrm{MTG} / \mathrm{d} \text {. }\end{array}$} & $\begin{array}{l}\text { The bulk vitrification technology/process has } \\
\text { not been fully demonstrated and accepted by } \\
\text { DOE and Ecology as the method for } \\
\text { supplemental treatment of LAW. }\end{array}$ & $\begin{array}{l}\text { Design, construct and operate the DBVS facility. } \\
\text { Establish BVS process parameters and system } \\
\text { improvements during DBVS. }\end{array}$ \\
\hline & & $\begin{array}{l}\text { DBVS relies on selective dissolution from tank } \\
\text { S- } 109 \text { to provide low cesium feed; BVS relies } \\
\text { on S-109 and S-105. }\end{array}$ & $\begin{array}{l}\text { Validate selective dissolution characteristics of } \\
\text { S- } 109 \text { and S- } 105 \text {. Conduct bench scale } \\
\text { dissolution testing. }\end{array}$ \\
\hline & & $\begin{array}{l}\text { The need for DBVS may be supplanted by the } \\
\text { additional cold testing required to mature the } \\
\text { technology prior to its deployment. }\end{array}$ & $\begin{array}{l}\text { Supplant DBVS/BVS with integrated full-scale } \\
\text { cold testing. }\end{array}$ \\
\hline \multirow[t]{2}{*}{12} & \multirow{2}{*}{$\begin{array}{l}\text { The Interim Pretreatment System (IPS) and } \\
\text { West Supplemental Treatment Plant (STP) } \\
\text { will start production operations July } 2014 . \\
\text { The East STP will start production } \\
\text { operations October } 2019 \text {. "Excess" } \\
\text { pretreated LAW from the WTP will be } \\
\text { routed to the East STP. It is assumed that } \\
\text { the East and West STPs will utilize the }\end{array}$} & $\begin{array}{l}\text { Bulk vitrification throughput necessary to } \\
\text { support the RPP mission has not been } \\
\text { demonstrated. }\end{array}$ & $\begin{array}{l}\text { Establish BVS process parameters and system } \\
\text { improvements and demonstrate bulk vitrification } \\
\text { throughput during DBVS. }\end{array}$ \\
\hline & & $\begin{array}{l}\text { The interim pretreatment technology has not } \\
\text { been selected and the IPS project has not been } \\
\text { defined in detail. Potential technical issues have } \\
\text { not been fully identified and investigated. }\end{array}$ & $\begin{array}{l}\text { Conduct pretreatment technology testing and } \\
\text { demonstrations. Develop pretreatment system } \\
\text { design requirements. }\end{array}$ \\
\hline
\end{tabular}


Table 4-2. Key Issues and Uncertainties for the Reference Case. (9 pages)

\begin{tabular}{|c|c|c|c|}
\hline Item & Assumption / Assertion & Key Issues and Uncertainties & Potential Mitigating Actions \\
\hline & $\begin{array}{l}\text { same technology and process flowsheet as } \\
\text { the DBVS. The net supplemental LAW } \\
\text { treatment capacity for the West and East } \\
\text { STP will be } 14.65 \text { MTG/d each. }\end{array}$ & $\begin{array}{l}\text { The deployment of half of the STP capacity in } \\
\text { West Area along with the necessary } \\
\text { pretreatment capability appears to result in less } \\
\text { than optimal configuration of the waste } \\
\text { treatment complex. }\end{array}$ & $\begin{array}{l}\text { Revisit the deployment strategy and capacity of } \\
\text { the supplemental LAW treatment plants and } \\
\text { supporting pretreatment system. This should } \\
\text { consider the potential early startup of the WTP } \\
\text { ILAW Facility and impacts from additional leach } \\
\text { caustic. }\end{array}$ \\
\hline \multirow[t]{4}{*}{13} & \multirow[t]{4}{*}{$\begin{array}{l}\text { Packaged CH-TRU waste and washed and } \\
\text { packaged RH-TRU waste will be acceptable } \\
\text { for disposal at the WIPP. }\end{array}$} & $\begin{array}{l}\text { The Class III Permit modification to enable the } \\
\text { WIPP disposal pathway is uncertain. } \\
\text { Agreement on TRU waste classification is } \\
\text { uncertain. }\end{array}$ & $\begin{array}{l}\text { Develop bases for TRU classification. Pursue } \\
\text { agreement with regulators and stakeholders. } \\
\text { Secure Class III permit modification. }\end{array}$ \\
\hline & & $\begin{array}{l}\text { WIPP is projected to close before Hanford TRU } \\
\text { tank waste is immobilized. }\end{array}$ & $\begin{array}{l}\text { Monitor WIPP developments. Work with } \\
\text { DOE-EM to align schedules. }\end{array}$ \\
\hline & & $\begin{array}{l}\text { Some tank waste assumed to be dispositioned as } \\
\text { CH-TRU may not meet CH-TRU dose } \\
\text { limitations. }\end{array}$ & $\begin{array}{l}\text { Assess existing characterization data and if } \\
\text { needed obtain additional waste samples before } \\
\text { waste retrieval. }\end{array}$ \\
\hline & & $\begin{array}{l}\text { Final criteria for Hanford CH-TRU and } \\
\text { RH-TRU may be more stringent than current } \\
\text { standards. TRU packaging may require } \\
\text { additional technology development and testing. }\end{array}$ & $\begin{array}{l}\text { Develop and test new technologies that will } \\
\text { support TRU waste retrieval and packaging. }\end{array}$ \\
\hline 14 & $\begin{array}{l}\text { The DSTs will remain fully operational for } \\
\text { the duration of the waste treatment mission. }\end{array}$ & $\begin{array}{l}\text { The likelihood of a major failure of a tank or } \\
\text { infrastructure component increases with time } \\
\text { due to the age of the tank farm facilities. As } \\
\text { found tank, equipment, and facility conditions } \\
\text { may lead to significant new scope. }\end{array}$ & $\begin{array}{l}\text { Execute DST Integrity, Field Projects, and DST } \\
\text { Life Extension work scope. }\end{array}$ \\
\hline 15 & $\begin{array}{l}\text { The 242-A Evaporator will continue to } \\
\text { operate as needed through the life of the } \\
\text { mission. }\end{array}$ & $\begin{array}{l}\text { Management of the water content of the tank } \\
\text { waste is one of the keys to effective utilization } \\
\text { of the DSTs. The likelihood of a major failure } \\
\text { of a } 242 \text {-A Evaporator component increases } \\
\text { with time due to the age of the facility. }\end{array}$ & $\begin{array}{l}\text { Execute } 242 \text {-A evaporator upgrades and } \\
\text { maintain evaporator readiness to support mission } \\
\text { needs. Evaluate evaporator replacement if } \\
\text { necessary. }\end{array}$ \\
\hline
\end{tabular}


Table 4-2. Key Issues and Uncertainties for the Reference Case. (9 pages)

\begin{tabular}{|c|c|c|c|}
\hline Item & Assumption / Assertion & Key Issues and Uncertainties & Potential Mitigating Actions \\
\hline \multirow[t]{5}{*}{16} & \multirow{5}{*}{$\begin{array}{l}\text { SST retrieval rates will be achieved based } \\
\text { on assumed tank-specific technologies; } \\
\text { demonstrated pumping rates; efficiency; } \\
\text { and as-retrieved waste volumes; as well as } \\
\text { the number of simultaneous retrieval } \\
\text { operations assumed to be feasible (see } \\
\text { Appendix B, Key Enabling Assumption } \\
\text { B2.2.3.3). } \\
\text { Selected technologies will be able to meet } \\
\text { retrieval (tank residual) requirements. }\end{array}$} & $\begin{array}{l}\text { Based on recent retrieval system experience, } \\
\text { tank wastes will be difficult to retrieve. } \\
\text { Multiple technologies beyond those currently } \\
\text { assumed may be required in a single tank to } \\
\text { meet retrieval (tank residual) requirements. }\end{array}$ & $\begin{array}{l}\text { Incorporate lessons learned into retrieval system } \\
\text { designs and operations. Develop, test, and } \\
\text { deploy new SST retrieval technologies. }\end{array}$ \\
\hline & & $\begin{array}{l}\text { Management of DST space is critical to success } \\
\text { of the RPP mission. If the DST system reaches } \\
\text { capacity SST retrievals must stop until } \\
\text { supplemental treatment capability is available or } \\
\text { the WTP is operational. }\end{array}$ & $\begin{array}{l}\text { Continue waste management initiatives to } \\
\text { increase usable storage space in existing DSTs. } \\
\text { Continue tank integrity and chemistry control } \\
\text { programs. Ensure } 242 \text {-A Evaporator viability. } \\
\text { Utilize SST retrieval experience and technology } \\
\text { development to increase waste retrieval } \\
\text { volumetric efficiencies. }\end{array}$ \\
\hline & & $\begin{array}{l}\text { Planned retrieval infrastructure may not be } \\
\text { adequate to support the number of concurrent } \\
\text { retrievals necessary to meet WTP feed rates. }\end{array}$ & $\begin{array}{l}\text { Update the Waste Feed Delivery Plan to } \\
\text { incorporate updated retrieval performance and } \\
\text { WTP processing schedules. }\end{array}$ \\
\hline & & $\begin{array}{l}\text { The waste receiver facilities planned in the } \\
\text { baseline to support waste retrieval have not been } \\
\text { fully defined. }\end{array}$ & $\begin{array}{l}\text { Complete pre-conceptual engineering and } \\
\text { conceptual design sufficiently in advance to } \\
\text { avoid delays. }\end{array}$ \\
\hline & & $\begin{array}{l}\text { Waste containing high concentrations of } \\
\text { phosphates could result in transfer line plugging } \\
\text { that would delay waste retrieval and/or } \\
\text { evaporator operations. }\end{array}$ & $\begin{array}{l}\text { Maintain operational controls for the transfer of } \\
\text { phosphate waste. Develop methods for } \\
\text { unplugging transfer lines and locating the plugs. }\end{array}$ \\
\hline 17 & $\begin{array}{l}\text { System lifecycle modeling assumes that no } \\
\text { waste will leak from SSTs or SST retrieval } \\
\text { systems during retrieval. For the purposes } \\
\text { of this System Plan, this assumption results } \\
\text { in the maximum amount of waste that may } \\
\text { need to be treated. }\end{array}$ & $\begin{array}{l}\text { The potential exists for an SST to leak during } \\
\text { retrieval operations. The discovery of a leak } \\
\text { may require the halting of retrieval and the } \\
\text { installation of a different type of retrieval } \\
\text { technology. }\end{array}$ & $\begin{array}{l}\text { Install secondary containment on retrieval } \\
\text { systems. Include provisions for leak detection } \\
\text { and monitoring. Address leak response actions } \\
\text { in the Tank Waste Retrieval Work Plans and } \\
\text { Process Control Plans. }\end{array}$ \\
\hline
\end{tabular}


Table 4-2. Key Issues and Uncertainties for the Reference Case. (9 pages)

\begin{tabular}{|c|c|c|c|}
\hline Item & Assumption / Assertion & Key Issues and Uncertainties & Potential Mitigating Actions \\
\hline 18 & $\begin{array}{l}\text { Closure activities for each tank farm can } \\
\text { begin after all tanks in that farm are interim } \\
\text { closed. }\end{array}$ & $\begin{array}{l}\text { Delays in completing the Tank Closure and } \\
\text { Waste Management EIS will impact progress in } \\
\text { developing closure plans and initiating field } \\
\text { closure activities. EIS alternatives and ROD } \\
\text { may not align with the baseline assumptions. } \\
\text { Assumed closure technologies have been tested } \\
\text { but not deployed. }\end{array}$ & $\begin{array}{l}\text { Monitor EIS progress and if necessary revise } \\
\text { planning to incorporate ROD provisions. Plan } \\
\text { and demonstrate closure technologies. }\end{array}$ \\
\hline 19 & $\begin{array}{l}\text { The timing, capacities, and capability of the } \\
\text { ETF, LERF, SALDS, and TEDF will be } \\
\text { driven by the needs of the waste treatment } \\
\text { mission and assumed to be available when } \\
\text { needed. If the treatment mission requires } \\
\text { that changes be made to the ETF, LERF, } \\
\text { SALDS, or TEDF or their operating plans, } \\
\text { the required changes will be made. }\end{array}$ & $\begin{array}{l}\text { The current Effluent Treatment Facility (ETF) is } \\
\text { inadequate to treat the projected liquid } \\
\text { secondary waste stream that will be generated } \\
\text { by the WTP and BVS. Currently planned ETF } \\
\text { upgrades may also not be adequate to treat } \\
\text { secondary waste streams for the Waste } \\
\text { Treatment Complex. }\end{array}$ & $\begin{array}{l}\text { Plan and execute upgrades to the ETF facility to } \\
\text { insure that the ETF can handle the quantity and } \\
\text { compositions of liquid secondary waste } \\
\text { generated by the Waste Treatment Complex } \\
\text { (WTP, DBVS/BVS, West STP, East STP, } \\
\text { CH-TRU and RH-TRU packaging, and the } \\
\text { 242-A evaporator). Of particular importance is } \\
\text { the ability to safely dispose of the ETF solid } \\
\text { product in the IDF. }\end{array}$ \\
\hline 20 & $\begin{array}{l}\text { Laboratory services required to support } \\
\text { waste characterization for tank farm } \\
\text { projects and operations as well as WTP } \\
\text { production operations are available and } \\
\text { provided in a timely manner. }\end{array}$ & $\begin{array}{l}\text { 222-S and associated support systems such as } \\
\text { core sampling trucks, are aging and prone to } \\
\text { increased failure rates and increased } \\
\text { maintenance attention. }\end{array}$ & $\begin{array}{l}\text { Include high-priority system upgrades in the } \\
\text { baseline. Perform critical and routine } \\
\text { maintenance on sampling systems and } \\
\text { components to ensure readiness of these systems. } \\
\text { Ensure appropriate integration with WTP } \\
\text { laboratory needs. }\end{array}$ \\
\hline
\end{tabular}


Table 4-2. Key Issues and Uncertainties for the Reference Case. (9 pages)

\begin{tabular}{|c|c|c|c|}
\hline Item & Assumption / Assertion & Key Issues and Uncertainties & Potential Mitigating Actions \\
\hline 21 & $\begin{array}{l}\text { The IDF will receive LAW glass packages } \\
\text { from the WTP; solid waste from the WTP } \\
\text { including spent LAW and HLW melters; } \\
\text { roll-off boxes containing glass from the } \\
\text { DBVS, BVS, East STP and West STP; and } \\
\text { solid waste from the ETF from treating } \\
\text { liquid effluent. The IDF can be expanded } \\
\text { as needed to support the mission. }\end{array}$ & $\begin{array}{l}\text { The performance of the IDF to safely dispose of } \\
\text { the projected quantities, forms and composition } \\
\text { of primary and secondary waste from the } \\
\text { treatment mission has not yet been } \\
\text { demonstrated. }\end{array}$ & $\begin{array}{l}\text { Update the projections of primary and secondary } \\
\text { waste to be disposed of in the IDF as underlying } \\
\text { flowsheets and processes evolve. } \\
\text { Upgrade the ETF to treat the projected liquid } \\
\text { effluents. } \\
\text { Engineer the BV process to reduce the quantity } \\
\text { of secondary waste as much as reasonably } \\
\text { achievable and incorporate as much of the waste } \\
\text { as possible in the glass. Operate the DBVS to } \\
\text { test the process. } \\
\text { Perform a performance assessment of the IDF to } \\
\text { verify the ability to safely dispose of the } \\
\text { projected primary and secondary waste forms. }\end{array}$ \\
\hline 22 & $\begin{array}{l}\text { The Waste Treatment Complex will be } \\
\text { bounded by the Tank Closure and Waste } \\
\text { Management EIS and consistent with the } \\
\text { Record of Decision. }\end{array}$ & $\begin{array}{l}\text { The TC\&WM EIS has not been completed nor } \\
\text { has a ROD been issued. }\end{array}$ & $\begin{array}{l}\text { Monitor EIS progress and if necessary revise } \\
\text { planning to incorporate ROD provisions. }\end{array}$ \\
\hline
\end{tabular}

24590-WTP-ES-PET-01-001, 2008, Technical and Risk Evaluation of Proposed ICD-19 rev 4, Rev 1, Bechtel National Inc., Richland, Washington.

24590-HLW-PL-RT-07-0001, 2008, IHLW Waste Form Compliance Plan for Hanford Tank Waste Treatment and Immobilization Plant, Rev 1, Bechtel National Inc., Richland, Washington.

$\begin{array}{lll}\text { BVS } & = & \text { Bulk Vitrification System. } \\ \text { DBVS } & = & \text { Demonstration Bulk Vitrification System } \\ \text { DST } & \text { double-shell tank. } \\ \text { EFRT } & = & \text { External Flowsheet Review Team. } \\ \text { EIS } & = & \text { Environmental Impact Statement. } \\ \text { ETF } & = & \text { Effluent Treatment Facility. } \\ \text { HLW } & = & \text { high-level waste. } \\ \text { IDF } & \text { Integrated Disposal Facility. } \\ \text { IHLW } & = & \text { immobilized high-level waste. } \\ \text { IAW } & = & \text { immobilized low-activity waste. } \\ \text { LAW } & = & \text { low-activity waste. } \\ \text { LERF } & = & \text { Liquid Effluent Retention Facility. } \\ \text { MTG } & = & \text { metric tons of glass. }\end{array}$

$\begin{array}{lll}\text { PNNL } & = & \text { Pacific Northwest National Laboratory. } \\ \text { RL } & = & \text { U.S. Department of Energy, Richland Operations Office. } \\ \text { ROD } & = & \text { Record of Decision. } \\ \text { RPP } & = & \text { River Protection Project. } \\ \text { SALDS } & = & \text { State Approved Land Disposal Site. } \\ \text { SST } & = & \text { single-shell tank. } \\ \text { STP } & = & \text { Supplemental Treatment Project. } \\ \text { TC\&WM } & \text { Tank Closure and Waste Management } \\ \text { TEDF } & = & \text { Treated Effluent Disposal Facility. } \\ \text { TRU } & = & \text { transuranic waste. } \\ \text { WESF } & = & \text { Waste Encapsulation and Storage Facility. } \\ \text { WIPP } & = & \text { Waste Isolation Pilot Plant. } \\ \text { WTP } & = & \text { Waste Treatment and Immobilization Plant. }\end{array}$




\subsection{FUTURE WORK}

The waste retrieval and treatment mission has evolved since Revision 2 of the System Plan and will continue to do so, driven primarily by the issues and uncertainties affecting the Reference Case. Due consideration to the potential risk mitigating actions in Table 4-2, Key Issues and Uncertainties for the Reference Case, should be made in refining and executing the waste treatment mission. Broad categories of follow-on work are required to ensure that the waste treatment mission is successful; these are summarized below:

- WTP Process:

- Evaluate methods to mitigate the impacts from additional leach caustic.

- Update the Flowsheet Basis, Assumptions and Requirements to ensure adequate capacity based on final outcome of the recent throughput reviews.

- Adopt the new ILAW glass formulation model for mission planning.

- Finish development and implementation of the new HLW glass formulation model for mission planning.

- Continue glass formulation work to improve waste loading to decrease the projected amount of LAW and HLW glass.

- Continue to assess implications of out-of-specification feed batches. Are these artifacts of modeling assumptions or input data? If not, are there impacts from treating them such as reduced capacity or are they purely a contractual issue?

- SST Retrieval System:

- Continue to test and refine SST retrieval technologies with consideration of minimizing the retrieval duration, water-usage, and tank residuals.

- Revisit the retrieval infrastructure deployment strategy, including interfaces with the DST system, cross-site transfer system, and WRFs, along with logistical constraints considering how to shorten the overall retrieval schedule.

- Waste Treatment Complex Configuration:

- Revisit the location, technologies and capacities of the Supplemental LAW Treatment processes.

- Pursue IPS in conjunction with early ILAW.

- Modify the cross-site system to allow for transfer of slurry into multiple DSTs to provide operational flexibility in management of waste and staging of feed.

- Establish the most likely disposition of the CH- and RH-TRU waste.

- Secondary Waste:

- Develop a secondary waste management strategy that deals with the disposition of the key contaminants of concern and addresses the ETF and IDF.

- Update partitioning assumptions (process splits) for secondary waste stream estimates as newer information is available for the treatment facilities. 
- DST System:

- Ensure continued availability of evaporator capability to manage waste volume through the end of SST retrieval.

- Revisit the allocation of the DSTs to support functions (early SST waste storage, SST receivers, HLW staging, LAW staging, cross-site receivers, RH-TRU washing, Evaporator feed staging and bottoms receivers, AN-102/107 Sr/TRU precipitation, etc).

- Seek opportunities to improve blending within the degrees of freedom afforded by other mission constraints.

- Explore the use of settle-decant operations in staging WTP feed to better control the solids concentration.

- Explore alternative methodologies that may improve upon the accuracy and utility of the solubility approximations (water wash factors) currently used in the retrieval and staging of the tank waste. 
ORP-11242, Rev 3

This page intentionally left blank. 


\subsection{REFERENCES}

04-WED-024, 2004, “Contract No. DE-AC27-01RV14136 - Summary and Actions from the U.S. Department of Energy, Office of River Protection (ORP) Oversight of Pretreatment (PT) Plant Ultrafiltration Process (UFP) System," (External letter from R. J. Schepens, to J. P. Henschel, Bechtel National, Inc., June 6, 2004) U.S. Department of Energy, Office of River Protection.

24590-HLW-PL-RT-07-0001, 2008, IHLW Waste Form Compliance Plan for Hanford Tank Waste Treatment and Immobilization Plant, Rev 1, Bechtel National Inc., Richland, Washington.

24590-HLW-RPT-PE-07-001, 2007, High Level Waste Vitrification Plant Capacity Enhancement Study, Rev 0, Bechtel National Inc., Richland, Washington.

24590-LAW-RTP-RT-04-0003, 2005, "Preliminary ILAW Formulation Algorithm Description," Rev 0, Bechtel National Inc., Richland, Washington.

24590-WTP-DB-ENG-01-001, 2007, Basis of Design, Rev. 1J, Bechtel National Inc., Richland, Washington.

24590-WTP-ES-PET-01-001, 2008, Technical and Risk Evaluation of Proposed ICD-19 rev 4, Rev 1, Bechtel National Inc., Richland, Washington.

24590-WTP-ICD-MG-01-005, 2003, ICD 05 - Interface Control Document for Nonradioactive, Nondangerous Liquid Effluents, Rev. 3, Bechtel National Inc., Richland, Washington.

24590-WTP-RPT-PE-07-001, 2007, WTP Waste Feed Analysis and Definition - EFRT M4 Final Report, Rev 1, Bechtel National Inc., Richland, Washington.

24590-WTP-RPT-PO-07-002, 2007, Dynamic (G2) Flowsheet Assessment of the Effect of M-12 Modifications on Pretreatment Capacity, Rev 0, Bechtel National Inc., Richland, Washington.

24590-WTP-RPT-PR-01-006, 2006, Risk Assessment Report, Rev 13, Bechtel National Inc., Richland, Washington.

30686-RT-0001, 2007, Demonstration Bulk Vitrification System (DBVS), Series 30 and 31 Testing, ES-30J, ES-30K, and ES-31F Test Report, Rev. 0, AMEC GeoMelt Division prepared for CH2M HILL, Hanford Group, Inc., Richland, Washington.

30686-RT-0003, 2007, Demonstration Bulk Vitrification System, Series 38 Full-Scale Testing, FS-38D Test Report, Rev. 0, AMEC GeoMelt Division, prepared for CH2M HILL Hanford Group, Inc., Richland, Washington.

AMEC07.02, 2007, "RE: Test and Analytical Results from IDMT" (external letter from T. M. Brouns to K. Witwer, AMEC, GeoMelt Division, November 9, 2007) Pacific Northwest National Laboratory, Richland, Washington

CH2M-0303565, 2003, “CH2M HILL Hanford Group, Inc. Recommendation for Further Testing of Supplemental Technologies," (external letter from E. S. Aromi to R. J. Schepens, U.S. Department of Energy, Office of River Protection, September 12), CH2M HILL Hanford Group, Inc., Richland, Washington. 
CORR-2008-0024, 2008, "Contract No. DE-AC27-99RL14047 - Prepare Baseline Change Requests (BCR) to: 1) Develop an Integrity Program for Single-Shell Tanks (SST), and 2) Support Mission Analysis and Preliminary Conceptual Design for Interim Pretreatment System,", (external letter from C. B. Reid to D. B. Cartmell, CH2M HILL Hanford Group, Inc., February 11, 2008) U.S. Department of Energy, Office of River Protection, Richland, Washington.

D-03-DESIGN-002, 2003, Design Oversight Report, Waste Treatment Plant LAW Melter Support System Capacities, Office of River Protection, Richland, Washington.

D-05-DESIGN-019, 2006, Design Oversight Report, Review of Balance of Facilities (BOF) Equipment, System and Facility Preservation Lay-Up and Turnover, Office of River Protection, Richland, Washington.

DE-RP27-07RV14800, Solicitation: Tank Operations Contract, U. S. Department of Energy, Washington, D.C.

DOE OCRM, 2007, "Yucca Mountain Repository -- About the Project" Web site, http://www.ocrwm.doe.gov/ym repository/about project/index.shtml, OCRWM-About the Project, accessed 8/31/2007 at 11:36 am PDT, U.S. Department of Energy, Office of Civilian Radioactive Waste Management, Las Vegas, Nevada.

DOE/NTP-96-1204, 2002, National TRU Waste Management Plan, Corporate Board Annual Report, Rev 3, U.S. Department of Energy, Carlsbad Field Office, Carlsbad, New Mexico.

DOE/RL-2006-35, 2006, Hanford Facility Dangerous Waste Permit Application, Waste Encapsulation and Storage Facility, Rev. 0 Reissue, U.S. Department of Energy, Richland, Washington.

DOE/RL-2006-35, 2007, Hanford Facility Dangerous Waste Permit Application, Waste Encapsulation and Storage Facility, Rev. 1 Reissue, U.S. Department of Energy, Richland, Washington.

DOEYMP01111, 2007, Regulatory Licensing Overview - Fact Sheet, accessed 8/31/2007 at 11:40 am PDT, U.S. Department of Energy, Office of Civilian Radioactive Waste Management, Las Vegas, Nevada, http://www.ocrwm.doe.gov/factsheets/doeymp0111.shtml.

Ecology et al., 1989, Hanford Federal Facility Agreement and Consent Order, 2 vols., Washington State Department of Ecology, U.S. Environmental Protection Agency, and U.S. Department of Energy, Olympia, Washington, as amended.

EDF-NSNF-072, 2007, Hanford Cs-Sr Repository Disposal Performance Analysis Using the TSPA-FEIS Model, Rev 0, National Spent Nuclear Fuel Program Engineering Design File, U.S. Department of Energy, Richland Operations Office, Richland, Washington.

HNF-14755, 2007, Documented Safety Analysis for the 242-A Evaporator, Rev. 1G, CH2M HILL Hanford Group, Inc., Richland, Washington.

HNF-22687, 2004, WESF Capsule Data Book, Rev 0, Fluor Hanford, Inc., Richland, Washington. 
HNF-26914, 2005, Conceptual Design Report for Effluent Treatment Facility Solidification Treatment Unit, Rev. 0, Fluor Hanford, Inc., Richland, Washington.

HNF-4669, 2000, Decision Document for the Low-Activity Waste Retrieval Strategy for Tanks 241-AN-103, 241-AN-104, 241-AN-105, and 241-AW-101, Rev 0, CH2M HILL Hanford Group, Inc., Richland, Washington.

HNF-EP-0182, 2006, Waste Tank Summary Report For Month Ending 02/28/2006, Rev. 215, CH2M HILL Hanford Group, Inc., Richland, Washington.

HNF-EP-0182, 2007, Waste Tank Summary Report For Month Ending 12/31/2006, Rev. 225, CH2M HILL Hanford Group, Inc., Richland, Washington.

HNF-SD-ETF-ASA-001, 2000, 200 Area Effluent Treatment Facility Auditable Safety Analysis Report, Rev. 4, Fluor Hanford, Inc., Richland, Washington.

HNF-SD-RE-TI-178, 2007, Single-Shell Tank Interim Stabilization Record, Rev. 9A, CH2M HILL Hanford Group, Inc., Richland, Washington.

HNF-SD-W049H-ICD-001, 2004, 200 Area Treated Effluent Disposal Facility Interface Control Document, Rev. 9, Fluor Hanford, Inc., Richland, Washington.

HNF-SD-WM-OCD-015, 2007, Tank Farm Waste Transfer Compatibility Program, Rev 17, CH2M HILL Hanford Group, Inc., Richland, Washington.

HNF-SD-WM-SAD-040, 2001, LERF Final Hazard Category Determination, Rev. 2, Fluor Hanford, Inc., Richland, Washington.

HNF-SD-WM-SP-012, 2007, Tank Farm Contractor Operation and Utilization Plan, Rev. 6, CH2M HILL Hanford Group, Inc., Richland, Washington.

HNF-SD-WM-TI-733, 2007, Supporting Calculations and Assumptions for Use in WESF Safety Analysis, Rev. 2B, Fluor Hanford, Inc., Richland, Washington.

IDMS 87687537, 2007, "RE: ORP IPABS FORECAST," (email to Y. M. Shehadeh, et al., Office of River Protection, December 11, 2007), from J. G. Kristofzski, CH2M HILL Hanford Group, Inc., Richland, Washington.

M-92-07-01, 2007, Modification of Hanford Federal Facility Agreement and Consent Order (Tri-Party Agreement) M-92-05, "Determine disposition path and determine interim agreement milestones for Hanford Site Cs/Sr capsules," State of Washington Department of Ecology, Richland, Washington.

National Environmental Policy Act of 1969, 42 USC 4321, et seq.

Nuclear Waste Policy Amendments Act of 1987, "Selection of Yucca Mountain Site," 42 USC 10172, et seq.

ORP M 413.3-1d, 2006, River Protection Project Federal Risk Management Plan, U.S. Department of Energy, Office of River Protection, Richland, Washington.

PNNL-12003, 1998, Summary of Uncertainty Estimation Results for Hanford Tank Chemical and Radionuclide Inventories, Rev 0, Pacific Northwest National Laboratory, Richland, Washington.

Resource Conservation and Recovery Act of 1976, 42 USC 6901, et seq. 
RPP-10435, 2002, Single-Shell Tank System Integrity Assessment Report, Rev. 0, CH2M HILL Hanford Group, Inc., Richland, Washington.

RPP-15479, 2004, Project Definition Criteria for the Integrated Disposal Facility, Rev. 0A, CH2M HILL Hanford Group, Inc., Richland, Washington.

RPP-15833, 2004, System Specification for the Integrated Disposal Facility, Rev. 0B, CH2M HILL Hanford Group, Inc., Richland, Washington.

RPP-19822, 2005, Hanford Defined Waste Model Revision 5.0, Rev. 0A, CH2M HILL Hanford Group, Inc., Richland, Washington.

RPP-20003, 2005, Sensitivity of Hanford Immobilized High-level Waste Glass Mass to Chromium and Aluminum Partitioning Assumptions, Rev 1, CH2M HILL Hanford Group, Inc., Richland, Washington.

RPP-20270, 2005 Hanford Shipping Facility System Specification, Rev. 0, CH2M HILL Hanford Group, Inc., Richland, Washington.

RPP-21216, 2008, Single-Shell Tank Retrieval Selection and Sequence, Rev. 3, CH2M HILL Hanford Group, Inc., Richland, Washington.

RPP-23584, 2004, Safety Evaluation of Waste Gel in the Tank Farms, Rev 0, CH2M HILL Hanford Group, Inc., Richland, Washington.

RPP-29981, 2007, Evaluation of Starting the Waste Treatment and Immobilization Plant (WTP) Low Activity Waste (LAW) Facility First, Rev. 1, CH2M HILL Hanford Group, Inc., Richland, Washington.

RPP-31314, 2006, A Comprehensive Technical Review of the Demonstration Bulk Vitrification System, Technical Assessment Conducted by an Independent and External Team of Experts, September 28, 2006, Volume 1, Rev. 0, CH2M HILL Hanford Group, Inc., Richland, Washington.

RPP-36870, 2008, Rough Estimate of TRU Drums per Shipment to WIPP, Rev 0, CH2M HILL Hanford Group, Inc., Richland, Washington.

RPP-6213, 2005, Hanford Waste Tank Bump Accident and Consequence Analysis, Rev. 4, CH2M HILL Hanford Group, Inc., Richland, Washington.

RPP-6548, 2001, Test Report, 241-AZ-101 Mixer Pump Test, Rev. 1, CH2M HILL Hanford Group, Inc., Richland, Washington.

RPP-7507, 2004, Design Requirements Document for Immobilized High-Level Waste Interim Storage Facility, Project W-464, Rev. 1B, CH2M HILL Hanford Group, Inc., Richland, Washington.

RPP-7574, 2007, Double-Shell Tank Integrity Program Plan, Rev 2, CH2M HILL Hanford Group, Inc., Richland, Washington.

RPP-7625, 2007, Best-Basis Inventory Process Requirements, Rev 7, CH2M HILL Hanford Group, Inc., Richland, Washington.

RPP-7771, 2001, Flammable Gas Safety Issue Resolution, Rev. 0A, CH2M HILL Hanford Group, Inc., Richland, Washington. 
RPP-PLAN-32249, 2007, Demonstration Bulk Vitrification System Project Implementation Plan, Response to the Demonstration Bulk Vitrification System Expert Review Panel Final Report, Rev. 0, CH2M HILL Hanford Group, Inc., Richland, Washington.

RPP-RPT-24887, 2005, The Long-Term Management of Tank Waste at Hanford, Rev. 0, CH2M HILL Hanford Group, Inc., Richland, Washington.

RPP-RPT-26040, 2006, Pairwise Blending of High-Level Waste, Rev. 0, CH2M HILL Hanford Group, Inc., Richland, Washington.

RPP-RPT-33214, 2008, HTWOS Model Data Package for the RPP System, Rev. 3 Case, Rev. 0, CH2M HILL Hanford Group, Inc., Richland, Washington.

SVF-1292, 2008, Transfer_File_Formatted_System Plan Rev 3(1-12-2008)-8.3r1-WC91778_M1.xls, Rev 0, CH2M HILL Hanford Group, Inc., Richland, Washington.

SVF-1360, 2008, SST_Retrieval_File_System Plan Rev 3(1-12-2008)-8.3r2-WC91778_M3.xls, Rev 1, CH2M HILL Hanford Group, Inc., Richland, Washington.

SVF-1361, 2008, DST_Space_File_System Plan Rev 3(1-12-2008)-8.3r1-WC91778_M3.xls, Rev 0, CH2M HILL Hanford Group, Inc., Richland, Washington.

SVF-1397, 2008, SP3 Total-Blend No-Blend v 2.xls, Rev. 0, CH2M HILL Hanford Group, Inc., Richland, Washington.

SVF-1412, 2008, SP3_Caustic_Sensitivity_v1.xls, Rev 0, CH2M HILL Hanford Group, Inc., Richland, Washington.

SVF-1420, 2008, HGR_Feed_Assessment_System Plan Rev 3(1-12-2008)-8.3r1-WC91778.xls, CH2M HILL Hanford Group, Inc., Richland, Washington.

SVF-1422, 2008, Specification_8 Assessment_System Plan Rev 3(1-12-2008)-8.3r1WC91778.xls, CH2M HILL Hanford Group, Inc., Richland, Washington.

SVF-1423, 2008, Specification_7_Assessment_System Plan Rev 3(1-12-2008)-8.3r1WC91778_M1.xls, Rev 1, CH2M HILL Hanford Group, Inc., Richland, Washington.

SVF-1427, 2008, SP3_HLW_Glass_Limit_Sensitivity.xls, Rev 0, CH2M HILL Hanford Group, Inc., Richland, Washington.

SVF-1429, 2008, Transfer_Plots_System Plan Rev 3(1-12-2008)-8.3r1-WC91778.xls, Rev 0, CH2M HILL Hanford Group, Inc., Richland, Washington.

SVF-1431, 2008, Balance Graphic System Plan Rev 3(1-12-2008)-8.3r1-WC91778_M4.xls, Rev 2, CH2M HILL Hanford Group, Inc., Richland, Washington.

SVF-1437, 2008, Transfer_File_Formatted_System Plan Rev 3(1-30-2008)-8.3r1WC91778_M1.xls, $\overline{\mathrm{CH}} 2 \overline{\mathrm{M}}$ HILL Hanford Group, Inc., Richland, Washington.

SVF-1438, 2008, DST_Space_File_System Plan Rev 3(1-30-2008)-8.3r1-WC91778_M1.xls, Rev 0, CH2M HILL Hanford Group, Inc., Richland, Washington.

SVF-1439, 2008, Production_Plots_System Plan Rev 3(1-30-2008)-8.3r1-WC91778_M1.xls, Rev 0, CH2M HILL Hanford Group, Inc., Richland, Washington. 
SVF-1460, 2008, Production_Plots_System Plan Rev 3(1-14-2008)-8.3r1-WC91778_M1.xls, Rev 0, CH2M HILL Hanford Group, Inc., Richland, Washington.

SWIFT-CWC, 2007, Web site, http://www.hanford.gov/swift/onsite/cwc.htm, SWIFT 2007.0Central Waste Complex, accessed 9/6/2007 at 11:01 am PDT, Solid Waste Integrated Forecast Technical (SWIFT) Report, U.S. Department of Energy, Richland Operations Office/Fluor Hanford, Richland, Washington.

TFC-PLN-39, 2006, Risk Management Plan, Rev B, CH2M HILL Hanford Group, Inc., Richland, Washington.

WA7890008967, 2003, “Dangerous Waste Permit Application, Central Waste Complex," Rev. 7, 07/16/2003, Approved 4/28/2004, Fluor Hanford, Inc., and U.S. Department of Energy, Richland Operations Office, Richland, Washington.

WBS 5.09.02.02.04.04, 2006, CH-TRU CSS WIPP Waste Facilities Cost Estimating Input Sheet, Revision Date 6/1/2006, CH2M HILL Hanford Group, Inc., Richland, Washington.

WBS 5.09.02.02.04.07, 2006, CH-TRU CSS Onsite Waste Storage Cost Estimating Input Sheet, CH2M HILL Hanford Group, Inc., Richland, Washington.

WBS 5.09.02.02.05.04, 2006, RH-TRU CSS WIPP Waste Facilities Cost Estimating Input Sheet, CH2M HILL Hanford Group, Inc., Richland, Washington.

WHC-SD-EN-ES-040, 1994, Engineering Study of 50 Miscellaneous Inactive Underground Radioactive Waste Tanks Located at the Hanford Site, Washington, Rev. 0, Westinghouse Hanford Company, Richland, Washington.

WIPP, 2007a, "Why WIPP?" (Fact sheet, updated February 5, 2007), WIPP Information Center, U. S. Department of Energy, Carlsbad Field Office, Carlsbad, New Mexico.

WIPP, 2007b, "WIPP Chronology,” (Fact sheet, updated February 5, 2007), WIPP Information Center, U. S. Department of Energy, Carlsbad Field Office, Carlsbad, New Mexico. 
ORP-11242, Rev 3

APPENDIX A

\section{GLOSSARY}


ORP-11242, Rev 3

This page intentionally left blank.

A-ii 


\section{APPENDIX A \\ GLOSSARY}

Term or Abbreviation

Buoyant-Displacement Gas Release Events (BDGREs)

Caustic Leach Factor

Cross-site Transfer

Feed Vector

No-Blend

Percent-of-span

Realized-Blend

Saltcake

\section{Definition or Expansion}

Tank waste generates flammable gasses through the radiolysis of water and organic compounds, thermolytic decomposition of organic compounds, and corrosion of a tank's carbon steel walls. Under certain conditions, this gas may accumulate in a settled solids layer until the waste becomes hydrodynamically unstable (less dense waste near the bottom of the tank). A BDGRE is the rapid release of this gas, partially restoring hydrodynamic equilibrium. The release may result in the temporary creation of flammable mixture in the headspace of the tank, depending on the size of the release relative to the capacity of the ventilation system.

The fraction of an analyte in previously washed solids that will go into solution by caustic leaching. N. B. - The term, Caustic Leach Factor, as used in this System Plan, is technically a Differential Caustic Leach Factor.

The Hanford waste tanks are located in two physically separated areas, called "East Area" and "West" area - about five miles apart. The cross-site transfer system is a pair of transfer pipelines and ancillary equipment that is used to transfer supernate and slurry from West Area to East Area.

The "feed vector" is a list of the individual feed batches projected to be delivered to a facility (such as the Waste Treatment and Immobilization Plant) and includes the associated waste composition and caustic leach factors.

The hypothetical case in which the waste from each individual tank is retrieved, pretreated, and the HLW fraction vitrified as a separate batch. No blending of waste between tanks is permitted.

This is the percent of the way the projected glass mass falls between the Total-Blend and the No-Blend glass mass. For example, 0 percent of span corresponds to the Total Blend, while 50 percent of span corresponds to halfway between the Total-Blend and No-Blend."

This refers to the actual blending that is predicted to occur during the evolution of a specific mission scenario.

Saltcake is a mixture of crystalline sodium salts that originally precipitated when alkaline liquid waste from the various processing facilities was evaporated to reduce waste volume. Saltcakes are comprised primary of the sodium salts of nitrate, nitrite, carbonate, phosphate and sulfate.

Transition metals such as iron, manganese and lanthanum and heavy metals such as uranium and lead are generally absent. Saltcake typically contains a small amount of interstitial liquid. The bulk of the saltcake will generally dissolve if contacted with sufficient water. 
Term or Abbreviation Sludge

Slurry

Supernate

Tank Bump

Total-Blend

Waste Treatment Complex

Water Wash Factor

\section{Definition or Expansion}

Sludge is a mixture of metal hydroxides and oxyhydroxides that originally precipitated when acid liquid waste from the various reprocessing facilities was made alkaline with sodium hydroxide. Sludge is comprised primary of the hydroxides and oxyhydroxides of aluminum, iron, chromium, silicon, zirconium and uranium, plus the majority of the insoluble radionuclides such as ${ }^{90} \mathrm{Sr}$ and the plutonium isotopes. Sludge typically contains a significant amount of interstitial liquid (up to nominal $40 \mathrm{wt} \%$ water). Sludge is mostly insoluble in water, however a significant amount of aluminum and chromium will dissolve if leached with sufficient quantities of sodium hydroxide.

The term slurry is used in two different contexts:

Slurry is a mixture of solids, such as sludge or un-dissolved saltcake, suspended in a liquid. For example, a slurry results when the sludge and supernate in a tank is mixed together. Slurries can be used to transfer solids by pumping though a pipeline.

Slurry also refers to a waste produced at Hanford that results from evaporating supernate originally removed from tanks containing saltcake so that aluminum salts begin to precipitate in addition to the sodium salts. This material, called "Double-Shell Slurry" or "Double-Shell Slurry Feed" is present in the DSTs (specifically, AN-103, AN-104, AN-105 and AW-101). For simplicity, this System Plan will use the term "settled salts" or "salt cake" instead of slurry in this context.

Supernate is technically the liquid floating above a settled solids layer. At Hanford, it is typically used to refer to any non-interstitial liquid in the tanks, even if no solids are present. Supernate is similar to saltcake in composition and contains many of the soluble radionuclides such as ${ }^{137} \mathrm{Cs}$ and ${ }^{99} \mathrm{Tc}$.

A tank bump is a postulated event in which gases, primarily water vapor, are suddenly emitted from the waste causing the tank headspace to pressurize due to vaporization of locally superheated liquid.

The Total-Blend represents the hypothetical case in which all of the waste is blended together, pretreated, and the HLW fraction vitrified as a single batch of uniform composition.

Comprises all of the existing and future facilities, pipelines and infrastructure needed for the storage, retrieval and treatment of the Hanford Tank Waste.

The fraction of an analyte in a solid waste phase that reports to solution upon contact with water. 
ORP-11242, Rev 3

APPENDIX B

KEY ENABLING ASSUMPTIONS

B-i 
ORP-11242, Rev 3

This page intentionally left blank. 


\section{APPENDIX B}

\section{KEY ENABLING ASSUMPTIONS}

The scope of this version of the System Plan is defined primarily by the Key Enabling Assumptions. For clarity, several important limitations on the scope are listed below:

- Only one case, the "Reference Case," will be addressed.

- There will be no analysis or discussion of cost.

- The System Plan will align itself with the Tank Farm Contractor planning assumptions to the extent agreed to in the Key Enabling Assumptions.

- The System Plan will align itself with the Waste Treatment Plant flowsheet assumptions to the extent agreed to in the Key Enabling Assumptions.

- The System Plan will communicate the potential impacts on the mission of key issues and uncertainties. This will be done using a qualitative discussion of the potential numerical range of impacts due to selected key issues and uncertainties, primarily the factors influencing the mass of HLW glass, the mission duration, and the mass of LAW glass from either WTP or the STPs. Full HTWOS runs will not be performed to evaluate the impacts.

During the modeling effort, several assumptions were updated or clarified. The signatures below indicate concurrence with the final set of assumptions. ${ }^{1}$

ORP Concurrence

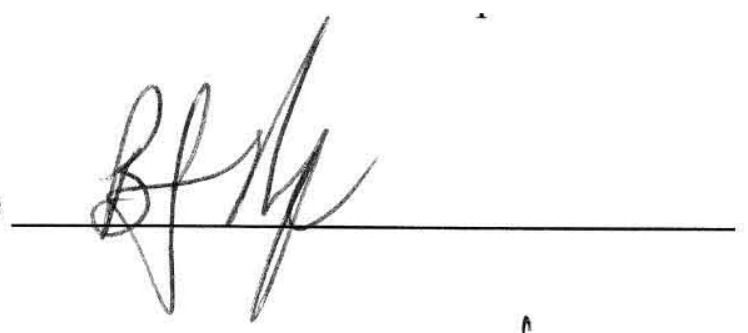

CH2M HILL Concurrence

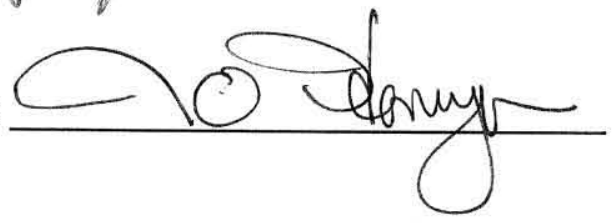

Date $10-10-67$

Date $10 / 1 / / 2007$

\footnotetext{
${ }^{1}$ Signature indicates concurrence with the Key Enabling Assumptions and the limitations on scope. Permission is given in advance to make editorial and formatting changes to these signed assumptions during the document preparation and review cycle without the need to obtain a second set of signatures.
} 
ORP-11242, Rev 3

This page intentionally left blank. 


\section{B1.0 GENERAL INFORMATION}

The key enabling assumptions listed in this section document the initial input for modeling and mission planning purposes as of February 2007 with updates made in October 2007. These were developed after reviewing existing assumptions from the previous River Protection Project (RPP) System Plan, the Waste Treatment and Immobilization Plant (WTP) contract ${ }^{2}$, the Hanford Tank Waste Operations Simulator (HTWOS) model run ${ }^{3}$ supporting the Tank Farm Contract (TFC) baseline submittal, ${ }^{4}$ and with considerations of the findings of two recent reviews ${ }^{5,6}$ of the WTP. They represent the major planning bases needed to develop an integrated dynamic flowsheet for the new System Plan case. They are not intended to address design-basis decisions or detailed equipment operating plans.

The scenario was not constrained to match current contracts, regulatory permits, performance based initiatives, funding, interface control documents, or other planning guidance except as captured by the key enabling assumptions. Changes in those areas may be required to implement a scenario built upon these modeling assumptions.

This version of the System Plan establishes a Reference Case that will be used to provide a description of how the mission could play out, and communicate the potential impacts on the mission of key issues and uncertainties.

The approach used in selecting assumptions for this Reference Case was to generally follow the submitted baseline, except for new production schedule and capacity assumptions, and routine updates of other modeling assumptions. Little or no attempt was made to second-guess the final outcome of the findings identified in the two reviews. Therefore, some of the assumptions used for this Reference Case are expected to change as those findings are resolved. The affected assumptions will be considered while preparing the Key Issues and Uncertainties.

${ }^{2}$ DE-AC27-01RV14136, Through Modification Number M051, 2006, WTP Contract.

${ }^{3}$ HNF-SD-WM-SP-012, 2007, Tank Farm Contractor Operation and Utilization Plan, Rev. 6, CH2M HILL Hanford Group, Inc., Richland, Washington.

${ }^{4}$ Baseline Change Request RPP-06-003, Rev. 1, “Alignment of TFC Lifecycle Baseline," November 2006.

5 "Comprehensive Review of the Hanford Waste Treatment Plant Flowsheet and Throughput, Assessment Conducted by an Independent Team of External Experts," March 2006, transmitted under cover of letter CCN: 132846.

${ }^{6}$ D-03-DESIGN-005, 2004, "HLW Feed Preparation System: Ultra-Filtration Process System", ORP WTP Engineering Division. NB - this document number was also used for a different report issued in 2003. 


\section{B2.0 KEY ENABLING ASSUMPTIONS}

\section{B2.1 WASTE TREATMENT COMPLEX}

B2.1.1 The overall configuration and process flow assumed for the waste treatment complex is shown in Figure 1-1, River Protection Project Simplified Process Flow Diagram., located in the body of this document.

\section{B2.2 TANK FARMS}

\section{B2.2.1 Single-Shell Tanks}

B2.2.1.1 The integrity and status of the 149 single-shell tanks (SST) is as described in the "Waste Tank Summary Report for Month Ending 12/31/2006."7

B2.2.1.2 For mission modeling purposes, interim closure ${ }^{8}$ of the SSTs will not be addressed.

B2.2.1.3 Closure activities for each tank farm can begin after all tanks in that farm are interim closed. $^{9}$

\section{B2.2.2 Double-Shell Tanks}

B2.2.2.1 The integrity and status of the 28 double-shell tanks (DST) is as described in the "Waste Tank Summary Report for Month Ending 07/31/2006." Furthermore, it is assumed that the DSTs will remain fully operational for the duration of the waste treatment mission.

B2.2.2.2 The maximum operating liquid levels for the DSTs are given in OSD-T-151-00007, Rev. 1, "Operating Specifications for the Double Shell Storage Tanks", March 2007. In this revision of the operating specifications, the maximum operating level for AP-Farm tanks was increased from $449 \mathrm{in}$. $(1.235 \mathrm{Mgal})$ to $454 \mathrm{in}$. $(1.2465 \mathrm{Mgal}){ }^{10}{ }^{\mathrm{It}}$ is assumed that each AP-Farm tank will successfully pass the in-service leak testing required to utilize this increased operating level.

B2.2.2.3 The volume of DST space allocated for tank farm emergencies and emergency returns from the WTP is $1.265 \mathrm{Mgal}^{11}{ }^{1}$ No space will be reserved for non-emergency returns of pretreated LAW or liquid effluents to the DST system.

B2.2.2.4 Solids are assumed to settle to approximately $40 \mathrm{wt} \%$ solids in the DSTs within 30 days. Solids from C-Farm retrieval are assumed to settle within 2 days to a solids loading comparable to that in the source SST. ${ }^{12}$

\footnotetext{
${ }^{7}$ HNF-EP-0182, Rev. 225.

${ }^{8}$ Interim closure comprises tank isolation and tank fill per Baseline Change Request RPP-06-003, Rev. 1.

${ }^{9}$ Baseline Change Request RPP-06-003, Rev. 1.

${ }^{10} \mathrm{NB}$ - At liquid levels above $426 \mathrm{in}$., the nominal 2750 gal per in. of tank level begins to decrease, dropping to 2603 gal per in. at 454 in.

${ }^{11}$ HNF-3484, Rev 8.
} 
B2.2.2.5 The solids management strategy for the DSTs assumes that ${ }^{12}$ :

- DSTs supporting C-Farm retrieval will be operated with a minimal supernatant layer so that they do not become Group A tanks even though they will be filled with significant quantities of solids.

- DSTs not supporting C-Farm retrieval are assumed to hold up to $10 \mathrm{wt} \%$ bulk solids based on the maximum operating level of each DST.

B2.2.2.6 The waste blending and segregation controls in the feed control list (HNF-SD-WM-OCD-015, Rev. 17, Table A-1) will be followed, with the following exceptions and clarifications:

- "Blend off high 233U solids": It is assumed that blending solids from tanks C-111 and C-112 with the solids from C-104 in Tank AN-101 will successfully mitigate the uranium enrichment issues with the $\mathrm{C}-104$ solids.

- "Prepare and protect hot commissioning feed": The HLW and LAW hot commissioning feeds have already been consolidated in AY-102 as of January 2007.

- "Segregate Envelope C": It is assumed that the strontium and transuranic (TRU) will be removed from the Envelope C waste currently stored in AN-102 and AN-107 in the DST system rather than in the WTP.

- "Segregate low-cesium SST waste for non-WTP supplemental treatment": Only waste from S-105 and S-109 need to be segregated for delivery to non-WTP supplemental treatment.

\section{B2.2.3 Waste Retrieval and Transfers}

B2.2.3.1 The SSTs to be retrieved in the near-term is provided by the eighteen "committed tanks" identified in the Single-Shell Tank Retrieval Selection and Sequence document. 13,14 These tanks are S-102, S-112 and all of C-Farm.

B2.2.3.2 The life-cycle priorities ${ }^{15}$ for sequencing the retrieval of SST waste are to minimize mission duration, ${ }^{16}$ by:

- Balancing feed to WTP, STP, and TRU;

- Balancing high-level waste (HLW) WTP feed and low-activity waste (LAW) WTP feed;

\footnotetext{
${ }^{12}$ HNF-SD-WM-SP-012, Rev. 6, Assumption A4.2.5.

${ }^{13}$ RPP-21216, Rev. 3, Single-Shell Tank Retrieval Selection and Sequence.

${ }^{14}$ The term "committed tanks" is used to indicate tanks with near-term Hanford Federal Facility Agreement and Consent Order (Ecology, EPA, and DOE, 1996) retrieval milestones.

${ }^{15}$ In the future, additional priorities may need to be considered such as risk or hazard based metrics, logistics, and tank closure strategy. The challenge will be to incorporate such considerations without adversely impacting the overall mission, particularly the amount of HLW glass produced and the mission duration.

${ }^{16}$ Minimizing treatment mission duration was used as placeholder goal due to lack of a practical metric for determining how well the entire retrieval sequence and associated timing impacts the risk to human health and the environment.
} 
- Providing for incidental blending; and

- Implementing designated intentional blends.

B2.2.3.3 Updated SST retrieval assumptions (assumed technology, minimum retrieval duration, and as-retrieved waste volumes) will be provided by SVF-1283, Rev. 2, "Single-Shell Tank Retrieval Assumptions for Mission Modeling."

B2.2.3.4 During retrieval of waste from SSTs to the DST system, sodium hydroxide and sodium nitrite will be added as needed so that the as-retrieved liquid phase composition satisfies the DST waste chemistry limits given in Table 3-4 of HNF-SD-WM-OCD-015, Rev. 17.

B2.2.3.5 Allow 210 days $^{17}$ to sample the staged feed and verify compliance with permits and the safety authorization basis before delivery to the WTP, starting from when each staging tank (DST) is first filled with feed.

B2.2.3.6 The feed for LAW hot commissioning will be delivered by decanting a portion of the supernate from AY-102 and transferring it to the WTP; the feed for HLW hot commissioning will be delivered by remobilizing the solids in AY-102 with the remaining supernate and additional dilution water and then transferring them to the WTP.

B2.2.3.7 Subsequent deliveries of feed to the WTP will be timed and sequenced to balance the production of HLW glass, LAW glass and excess pretreated LAW supernate.

B2.2.3.8 All HLW batches delivered to the WTP should be at least $130 \mathrm{Kgal}$ total volume whenever possible ${ }^{18}$ and contain between 10 and 200 grams of unwashed solids per liter of slurry. $^{19}$

B2.2.3.9 The residual waste remaining in the SSTs and DSTs after retrieval is complete will be estimated as follows:

- The residual inventory in a 200 Series SST will be best-basis inventory (BBI) data for SSTs where waste retrieval actions have been completed, when that information are available, or will be estimated as $30 \mathrm{ft}^{3}$ of "selected phase", calculated for the BBI used as input to the model run. ${ }^{20}$

- The residual waste inventory in a 100 Series SST will be BBI data for SSTs where waste retrieval actions have been completed, when that information are available, or will be estimated as $360 \mathrm{ft}^{3}$ of slurry containing $35 \%$ water-washed solids with liquids at $1 / 2$ the concentration of the bulk as-retrieved supernate. ${ }^{20}$

- DSTs: 100 gal with composition of the last waste contained in the tank. ${ }^{21}$

\footnotetext{
${ }^{17}$ The 210 days comprises the 180 days required by ICD-19 (24590-WTP-ICD-MG-01-019) with an additional 30 days allocated for the TFC to sample the staged waste.

${ }^{18}$ This operational consideration reduces the number of transfers needed to deliver a DST of staged HLW to the WTP.

${ }^{19}$ The WTP Contract (DE-AC27-01RV14136), Section C, Specification 8, Paragraph 8.2.2.1, establishes the range of acceptable solids concentration in the delivered HLW feed. This version of the System Plan will attempt to target a nominal $8 \mathrm{wt} \%$ solid concentration to facilitate more efficient WTP operations.

${ }^{20}$ HNF-SD-WM-SP-012, Rev. 6, Assumption A3.10, "Single-Shell Tank Waste Residuals."

${ }^{21}$ HNF-SD-WM-SP-012, Rev. 6, Assumption A4.2.12, "Waste Transfer Rates and Timing."
} 
B2.2.3.10 No waste is assumed to leak from the SSTs during retrieval. ${ }^{22,23}$

\section{B2.2.4 Tank Farm Waste Evaporator (242-A)}

B2.2.4.1 The 242-A Evaporator will be available, as needed, to support SST retrieval. The evaporator will not be available during scheduled maintenance outages. ${ }^{24}$

B2.2.4.2 If there are periods greater than 11 months during which the 242-A Evaporator is not used to concentrate waste, a "cold run" of 82,000 gal of water will be performed to maintain personnel qualifications and avoid the need for a full readiness review. ${ }^{25}$

B2.2.4.3 A 3-month period is allocated for the sampling and analysis of dilute feed staged in one or more DSTs, and preparation of the process control plan before that feed can be run through the evaporator. ${ }^{25}$

B2.2.4.4 When processing waste, the evaporator is assumed to run at the lesser of $50 \mathrm{gpm}$ boil-off or $140 \mathrm{gpm}$ feed. ${ }^{25}$

B2.2.4.5 Dilute waste will be concentrated until it reaches a bulk concentration of $1.43 \mathrm{~g} / \mathrm{mL}^{25,26}$

B2.2.4.6 The composition of process condensate from the 242-A Evaporator will be estimated using the formulas and partition factors given in RPP-17239. The volume of process condensate will be 1.15 times the waste volume reduction to account for the vacuum system steam jets. ${ }^{27}$

B2.2.4.7 The releases from the condenser to the atmosphere will be estimated using the release factors given in Table D-6 of RPP-17239. ${ }^{27}$

\footnotetext{
${ }^{22}$ While Performance Assessments assume nominal leakage during retrieval operations, the System Plan assumes no leakage occurs to ensure that maximum waste inventory is modeled through the Waste Treatment Complex.

${ }^{23}$ HNF-SD-WM-SP-012, Rev. 6, Assumption A3.11, "SST Waste Leaks."

${ }^{24}$ HNF-SD-WM-SP-012, Rev. 6, Assumption A4.3.1, "Evaporator Availability."

${ }^{25}$ HNF-SD-WM-SP-012, Rev. 6, Assumptions A4.3.2, "Evaporator Operation."

${ }^{26}$ This density is expected to be the average density selected for future evaporator campaigns - it is not an inherent limitation of the evaporator. The feed for each evaporator campaign will be evaluated and a target density for specific for that feed will be determined considering the ability of the transfer system to maintain solids in suspension and the DSTs ability to stay within buoyant displacement gas release event (BDGRE) controls. In the future, a lower value may be used for waste containing high concentrations of phosphates.

${ }^{27}$ HNF-SD-WM-SP-012, Rev. 6, Assumption A4.3.3, "Evaporator Process Chemistry."
} 


\section{B2.3 WASTE TREATMENT PLANT}

The assumptions for the performance of the WTP used in this System Plan are consistent with the U.S. Department of Energy, Office of River Protection (ORP) assessment of the potential performance of the WTP after specific enhancements in design, flowsheet, or operating modes have been made. The technical issues identified in two specific reviews (a design oversight review $^{28}$ of the ultra-filters and a comprehensive independent review ${ }^{29}$ ) are assumed to be successfully resolved without adverse impact to the assumed performance.

\section{B2.3.1 General}

B2.3.1.1 The WTP will be operable for 40 years, from the start of hot commissioning through 2058.

B2.3.1.2 The Balance of Facilities (BOF), the Laboratory, and other support facilities are assumed to be capable of supporting the WTP. WTP sampling and analysis times will support production.

B2.3.1.3 Hot commissioning will begin on May 1, 2018 and end on September 30, 2018. ${ }^{30}$

B2.3.1.4 Delivery of the first batch of LAW feed will begin on May 1, 2018. ${ }^{31}$

B2.3.1.5 Delivery of the first batch of HLW feed will begin on May $15,2018 .^{32}$

B2.3.1.6 Full WTP operations will begin on October $1,2018^{33}$ and continue until the end of the treatment mission.

B2.3.1.7 The WTP is assumed to not return any waste streams or wastewater back to the tank farms.

B2.3.1.8 It is assumed that the delivered feed and internal WTP material flows and accumulations will be consistent with the WTP authorization basis. ${ }^{34}$

${ }^{28}$ D-03-DESIGN-005, 2004, "HLW Feed Preparation System: Ultra-Filtration Process System," ORP WTP Engineering Division. NB - this document number was also used for a different report issued in 2003.

29 "Comprehensive Review of the Hanford Waste Treatment Plant Flowsheet and Throughput, Assessment Conducted by an Independent Team of External Experts," March 2006, transmitted under cover of letter CCN: 132846.

${ }^{30}$ This is more aggressive than BNI's schedule which shows hot commissioning ending on May 20, 2019.

${ }^{31}$ Date is set to match the start of hot commissioning (see Assumption B2.3.1.3).

${ }^{32}$ Date is set to match the start of HLW vitrification (see Assumption B2.3.3.1).

${ }^{33}$ There may be a contractor transition once hot commissioning has been completed - the effects of which are assumed to be consistent with the various facility ramp-ups.

${ }^{34}$ This assumption is not necessarily true for all feed to the WTP. It is assumed that the integrated management process for ICD-19 (24590-WTP-ICD-MG-01-019), as described in 24590-WTP-PL-MG-01-001 will be used to successfully address any feed not consistent with this assumption. For example, the Feed Control List (see HNF-SD-WM-OCD-015, Rev. 17, Table A-1) requires blending of the solids in AZ-101 to reduce the hydrogen generation rate and blending of solids in C-104 to reduce the concentration of ${ }^{233} \mathrm{U}$. 
B2.3.1.9 Key features of the WTP that will be modeled for purposes of mission planning and estimation of secondary waste streams include:

- Feed Receipt Tanks (simplified and LAW tanks lumped)

- Front End Evaporator (simplified - no feed tanks)

- Ultrafilter System (with modified $\left[\mathrm{OH}^{-}\right]$endpoint and oxidative leach)

- Pretreated HLW Lag Storage and Blend Tanks (simplified - only take credit for the $81 \mathrm{Kgal}$ capacity of the Blend Tank)

- Cesium Ion-Exchange (as a black-box)

- Back-End Evaporator and Pretreated LAW Storage (simplified and product routing modified to interface with the East Supplemental Treatment Plant [East STP])

- HLW Melter Feed Preparation (simplified)

- HLW Melter (model total capacity, not individual melters)

- LAW Melter Feed Preparation (simplified)

- LAW Melter (model total capacity, not individual melters)

- Off-Gas Treatment Systems (except for Pretreatment Facility off-gas system)

- Recycle of both LAW submerged bed scrubber (SBS) and wet electrostatic precipitator (WESP) Condensate to the Back-End Evaporator.

- Recycle of HLW Condensate (from SBS, WESP, and high-efficiency mist eliminator (HEME) - neglect canister wash water) to the HLW Feed Receipt Tank

- Discharge of LAW Caustic Scrubber effluent and evaporator condensate to the Liquid Effluent Retention Facility (LERF)/ Effluent Treatment Facility (ETF) via Pretreatment.

B2.3.1.10 The basis for modeled chemical reactions and extents for estimating primary streams and secondary waste streams will be the 24590-WTP-MDD-PR-01-002, Rev. 6, with flowsheet and operating mode modifications as needed to implement the other assumptions in this System Plan. Off-gas system configuration and updated split factors for all unit operations will be obtained from 24590-WTP-MDD-PR-01-002, Rev. 8, with additional clarification provided by 24590-WTP-RPT-PT-02-005, Rev. 3, "Flowsheet Bases, Assumptions, and Requirements." 35

\footnotetext{
${ }^{35}$ The last major revision of the HTWOS model aligned the model with 24590-WTP-MDD-PR-01-002, Rev. 6, per ORP direction. A subset of the changes that have occurred since that alignment are being addressed in this assumption set to better reflect the WTP flowsheet, with the focus on providing reasonable estimates of the secondary waste streams. The specific clarifications that were needed comprise the use of split factors from 24590-WTP-RPT-PT-02-005, Rev. 3, for Feed Evaporator $\left({ }^{129} \mathrm{~N}\right)$, Feed Evaporator Condenser $\left({ }^{129} \mathrm{I}\right.$, ${ }^{99} \mathrm{Tc}$, Hg), LAW Melter $\left({ }^{129} \mathrm{I}\right)$, LAW SBS $\left({ }^{129} \mathrm{I},{ }^{99} \mathrm{Tc}\right)$, HLW Melter $\left({ }^{129} \mathrm{I}\right)$ and HLW WESP $\left({ }^{129} \mathrm{I},{ }^{99} \mathrm{Tc}, \mathrm{Hg}\right)$ and the use of an updated ${ }^{99}$ Tc split factor for the LAW Melter per CCN 150375.
} 
B2.3.1.11 One LAW Melter is assumed to be replaced every 2.5 years and contains approximately $6900 \mathrm{gal}$ of glass. ${ }^{36}$

B2.3.1.12 One HLW Melter is assumed to be replaced every 2.5 years and contains approximately 823 gal of glass. ${ }^{37}$

\section{B2.3.2 Pretreatment}

B2.3.2.1 For planning purposes, all solids delivered with the HLW feed and entrained solids delivered with the LAW feed will undergo caustic and oxidative leaching with the insoluble fraction incorporated into HLW glass.

B2.3.2.2 When the WTP requests delivery of HLW feed, the HLW feed receipt tanks at the WTP will have sufficient space to receive $160,000 \mathrm{gal}\left(600 \mathrm{~m}^{3}\right)$ of HLW feed without interruption. $^{38}$

B2.3.2.3 When the WTP requests delivery of LAW feed, the LAW feed receipt tanks at the WTP will have sufficient space to receive $1 \mathrm{Mgal}$ of feed without interruption. ${ }^{38}$

B2.3.2.4 The WTP pretreatment facility will be configured so that a portion of concentrated pretreated LAW from the Treated LAW Concentrate Tank can be transferred to the East STP as feed. This is downstream of the point to which LAW SBS condensate is recycled, so the STP feed will include a proportional fraction of SBS condensate.

B2.3.2.5 Any "excess" pretreated LAW beyond that which the LAW Vitrification Facility can process will be routed to the East STP.

B2.3.2.6 Sufficient caustic will be added to the waste during caustic leaching so that $3.0 \mathrm{M}$ $\left[\mathrm{OH}^{-}\right]$remains in solution after the leach reactions are complete.

B2.3.2.7 An oxidative leach process that removes chromium from the HLW sludge without impact on cycle time ${ }^{39}$ or other species will be implemented in the ultrafilters. Reaction stoichiometry and endpoint $(5,000 \mu \mathrm{g} \mathrm{Cr} / \mathrm{g}$ dried solids) are described in RPP- 15552 .

B2.3.2.8 The technical issues surrounding the capacity and flowsheet of WTP Pretreatment Facility, as identified in an ORP Design Oversight Report (D-03-DESIGN-005), are assumed to

\footnotetext{
${ }^{36}$ Replacement of spent melters is already accounted for in the assumed net production capacity assumptions. Assumes two melters, each with a 5-year minimum design life per 24590-LAW-3PS-AE00-T0001. Volume of glass in the melter does not include an allowance for increased volume due to corrosion of refractory and reflects the set point of 6891 gals per 24590-WTP-MDD-PR-01-002, Appendix D; other contributions to source term are neglected. No credit taken for purging melter with "cold" glass, nor draining the melter, prior to removal from service.

${ }^{37}$ Replacement of spent melters is already accounted for in the assumed net production capacity assumptions. Assumes two melters, each with a 5-year minimum design life per 24590-HLW-3PS-AE00-T0001. Volume of glass in the melter is assumed to reflect the 25 -inch heel remaining after the maximum pour and includes an allowance for increased volume due corrosion of refractory (CCN: 102476); other contributions to source term are neglected. No credit taken for purging melter with "cold" glass, prior to removal from service.

${ }^{38}$ These are operational considerations.

${ }^{39}$ This is an optimistic assumption - the emerging oxidative leach process may increase cycle time on the order of 10 percent.
} 
be successfully resolved. For modeling purposes, the UF permeate rate is assumed to be 15.6 gpm per ultrafilter train. ${ }^{40}$

B2.3.2.9 There will be approximately $300 \mathrm{gal}(2005 \mathrm{lb}$ air-dried $)$ of spent cesium ion exchange resin generated for every 300,000 gal of supernate treated through the cesium ion exchange system. $^{41}$

B2.3.2.10 An estimate of the constituents that remain on the spent cesium ion exchange resin will be obtained by averaging the values reported in Table 2.5-8a "Summary of Spent Resin Metals and Radionuclide Concentrations after Processing a Sequence of Actual Waste Samples in Column Tests", ignoring the "less-than" values. ${ }^{42}$

\section{B2.3.3 High-Level Waste Vitrification}

B2.3.3.1 HLW Vitrification at the WTP will begin on May 15, 2018.

B2.3.3.2 During hot commissioning, the WTP will produce 56 Canisters ${ }^{43}$ of HLW glass.

B2.3.3.3 During full operations, the net WTP HLW vitrification capacity will be ramped as follows:

\begin{tabular}{|cc|cc|}
\hline \multicolumn{2}{|c|}{ Starting On } & \multicolumn{2}{c|}{$\begin{array}{c}\text { Rate } \\
\text { MTG/d }\end{array}$} \\
\hline $\mathbf{A 1 . 0}$ & $10 / 1 / 2018$ & $\mathbf{A 2 . 0}$ & 3.0 \\
\hline $\mathbf{A 3 . 0}$ & $1 / 1 / 2020$ & $\mathbf{A 4 . 0}$ & 4.0 \\
\hline $\mathbf{A 5 . 0}$ & $1 / 1 / 21$ & $\mathbf{A 6 . 0}$ & $4.2^{44}$ \\
\hline $\mathbf{A 7 . 0}$ & $2 / 6 / 2024$ & $\mathbf{A 8 . 0}$ & $5.25^{45}$ \\
\hline
\end{tabular}

${ }^{40}$ This assumes that the effective surface area of each ultrafilter train has been increased to $1162 \mathrm{ft}^{2}$, operates at $25^{\circ} \mathrm{C}$, and is representative of concentrating a $5 \mathrm{M}[\mathrm{Na}]$ feed from $5 \mathrm{wt} \%$ to $20 \mathrm{wt} \%$ undissolved solids (RPP-35320). Also, it is assumed that the cesium ion-exchange system will support this permeate rate.

${ }^{41}$ This assumes that all supernate is Envelope A and is based on operating the system as four column carousel (lead, lag, polish, regeneration), with the columns swapping function every 100 column volumes, 300 gal per column volume, resin change-out after the $10^{\text {th }}$ regeneration cycle (24590-WTP-MDD-PR-01-002, Section 4.7.4). Using the air-dried bulk density of SuperLig resin from Flow Properties Test Report Sodium Form Resin Samples, 4716-1, Jenike \& Johanson, 2003, summary page 2, the bulk density is about $50 \mathrm{lb}$ per cubic foot of resin. Note - recent testing has shown that a new spherical resorcinol formaldehyde resin will last at least 25 cycles.

42 24590-WTP-RPT-PT-02-005, Rev. 3.

${ }^{43}$ The BNI Contract, Standard 5, Table C.6-5.2, requires that 56 canisters of HLW glass be produced during hot commissioning. For modeling purposes, the average WTP glass production rate during hot commissioning is set (about $1.3 \mathrm{MTG} / \mathrm{d}$ ) so that the contract goal is just met by the end date for hot commissioning.

${ }^{44}$ Assumes two HLW melters, each $3 \mathrm{MTG} / \mathrm{d}$ design at a 0.7 total operating efficiency (TOE).

${ }^{45}$ Assumes two second generation HLW melters, each $3.75 \mathrm{MTG} / \mathrm{d}$ design at a $0.70 \mathrm{TOE}$. 
B2.3.3.4 Average density of immobilized high-level waste (IHLW) glass will be $2.7 \mathrm{Kg} / \mathrm{L}$.

B2.3.3.5 Each thin-walled canister of IHLW will contain 3.2 MT of HLW glass on the average. $^{46}$

B2.3.3.6 The composition and waste oxide loading of HLW glass will be estimated using the same mathematical model and computer code that was used for the RPP System Plan (ORP-11242, Rev. 2,) and the Tank Farm Contractor Operation and Utilization Plan (TFCOUP) (HNF-SD-WM-SP-012, Rev. 6). The references for the various property models and constraints are taken from a variety of sources and are consolidated in RPP-18592. They are restated here for convenience.

The physical property constraints are summarized in Table B-1. The terms "default" and "relaxed," identified in Table B-1, refer to two levels of parameters. The "relaxed" levels, discussed in Section 2.3.6.4 of the System Plan (ORP-11242, Rev. 2) incorporate potential improvements in the HLW waste oxide loading by relaxing the glass viscosity, $\mathrm{Cr}_{2} \mathrm{O}_{3}$ solubility, and the spinel liquidus temperature constraints. The "default" levels are the more conservative levels that had been used for HLW glass projections up until 2002 and are shown for comparison. This revision (Revision 3) of the System Plan will continue to use the "relaxed" limits. The melter was assumed to operate at a nominal temperature of $1150^{\circ} \mathrm{C}$.

Table B-1. Glass Property Constraints.

\begin{tabular}{|l|l|l|}
\hline \multicolumn{1}{|c|}{ Property } & Lower Limit & \multicolumn{1}{c|}{ Upper Limit } \\
\hline Liquidus Temperature (Spinel) & $850{ }^{\circ} \mathrm{C}$ & $\begin{array}{l}1100{ }^{\circ} \mathrm{C} \text { (relaxed) } \\
1050{ }^{\circ} \mathrm{C} \text { (default) }\end{array}$ \\
\hline Liquidus Temperature (Zircon) & None & $1050^{\circ} \mathrm{C}$ \\
\hline Melt Viscosity at $1150{ }^{\circ} \mathrm{C}$ & $4.5 \mathrm{~Pa} \cdot \mathrm{s}$ & $\begin{array}{l}10 \mathrm{~Pa} \cdot \mathrm{s} \text { (relaxed) } \\
5.5 \mathrm{~Pa} \cdot \mathrm{s} \text { (default) }\end{array}$ \\
\hline PCT $(\mathrm{B}, \mathrm{Li}, \mathrm{Na})$ & None & $2 \mathrm{~g} / \mathrm{m}^{2}$ \\
\hline $\begin{array}{l}\mathrm{Nepheline} \mathrm{precipitation} \mathrm{rule} \\
{\left[\mathrm{SiO}_{2}\right]}\end{array}$ & & \\
\hline$\left[\mathrm{SiO}_{2}\right]+\left[\mathrm{Al}_{2} \mathrm{O}_{3}\right]+\left[\mathrm{Na}_{2} \mathrm{O}\right]$ & 0.62 & None \\
\hline
\end{tabular}

${ }^{46}$ This is based on an average fill of $1.185 \mathrm{~m}^{3}$ per canister. 
Additional constraints (Table B-2) were also applied to either limit the glass composition to the approximate region of validity (domain) of the various property models, or to limit the allowable concentration of components that impact the waste oxide loading in the resulting glass. The limits in Table B-2 should not be confused with those in Table TS-1.1 of the WTP contract (DE-AC27-01RV14136), which establishes minimum component limits in HLW glass for contractual purposes.

Table B-2. Glass Composition Constraints.

\begin{tabular}{|c|c|c|c|c|}
\hline & Component & $\begin{array}{l}\text { Minimum } \\
\text { (wt \%) }\end{array}$ & $\begin{array}{l}\text { Maximum } \\
\text { (wt \%) }\end{array}$ & $\begin{array}{c}\text { Allowed as glass } \\
\text { forming } \\
\text { chemicals? }\end{array}$ \\
\hline \multirow{9}{*}{ 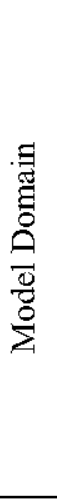 } & $\mathrm{SiO}_{2}$ & 38.0 & 57.0 & Yes \\
\hline & $\mathrm{B}_{2} \mathrm{O}_{3}$ & 5.0 & 20.0 & Yes \\
\hline & $\mathrm{Na}_{2} \mathrm{O}$ & 5.0 & 20.0 & Yes \\
\hline & $\mathrm{Li}_{2} \mathrm{O}$ & 1.0 & 4.0 & Yes \\
\hline & $\mathrm{Al}_{2} \mathrm{O}_{3}$ & None & 17.0 & Yes \\
\hline & $\mathrm{Fe}_{2} \mathrm{O}_{3}$ & 2.0 & 15.0 & Yes \\
\hline & $\mathrm{CaO}$ & None & 10.0 & No \\
\hline & $\mathrm{MgO}$ & None & 8.0 & No \\
\hline & $\mathrm{ZrO}_{2}$ & None & 15.0 & No \\
\hline \multirow{4}{*}{ 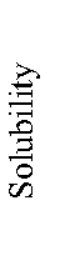 } & $\mathrm{Cr}_{2} \mathrm{O}_{3}$ & None & $\begin{array}{l}0.5 \text { (default) } \\
1.0 \text { (relaxed) }\end{array}$ & No \\
\hline & $\mathrm{P}_{2} \mathrm{O}_{5}$ & None & 3.0 & No \\
\hline & $\mathrm{SO}_{3}$ & None & 0.5 & No \\
\hline & $\mathrm{Rh}_{2} \mathrm{O}_{3}+\mathrm{Ru}_{2} \mathrm{O}_{3}$ & None & 0.25 & No \\
\hline
\end{tabular}

${ }^{47}$ For modeling purposes, the glass forming chemicals are assumed to be pure oxides rather than minerals with impurities. 


\section{B2.3.4 Low-Level Waste Vitrification}

B2.3.4.1 LAW Vitrification at the WTP will begin on May $15,2018 .^{48}$

B2.3.4.2 During hot commissioning, the WTP will produce 188 Packages $^{49}$ of LAW glass.

B2.3.4.3 During full operations, the net WTP LAW vitrification capacity will be ramped as follows:

\begin{tabular}{|l|l|}
\hline \multicolumn{1}{|c|}{ Starting On } & \multicolumn{1}{c|}{$\begin{array}{c}\text { Rate } \\
\text { MTG/d }\end{array}$} \\
\hline $10 / 1 / 2018$ & 9.0 \\
\hline $1 / 1 / 2020$ & 18.0 \\
\hline $1 / 1 / 2021$ & $21.0^{50,51}$ \\
\hline
\end{tabular}

B2.3.4.4 The average density of immobilized low-activity waste (ILAW) glass will be $2.6 \mathrm{Kg} /$ liter.

B2.3.4.5 Each package of ILAW will contain 5.92 MT of LAW glass on the average. ${ }^{52}$

B2.3.4.6 The total sodium loading of LAW glass from pretreated feed will be determined using the DOE Model (D-03-DESIGN-004), which maximizes the sodium oxide loading in the LAW glass subject to the following constraints:

$$
\begin{aligned}
& {\left[\mathrm{Na}_{2} \mathrm{O}\right] \leq 20 w t \%} \\
& {\left[\mathrm{SO}_{3}\right] \leq 0.8 w t \%}
\end{aligned}
$$

B2.3.4.7 The composition of the LAW glass will be estimated using a glass recipe model similar to that described in 24590-WTP-MRQ-PO-04-0065 (DRAFT). Sulfate volatilization will be estimated using Equation 3.1-5f of 24590-WTP-RPT-PT-02-005.

\footnotetext{
${ }^{48}$ ORP may direct BNI to begin commissioning of the LAW Vitrification Facility by 2013, which would require significant changes in the TFC baseline.

${ }^{49}$ The BNI Contract, Standard 5, Table C.6-5.2, requires that 188 packages of LAW glass be produced during hot commissioning. For modeling purposes, the average WTP glass production rate during hot commissioning is set so that the contract goal is just met by the end date for hot commissioning. The average LAW vitrification rate during hot commissioning is about $8.1 \mathrm{MTG} / \mathrm{d}$.

${ }^{50}$ Assumes two LAW melters, each $15 \mathrm{MTG} / \mathrm{d}$ design at a 0.7 TOE.

${ }^{51}$ No credit is taken for expanded LAW vitrification capacity in this version of the System Plan.

${ }^{52}$ This is based on a $601 \mathrm{gal}\left(2.275 \mathrm{~m}^{3}\right)$ container per 24590-WTP-MDD-PR-01-002, Section 4.7.14.
} 


\section{B2.4 SUPPLEMENTAL TREATMENT}

\section{B2.4.1 Demonstration Bulk Vitrification System (DBVS)}

B2.4.1.1 The DBVS will be located in 200 West Area adjacent to S-Farm.

B2.4.1.2 The DBVS will begin operation on $3 / 1 / 2011$ and treat low-curie waste containing $260 \mathrm{MT}$ Na by October 23, 2012, not to exceed its net treatment rate of $3.66 \mathrm{MTG} / \mathrm{d}^{53,54}$

B2.4.1.3 The DBVS will be modeled using a simplified continuous flowsheet that implements the overall mass balances for the primary and secondary waste streams as shown in Figures 8-1 and 8-4 of the process flowsheet (RPP-20528, Rev. 1) and described in the rest of the document. The mass balance spreadsheet developed for the flowsheet and documented in SVF-1102, Rev. 0, consolidates and elaborates on many of the underlying technical assumptions, most notably, the basis for many of the process splits. Any parameters not specifically addressed by those two documents may be obtained from the process design criteria provided in 145579-A-DC-002, Rev. 0F. However, the mixture of glass-forming minerals specified in Table 1 of ST07.004 will be used instead of Hanford soil.

B2.4.1.4 The feed for the DBVS will be supplied from S-109 using the selective dissolution assumptions described in Table A-14, "Selective Dissolution Separation Assumptions." The S-109 retrieval will be controlled to limit the total activity in the retrieved waste to $0.0062 \mathrm{Ci}$ per liter at a $5 \mathrm{M}[\mathrm{Na}]$ feed concentration and to prevent entrainment of solids in the feed. ${ }^{55}$

B2.4.1.5 For modeling purposes, the density of the bulk vitrification product (glass) is 2.65 MT/m ${ }^{3}{ }^{55,56}$

B2.4.1.6 The $\mathrm{Na}_{2} \mathrm{O}$ loading in the product will be a nominal $21.24 \mathrm{wt} \%$ based on waste sodium. $55,57,58$

B2.4.1.7 The product is packaged in $35-\mathrm{m}^{3}$ roll-off boxes, each filled with 42.6 MT radioactive glass. ${ }^{55,56}$ The mass of clean fill glass used to top off each box will be neglected.

B2.4.1.8 The roll-off boxes will be temporarily stored on a cooling pad located near the DBVS until the IDF is ready to accept them for disposal.

\footnotetext{
${ }^{53}$ HNF-SD-WM-SP-012, Rev. 6, Assumption A2.4.1, "Supplemental LAW Processing." This is based on a target design rate of $1.09 \mathrm{gpm}$ of $5 \mathrm{M}[\mathrm{Na}]$ nominal feed, a 17.6 -wt \% waste sodium oxide loading, and a $0.70 \mathrm{TOE}$ (see 145579-A-DC-002, Rev. 0F, "Process Design Criteria").

${ }^{54}$ For modeling purposes, the average DBVS glass production rate is set so that the treatment goal is just met by the end date. The average vitrification rate is about $2.74 \mathrm{MTG} / \mathrm{d}$.

${ }^{55}$ HNF-SD-WM-SP-012, Rev. 6, Assumption A2.4.1, "Supplemental LAW Processing."

${ }^{56}$ 145579-A-DC-002, Rev. 0F, "Process Design Criteria," Section 3.5.1.

${ }^{57}$ 145579-A-DC-002, Rev. 0F, "Process Design Criteria," Section 3.4.1.

${ }^{58}$ The assumed $\mathrm{Na}_{2} \mathrm{O}$ loading takes into consideration the recent decision to replace Hanford soil with a mixture of glass forming minerals. See ST07.004 for details.
} 


\section{B2.4.2 Bulk Vitrification System (BVS)}

B2.4.2.1 The DBVS facility will be refurbished and re-permitted for extended operation as the Bulk Vitrification Facility (BVS) after a one-year ${ }^{59}$ outage.

B2.4.2.2 The BVS starts operating on $10 / 23 / 2013^{59}$ at a net rate of $3.66 \mathrm{MTG} / \mathrm{d}$ and operates as long as low-curie feed is available. ${ }^{60}$

B2.4.2.3 The feed for the DBVS will be supplied from S-109 and S-105 using the selective dissolution assumptions described in Table A-14, "Selective Dissolution Separation Assumptions." The retrievals will be controlled to prevent entrainment of solids in the feed. ${ }^{60}$

B2.4.2.4 For planning purposes, it is assumed that the BVS will utilize the same technology and process flowsheet as the DBVS ${ }^{61}$. See assumptions 2.4.1.3, 2.4.1.5, 2.4.1.6, and 2.4.1.7.

\section{B2.4.3 East Supplemental Treatment Plant (East STP)}

B2.4.3.1 A production scale supplemental LAW treatment facility, East STP, will be located in 200E, northeast of the WTP pretreatment facility, on the plot of land originally reserved for the second LAW Vitrification Facility.

B2.4.3.2 For planning purposes, it is assumed that the East STP will utilize the same technology and process flowsheet as the DBVS. ${ }^{61}$ See assumptions 2.4.1.3, 2.4.1.5, 2.4.1.6, and 2.4.1.7.

B2.4.3.3 The East STP will start hot testing on $2 / 1 / 2019^{62}$ and operate at $3.66 \mathrm{MTG} / \mathrm{d}$ for eight months. $^{60,63}$

B2.4.3.4 The East STP will start production operations on 10/1/2019 at a net capacity of $14.65 \mathrm{MTG} / \mathrm{d} .^{60,64,65}$

B2.4.3.5 The "excess" pretreated LAW from the WTP will be used to feed the East STP. ${ }^{60}$

\footnotetext{
${ }^{59}$ Personal communication with P. K. Brockman, March 8, 2007.

${ }^{60}$ HNF-SD-WM-SP-012, Rev. 6, Assumption A2.4.1, "Supplemental LAW Processing."

${ }^{61}$ The process flowsheet will be revisited after evaluating the operation of the DBVS. It is anticipated that changes will be required to control the amount and distribution of key constituents of concern such as ${ }^{129} \mathrm{I}$ in the secondary waste streams.

${ }^{62}$ Maintained same relationship with start of WTP full operations.

${ }^{63}$ This assumes that the four melter lines will be tested one at a time.

${ }^{64}$ This assumes four melter lines, each with a design capacity of $5.24 \mathrm{MTG} / \mathrm{d}$, with a $0.70 \mathrm{TOE}$.

${ }^{65}$ The capacity of the East STP may be adjusted by even numbers of melters to bring the LAW treatment completion date closer to the HLW treatment completion date if there is a gross mismatch.
} 


\section{B2.4.4 Interim Pretreatment System}

B2.4.4.1 The Interim Pretreatment System is assumed to pretreat liquid waste using rotary micro-filtration units ${ }^{66}$ to remove entrained solids and a regenerable ion exchange to remove cesium as described in HNF-SD-WM-SP-012, Rev. 6, Assumption A2.4.1, "Supplemental LAW Processing."

B2.4.4.2 For planning purposes, the rotary micro-filtration units are assumed to remove essentially all entrained solids from the feed.

B2.4.4.3 For planning purposes, the regenerable ion exchange system is assumed to perform similarly to the WTP Pretreatment Facility ion exchange system, except that the average ${ }^{137} \mathrm{Cs}$ concentration in the pretreated waste is assumed to be $1.5 \mathrm{E}-5 \mathrm{Ci}$ per mole of sodium. ${ }^{67}$

B2.4.4.4 For planning purposes, the capacity of the Interim Pretreatment System is assumed to exceed the capacity of the West Supplemental Treatment Plant.

\section{B2.4.5 West Supplemental Treatment Plant (West STP)}

B2.4.5.1 A production scale supplemental LAW treatment facility, West STP, will be located in 200W, near the SY-Farm and the Interim Pretreatment Facility.

B2.4.5.2 For planning purposes, it is assumed that the West STP will utilize the same technology and process flowsheet as the DBVS. ${ }^{61}$ See assumptions 2.4.1.3, 2.4.1.5, 2.4.1.6, and 2.4.1.7.

B2.4.5.3 The West STP will start hot testing on 7/2/2014 and operate at 3.66 MTG/d for eight months. $^{68,69}$

B2.4.5.4 The West STP will start production operations on $3 / 2 / 2015$ at a net capacity of 14.65 MTG/d and will be operated to process as much liquid waste from West Area as practical. $^{68,70,71}$

\footnotetext{
${ }^{66}$ These are assumed to be similar to the rotary micro-filtration unit jointly designed and tested by Savannah River Site (SRS) and Oak Ridge National Laboratory (ORNL) personnel for separating entrained solids from SRS waste solutions. See WSRC-MS-2005-00147, 2005, "Small Column Ion Exchange Alternative Overview," D. McCabe et al, Westinghouse Savannah River Company, Aiken South Carolina."

${ }^{67}$ RPP-RPT-30160, Rev. 0, "Supporting Information for the Evaluation of Waste Treatment and Immobilization Plant (WTP) Low Activity Waste (LAW) Startup First Scenarios", Appendix A, Section A.2, "Cesium Removal." This report evaluates a cesium ion-exchange system similar in function to the Supplemental Pretreatment System.

${ }^{68}$ HNF-SD-WM-SP-012, Rev. 6, Assumption A2.4.1, "Supplemental LAW Processing."

${ }^{69}$ This assumes that the four melter lines will be tested one at a time.

${ }^{70}$ This assumes four melter lines, each with a design capacity of $5.24 \mathrm{MTG} / \mathrm{d}$, with a $0.70 \mathrm{TOE}$.

${ }^{71}$ The capacity of the West STP may be adjusted by even numbers of melters to bring the LAW treatment completion date closer to the HLW treatment completion date if there is a gross mismatch.
} 


\section{B2.4.6 Supplemental TRU Sludge Treatment}

B2.4.6.1 The contact-handledSupplemental TRU (transuranic) Treatment and Packaging process will be available on October $1,2013^{72}$ and treat a maximum of 8,040 gal of slurry from retrieved TRU tank waste per day. ${ }^{73}$

B2.4.6.2 The SSTs assumed to provide contact-handled sludge are [B-201, B-202, B-203, B-204], [T-201, T-202, T-203, T-204], T-111, T-110, and T-104, in the stated order except that the tank order within the [brackets] can be changed. ${ }^{74,75,76}$

B2.4.6.3 The contact-handled Supplemental TRU Treatment and Packaging system will first be located near B-Farm and then moved to T-Farm. There will be a 10-day outage between tanks and 60 -day outage to move equipment between farms. ${ }^{74}$

B2.4.6.4 The remote-handled Supplemental TRU Treatment and Packaging process will be available on $5 / 9 / 2025^{77}$ and treat a maximum of 8,040 gal of slurry from retrieved TRU tank waste per day. ${ }^{78}$

B2.4.6.5 The SSTs assumed to provide remote-handled sludge are T-105, T-107, T-112, B-107, B-110, and B-111; the DSTs assumed to provide remote-handled sludge are SY-102, AW-103, and $\mathrm{AW}-105 .^{74}$

B2.4.6.6 All remote-handled sludge will be water-washed before treatment to remove soluble waste constituents. The SSTs will be retrieved, transferred to the nearest WRF and then water-washed. The sludge in SY-102 will be consolidated with the sludge in AW-103 and/or AW-105, and then the sludge will be water washed in their respective tanks. ${ }^{74,77}$

B2.4.6.7 The remote-handled Supplemental TRU Treatment and Packaging process is initially assumed to be located near AW-Farm for treating water washed TRU tank waste from SY-102, AW-103 and AW-105; then near B-Farm for tanks B-107, B-110, and B-111; and finally near T-Farm for T-105, T-107, and T-112. ${ }^{77}$

\footnotetext{
${ }^{72}$ Baseline Change Request RPP-06-003, Rev. 1.

${ }^{73}$ The assumed rate is based on 1:1 dilution of solids with water during retrieval and a 0.67 TOE per RPP-21970, Rev. 0, "CH-TRUM WPU\&SE 11-Tank Material Balance," Section 3.0.

${ }^{74}$ HNF-SD-WM-SP-012, Rev. 6, Assumption A2.3.1, "TRU Sludge Processing."

${ }^{75}$ These are operational considerations.

${ }^{76}$ RPP-21970, Rev. 0, “CH-TRUM WPU\&SE 11-Tank Material Balance," Section 3.0 and Section 5.0, Assumption 2.

${ }^{77}$ The timing of all activities that depend upon the water washing of the RH-TRU DST solids may be adjusted based on available DST space and operational logistics.

${ }^{78}$ The assumed rate is based on 1:1 dilution of solids with water during retrieval and a 0.67 TOE per RPP-21970, Rev. 0, "CH-TRUM WPU\&SE 11-Tank Material Balance," Section 3.0.
} 
B2.4.6.8 The process flowsheet for the contact-handled TRU (CH-TRU) sludge treatment is described in the material balance for the CH-TRU tanks and is assumed to use the "dry batch mode." 79 For modeling purposes, the two dryers may be lumped into one dryer of equivalent treatment capacity. For planning purposes, the same flowsheet will be used for processing the water-washed sludge from the RH-TRU tanks. ${ }^{80}$

B2.4.6.9 The dried waste product from the CH-TRU process is assumed to be packaged in 55-gal drums containing $620 \mathrm{lb}_{\mathrm{m}}$ product per drum. ${ }^{81}$ Although not explicitly modeled, the CH-TRU drums are loaded up to fourteen drums to into a Transuranic Package Transporter-II (TRUPACT-II) shipping container, three TRUPACT-IIs in a shipment, for a maximum of 42 drums per shipment.

B2.4.6.10 The dried waste product from the RH-TRU process is assumed to be packaged in an RH-TRU Waste Canister containing about $2825 \mathrm{lb}_{\mathrm{m}}$ product per canister. ${ }^{82}$ Each canister will be shipped to Waste Isolation Pilot Plant (WIPP) in an RH-TRU 72-B Shipping Package.

B2.4.6.11 Liquid effluent will either be transferred to the LERF via Tank Truck or recycled to the Retrieval project. For planning purposes, it will be assumed that the liquid effluent is transferred only to LERF (no recycle) and will be modeled as a continuous transfer.

\footnotetext{
${ }^{79}$ RPP-21970, Rev. 0, CH-TRUM WPU\&SE 11-Tank Material Balance.

${ }^{80}$ HNF-SD-WM-SP-012, Rev. 6, Assumption A2.3.1, "TRU Sludge Processing."

${ }^{81}$ RPP-21970, Rev. 0, CH-TRUM WPU\&SE 11-Tank Material Balance, Section 5.0, Assumption 4.

${ }^{82}$ This assumes an inner canister volume of $0.89 \mathrm{~m}^{3}$ per DOE/CAO $95-1095$ Appendix I, a $90 \%$ fill, and a bulk dried waste product density of $1.60 \mathrm{Kg} / \mathrm{L}$. The density of the dried RH-TRU product is assumed to be the same as the dried CH-TRU product as stated in RPP-21970 Rev 0, Assumption 3.
} 


\section{B2.5 INTERFACING FACILITIES}

\section{B2.5.1 Liquid Effluents}

B2.5.1.1 The timing, capacities, and capability of the ETF, LERF, State Approved Land Disposal Site (SALDS), and TEDF will be driven by the needs of the waste treatment mission and assumed to be available when needed. ${ }^{83}$ If the treatment mission requires that changes be made to the ETF, LERF, SALDS, or TEDF or their operating plans, the ORP is assumed to successfully drive the changes.

B2.5.1.2 The LERF consists of three basins, each with an operating volume of $7.8 \mathrm{Mgal}$ (HNF-SD-WM-SAD-040, LERF Final Hazard Category Determination), which are used to provide lag-storage of liquid effluent. For planning purposes, only two of the basins will be allocated to supporting the waste treatment mission; the third basin will be reserved for CERCLA effluents. ${ }^{83}$

B2.5.1.3 The ETF will be modeled as a black-box. Overall partitioning of feed into solid waste and treated effluent will be approximated per HNF-4573, Appendix A. ${ }^{83}$

B2.5.1.4 The SALDS will not be modeled; however, the demand on the SALDS from ETF will be estimated.

B2.5.1.5 The TEDF will not be modeled.

\section{B2.5.2 Central Waste Complex}

B2.5.2.1 The Central Waste Complex (CWC) is assumed to support the needs of the waste treatment mission and is assumed to be available when needed; the demand on the CWC will not be modeled.

\section{B2.5.3 Canister Storage Building and Hanford Shipping Facility}

B2.5.3.1 The IHLW interim storage facility (the Canister Storage Building), being upgraded by Project W-464, will be operational on $9 / 29 / 2015^{84}$ and provide interim storage for up to 880 IHLW canisters. $^{85}$

B2.5.3.2 The need date for the Canister Storage Building will be the date on which the first radioactive HLW canister is produced (estimated to be May 17, 2018). ${ }^{86}$

B2.5.3.3 For planning purposes, the first 880 IHLW canisters will be stored in the CSB. No credit will be taken for the 24 canisters of WTP-provided storage for cooling IHLW canisters, nor for the 24 canisters of WTP-provided buffer capacity. ${ }^{87}$

\footnotetext{
${ }^{83}$ HNF-SD-WM-SP-012, Rev. 6, Assumption A4.3.4, "ETF and LERF."

${ }^{84}$ Baseline Change Request RPP-06-003, Rev. 1, "Alignment of TFC Lifecycle Baseline," November 2006.

${ }^{85}$ RPP-12364, Rev. 0, "Project W-464, Immobilized High-Level Waste Interim Storage Facility, Preliminary Design Report," November 2002.

${ }^{86}$ HNF-SD-WM-SP-012, Rev. 6, Assumption A2.6 "Waste Disposal Sites," with adjustments for WTP schedule.

${ }^{87}$ Cooling and buffer capacity obtained from 24590-HLW-3YD-HPH-00001, Rev. 1.
} 
B2.5.3.4 The Hanford Shipping Facility (HSF) for IHLW will be located in the 200 Area and will be operational on $4 / 5 / 2019 .^{88}$ If this date is later than the date determined by the model run, it will be accelerated to match that date.

B2.5.3.5 The shipping rate is up to 2 canisters of IHLW per day ${ }^{89}$ - first priority given to shipping newly created IHLW canisters beyond the 880 stored at the CSB - second priority is given to emptying the CSB after HLW vitrification is finished.

\section{B2.5.4 Yucca Mountain (Offsite Repository)}

B2.5.4.1 Yucca will be ready to accept IHLW from Hanford on 4/8/2019. ${ }^{88}$

B2.5.4.2 IHLW canisters will be shipped to Yucca starting when the Canister Storage Building is full ( 880 canisters).

B2.5.4.3 It is assumed that the WTP-prepared delisting petition for the IHLW is accepted by Ecology before shipping the waste to Yucca.

\section{B2.5.5 Integrated Disposal Facility}

B2.5.5.1 The Integrated Disposal Facility (IDF) will be operational on 10/1/2010 and will provide permanent disposal for the ILAW, other mixed low-level waste, and low-level waste (LLW). It is assumed that the ILAW produced by the DBVS can be safely stored until the IDF is available. $^{90}$

B2.5.5.2 The IDF will receive LAW glass packages from the WTP; solid waste from the WTP including spent LAW and HLW melters; roll-off boxes containing glass from the DBVS, BVS, East STP and West STP; and solid waste from the ETF from treating liquid effluent. Only that portion of the primary and secondary waste streams directly related to treatment of the tank waste will be modeled. ${ }^{91}$

B2.5.5.3 For planning purposes, the IDF can be expanded as needed to support the mission without interference from other users.

\section{B2.5.6 222-S Laboratory}

B2.5.6.1 It is assumed that the laboratory services required to support waste characterization for TFC projects and operations are available and provided in a timely manner.

\footnotetext{
${ }^{88}$ Baseline Change Request RPP-06-003, Rev. 1, “Alignment of TFC Lifecycle Baseline,” November 2006.

${ }^{89}$ RPP-20270, Rev. 0, Section 3.2.1.1.1, "Canister Receipt Rate Requirements."

${ }^{90}$ HNF-SD-WM-SP-012, Rev. 6, Assumption A2.6 "WASTE DISPOSAL SITES."

${ }^{91}$ For example, the inventory that is retained on a disposable filter will be modeled, but the mass, composition and overall volume of the filter itself will not be tracked.
} 
ORP-11242, Rev 3

\section{B2.5.7 Waste Encapsulation and Storage Facility}

B2.5.7.1 Cesium and strontium capsules are assumed to be dispositioned outside of the WTP and tank farm facilities by DOE-RL. ${ }^{92}$

\section{B2.5.8 Waste Isolation Pilot Plant}

B2.5.8.1 It is assumed that WIPP will be ready to accept contact-handled TRU waste starting on $10 / 1 / 2013 .^{88}$

B2.5.8.2 It is assumed that WIPP will be ready to accept remote-handled TRU (RH-TRU) waste one year before the modeled need date (per Assumption B2.4.6.4), but no earlier than the current baseline date of $6 / 18 / 2022$.

\section{B2.5.9 Other Hanford Site Facilities}

(No unique assumptions)

${ }^{92}$ Pretreatment can connect to a potential new facility designed to receive and treat the Hanford Cs and Sr capsules prior to incorporation into the HLW feed for immobilization in the HLW Vitrification Facility (Section C.7(c)(2) of DE-AC27-01RV14136). 


\section{B2.6 CROSS-CUTTING ASSUMPTIONS}

B2.6.1 The starting tank inventory reflects the contents of the tanks as of January 2007. This is called the "FY 2007" inventory and is based on BBI downloaded from Tank Waste Information Network System (TWINS) circa May 2007 as documented in RPP-33715. Adjustments will be made in the Hanford Tank Waste Operations Simulator (HTWOS) model for historical transfers as needed.

B2.6.2 Assumed addition of "new" waste into the DSTs from retrieval of the IMUSTs and from deactivation of other Hanford Site facilities is described in HNF-SD-WM-SP-012, Tank Farm Contractor Operation and Utilization Plan, Rev. 6, Assumption A2.1.1, "New Waste Introduced Via Deactivation." Waste added due to other TFC activities is described in HNF-SD-WM-SP-012, Rev. 6, Assumption A2.1.2, "New Waste Introduced via Operations."

B2.6.3 The water wash factors ${ }^{93}$ in TWINS circa March 2007 will be used to partition waste into solid and liquid phases during retrieval and staging; strontium partitioning will be modeled per RPP-21807. The feed vector will be reported on a fully water-washed basis.

B2.6.4 The caustic leach factors ${ }^{93}$ in the TWINS circa March 2007 will be used as the basis for computing the caustic leach factors associated with each delivered batch of HLW solids.

B2.6.5 For modeling purposes, the approximations to waste chemistry in the tank farms are described in HNF-SD-WM-SP-012, Rev. 6, Assumption A6.6, "Waste Chemistry and Mass Balances."

B2.6.6 Total organic carbon (TOC) will not be speciated. ${ }^{94}$ However, for modeling purposes, all TOC will be treated as oxalate once it enters the WTP or STP to allow for reaction stoichiometry.

B2.6.7 The composition waste retrievals from SSTs and DSTs will be homogeneous. ${ }^{95}$ Tanks S-105 and S-109 are exceptions in that they use selective dissolution assumptions (see B2.4.1.4 and B2.4.2.3).

\footnotetext{
${ }^{93}$ Uncertainties and biases in the water wash and caustic leach factors can significantly influence the canister counts and end dates; some of these have been addressed in TWINS since the last revision of the System Plan (for example, $\mathrm{Cr}, \mathrm{Al}, \mathrm{PO}_{4}$ and $\mathrm{SO}_{4}$ wash and leach factors; S-complex ${ }^{99} \mathrm{Tc}$ wash factors; ${ }^{90} \mathrm{Sr}$ wash factors; and miscellaneous corrections).

${ }^{94}$ An enabling assumption for speciating TOC into its constituent organic compounds is not available. Therefore, the organic content of the various secondary waste streams will not be estimated.

${ }^{95}$ HNF-SD-WM-SP-012, Rev. 6, Assumption A6.1, "Estimating Waste Compositions."
} 
B2.6.8 The design, flowsheet, operating modes, and operating plans of all facilities or processes will drive the permit conditions, and the permits will be modified as the processes evolve. 


\section{B3.0 REFERENCES}

145579-A-DC-002, 2005, Bulk Vitrification Process Improvement Design Criteria - Full DBVS, Rev. 0F, April 8, 2005, AMEC Earth \& Environmental and Geomelt, Richland, Washington.

24590-HLW-3PS-AE00-T0001, 2003, Engineering Specification for High Level Waste Melters, Rev. 2, Bechtel National, Inc., Richland, Washington.

24590-HLW-3YD-HPH-00001, System Description for HLW System HPH Canister Pour Handling, Rev. 1, Bechtel National, Inc., Richland, Washington.

24590-LAW-3PS-AE00-T0001, 2003, Engineering Specification for Low Activity Waste Melters, Rev. 2, Bechtel National, Inc., Richland, Washington.

24590-WTP-ICD-MG-01-019, 2003, ICD 19 - Interface Control Document for Waste Feed, Rev. 3, Bechtel National, Inc., Richland, Washington.

24590-WTP-MDD-PR-01-002, 2003, Dynamic (G2) Model Design Document, Rev. 6, Bechtel National Inc., Richland, Washington.

24590-WTP-MDD-PR-01-002, 2005, Dynamic (G2) Model Design Document, Rev. 8, Bechtel National Inc., Richland, Washington.

24590-WTP-MRQ-PO-04-0065, 2004, Model Run Request, Supplemental LAW Data Collection, 8/16 Rev. 0 DRAFT, Bechtel National, Inc., Richland, Washington.

24590-WTP-PL-MG-01-001, 2003, Interface Management Plan, Rev. 1, Bechtel National, Inc., Richland, Washington.

24590-WTP-RPT-PT-02-005, 2005, Flowsheet Bases, Assumptions, and Requirements, Rev. 3 , Bechtel National, Inc., Richland, Washington.

Baseline Change Request RPP-06-003, 2006, Alignment of TFC Lifecycle Baseline, Rev. 1, CH2M HILL Hanford Group, Inc., Richland, Washington.

CCN: 102476, "HLW Melter Glass Inventory", October 14, 2004, Mark Hall to Distribution, Bechtel National, Inc., Richland, Washington.

CCN: 132846, "Comprehensive Review of the Hanford Waste Treatment Plant Flowsheet and Throughput, Assessment Conducted by an Independent Team of External Experts," March 2006, transmitted under cover of letter CCN: 132846, Bechtel National, Inc., Richland, Washington.

CCN: 150375, "Justification to Revise the LAW Vitrification Technetium $\left(\mathrm{Tc}^{+4} \&{ }^{99} \mathrm{Tc}\right)$ Decontamination Factors in the Flowsheet Bases, Assumptions, and Requirements Document," March 19, 2007, Joe Perez to Scott Saunders, Bechtel National, Inc., Richland, Washington.

D-03-DESIGN-004, 2003, An Assessment of the Factors Affecting the Ability to Increase the Na2O Loading in the Waste Treatment and Immobilization Plant (WTP) Low Activity Waste (LAW) Glass, ORP WTP Engineering Division, U.S. Department of Energy, Office of River Protection, Richland, Washington. 
D-03-DESIGN-005, 2004, HLW Feed Preparation System: Ultra-Filtration Process System, ORP WTP Engineering Division, U.S. Department of Energy, Office of River Protection, Richland, Washington.

DE-AC27-01RV14136, 2000, WTP Contract, U.S. Department of Energy, Office of River Protection, Richland, Washington, as modified and amended through M051, dated 2006.

DOE/CAO 95-1095, 1995, Remote-Handled Transuranic Waste Study, U.S. Department of Energy, Carlsbad Area Office, Carlsbad, New Mexico.

Ecology, EPA, and DOE, 1996, Hanford Federal Facility Agreement and Consent Order, as amended, State of Washington Department of Ecology, U.S. Environmental Protection Agency, and U.S. Department of Energy, Olympia, Washington.

HNF-3484, 2007, Double-Shell Tank Emergency Pumping Guide, Rev. 8, CH2M HILL Hanford Group, Inc., Richland, Washington.

HNF-4573, 1999, Liquid Effluent "Retention Facility Basin 44 Process Test Post-Report, Rev. 0A, Waste Management Federal Services of Hanford, Inc., Richland, WA.

HNF-EP-0182, 2007, Waste Tank Summary Report For Month Ending 12/31/2006, Rev. 225, CH2M HILL Hanford Group, Inc., Richland, Washington.

HNF-SD-WM-OCD-015, 2007, Tank Waste Transfer Compatibility Program, Rev. 17, CH2M HILL Hanford Group, Inc., Richland, Washington.

HNF-SD-WM-SAD-040, 2001, Liquid Effluent Retention Facility Final Hazard Category Determination, Rev. 2, Fluor Hanford, Inc., Richland, Washington.

HNF-SD-WM-SP-012, 2007, Tank Farm Contractor Operation and Utilization Plan, Rev. 6, CH2M HILL Hanford Group, Inc., Richland, Washington.

ORP-11242, 2003, River Protection Project System Plan, Rev. 2, U.S. Department of Energy, Office of River Protection, Richland, Washington.

OSD-T-151-00007, 2007, Operating Specifications for the Double Shell Storage Tanks, Rev. 1, CH2M HILL Hanford Group, Inc., Richland, Washington.

RPP-12364, 2002, Project W-464, Immobilized High-Level Waste Interim Storage Facility, Preliminary Design Report, Rev. 0, CH2M HILL Hanford Group, Inc., Richland, Washington.

RPP-15552, 2003, Hanford Tank Waste Oxidative Leach Behavior Analysis, Rev. 0, CH2M HILL Hanford Group, Inc., Richland, Washington.

RPP-17239, 2004, Process Control Plan for 242-A Evaporator Campaign 04-01, Rev. 0, CH2M HILL Hanford Group, Inc., Richland, Washington.

RPP-18592, 2005, Software Verification \& Validation Plan \& Results for Hanford Tank Waste Operations Simulator Model Reference Version 1.1, Rev. 2, CH2M HILL Hanford Group, Inc., Richland, Washington.

RPP-20270, 2005, Hanford Shipping Facility System Specification, Rev. 0, CH2M HILL Hanford Group, Inc., Richland, Washington. 
RPP-20528, 2006, Demonstration Bulk Vitrification System Flowsheet, Rev. 1, CH2M HILL Hanford Group, Inc., Richland, Washington.

RPP-21216, 2006, Single Shell Tank Retrieval Selection and Sequence, Rev. 2, CH2M HILL Hanford Group, Inc., Richland, Washington.

RPP-21807, 2004, Strontium-90 Liquid Concentration Solubility Correlation in The Hanford Tank Waste Operations Simulator, Rev. 0, CH2M HILL Hanford Group, Inc., Richland, Washington.

RPP-21970, 2005, CH-TRUM WPU\&SE 11-Tank Material Balance, Rev. 0, CH2M HILL Hanford Group, Inc., Richland, Washington.

RPP-33715, 2007, Double \& Single-Shell Tank Inventory Input To the HTWOS Model - 2007 Update, Rev. 0, CH2M HILL Hanford Group, Inc., Richland, Washington.

RPP-35320, 2007, WTP Ultra-Filter Permeate Assumption for System Modeling, Rev 0, CH2M HILL Hanford Group, Inc., Richland, Washington.

RPP-RPT-30160, Supporting Information for the Evaluation of Waste Treatment and Immobilization Plant (WTP) Low Activity Waste (LAW) Startup First Scenarios, Rev. 0, CH2M HILL Hanford Group, Inc., Richland, Washington.

ST07.004, 2007, "RE: Bulk Vitrification Baseline Glass Formulation for FY07 System Plan," (Letter to J. E. Van Beek, March 19, 2007, from L. M. Bagaasen), Pacific Northwest National Laboratory, Richland, Washington.

SVF-1283, 2008, "Single-Shell Tank Retrieval Assumptions for Mission Modeling, SVF-1283 Rev1.xls," Rev 2, CH2M HILL Hanford Group, Inc., Richland, Washington.

WSRC-MS-2005-00147, 2005, "Small Column Ion Exchange Alternative Overview," D. McCabe et al, Westinghouse Savannah River Company, Aiken, South Carolina. 
ORP-11242, Rev 3

This page intentionally left blank. 
ORP-11242, Rev 3

APPENDIX C

OVERALL SYSTEM MASS BALANCE

C-i 
ORP-11242, Rev 3

This page intentionally left blank.

C-ii 


\section{APPENDIX C \\ OVERALL SYSTEM MASS BALANCE}

The overall system mass balance for the Reference Case is keyed to the streams shown on Figure 1-1, River Protection Process Simplified Process Flow Diagram, and is available in an Excel spreadsheet. ${ }^{1}$ The spreadsheet includes a copy of the process flow diagram with stream numbers, the full mass balance table mapped to the stream numbers. The spreadsheet also contains a copy of the flow diagram that can be overlaid with the activity balance for the individual radionuclides or the mass balance on an elemental basis.

For convenience, this Appendix includes the following balances:

RPP Simplified Process Flow Diagram - Na Balance. RPP Simplified Process Flow Diagram - Total Activity Balance. RPP Simplified Process Flow Diagram - ${ }^{129}$ I Balance. RPP Simplified Process Flow Diagram $-{ }^{99}$ Tc Balance. RPP Simplified Process Flow Diagram - Hg Balance.

\footnotetext{
${ }^{1}$ SVF-1431, 2008, Balance Graphic System Plan Rev 3(1-12-2008)-8.3r1-WC91778_M4.xls, Rev 2, CH2M HILL
} Hanford Group, Inc., Richland, Washington. 
ORP-11242, Rev 3

This page intentionally left blank. 
Figure C-1. RPP Simplified Process Flow Diagram - Na Balance.

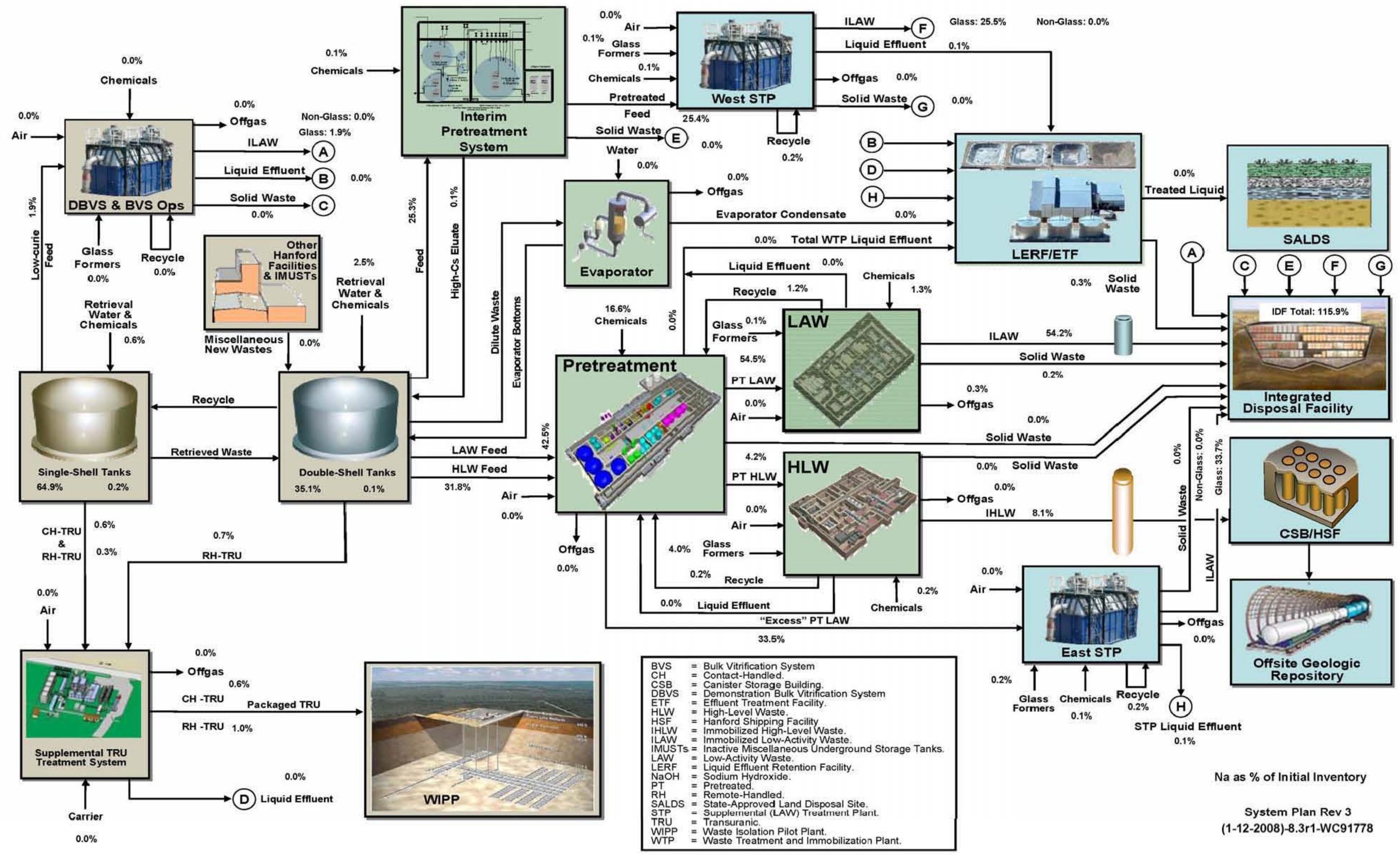


Figure C-2. RPP Simplified Process Flow Diagram - Total Activity Balance.

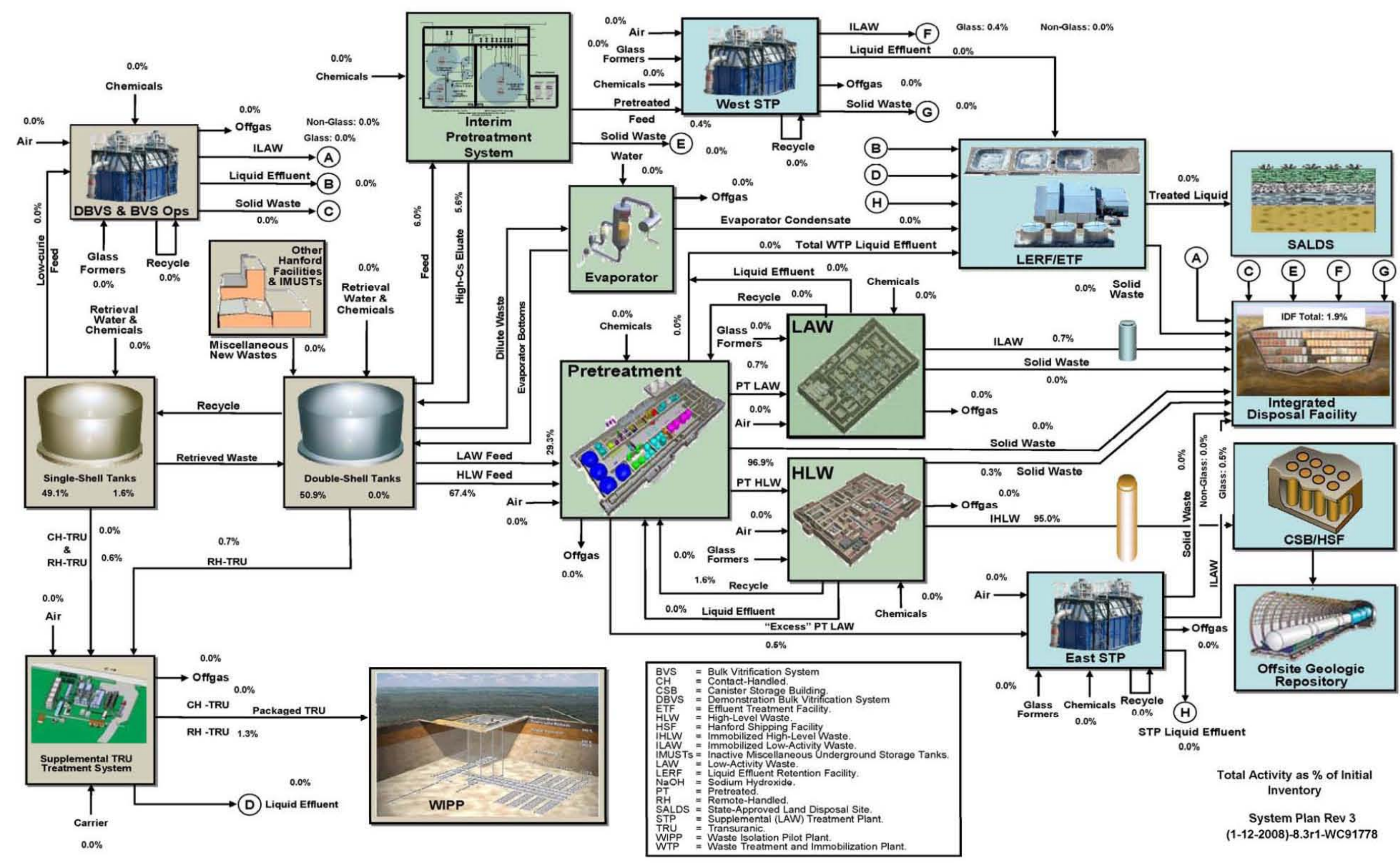


Figure C-3. RPP Simplified Process Flow Diagram $-{ }^{129}$ I Balance.

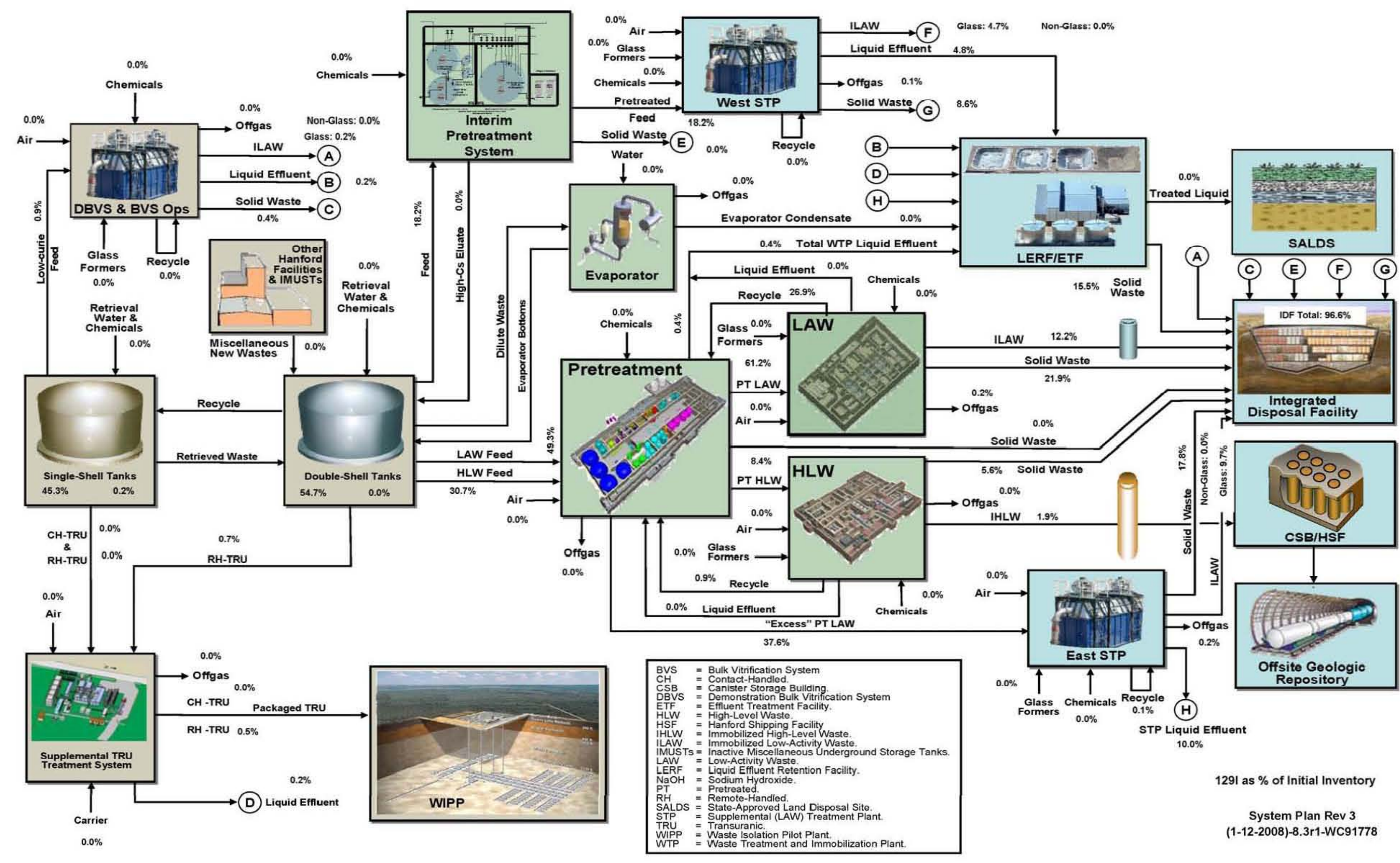


Figure C-4. RPP Simplified Process Flow Diagram $-{ }^{99} \mathrm{Tc}$ Balance.

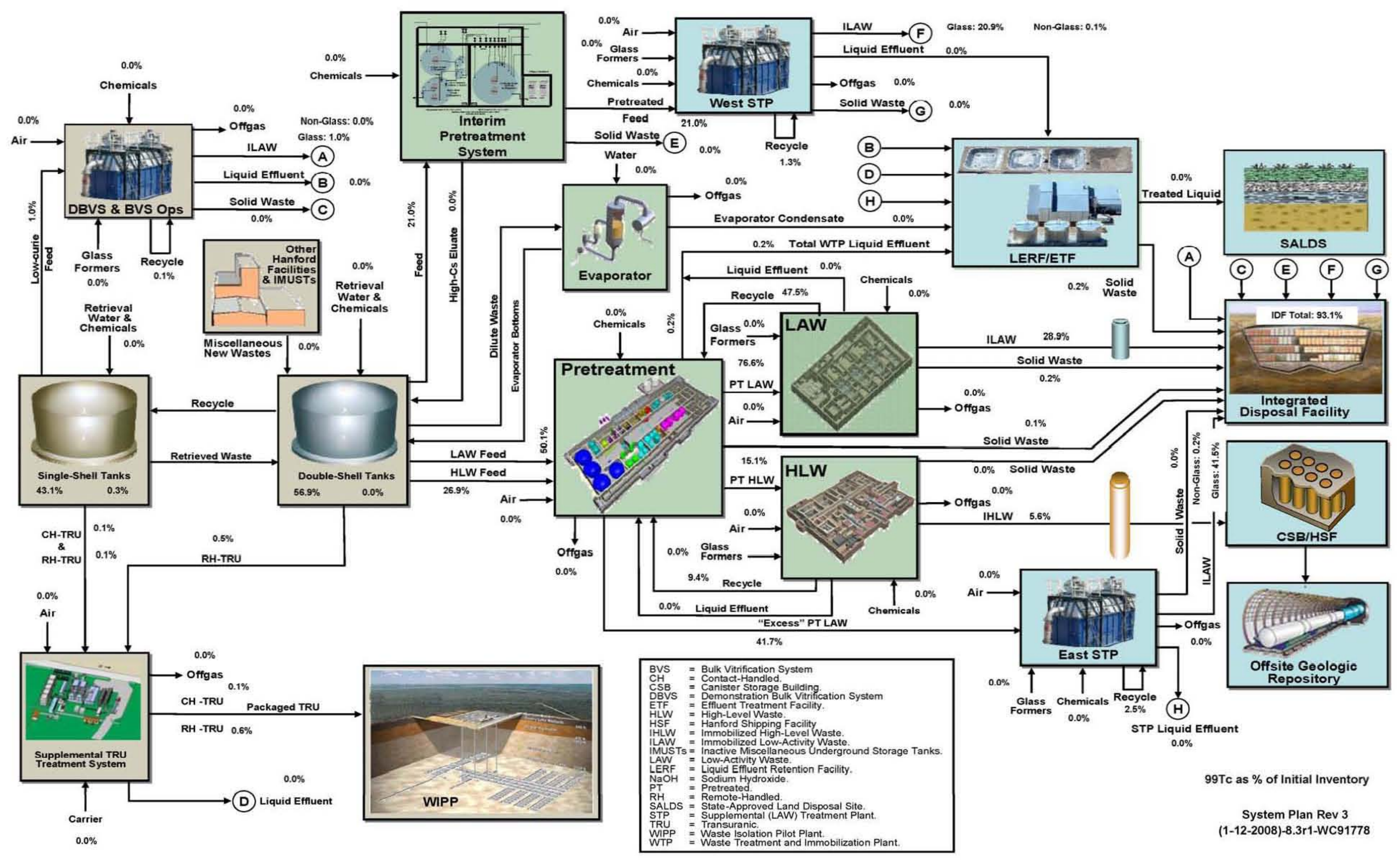


Figure C-5. RPP Simplified Process Flow Diagram - Hg Balance

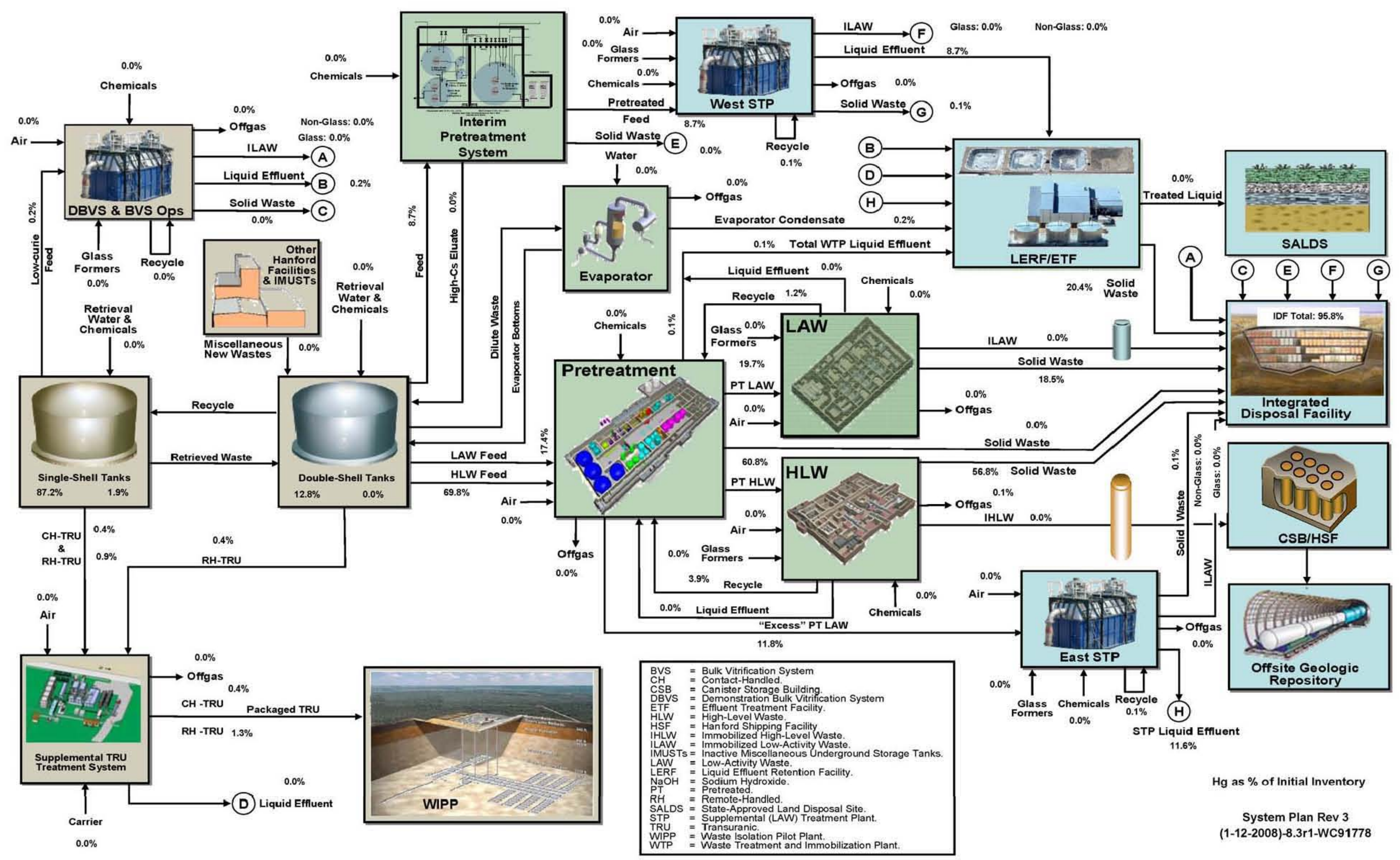

